Aus der Klinik für Allgemein-, Viszeral- und Kinderchirurgie

(Direktor: Prof. Dr. med. M. Ghadimi)

im Zentrum Chirurgie

der Medizinischen Fakultät der Universität Göttingen

\title{
Die Bedeutung der Thymidinphosphorylase bei Patienten mit lokal fortgeschrittenem Rektumkarzinom (UICC-Stadium-II/-III) im Kontext einer 5-FU basierten multimodalen Therapie
}

\author{
Eine immunhistochemische, patientenorientierte Studie mit \\ Langzeit-Follow-Up
}

\author{
INAUGURAL - DISSERTATION \\ zur Erlangung des Doktorgrades \\ der Medizinischen Fakultät \\ der Georg-August-Universität zu Göttingen
}

vorgelegt von

Matthias Specking

aus

München

Göttingen 2013 
Dek a n:

Prof. Dr. rer. nat. H. K. Kroemer
I. Berichterstatter:
PD Dr. med. T. Liersch
II. Berichterstatter/in:
III. Berichterstatter/in:

Tag der mündlichen Prüfung:
23.Juni 2014 


\section{Inhaltsverzeichnis}

\section{Abkürzungsverzeichnis}

II. Abbildungsverzeichnis

\section{Tabellenverzeichnis}

$1 \quad$ Einleitung und Zielsetzung...................................................................... 1

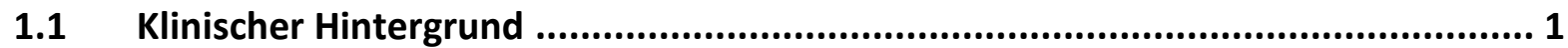

1.1.1 Inzidenz und Risikofaktoren kolorektaler Karzinome ........................................... 1

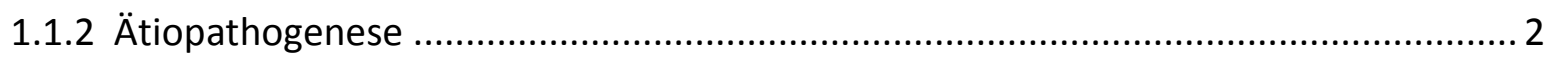

1.2 Prätherapeutische Diagnostik des Rektumkarzinoms ...................................... 3

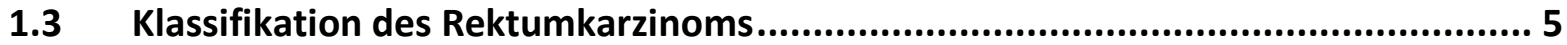

1.4 Neoadjuvante Therapie des lokal fortgeschrittenen Rektumkarzinoms ................ 6

1.4.1 Aktuelle Therapieansätze zum Zeitpunkt der Untersuchung.................................. 7

1.5 Chirurgische Therapie des Rektumkarzinoms.................................................9

1.6 Adjuvante Therapie des lokal fortgeschrittenen Rektumkarzinoms .................... 10

1.7 Pharmakokinetische und pharmakodynamische Eigenschaften von 5-Fluoruracil 10

1.8 Molekulare Biomarker beim Rektumkarzinom............................................. 13

1.9 Intrazelluläre und therapeutische Bedeutung von TP und TS............................. 14

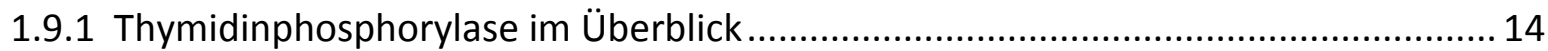

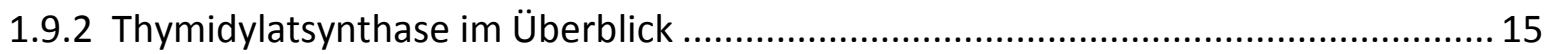

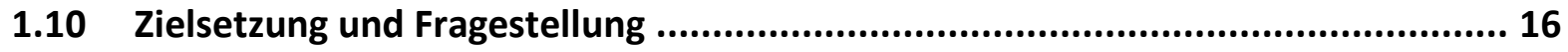

2 Patienten, Material und Methoden ..................................................... 18

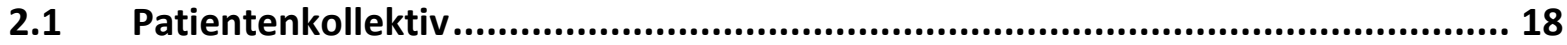

2.2 Klinische Patientencharakteristika und prätherapeutische Stagingergebnisse ..... 19

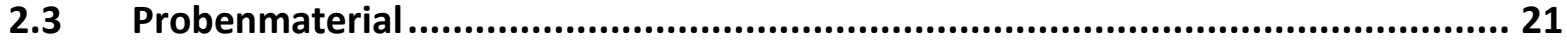

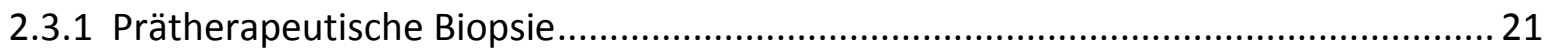

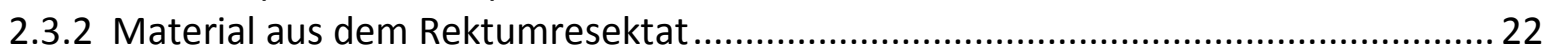

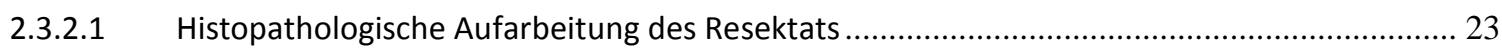

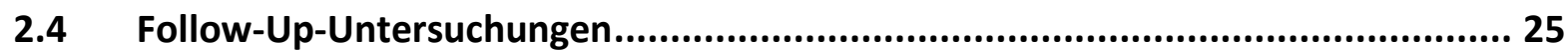

2.5 Herstellung der immunhistochemischen Präparate........................................ 26 


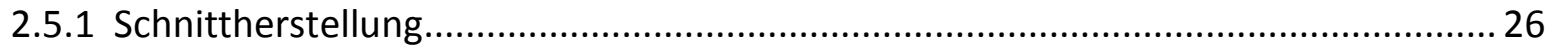

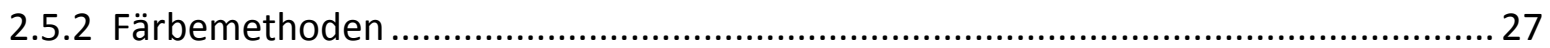

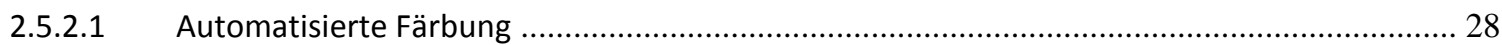

2.6 Mikroskopische Beurteilung der Präparate ............................................... 30

2.7 Vorkehrungen zur Analyse der Korrespondenz von TP und TS .......................... 32

2.8 Statistische Auswertungsmethoden .............................................................. 33

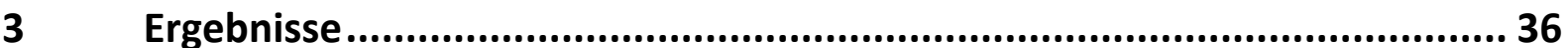

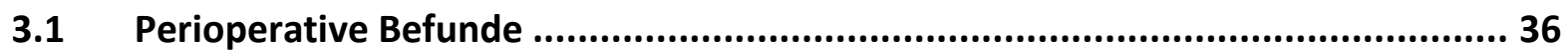

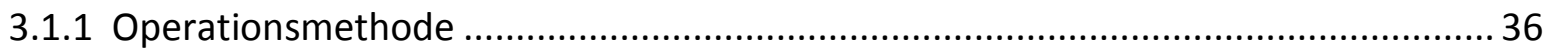

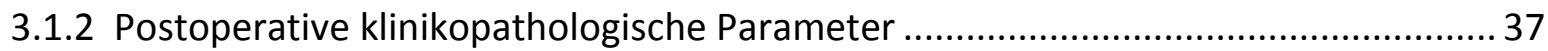

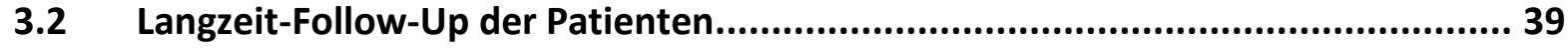

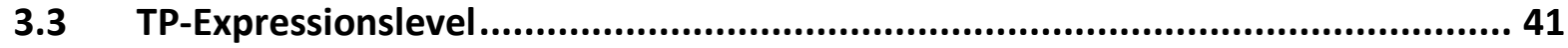

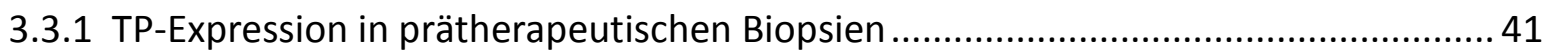

3.3.2 TP-Expression in Rektumresektaten.................................................................... 42

3.3.3 TP-Expressionsgrad im direkten Vergleich prätherapeutischer Biopsien und OP-

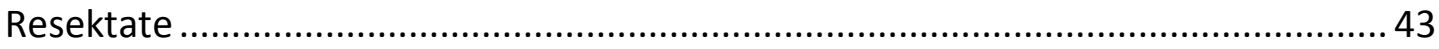

3.3.4 Histogramme zur Darstellung der TP-Expressionslevel....................................... 46

3.3.5 Errechnete Differenz des H-Scores zwischen Biopsien und Resektaten .................... 48

3.4 Korrelation des prätherapeutischen TP-Expressionsgrades mit dem Tumorregressionsgrad

3.5 Korrelation von TRG und Nodalstatus.

3.6 Ergebnisse der Langzeit-Analyse in Abhängigkeit von der TP-Expression ............. 54

3.6.1 Korrelation des TP-Expressionsstatus mit der Lokalrezidivrate ............................... 55

3.6.1.1 Korrelation der Lokalrezidivrate mit der TP-Expression in Biopsien ........................................ 55

3.6.1.2 Korrelation der Lokalrezidivrate mit der TP-Expression im residuellen Tumorgewebe ........... 56

3.6.1.3 Korrelation der Lokalrezidivrate mit der TP-Expression in Biopsien der Patientenkohorte A . 57

3.6.2 Korrelation des TP-Expressionsstatus mit dem Auftreten von Fernmetastasen ....... 58

3.6.2.1 Korrelation der Metastasierungsrate mit der TP-Expression in Biopsien..............................5 58

3.6.2.2 Korrelation der Metastasierungsrate mit der TP-Expression im residuellen Tumorgewebe ... 59

3.6.2.3 Korrelation der Metastasierungsrate mit der TP-Expression in Biopsien der Patientenkohorte

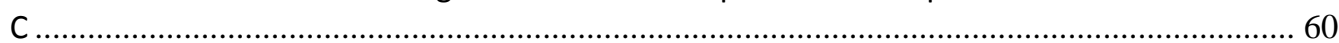

3.6.3 Korrelation des TP-Expressionsstatus aus prätherapeutischen Biopsien und

Tumorresektaten mit dem tumorfreien Überleben

3.6.3.1 Korrelation des TP-Expressionsstatus aus prätherapeutischen Biopsien mit dem tumorfreien

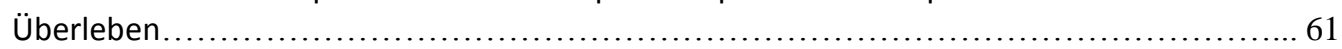

3.6.3.2 Korrelation des TP-Expressionsstatus aus residuellem Tumorgewebe mit dem tumorfreien

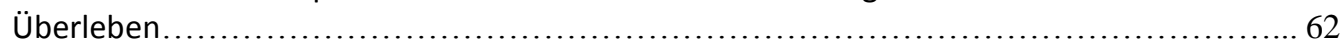

3.6.3.3 Korrelation des TP-Expressionsstatus aus prätherapeutischen Biopsien mit dem tumorfreien Überleben der Patientenkohorte $C$

3.6.4 Korrelation des TP-Expressionsstatus aus prätherapeutischen Biopsien und residuellem Tumorgewebe mit dem krankheitsspezifischen Gesamtüberleben ......64 64

3.6.4.1 Korrelation der TP-Expression aus prätherapeutischen Biopsien mit dem CSS 


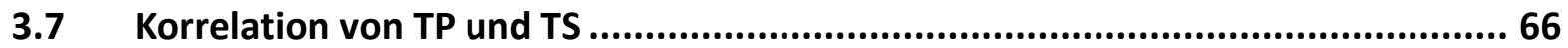

3.7.1 TP- und TS-Expressionslevel korrespondierender Präparate ...................................66

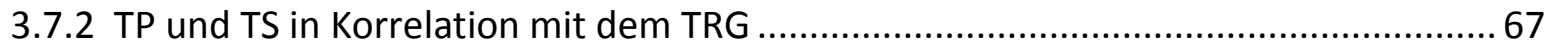

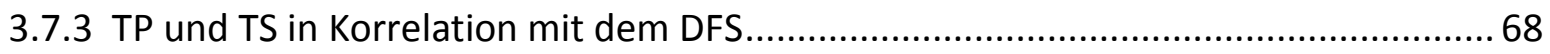

3.8 Capecitabin in der neoadjuvanten Therapie................................................ 69

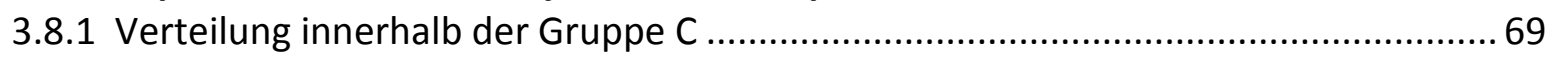

3.8.2 Überlebenskurven in Bezug auf die Behandlung mit Capecitabin ........................... 72

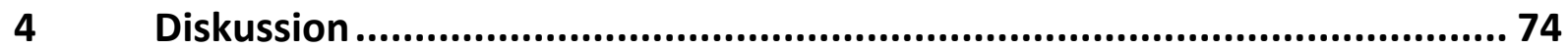

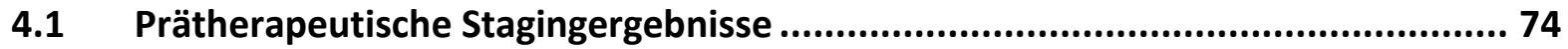

4.2 Perioperative Befunde, klinische Patientencharakteristika und Nachbeobachtungen ................................................................................... 75

4.3 TP-Expressionslevel in prätherapeutischen Biopsien und Resektaten ................ 77

4.4 Einfluss des prätherapeutischen TP-Expressionslevels auf den TRG .................... 79

4.5 Prognostische Bedeutung des postoperativen Nodalstatus im Vergleich zum

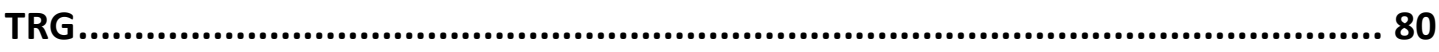

4.6 Die prognostische Bedeutung der Thymidinphosphorylase ................................ 81

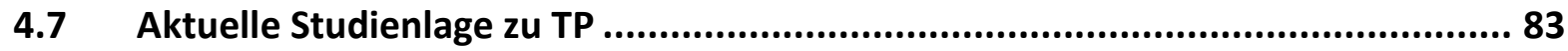

4.8 Korrelation der Ergebnisse von TP und TS ............................................... 87

4.9 Capecitabin in der neoadjuvanten Therapie.................................................... 88

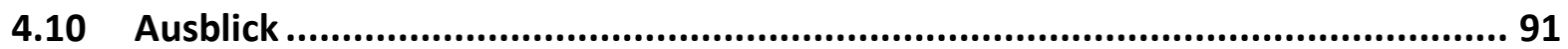

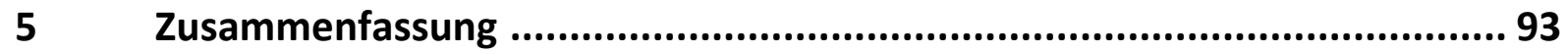

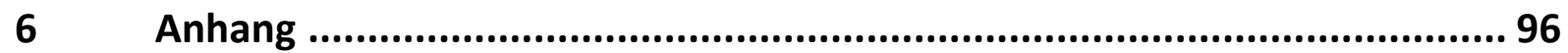

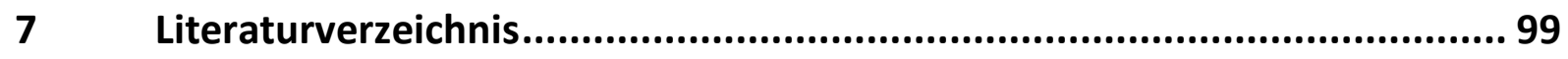

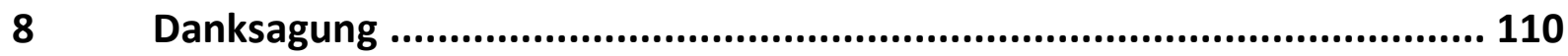




\section{Abkürzungsverzeichnis}

AIO

APC

APR

ARO

Art.

CAO

cTNM

CT

CTx

d

DFS

5-FU

GRCSG

Gy

KRK

Min

OS

pCR

PCR

PME

pTNM

rES

RT

$\mathrm{RT} / \mathrm{CTx}$

RT-PCR

TARR

TME

TNM

TP

TRG

TS

UICC

(y)pUICC
Arbeitsgemeinschaft Internistische Onkologie

Adenomatöse Polyposis Coli (Tumorsuppressorgen)

Abdominoperineale Rektumexstirpation

Arbeitsgemeinschaft Radiologische Onkologie

Arteria

Chirurgische Arbeitsgemeinschaft Onkologie

TNM-Klassifikation nach klinischen Stagingergebnissen

Computertomographie

Chemotherapie

day (Tag)

Disease Free Survival

5-Fluorouracil

German Rectal Cancer Study Group

Gray

Kolorektales Karzinom

Minuten

Overall Survival

pathologische Komplettremission

Polymerase Chain Reaction

Partielle Mesorektale Exzision

TNM-Klassifikation nach histopathologischem Befund

rektale Endosonographie

Radiotherapie

Radio-/Chemotherapie

Real-Time-Polymerasekettenreaktion

Tiefe anteriore Rektumresektion

Totale Mesorektale Exzision

Klassifikationssystem maligner Tumore

Thymidinphosphorylase

Tumor Regression Grading / Tumorregressionsgrad

Thymidylatsynthase

Union Internationale Contre le Cancer

UICC-Klassifikation nach histopatholgischem Befund nach neoadjuvanter Therapie 


\section{Abbildungsverzeichnis}

Abbildung 1: Adenom-Karzinom-Sequenz (modifiziert nach Arastéh 2009, S.553) ................. 3

Abbildung 2: Aufbau der GAST-05 und der CAO/ARO/AIO-04 Studie (Liersch et al. 2009)....... 8

Abbildung 3: Intrazellulärer 5-FU-Metabolismus............................................................... 13

Abbildung 4: CONSORT-Schema zum Therapieablauf und Studiendesign ............................ 19

Abbildung 5: Beispiel für perioperative Qualitätskontrolle des Rektumresektats .................. 22

Abbildung 6: Qualitätsbeurteilung der TME (Grad I bis III) nach Methylenblau-Applikation.. 23

Abbildung 7: Indirekte Färbemethode durch Antigen-Antikörper-Reaktion........................... 28

Abbildung 8: Färbeautomat Benchmark XT der Firma Ventana .............................................. 29

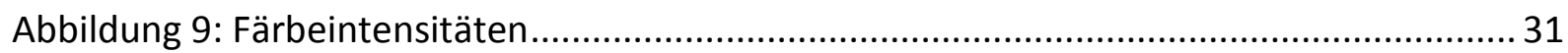

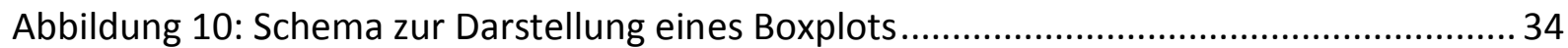

Abbildung 11: Boxplot zur Darstellung der TP-Intensität in Biopsien.................................... 42

Abbildung 12: Boxplot zur Darstellung der TP-Intensität in den ungepaarten Resektaten .... 43

Abbildung 13: Boxplot zur Darstellung der TP-Intensitäten in den korrespondierenden

Biopsien und Resektaten ...................................................................... 45

Abbildung 14: Histogramme zur Darstellung der TP-Level in Biopsien und Resektaten ......... 47

Abbildung 15: Boxplot und Wasserfall-Balkendiagramm zur Darstellung der errechneten

Differenz von Biopsie und Resektat ............................................................. 50

Abbildung 16: Häufigkeitsverteilung der Tumorregressionsstadien in den

Therapiegruppen B und C

Abbildung 17: Korrelation des Tumorregressionsgrades mit dem DFS der Therapiegruppen

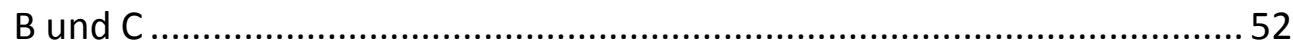

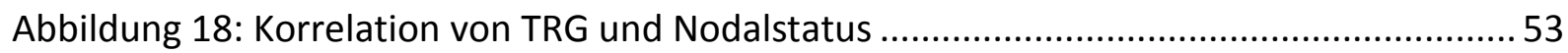

Abbildung 19: Lokalrezidivrate (LR) in Korrelation zur TP-Expression der Biopsien (alle

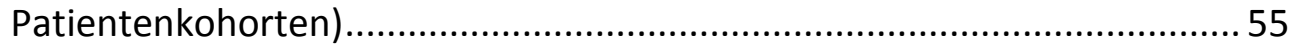

Abbildung 20: Lokalrezidivrate (LR) in Korrelation zur TP-Expression der Resektate (alle

Patientenkohorten) ........................................................................... 56

Abbildung 21: Lokalrezidivrate (LR) in Korrelation zur TP-Expression der Biopsien

(Patientenkohorte A) .............................................................................. 57

Abbildung 22: Fernmetastasenrate in Korrelation zur TP-Expression der Biopsien (alle

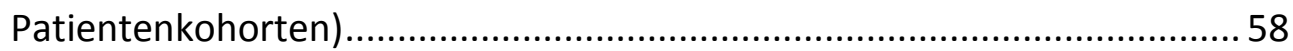

Abbildung 23: : Fernmetastasenrate in Korrelation zur TP-Expression der Resektate (alle

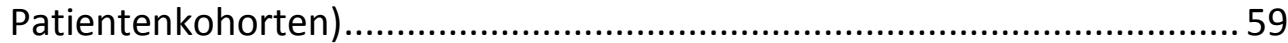

Abbildung 24: Fernmetastasenrate in Korrelation zur TP-Expression der Biopsien

(Patientenkohorte C)

Abbildung 25: Krankheitsfreies Überleben (DFS) in Abhängigkeit von der TP-Expression

innerhalb der Biopsien (alle Patientenkohorten)

Abbildung 26: Krankheitsfreies Überleben (DFS) in Abhängigkeit von der TP-Expression innerhalb der Resektate (alle Patientenkohorten)

Abbildung 27: Krankheitsfreies Überleben (DFS) in Abhängigkeit von der TP-Expression

innerhalb der Biopsien (Patientenkohorte C) ...........................................63

Abbildung 28: Krankheitsspezifisches Gesamtüberleben (CSS) in Abhängigkeit von der TP-

Expression innerhalb der Biopsien (alle Patientenkohorten).

Abbildung 29: Krankheitsspezifisches Gesamtüberleben (CSS) in Abhängigkeit von der TP-

Expression innerhalb der Resektate (alle Patientenkohorten)................... 65

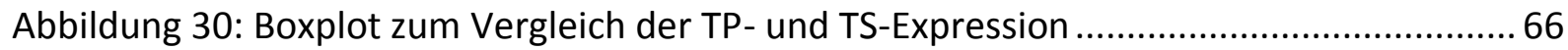

Abbildung 31: Korrelation der TP- und TS-Expression mit dem TRG ...................................67 67

Abbildung 32: Korrelation der TP- und TS-Expression mit dem DFS .................................... 68 
Abbildung 33: Verteilung der Biopsien von Patienten aus der neoadjuvanten

Therapiegruppe $\mathrm{C}$ bezogen auf die Applikationsform von 5-FU und die

TP-Expression

Abbildung 34: Verteilung der Resektate von Patienten aus der neoadjuvanten

Therapiegruppe $\mathrm{C}$ bezogen auf die Applikationsform von 5-FU und die

TP-Expression

Abbildung 35: DFS der Patienten aus der neoadjuvanten Therapiegruppe $C$ der Resektate in Bezug auf eine Behandlung mit oral oder intravenös appliziertem 5 -FU

Abbildung 36: DFS und CSS von Patienten aus Therapiegruppe $C$ in Bezug auf eine Behandlung mit oder ohne Capecitabin und einen möglichen Einfluss von TP

\section{Tabellenverzeichnis}

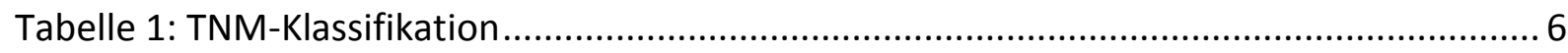

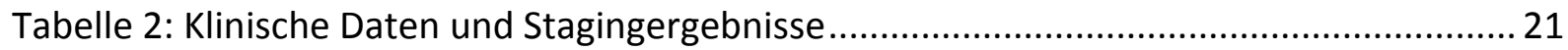

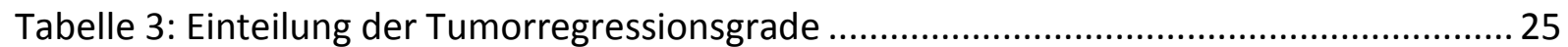

Tabelle 4: Tumornachsorgeplan bei Patienten mit Rektumkarzinom im UICC-Stadium-II/-III in der vorliegenden Arbeit ......................................................................... 25

Tabelle 5: Unbearbeitete Tabelle zur Beurteilung der Präparate....................................... 30

Tabelle 6: Beispiel einer Tabelle zur Dokumentation einer Präparatbeurteilung ................... 32

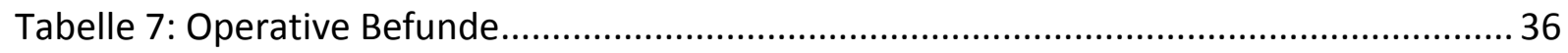

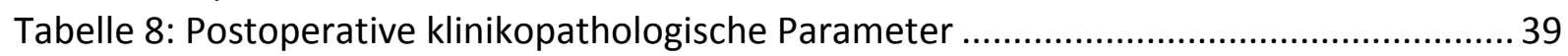

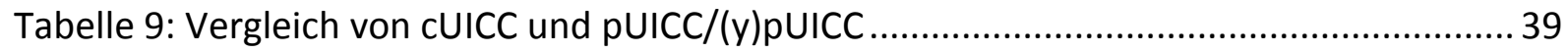

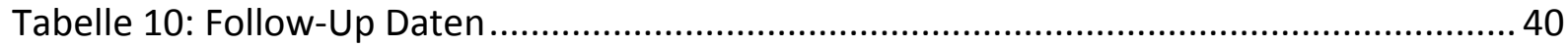

Tabelle 11: Studienlage zur Ermittlung des prognostischen Potentials von TP....................... 86

Tabelle 12: Studienlage zur neoadjuvanten Therapie mit Capecitabin bei 


\section{Einleitung und Zielsetzung}

Die vorliegende Arbeit befasst sich mit der Bedeutung der intratumoral exprimierten Thymidinphosphorylase bei Patienten mit einem Rektumkarzinom im UICC-Stadium-II/-III als potentiellen Biomarker zur Therapieoptimierung. Die immunhistochemischen Untersuchungen wurden im Teilprojekt 5a (Prädiktive und prognostische Biomarker beim lokal fortgeschrittenen Rektumkarzinom) der Klinischen Forschergruppe 179 (Biological Basis of Individual Tumor Response in Patients with Rectal Cancer, http://www.kfo179.de) retrospektiv an einer monozentrischen Studienpopulation von 223 Rektumkarzinom-Patienten mit klinischem Langzeit-Follow-Up durchgeführt.

\subsection{Klinischer Hintergrund}

\subsubsection{Inzidenz und Risikofaktoren kolorektaler Karzinome}

Die Gruppe kolorektaler Karzinome (KRK, Zusammenfassung von Kolon- und Rektumkarzinomen) stellt mit 143.460 Neuerkrankungen im Jahr 2008 (73.420 Männer und 70.040 Frauen) die dritthäufigste Krebserkrankung in den Vereinigten Staaten von Amerika (Siegel et al. 2012) dar. In Deutschland treten vergleichbare Inzidenzen für das KRK auf. Das KRK ist sowohl für Männer (mit 14,3\%) als auch für Frauen (mit 13,5\%) die zweithäufigste Krebstodesursache in der Bundesrepublik Deutschland (Robert Koch Institut 2012). Im Vergleich mit anderen Ländern in der Europäischen Union hat Deutschland die höchste Inzidenz für KRK. Einwohner in der Bundesrepublik haben ein etwa 4-fach höheres Risiko, ein KRK zu entwickeln als Menschen in lateinamerikanischen Ländern (Wingo et al. 1995). Daten der EPIC-Studie (European Prospective Investigation into Cancer and Nutrition) belegen, dass das Risiko an Darmkrebs zu erkranken mit den Ernährungsgewohnheiten korreliert. Rotes Fleisch, ballaststoffarme Kost und fettreiche Ernährung erhöhen das Risiko, während Fisch und ballaststoffreiche Kost das Risiko reduzieren (Weiß 2007; Robert Koch Institut 2006). So stieg die Neuerkrankungsrate in Deutschland zwischen 1980 und 2006 um $34 \%$ bei Männern und um 26\% bei Frauen (Robert Koch Institut 2012).

Über 90\% der Patienten mit neu diagnostiziertem KRK sind älter als 55 Jahre. Die gesetzliche Krankenversicherung übernimmt daher die Kosten für eine Vorsorgeuntersuchung mit kompletter Koloskopie ab dem 55. Lebensjahr. Bei gleichzeitiger Entfernung gutartiger Adenome senkt dieses Verfahren die Neubildung von KRK um bis zu 77\% (Brenner 2011). 
Die Sterberate für Darmkrebs ist in Deutschland von 1980 bis 2006 bei Männern um 24\% und bei Frauen um 38\% gesunken (Robert Koch Institut 2012).

\subsection{2 Ätiopathogenese}

Nach der Hypothese der „Adenom-Karzinom-Sequenz“ nach Fearon und Vogelstein aus dem Jahr 1990 entstehen KRK durch die Ansammlung genetischer Mutationen in einem aus drei Stufen verlaufenden Prozess: Initiation, Promotion und Progression (Fearon und Vogelstein 1990). Für die Manifestation eines KRK wird eine Dauer von 10 bis 15 Jahren angenommen. Zunächst entwickeln sich Adenome durch monoklonale Expansion aus einer einzigen genetisch veränderten mukösen Zelle. Morphologisch äußert sich diese Entwicklung in einer tubulär, tubulovillös oder villös konfigurierten, meist gestielten Schleimhautveränderung (Munding und Tannapfel 2009). Das von Vogelstein et al. 1988 beschriebene Modell der Adenom-Karzinom-Sequenz zur Entstehung von KRK beschreibt die potentielle Entwicklung eines Malignoms aus dieser gutartigen Vorstufe (siehe Abbildung 1). Mittlerweile wurden unterschiedliche molekulare Signalwege, die zur Manifestation eines KRK führen können, entschlüsselt und dem Modell der „Adenom-Karzinom-Sequenz“ hinzugefügt. Hierzu zählen Veränderungen in Onkogenen (z.B. Kirsten-ras-Protoonkogen $=$ k-ras) und Tumorsupressorgenen (z.B. Adenomatous-polyposis-coli = APC). Laut Fearon und Vogelstein aus dem Jahr 1990 ist hierbei weniger die Reihenfolge als vielmehr die Akkumulation der einzelnen Ereignisse ausschlaggebend. Dieser Ansatz beschreibt die sporadische Entstehung der KRK.

Demgegenüber stehen die heriditär entstandenen Karzinome, die im Rahmen verschiedener Syndrome mit einem erhöhten Risiko entstehen können. Sie umfassen etwa 5-10\% aller KRK (Al-Taie et al. 2001). So weisen z.B. Patienten mit der autosomal-dominant vererbten familiären adenomatösen Polyposis (FAP) eine Keimbahnmutation des APC-Gens auf, welches somit seine tumorsuppressive Funktion verliert (Fendrich und Bartsch 2005).

Das mit einem Anteil von 2-5\% am häufigsten vererbte KRK-Syndrom stellt das hereditäre non-polypöse kolorektale Karzinom (HNPCC) dar. Etwa $2 \%$ aller KRK sind mit diesem hereditären Syndrom assoziiert (Aaltonen et al. 1998). Ursächlich für diese Erkrankung sind Keimbahnmutationen in DNA-Mismatch-Reparatur-Genen MLH-1, MSH2 und MSH6 (AlTaie et al. 2001). Diese Mikrosatelliteninstabilität führt $\mathrm{zu}$ einer Akkumulation von Replikationsfehlern und beschleunigt die Karzinogenese (Aaltonen et al. 1998). 


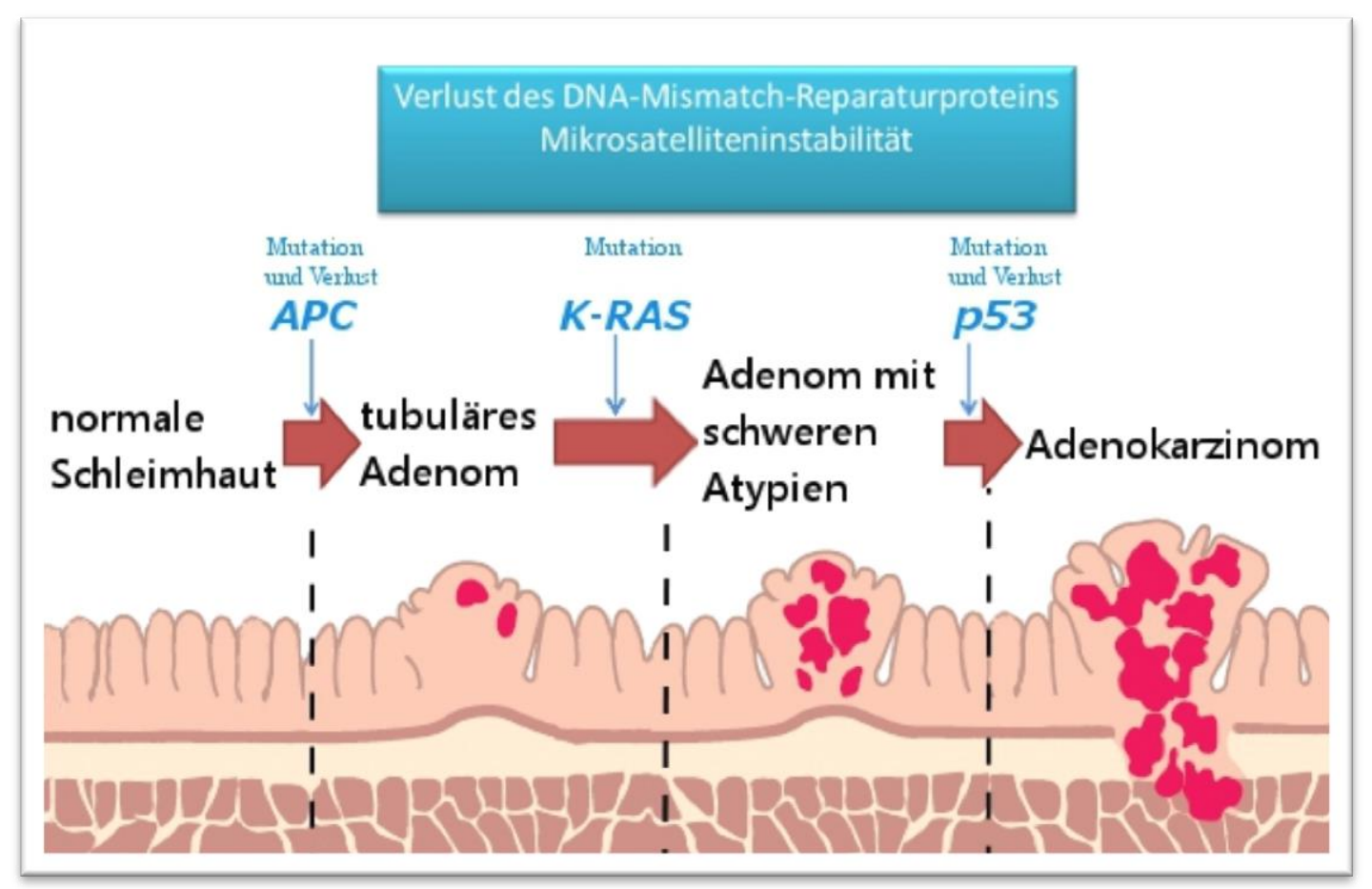

Abbildung 1: Adenom-Karzinom-Sequenz (modifiziert nach Arastéh 2009, S.553)

Bei der Karzinogenese des KRK spielt die „Adenom-Karzinom-Sequenz“ eine wesentliche Rolle. Innerhalb der Schleimhaut (lamina epithelialis mucosae) bildet sich unter Inaktivierung des Tumorsuppressorgens APC ein tubuläres Adenom aus. Diese Adenome können in verschiedenen Formen wachsen und haben unterschiedliche Entartungswahrscheinlichkeiten. So entstehen aus villösen und breitbasig wachsenden Adenomen eher Karzinome als aus tubulären und gestielten. Sobald das Adenom die lamina muscularis mucosae durchbrochen hat, gilt es als maligne entartet. Im Durchschnitt entarten etwa 5\% aller Adenome (Arastéh 2009).

\subsection{Prätherapeutische Diagnostik des Rektumkarzinoms}

Obwohl die anatomischen und physiologischen Unterschiede das Rektum als ein eigenes Organ definieren (Becker und Liersch 2006), wird in epidemiologischen Studien nur selten zwischen Kolon- und Rektumkarzinomen unterschieden (zusammengefasst als KRK). Um eine effektive, moderne und zugleich gezieltere, individuellere Therapie durchführen zu können, sollten Kolon- und Rektumkarzinome nach eigenen „Organ-spezifischen“ Therapieverfahren behandelt werden (Hong et al. 2012). Zudem sind im vergangenen Jahrzehnt erhebliche Fortschritte in der Diagnostik und Therapie des Rektumkarzinoms erzielt worden (Liersch et al. 2005). Daher wird nach der aktuellen UICC/TNM-Klassifikation (siehe unten) zwischen Kolon- und Rektumkarzinomen unterschieden (Wittekind und Sobin 2002; Wittekind und Meyer 2010). In der vorliegenden Arbeit wurden ausschließlich Rektumkarzinome untersucht (siehe unten).

Für eine patientenorientierte und tumorstadiengerechte Therapie sind folgende Staginguntersuchungen notwendig: 
Bei der digital rektalen Untersuchung kann die Schleimhaut des Rektums und die Funktion des Sphinkters beurteilt werden. Gleichzeitig kann bei klinischem Verdacht auf ein Rektumkarzinom die Verschieblichkeit des Tumors gegenüber der Schleimhaut, der Darmwand und dem umgebenden Gewebe geprüft werden (Klassifikation nach Mason, siehe Anhang).

Durch eine Messung per starrer Rektoskopie wurde die Höhe des Tumors und dessen Lokalisation im Rektum (bis $\leq 16 \mathrm{~cm}$ ab der Anokutanlinie) erfasst (Fieldling et al. 1991). Zudem wurden die Malignome dem unteren $(<6 \mathrm{~cm})$, dem mittleren $(6 \mathrm{bis}<12 \mathrm{~cm})$ und dem oberen (12 bis $16 \mathrm{~cm}$ ) Rektumdrittel zugeordnet.

Weiterhin wurde während der Rektoskopie ein rektaler Ultraschall (rES) durchgeführt. Bei dieser Untersuchung wurde ein Rotorschallkopf transrektal eingeführt. In der Hand des geübten Untersuchers weist die rES eine hohe Sensitivität und Spezifität auf. Die rES ist der konventionellen Computertomographie (CT) in Bezug auf die Diagnostik der lokoregionären Tiefeninfiltration des Karzinoms signifikant überlegen (Liersch et al. 2003).

Zuletzt erfolgte während der starren Rektoskopie eine Biopsie des Tumors. Diese wurde durch einen Pathologen beurteilt und diente dem prätherapeutischen Karzinomnachweis und Grading (siehe Kapitel 1.3). Nach Möglichkeit wurde darauf geachtet, die Biopsie und die rES während derselben Rektoskopie durchzuführen. Auf diese Weise verhinderte man ein Overstaging des Tumors während der rES durch den untersuchenden Arzt, hervorgerufen durch eine reaktive Lymphknotenvergrößerung nach der Biopsie (Liersch et al. 2007). Als Goldstandard gilt heutzutage neben der rES eine pelvine Magnetresonanztomographie (MRT) zur Beurteilung der Tumorausdehnung und der Lymphknoteninfiltration (Borsdorff 2010; Schmiegel et al. 2008a), dieses ist jedoch in Deutschland noch nicht flächendeckend verfügbar.

Zusätzlich wird bei der prätherapeutischen Staginguntersuchung eine Koloskopie zum Ausschluss eines Zweitkarzinoms durchgeführt. Eine laborchemische Blutbildkontrolle umfasst die prätherapeutische Untersuchung der Tumormarker (CEA, CA-19-9). Diese dienen in der Nachsorge des Patienten als Verlaufsparameter (Schmiegel et al. 2008a). Eine Abdomen-Sonographie und ein Röntgen-Thorax in zwei Ebenen dienen vor allem dem Ausschluss von möglicherweise bereits vorhandenen Fernmetastasen.

Das Stagingsergebnis mit Festlegung des cUICC-Stadiums (Union internationale contre le cancer) entscheidet über die Wahl der Operationstechnik und das ggf. notwendige multimodale Behandlungskonzept. 


\subsection{Klassifikation des Rektumkarzinoms}

Nach erfolgter histopathologischer Aufarbeitung des Resektates erfolgt die TNM-/UICCKlassifikation:

Der $\underline{\text { T-Status }}$ beschreibt hierbei die Infiltrationstiefe des Primärtumors in die umliegenden Wandschichten (siehe Tabelle 1).

Die Erfassung des regionären Lymphknotenbefalls (N-Status) sollte nach TNM-/UICCKriterien wenigstens auf 12 intraoperativ entnommenen und histopathologisch untersuchten Lymphknoten basieren (die American Association for Cancer Research fordert 14 Lymphknoten) (Hermanek, P 1995; Leibl et al. 2003; Wittekind und Meyer 2010). Um eine möglichst genaue Beurteilung des N-Status zu gewährleisten, sollten alle Lymphknoten eines Resektates untersucht werden. Diese Forderung zu erfüllen, ist mit der üblichen manuellen Lk-Dissektion zeitaufwendig und nach einer präoperativen Radiochemotherapie häufig erschwert. Derzeit gibt es Bemühungen die histopathologische Aufarbeitung der Lymphknoten zu verbessern. Zu diesen Methoden zählt die Acetonkompression des mesorektalen Weichgewebes, als alternative oder ergänzende Maßnahme zur manuellen LKDissektion (Gehoff et al. 2012).

Auch Ergebnisse aus einer Arbeitsgruppe innerhalb unserer Klinischen Forschergruppe 179 konnten, in Bezug auf das Auftreten von Rezidiven und das Gesamtüberleben, die prognostische Bedeutung der Lymphknotenmetastasen bei Patienten mit lokal fortgeschrittenem Rektumkarzinom (UICC-II/-III) hervorheben (Sprenger et al. 2010a; Sprenger et al. 2010b).

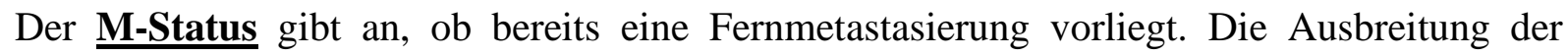
Metastasierung erfolgt bedingt durch das venöse System und die ableitenden Lymphbahnen. Je nach Lokalisation des Tumors im Rektum kann dies über unterschiedliche Wege erfolgen:

- über die Arteria rectalis superior zur Vena porta in die Leber $(8,1 \%)$

- über die Arteria rectalis inferior zur Vena cava inferior in die Lunge (7,2\%). Auch andere Organe, wie umliegende Lymphknoten, Peritoneum und das Skelettsystem $(9,0 \%)$ können betroffen sein.

In der vorliegenden Dissertation wurde die zum Zeitpunkt der Untersuchung gültige UICCKlassifikation 2002 genutzt (siehe Tabelle 1). Seit 2010 gibt es eine aktualisierte Version der UICC-Klassifikation (siehe Anhang). 


\begin{tabular}{|llc|}
\hline TNM-Klassifikation & & UICC-Stadium \\
\hline Tis & Primärtumor & \\
T1 & Carcinoma in situ & - \\
T2 & Tumor infiltriert die Submukosa & I \\
T3 & Tumor infiltriert Tunica muscularis & I \\
& Tumor infiltriert Subserosa und perirektales & II \\
T4 & Gewebe & \\
& Tumor infiltriert angrenzende Organe und/oder & II \\
N & das viszerale Peritoneum & \\
\cline { 2 - 3 } N0 & Regionäre Lymphknoten & \\
N1 & Keine regionären Lymphknotenmetastasen & III \\
N2 & Metastasen in 1-3 regionären Lymphknoten & III \\
& Metastasen in 4 oder mehr regionären & \\
M & Lymphknoten & \\
M0 & Fernmetastasen & IV \\
M1 & Keine Fernmetastasen & \\
\hline
\end{tabular}

Tabelle 1: TNM-Klassifikation nach Wittekind und Sobin, 2002

Im Rahmen des Stagings kommt es zu einer Beurteilung des Tumors nach den TNM-Stadien. In diesem Rahmen wird die Ausdehnung des Primärtumors (Tx-T4), der Lymphknotenstatus (Nx-N2) und der Metastasierungsstatus (M0-M1) beurteilt. Anhand der TNM-Klassifikation werden außerdem Tumoren nach den UICC Stadien von 0 bis IV eingeteilt.

\subsection{Neoadjuvante Therapie des lokal fortgeschrittenen Rektumkarzinoms}

Nach den aktuellen S3-Leitlinien und ESMO-Guidelines (European Society for Medical Oncology) wird für das lokal fortgeschrittene Rektumkarzinom (cUICC-II/-III-Stadien) eine präoperative (d.h. in neoadjuvanter Intention) kombinierte Radiochemotherapie (RT/CTx), mit 5-FU als Radiosensitizer, empfohlen (Schmiegel et al. 2008a; Schmoll et al. 2012).

Das Risiko, innerhalb von 5 Jahren an einem Lokalrezidiv zu erkranken, konnte durch Anwendung der totalen mesorektalen Exzision (TME) in den vergangenen 20 Jahren um bis zu 30\% (auf unter 15\%) reduziert werden (Liersch et al. 2009). Dies resultiert aus den 2004 publizierten 5-Jahres Ergebnissen der CAO/ARO/AIO-94-Phase-III-Studie (Fördernummer der Krebshilfe: 70-587) der German Rectal Cancer Study Group (GRCSG). In dieser Studie wurden die Auswirkungen einer neoadjuvanten RT/CTx gegenüber der bis dahin üblichen postoperativen RT/CTx (50,4 Gy und 5-Fluorouracil-Mono-Chemotherapie), bezogen auf die Lokalrezidivrate und das Gesamtüberleben, geprüft. Verglichen mit der Kontrollgruppe 
konnte durch die neoadjuvante RT/CTx das Risiko für ein Lokalrezidiv von $13 \%$ auf $6 \%$ gesenkt werden. Dieser Effekt war auch nach 10 Jahren noch signifikant nachweisbar (Sauer et al. 2012). Zudem traten weniger akute und späte Nebenwirkungen in der neodajuvanten Therapie-Gruppe auf. Für das Gesamtüberleben konnte jedoch kein signifikanter Unterschied festgestellt werden (Sauer et al. 2004; Sauer et al. 2012).

Durch die neoadjuvanten RT/CTx konnte bei $8 \%$ der Patienten eine komplette Tumorremission mit einem tumorfreien 5-Jahres-Überleben (Disease Free Survival: DFS) von $86 \%$ festgestellt werden (Rödel et al. 2005). Außerdem zeigten die Ergebnisse der CAO/ARO/AIO-94, dass die neoadjuvante Therapie bei bis zu 19\% der Patienten zu einer Modifizierung der ursprünglich geplanten Operationsstrategie im Hinblick auf einen Kontinenzerhalt führte (Liersch et al. 2005).

\subsubsection{Aktuelle Therapieansätze zum Zeitpunkt der Untersuchung}

Nach dem derzeitigen Kenntnisstand ist das individuelle Ansprechen des Rektumkarzinoms auf eine RT/CTx sehr unterschiedlich und kann vom kompletten Therapieversagen („Nonresponder"), über ein intermediäres Therapieansprechen bis zur kompletten Tumorregression („Komplettresponder“, ypT0 ypN0 M0) reichen. Um diesen Unterschieden therapeutisch gerecht zu werden, sind neue Medikamente, die zeitliche Sequenz der einzelnen therapeutischen Schritte und die Einführung molekularer Marker zur Responseprädiktion Gegenstand klinischer Forschung und Studien. Man hofft, dass Patienten zukünftig Responseadaptiert behandelt werden können. Komplettresponder könnte man weiterhin nach den gegenwärtigen Leitlinien therapieren, Nonresponder müssten alternativ behandelt werden. Unter Nutzung evaluierter, prädiktiver Biomarker könnten so z.B. intermediäre Responder mit einer intensivierteren RT/CTx (mit 5FU+Oxaliplatin), und anschließender adjuvanter CTx behandelt werden (Liersch et al. 2010).

Als Nachfolgestudie der im Jahr 2004 erstmals publizierten CAO/ARO/AIO-94-Studie wurde die CAO/ARO/AIO-04 durch die GRCSG initiiert (Studiennummer: NCT 00349076). Hierbei handelt es sich um eine Phase-III-Studie für lokal fortgeschrittene Rektumkarzinome der beiden unteren Rektumdrittel ( 0 bis $<12 \mathrm{~cm}$ ab Anokutanlinie) (Rödel et al. 2012). Im Rahmen dieser Studie wird im Prüfarm zusätzlich zur präoperativen RT/CTx Oxaliplatin eingesetzt. Während der postoperativen Phase erhält diese Gruppe Oxaliplatin und zusätzlich Folinsäure (Leukovorin) zur Verstärkung der Wirkung von 5-FU. Die Kontrollgruppe erhält die bisherige 
Standard-Monotherapie mit 5-FU. Mit dieser Studie wird konsequent aufbauend auf der CAO/ARO/AIO-94-Studie versucht, die Komplettremissionsrate zu steigern und das DFS und OS zu verbessern.

Rektumkarzinome mit UICC-Stadium-II und -III des oberen Rektumdrittels (12 bis $16 \mathrm{~cm}$ ab Anokutanlinie) werden gegenwärtig im Rahmen der GAST-05 (German Advanced Surgical Trial Group)-Studie (internationale Studiennummer: ISRCTN35198481), einer multizentrischen Add-on-Studie zur CAO/ARO/AIO-04, primär mit einer Operation behandelt: Dabei wird im Studienarm A eine TME, im Arm B eine potentiell nervenschonendere, partielle mesorektale Exzision (PME) durchgeführt. Eine adjuvante CTx mit 5-FU, Folinsäure und Oxaliplatin erfolgt für beide Gruppen gemäß den Vorgaben der CAO/ARO/AIO-04-Studie.

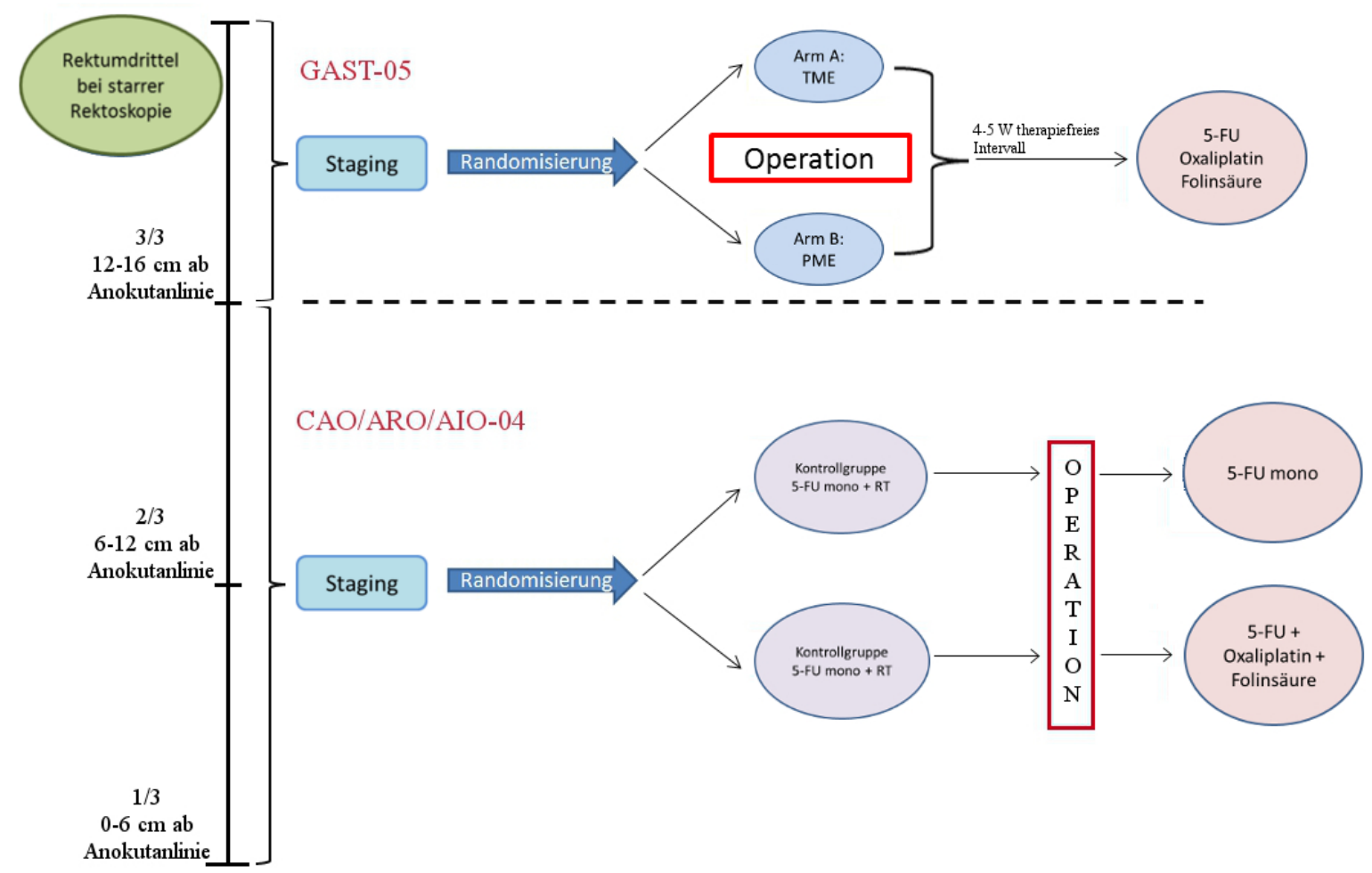

\section{Abbildung 2: Aufbau der GAST-05- und der CAO/ARO/AIO-04-Studie (modifiziert nach Liersch et al. 2009)}

Therapiestratifizierung beim (c)UICC-II/III-Rektumkarzinom nach Höhenlokalisation ab Anokutanlinie. Tumoren im unteren und mittleren Rektumdrittel $(0-12 \mathrm{~cm})$ werden nach dem Therapieregime der CAO/ARO/AIO-04 behandelt. Gegenwärtig wird zusätzlich in der GAST-05-Studie geprüft, ob Tumoren im oberen Rektumdrittel $(12-16 \mathrm{~cm})$ mit einer PME ausreichend versorgt werden können. 


\subsection{Chirurgische Therapie des Rektumkarzinoms}

Für die Wahl der Therapie (primäre Operation oder neoadjuvante Therapie) sind das Tumorstadium und die Tumorlokalisation des KRK entscheidend. Ebenso muss das individuelle Risikoprofil (Komorbidität, verbleibende Lebensqualität nach der multimodalen Therapie, rezidivfreies Überleben, Gesamtüberleben etc.) des Patienten berücksichtigt werden (Liersch et al. 2005). Bei allen Operationstechniken sollten onkologische Resektionsprinzipien wie die „En-bloc-Resektion“ und die „no-touch-Technik“ gewahrt werden (Liersch et al. 2007). Diese sollen die mechanisch bedingte (iatrogene) Streuung einzelner Tumorzellen in das umliegende Gewebe oder den Blutkreislauf verhindern.

Gemäß den S3-Leitlinien und der aktuellen ESMO-Guideline (Schmoll et al. 2012) sind folgende drei Resektionsverfahren bei primären Rektumkarzinomen üblich: die tiefe anteriore Rektumresektion (TARR), die abdomino-perineale Rektumextirpation und die intersphinktäre Rektumresektion.

Das jeweilige OP-Verfahren richtet sich nach der Höhenlokalisation und Tiefeninfiltration des Karzinoms, wobei grundsätzlich das Verfahren mit größter onkologischer Sicherheit bei gleichzeitig geringstem Risiko für einen Funktionsverlust zu bevorzugen ist.

Lokal fortgeschrittene Rektumkarzinome erfordern bei einem kurativen therapeutischen Ziel eine umfassende multimodale und interdisziplinäre Behandlung, eine alleinige lokale chirurgische Tumorresektion gilt als nicht ausreichend. Neben einer Resektion des Tumors im gesunden Gewebe (R0-Resektion) ist die TME hierbei die Therapie der Wahl, da sie die komplette Entfernung des Lymphabflusses gewährleistet und das Lokalrezidivrisko verringert (Heald et al. 1982).

Ist der Tumor im unteren (bis $<6 \mathbf{~ c m}$ ab Anokutanlinie) oder mittleren Rektumdrittel (6 bis $<12 \mathrm{~cm}$ ab Anokutanlinie) lokalisiert, folgt eine tiefe anteriore Rektumresektion (TARR) mit TME nach neoadjuvanter RT/CTx.

Eine PME hingegen umfasst die Durchtrennung des Rektums und des Mesorektums $5 \mathrm{~cm}$ distal des aboralen Tumorrandes im rechten Winkel zur Darmlängsachse und wird kurativ lediglich bei Tumoren im oberen Rektumdrittel (12 bis $<\mathbf{1 6} \mathbf{~ c m}$ ab Anokutanlinie) durchgeführt (siehe Kapitel 1.4.1). Sowohl die TME als auch die PME sollten unter größtmöglicher Schonung des Plexus hypogastricus superior, der Nn. hypogastrici und der Plexus hypogastrici inferiores sinister und dexter erfolgen.

Direkt supraanal gelegene Tumoren (>cT2) infiltrieren häufig den Sphinkter und erlauben keine kontinenzerhaltende Operation. Daher ist in diesen Fällen die radikalste 
Rektumresektion, eine abdominoperineale Rektumextirpation, notwendig (Becker und Liersch 2006). Bei der abdominoperinealen Rektumextirpation (APR) wird zur TME en bloc der Sphinkterapparat, ein Teil der Beckenbodenmuskulatur und das perineale Fettgewebe entfernt.

Eine alternative Operationstechnik ist die erweiterte abdomino-sakrale Rektumexstirpation nach Holm mit Teil- oder Komplettresektion des M. levator ani und des Sakrums bzw. der Steißbeinspitze (Holm et al. 2007).

\subsection{Adjuvante Therapie des lokal fortgeschrittenen Rektumkarzinoms}

Eine postoperative Therapie in adjuvanter Intention ist bei Rektumkarzinomen im UICC-IStadium nach einer R0-Resektion nicht indiziert.

Eine leitliniengerechte Therapie sieht aber vor, dass Patienten mit einem Rektumkarzinom im (y)pUICC-Stadium-II und -III (der Buchstabe $(y)$ beschreibt den Zustand nach erfolgter neoadjuvanter Radiochemotherapie) eine adjuvante Chemotherapie mit 5-FU mono in einem Abstand von 4-6 Wochen nach der Operation erhalten (Schmiegel et al. 2008a; Schmoll et al. 2012).

Patienten im selben Tumorstadium, die zuvor aber keine neoadjuvante Therapie bekommen konnten, sollten eine adjuvante Kombinationstherapie aus 5-FU mono und Bestrahlung erhalten (Schmiegel et al. 2005; Schmiegel et al. 2008b). Durch die zusätzlich zur Bestrahlung hinzugefügte Chemotherapie konnte, im Vergleich zur Kontrollgruppe, die Lokalrezidivrate gesenkt und das Gesamtüberleben verbessert werden (Krook et al. 1991; Gastrointestinal Tumor Study Group 1985). Bei einer R1-Resektion oder einem intraoperativen Tumoreinriss sollte stets eine adjuvanten RT/CTx zur Reduktion des Lokalrezidiv-Risikos erfolgen (Liersch et al. 2005).

\subsection{Pharmakokinetische und pharmakodynamische Eigenschaften von}

\section{5-Fluoruracil}

5-Fluoruracil (5-FU) ist ein Medikament aus der Gruppe der Pyrimidinanaloga und wird seit über 50 Jahren als Zytostatikum beim metastasierten Mammakarzinom und beim KRK eingesetzt. 5-FU wird, aufgrund der variablen Resorption nach oraler Applikation, vorzugsweise intravenös verabreicht oder seit dem Jahr 2001 in Form des oralen Prodrugs Capecitabin (Xeloda ${ }^{\circledR}$ ) appliziert (Petz 2006; Aktories et al. 2006). 
5-FU ist ein Analogon der Nukleinbase Uracil und unterscheidet sich von dieser durch eine Fluorierung am 5. Kohlenstoffatom des Pyrimidinringes. Nach Aufnahme aus dem Blutkreislauf erreicht 5-FU intrazellulär seine Wirksamkeit; indem es mit einer Ribose phosphoryliert wird; es entsteht 5-Fluoruridinmonophosphat (5-FUMP).

Wird 5-FU durch TP mit einer Desoxyribose phosphoryliert, so entsteht hingegen 5-Fluoro- 2'-deoxyuridine (5-FdUrd). Die zytotoxische Wirkung von 5-FU beruht im Wesentlichen auf den beiden genannten Molekülen und den folgenden metabolischen Schritten (Schilsky 1998):

1. 5-FUMP wird zu 5-Fluoruridintriphosphat (5-FUTP) phosphoryliert und konkurriert nun mit dem physiologischen Nukleosid, dem Uridintriphosphat (UTP), um den Einbau in die RNA. Dies führt zu einer fehlerhaften RNA-Synthese und schließlich zu einer gestörten Proteinbiosynthese.

2. 5-FdUrd wird zytoplasmatisch von der Thymidin-Kinase zu 5-Fluordesoxyuridinmonophosphat (5-FdUMP) umgewandelt. Die folgenden beiden enzymatischen Mechanismen basieren auf der Wirkung von 5-FdUMP:

a) 5-FdUMP kann zu 5-Fluordesoxyuridintriphosphat (5-FdUTP) phosphoryliert und von der DNA-Polymerase anstelle von Desoxythymidintriphosphat (dTTP) in die DNA eingebaut werden. In der Folge kommt es zu einem Abbruch der Transkription.

b) 5-FdUMP hemmt TS und inhibiert somit die Umwandlung von Desoxyuridinmonophosphat (dUMP) zu Desoxythymidinmonophosphat (dTTP). In der Folge wird die Synthese des DNA-Strangs verhindert und es kommt zu einer Wachstumshemmung mit anschließendem Zelltod (,thymidine-less cell death“) (Efferth 2006). Dieser zuletzt genannte metabolische Mechanismus scheint primär verantwortlich für die zytotoxische Wirkung von 5-FU zu sein (Schilsky 1998).

Ein geringer Teil von 5-FU wird unverändert über die Niere ausgeschieden, der größte Teil wird aber in der Leber abgebaut (Pinedo und Peters 1988). Die Halbwertszeit im Blutplasma beträgt nur etwa 10-20 min (TEVA Deutschland Fachinformation 2007). Ein Schlüsselenzym für den Abbau und die Ausscheidung von 5-FU ist die Dihydropyrimidin-Dehydrogenase (DPD). Dieses Enzym kommt vor allem in der Leber vor und katalysiert sowohl den Abbau von körpereigenen Pyrimidinen als auch den Abbau von 5-FU. Durch einen genetischen Polymorphismus in der Bevölkerung kommt es zu variablen Ausprägungsgraden dieses Enzyms im Tumorgewebe von betroffenen Patienten. Dies führt zu abweichenden Bio- 
verfügbarkeiten von 5-FU mit unterschiedlich hohen Blutplasmaspiegeln. Daraus resultieren verschieden starke zytostatische Wirkungen des Medikaments im Karzinomgewebe. Außerdem führen die Unterschiede in der DPD-Expression und -Aktivität zu ganz unterschiedlichen, therapieassoziierten Toxizitäten bzw. unerwünschten Nebenwirkungen (Lordick et al. 2010). So können einzelne Patienten eine starke Diarrhö, Mukositis und Panzytopenie entwickeln.

Weitere bekannte Nebenwirkungen sind Übelkeit und Erbrechen, rektale Blutungen, Volumenmangel, Hautveränderungen und neurologische Störungen wie zerebelläre Ataxien und kognitive Dysfunktionen (Wollmer und Neubauer 2011). Treten unter der Therapie mit 5-FU schwere kardiale Nebenwirkungen, wie Koronarspasmen oder ein Myokardinfarkt auf, muss das Chemotherapieregime unter Verzicht auf 5-FU gewechselt werden (Spencker et al. 2007).

Bei Patienten mit einem seltenen kompletten DPD-Mangel akkumuliert 5-FU im Körper und kann zu einer lebensbedrohlichen Intoxikation führen (Lordick et al. 2010). 


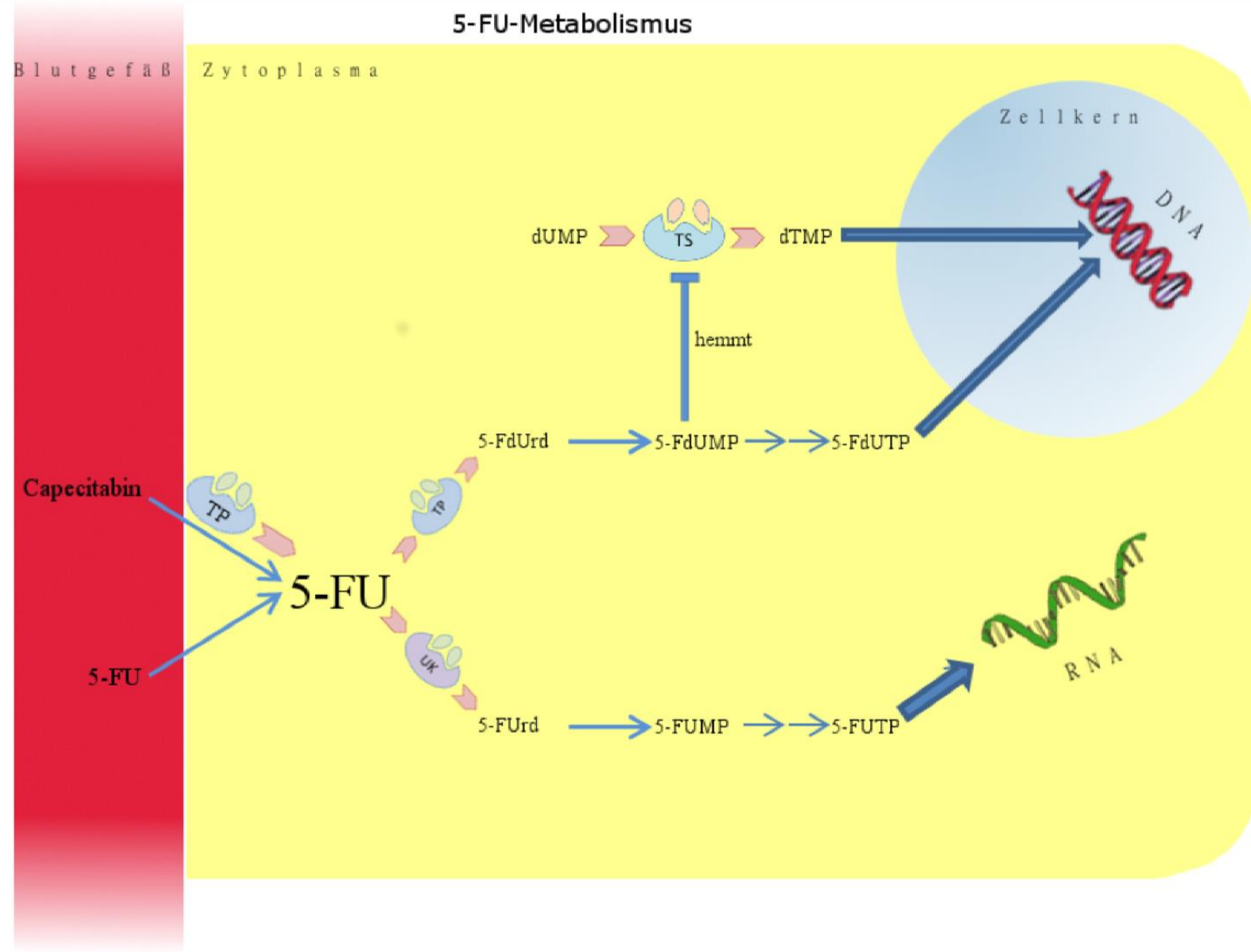

\section{Abbildung 3: Intrazellulärer 5-FU-Metabolismus}

5-FU bzw. Capecitabin gelangt über die Blutgefäße zu den Tumorzellen und wird von den Zellen aufgenommen. TP sorgt für eine Umwandlung von Capecitabin zu 5-FU. Anschließend wird 5-FU durch TP zu 5-FdUrd oder durch die Uridinphosphorylase (UP) zu 5-FUrd umgewandelt. Die Metaboliten von 5-FU können aufgrund ihrer Ähnlichkeit zu den Pyrimidinbasen Cytosin, Thymidin und Uracil in die DNA bzw. RNA eingebaut werden und bewirken somit eine fehlerhafte Synthese des Erbmaterials. Dies führt zu einer Hemmung des Zellwachstums und der Zellteilung.

Außerdem sorgt der Metabolit 5-FdUMP für eine Hemmung des Enzyms Thymidylat-Synthase (TS), welches normalerweise für die katalytische Umsetzung von dUMP zu dTMP zuständig ist. Das Zellwachstum und die Zellteilung werden somit auf diesem Weg zusätzlich unterbunden.

\subsection{Molekulare Biomarker beim Rektumkarzinom}

Obwohl etwa $45 \%$ aller Patienten auf eine neoadjuvante Therapie mit einem T-Leveldownsizing reagieren, ist es bis heute nicht möglich vorherzusagen, welche Patienten von diesem Therapieeffekt profitieren können. Ein möglicher Ansatz zur prädiktiven (d.h. der Einfluss auf das Ansprechen einer bestimmten Therapie) und prognostischen (d.h. der Einfluss auf das Überleben) Beurteilung einer neoadjuvanten Therapie liegt in der 
Identifizierung molekularer Biomarker. In einer großen Metaanalyse wurden sechs bisher am häufigsten untersuchte Biomarker beim Rektumkarzinom geprüft (Kuremsky et al. 2009). Dies waren $\mathrm{p} 53$, der epidermale Wachstumsfaktorrezeptor (epidermal growth factor receptor: EGFR), die Thymidylatsynthase (TS), Ki-67, p21 und bcl-2/bax.

Die Ergebnisse machten deutlich, dass das Ansprechen eines KRK auf eine neoadjuvante Therapie nicht anhand eines einzelnen Biomarkers bestimmt werden kann. Eine höhere Aussagekraft wird vielmehr von einer multifaktoriellen Analyse erhofft. Weitere Ergebnisse der oben genannten Metaanalyse machen deutlich, dass die molekularen Marker TS, EGFR und p21 künftig in umfangreichen, prospektiven klinischen Studien überprüft werden müssen, um detaillierte Aussagen über den Nutzen der Biomarker treffen zu können.

In einer Untersuchung an 40 Patienten prüften Jakob et al. (2006) den prognostischen Wert der Biomarker TS, TP und der Dihydropyrimidin-Dehydrogenase (DPD) bei Patienten mit einem lokal fortgeschrittenem Rektumkarzinom im UICC-Stadium-II/-III nach neoadjuvanter RT/CTx. Diese Untersuchung konnte keine Auswirkung bezüglich der intratumoralen TPExpression auf das outcome der Patienten nachweisen. Die Autoren berichteten zudem, dass es in der Literatur zum Zeitpunkt ihres Projekts keine umfangreichen vergleichbaren Daten an größeren Patientenkollektiven unter standardisierten Therapiebedingungen gab und zukünftig weitere Forschungsprojekte notwendig seien (Jakob et al. 2006).

In der vorliegenden Arbeit wird daher die Relevanz der detaillierten Analyse von TP als Biomarker in einer umfangreichen, patientenorientierten klinischen Studie überprüft.

\subsection{Intrazelluläre und therapeutische Bedeutung von TP und TS}

\subsubsection{Thymidinphosphorylase im Überblick}

Die Thymidinphosphorylase (TP), auch unter dem Namen „Platelet-derived endothelial cell growth factor" (PDGF1) bekannt, dient im Gewebe als angiogener Faktor und katalysiert mindestens drei bekannte Reaktionen, die im Zusammenhang mit 5-FU stehen. In Krebszellen konnten gegenüber normalem Gewebe erhöhte Konzentrationen von TP gemessen werden (Yoshimura et al. 1990). Als angiogener Faktor sorgt TP für ein Wachstum des Tumors in die Tiefe des Gewebes und eine starke Vaskularisierung des Tumors. Es wird berichtet, dass eine hohe Gefäßdichte mit einer erhöhten Wahrscheinlichkeit für Metastasen und Rezidive des Primärtumors einhergeht (Takebayashi et al. 1996). 
TP ist ebenfalls ein Schlüsselenzym bei der Umsetzung von 5-FU zu 5-Fluorodeoxyuridin (5-FdUrd), welches in den aktiven Metaboliten 5-FdUTP umgesetzt wird (siehe Abbildung 3). Außerdem katalysiert TP intrazellulär die Umsetzung von oral eingenommenem Capecitabin zu 5-FU (Boskos et al. 2010). Studien haben gezeigt, dass bei Patienten mit metastasiertem KRK die TP-Expression signifikant mit dem Ansprechen auf eine Therapie mit Capecitabin und dem Gesamtüberleben korreliert (Lordick et al. 2010).

\subsubsection{Thymidylatsynthase im Überblick}

Die Thymidylatsynthase katalysiert die intrazelluläre Reduktion von dUMP zu dTMP (siehe Abbildung 3) (Lordick et al. 2010). Somit ist sie entscheidend am Pyrimidinstoffwechsel beteiligt und für die Synthese der Desoxyribonukleinsäure (DNA) unentbehrlich. Daher gilt TS als Schlüsselenzym im 5-FU Metabolismus und ist essentiell für die zytostatische 5-FU-Wirkung.

Die Rolle der Thymidylatsynthase als prognostischer und prädiktiver Biomarker wurde in den vergangenen Jahren in unterschiedlichen Studien analysiert. Die bereits in Kapitel 1.8 erwähnte Metaanalye von Kuremsky et al. evaluierte, dass vier von fünf Studien eine signifikante Assoziation zwischen der TS-Expression und einem klinisch messbaren Ereignis feststellen konnten. Drei dieser Studien konnten ein besseres outcome für Patienten mit geringer TS-Expression nachweisen (Kuremsky et al. 2009). Auch Jakob et al. konnten im Jahr 2006 einen solchen Verlauf für Patienten mit einer geringen TS-Expression zeigen. Kuremsky et al. schlussfolgerte 2009 in der Metaanalyse, dass weitere Studien zur Untersuchung der TS-Expressionsmuster durchgeführt werden müssten.

In Vorarbeiten der Arbeitsgruppe innerhalb der KFO 179 konnte bereits im Jahr 2010 retrospektiv gezeigt werden, dass Patienten mit einem positiven Nodalstatus nach neoadjuvanter Radiochemotherapie bei geringer immunhistochemischer Expression von TS ein kürzeres DFS hatten. Die Analyse der prätherapeutischen Biopsien ergab für Patienten mit geringer TS-Expression eine signifikante Korrelation mit einem verringerten OS (Conradi 2010). Folglich könnte die Bestimmung der TS nach prospektiver Re-Validierung der Daten durch unsere Forschergruppe, neben weiteren Biomarkern, in die histopathologische Routinediagnostik implementiert werden, um zukünftig eine individualisiertere Therapiestratifizierung zu ermöglichen. 


\subsection{Zielsetzung und Fragestellung}

Bei allen Patienten der vorliegenden Studie wurde ein lokal fortgeschrittenes Rektumkarzinom (UICC-Stadium-II/-III) diagnostiziert. Die 5-FU-basierte multimodale Therapie erfolgte interdisziplinär in der Universitätsklinik Göttingen (siehe Kapitel 2.1) entsprechend der aktuellen S3-Leitlinie zum Rektumkarzinom (Schmiegel et al. 2008a) oder in randomisierten, kontrollierten Phase-II/-III Studien (siehe Kapitel 1.3.1).

Unterschiedliche Studien konnten belegen, dass das Ansprechen der Patienten mit lokal fortgeschrittenem Rektumkarzinom auf die neoadjuvante, 5-FU-basierte RT/CTx, gemessen am Grad der Tumorregression, sehr variabel sein kann. Die Unterschiede reichen hierbei von Nonrespondern (TRG 0) bis hin zu Komplettrespondern (TRG 4) (Rödel et al. 2005; Liersch et al. 2009). Für diese Beobachtung ist am ehesten die individuelle genomische und proteomische Struktur des Karzinoms ursächlich. In der KFO 179 wird daher mit unterschiedlichen Methoden (siehe KFO http://www.kfo179.de) versucht, Einblicke in die komplexe Tumorbiologie des Rektumkarzinoms zu erhalten.

Aus klinischer Sicht sollen zukünftig Therapiestrategien etabliert werden, die das individuelle Therapieansprechen und das Risiko fernmetastatischer Rezidive berücksichtigen. Vor diesem Hintergrund werden in der KFO179 verschiedene Biomarker erforscht in Bezug auf ihr prädiktives und prognostisches Potential.

Einer dieser Biomarker ist die TP, deren Stellenwert bzgl. einer Response-Prädiktion auf die RT/CTx unklar ist.

In der vorliegenden Arbeit wird Material von 223 Rektumkarzinom-Patienten untersucht, die im Rahmen einer standardisierten Tumornachsorge 66 Monate (Mittelwert) klinisch nachkontrolliert wurden.

Folgende Fragen sollen beantwortet werden:

1. Wie hoch ist der Expressionsgrad von TP in Zellen der prätherapeutischen Biopsie?

2. Wie hoch ist der Expressionsgrad von TP in Zellen des Rektumresektates nach erfolgter präoperativer RT/CTx?

3. Können inter-/intraindividuelle Veränderungen der TP-Expression in Tumorzellen aus der Biopsie gegenüber Tumorzellen aus dem Rektumresektat nach erfolgter RT/CTx festgestellt werden? 
4. Hat die gemessene TP-Expression in Tumorzellen aus der prätherapeutischen Biopsie einen prädiktiven Wert bezüglich des Ansprechens auf eine neoadjuvante RT/CTx?

5. Hat die gemessene TP-Expression in Tumorzellen aus der prätherapeutischen Biopsie einen prognostischen Wert bezüglich des rezidivfreien Überlebens (disease free survival: DFS) oder dem Malignom-spezifischen Gesamtüberleben (cancer specific survival: CSS)?

6. Hat die gemessene TP-Expression aus residuellen Tumorzellen aus dem Rektumresektat nach RT/CTx einen prognostischen Wert bezüglich des DFS oder dem CSS?

7. Wird eine Therapiestratifizierung mit TP als immunhistochemischer Laborparameter möglich sein? Wäre eine Eingliederung in den klinischen Alltag sinnvoll?

8. Gibt es einen Zusammenhang zwischen der Expression von TP und TS? Ist eine Korrelation der beiden Enzyme zur Therapiestratifizierung möglich/sinnvoll? 


\section{Patienten, Material und Methoden}

\subsection{Patientenkollektiv}

Insgesamt wurden in dieser Arbeit 223 Patienten mit einem lokal fortgeschrittenen Rektumkarzinom im (c)UICC-Stadium-II und -III untersucht. Bei den Patienten handelte es sich um 66 Frauen und 157 Männer (siehe Tabelle 2) mit einem durchschnittlichen Alter von 67,96 Jahren (zwischen 37 und 87 Jahren alt).

Vor dem Beginn der Therapie unterzeichneten alle Patienten eine schriftliche Einverständniserklärung, zur Auswertung der personenbezogenen Daten, zur Durchführung der multimodalen Therapie, den notwendigen diagnostischen Maßnahmen und der Follow-Up Untersuchungen.

Die Patienten wurden in der Klinik für Allgemein-, Viszeral- und Kinderchirurgie (ehemaliger Direktor: Prof. Dr. Heinz Becker; Direktor seit April 2012: Prof. Dr. Michael Ghadimi) im Rahmen der KFO 179 der Universität Göttingen zwischen Januar 1996 und Januar 2010 behandelt. Die Patienten wurden einer multimodalen, interdisziplinären Therapie in Zusammenarbeit mit der Abt. Strahlentherapie und Radioonkologie (Direktor: Prof. Dr. Dr. Clemens-F. Hess) unterzogen.

Zunächst wurde im Rahmen des prätherapeutischen Stagings das (c)UICC-Stadium (cT, cN, cM) diagnostiziert. Anschließend wurde eine starre Rektoskopie zur standardisierten Höhenlokalisation des Tumors durchgeführt, gefolgt von einer rES (vgl. Kapitel 1.2). Nach der rES wurde Material bioptisch entnommen, sodass die Diagnose Rektumkarzinom verifiziert werden konnte. Insgesamt wurde das Gewebe von 186 prätherapeutischen Biopsien und 223 OP-Resektate im Rahmen dieser Arbeit immunhistochemisch gefärbt (siehe Kapitel 2.5) und mikroskopisch untersucht (siehe Kapitel 2.6).

Im Rahmen der Ergebnisauswertung dieser Arbeit wurde das Patientenkollektiv in 3 Subgruppen aufgeteilt (siehe Abbildung 4): Gruppe A umfasst 42 Patienten (18,8\%) aus dem Kontrollarm der CAO/ARO/AIO-94-Studie, die alle primär operiert wurden, gefolgt von einer adjuvanten CTx. Gruppe B enthält 113 Patienten (50,4 \%) die einer neoadjuvanten 5-FUMonotherapie mit RTx und anschließend einer adjuvanten 5-FU-Monotherapie zugeführt wurden. Diese Patienten stammen aus dem Prüfarm der CAO/ARO/AIO-94-Studie oder dem Kontrollarm der CAO/ARO/AIO-04-Studie. Gruppe C enthält 69 Patienten (30,8 \%) aus dem 
Kontrollarm der CAO/ARO/AIO-04-Studie, die eine intensivierte neoadjuvante RT/CTx mit 5-FU und Oxaliplatin erhielten. Es folgte eine adjuvante Therapie mit 5-FU, Oxaliplatin und Folinsäure.

Die postoperative, histopathologische Aufarbeitung der Tumorresektate und die Bestimmung des Tumorregressionsgrades erfolgte in der Abteilung für Gastroenteropathologie durch Ö̈. Dr. med. Hilka Rothe.

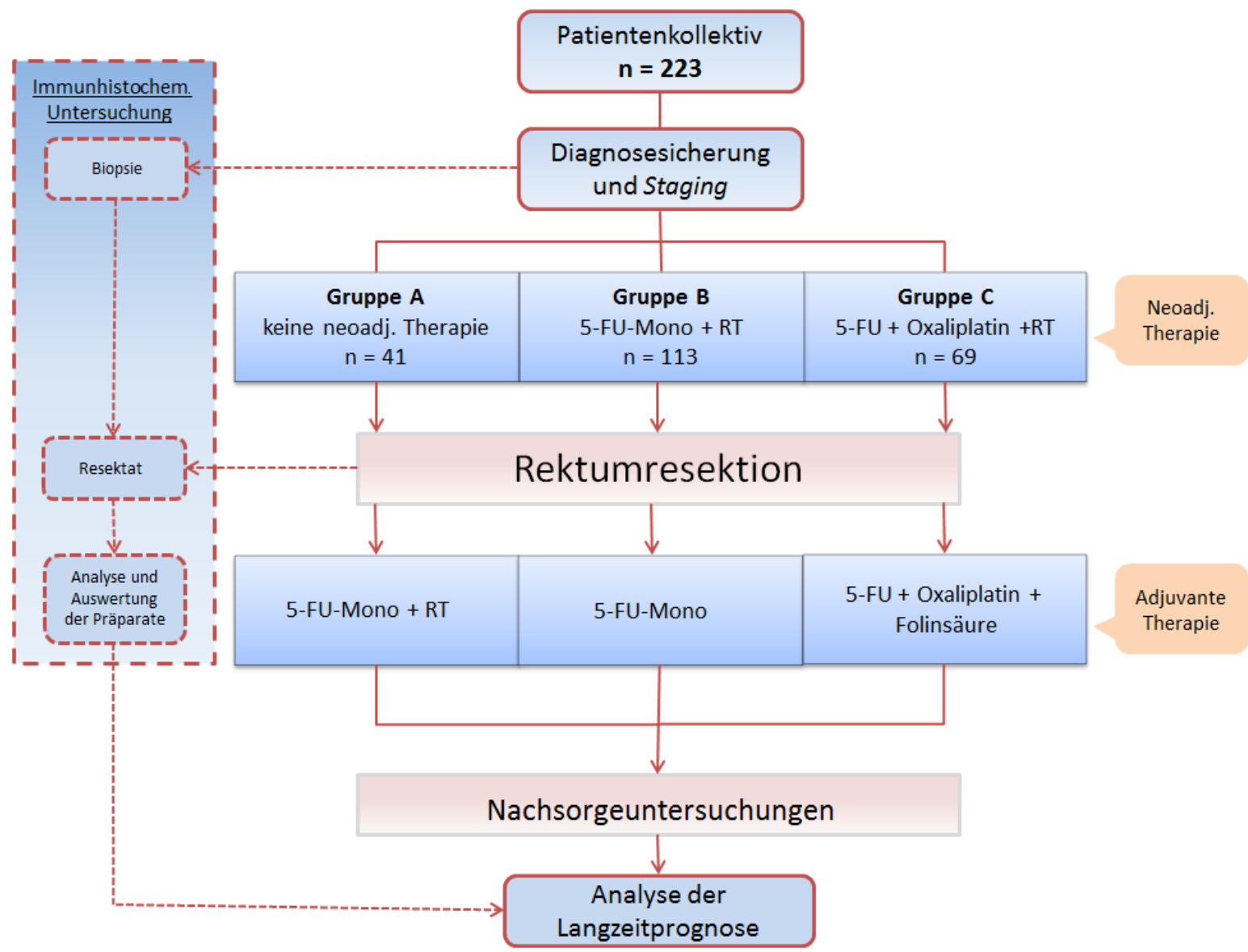

Abbildung 4: CONSORT-Schema zum Therapieablauf und Studiendesign

Schematische Darstellung des Ablaufs, der Therapie und der Studie. Durchgezogene Linien beschreiben den Weg der Therapie, gestrichelte Linien den Weg der immunhistochemischen Analyse und Auswertung. Darstellung der verschiedenen Therapiegruppen (A, B und C) bzgl. der neoadjuvanten Behandlung.

\subsection{Klinische Patientencharakteristika und prätherapeutische Stagingergebnisse}

Eine neoadjuvante Therapie erhielten 182 Patienten (81,3\%), davon wurden 113 Patienten durch eine kombinierten RT/CTx mit einer 5-FU-Monotherapie behandelt, 69 Patienten erhielten zusätzlich Oxaliplatin. Die verbliebenen nicht vorbehandelten 41 Patienten 
(Gruppe A) wurden, gemäß des Kontrollarms der CAO/ARO/AIO-94-Studie (siehe Anhang), einer primären Operation mit anschließender adjuvanter RT/CTx zugeführt.

Bei 196 (87,9 \%) Patienten wurde ein Primärtumor mit uT3-Status festgestellt, nur 11 (4,9\%) Patienten hatten einen Tumor mit uT2-Status. Bei 16 (7,2 \%) weiteren Patienten konnte bereits ein organüberschreitendes Wachstum mit einer Infiltration der Nachbarorgane oder des Peritoneums im Sinne eines uT4-Status festgestellt werden. Außerdem wurde bei 155 $(69,5 \%)$ Patienten des gesamten untersuchten Kollektivs eine lymphogene Metastasierung (positiver Nodalstatus $\mathrm{cN}+$ ) diagnostiziert, eine Fernmetastasierung $(\mathrm{cM})$ konnte jedoch durch weiterführende Untersuchungen (z.B. Lebersonographie und Röntgen Thorax) zumeist ausgeschlossen werden. Somit hatten 66 Patienten $(29,6 \%)$ einen Tumor im (c)UICC-Stadium-II, 145 Patienten (65\%) einen lokal lymphogen metastasierten Tumor im (c)UICC-Stadium-III. Bei 12 Patienten (5,4\%) ergab sich, durch den Verdacht auf eine Fernmetastasierung, ein (c)UICC-Stadium-IV.

Durch die starre Rektoskopie wurde bei 86 Patienten (38,5 \%) ein Tumor im unteren Drittel des Rektums ( 0 bis $<6 \mathrm{~cm}$ ab Anokutanlinie), bei 120 (53,8 \%) im mittleren Drittel (6 bis $<12 \mathrm{~cm}$ ab Anokutanlinie) und bei 17 (7,7\%) im oberen Bereich (12 bis $16 \mathrm{~cm}$ ab Anokutanlinie) diagnostiziert.

Im Rahmen der XELOX Studie aus dem Jahr 2003 wurde die Wirksamkeit und Sicherheit des Medikaments Capecitabin (Xeloda $\left.{ }^{\circledR}\right)$ zunächst allein, später im Sinne einer intensivierten neoadjuvanten Therapie in Kombination mit Oxaliplatin geprüft. Zu diesem Zweck wurde Xeloda ${ }^{\circledR}$ im direkten Vergleich mit intravenös verabreichtem 5-FU getestet. Das mit 5-FU und Oxaliplatin neoadjuvant vorbehandelte Kollektiv enthält 12 Patienten (17,4\%), welche mit Capecitabin (Xeloda $\left.{ }^{\circledR}\right)$ behandelt wurden.

\begin{tabular}{|c|c|c|c|c|c|c|c|}
\hline präoperative Therapiegruppe & \multicolumn{2}{|c|}{$\underset{n=41(18,4 \%)}{\text { Gruppe A }}$} & \multicolumn{2}{|c|}{$\begin{array}{c}\text { Gruppe B } \\
n=113(50,7 \%)\end{array}$} & \multicolumn{2}{|c|}{$\underset{\mathrm{n}=69(30,9 \%)}{\text { Gruppe C }}$} & p-Wert \\
\hline $\begin{array}{l}\text { Alter (Jahre) } \\
\text { Durchschnitt (Mittelwert) } \\
\text { Bereich }\end{array}$ & \multicolumn{2}{|c|}{$\begin{array}{c}71,780 \\
51-85\end{array}$} & \multicolumn{2}{|c|}{$\begin{array}{c}67,734 \\
40-87\end{array}$} & \multicolumn{2}{|c|}{$\begin{array}{r}66,057 \\
37-85\end{array}$} & -- \\
\hline $\begin{array}{l}\text { Geschlecht } \\
\text { Männer } \\
\text { Frauen }\end{array}$ & $\begin{array}{l}29 \\
12\end{array}$ & $\begin{array}{c}70,7 \\
29,3\end{array}$ & $\begin{array}{l}84 \\
29\end{array}$ & $\begin{array}{l}74,3 \\
25,7\end{array}$ & $\begin{array}{l}44 \\
25\end{array}$ & $\begin{array}{l}63,8 \\
36,2\end{array}$ & 0,32 \\
\hline $\begin{array}{l}\text { Tumorbeginn ab Anokutanlinie (cm) } \\
\text { 0-6 cm } \\
>6-12 \mathrm{~cm} \\
12-16 \mathrm{~cm}\end{array}$ & $\begin{array}{c}11 \\
22 \\
8\end{array}$ & $\begin{array}{l}26,9 \\
53,8 \\
19,3\end{array}$ & $\begin{array}{c}46 \\
62 \\
5\end{array}$ & $\begin{array}{r}40,7 \\
54,9 \\
4,4\end{array}$ & $\begin{array}{c}29 \\
36 \\
4\end{array}$ & $\begin{array}{r}42,0 \\
52,2 \\
5,8\end{array}$ & 0,02 \\
\hline
\end{tabular}




\begin{tabular}{|l|c|c|c|c|c|c|c|}
\hline uT Status & 6 & 14,6 & 3 & 2,7 & 2 & 2,9 & \\
$\mathbf{2}$ & 33 & 80,5 & 100 & 88,5 & 63 & 91,3 & 0.03 \\
$\mathbf{3}$ & 2 & 4,9 & 10 & 8,8 & 4 & 5,8 & \\
\hline $\mathbf{4}$ & 24 & 58,5 & 82 & 72,6 & 49 & 71,0 & 0,23 \\
\hline uN Status & 17 & 41,5 & 31 & 27,4 & 20 & 29,0 & \\
Positiv & & & & & & & \\
Negativ & 17 & 41,5 & 31 & 27,4 & 18 & 26,1 & 0,12 \\
(c)UICC-Stadium & 21 & 51,2 & 79 & 69,9 & 45 & 65,2 & \\
III & 3 & 7,3 & 3 & 2,7 & 6 & 8,7 & \\
IV & & &
\end{tabular}

Tabelle 2: Klinische Daten und Stagingergebnisse

In dieser Tabelle werden Parameter bezüglich der Anamnese und der Diagnostik der Patienten aufgelistet. Die 223 Patienten sind nach den Therapieverfahren aufgeteilt (Gruppenaufteilung siehe Abbildung 4). Die Daten werden in absoluten Zahlen und in Prozentangaben aufgeführt.

\subsection{Probenmaterial}

Für die Analyse der 223 Patienten, die in der vorliegenden Arbeit untersucht worden sind, standen 186 Biopsien und 223 Rektumresektate zur Verfügung. Einigen Patienten wurde die zur Diagnosesicherung notwendige Biopsie nicht in der UMG entnommen. Die histopathologische Aufarbeitung und Beurteilung erfolgte somit in einem auswärtigen Institut, sodass für immunhistochemische Untersuchungen lediglich 186 bioptische Gewebeproben zur Verfügung standen. Zudem wurden zwar 223 Rektumresektionen durchgeführt, jedoch konnte aufgrund einer kompletten Tumorremission (siehe Kapitel 2.3.2.1) nicht aus allen Resektaten eine für die immunhistochemische Analyse notwendige Anzahl vitaler Tumorzellen gewonnen werden.

\subsubsection{Prätherapeutische Biopsie}

Die Biopsie wurde im Rahmen der starren Rektoskopie, wie in Kapitel 1.2 beschrieben, entnommen. Das Material wurde anschließend für mindestens 24 Stunden in Formaldehyd eingelegt und in Paraffin eingebettet. Der entstandene Paraffinblock härtete aus und konnte gelagert werden. Somit war das Biomaterial für die mikroskopische Beurteilung konserviert und konnte immunhistochemisch angefärbt werden (siehe Kapitel 2.5). 


\subsubsection{Material aus dem Rektumresektat}

Perioperativ wurde zur Qualitätssicherung eine durch Fotodokumentation gesicherte Darstellung des entfernten Mesorektums durchgeführt. Die Intaktheit des Mesorektums wurde durch eine Injektion von Methylenblau in die Arteria mesenterica inferior überprüft (siehe Abbildung 5).

Die Einteilung des Farbaustritts erfolgte in drei Kategorien: bei einer kompletten TME verblieb die gesamte Farbe in den Gefäßen und es kam zu keinem makroskopisch sichtbaren Austritt. Eine inkomplette TME wurde durch flächigen Austritt von Farbe am Rand des Präparates definiert. Kam es $\mathrm{zu}$ einem großflächigen Farbaustritt aus angeschnittenen Gefäßabschnitten, wurde die TME als unvollständig bezeichnet (Sterk et al. 2000) (siehe Abbildung 6).

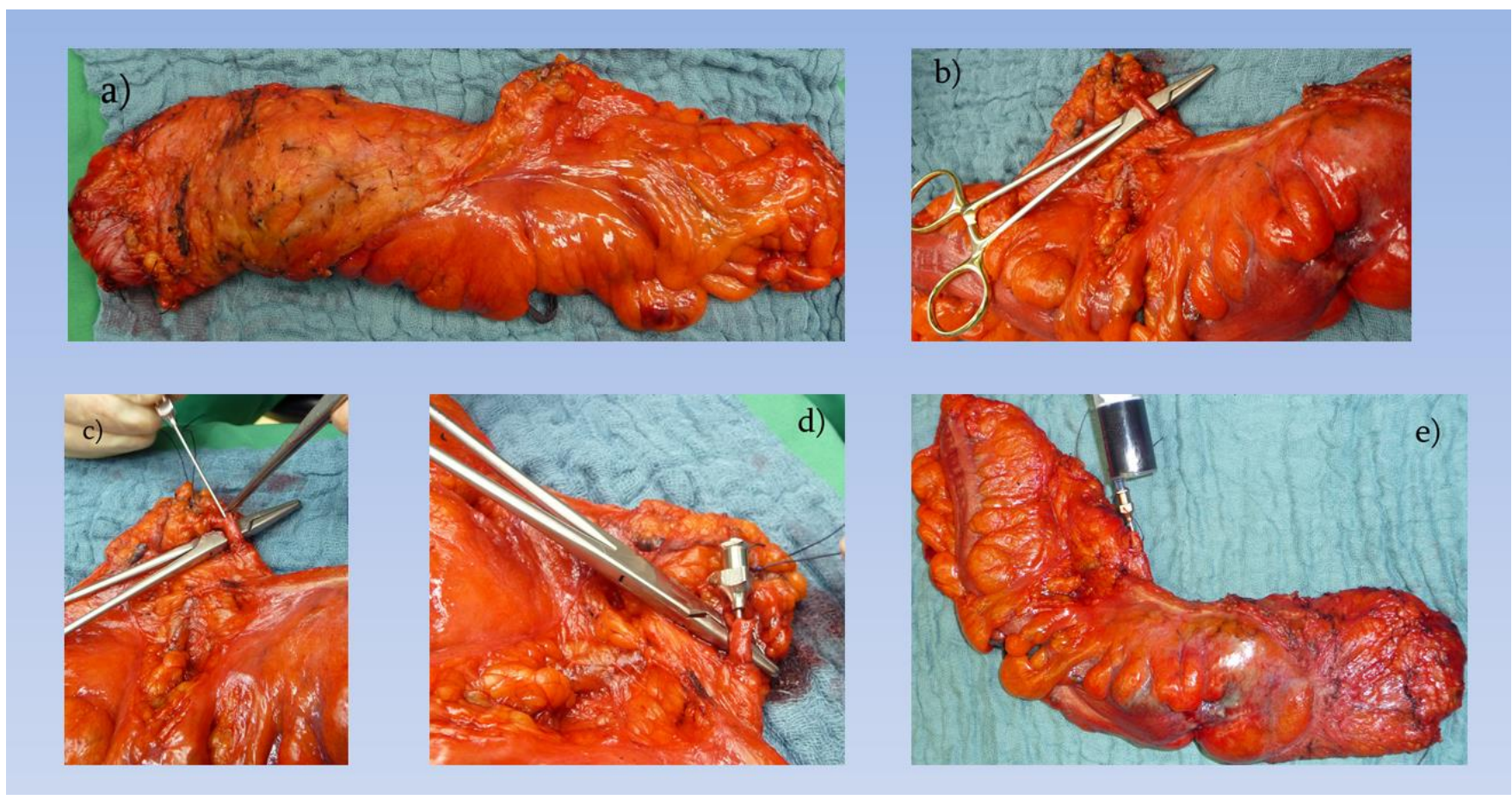

\section{Abbildung 5: Beispiel für perioperative Qualitätskontrolle des Rektumresektats}

a) Fotodokumentation des entnommenen Rektumresektats

b) Die Arteria mesenterica inferior (hier quer über den Nadelhalter verlaufend) wird aufgesucht und dargestellt

c) Kanülierung der Arterie

d) Nach Abschluss der Kanülierung der Arterie

e) Injektion von Methylenblaulösung in die Arterie. Diese verteilt sich somit über das gesamte Versorgungsgebiet der A. mesenterica inferior. Farbaustritte können Einrisse des Mesorektums hervorheben. 


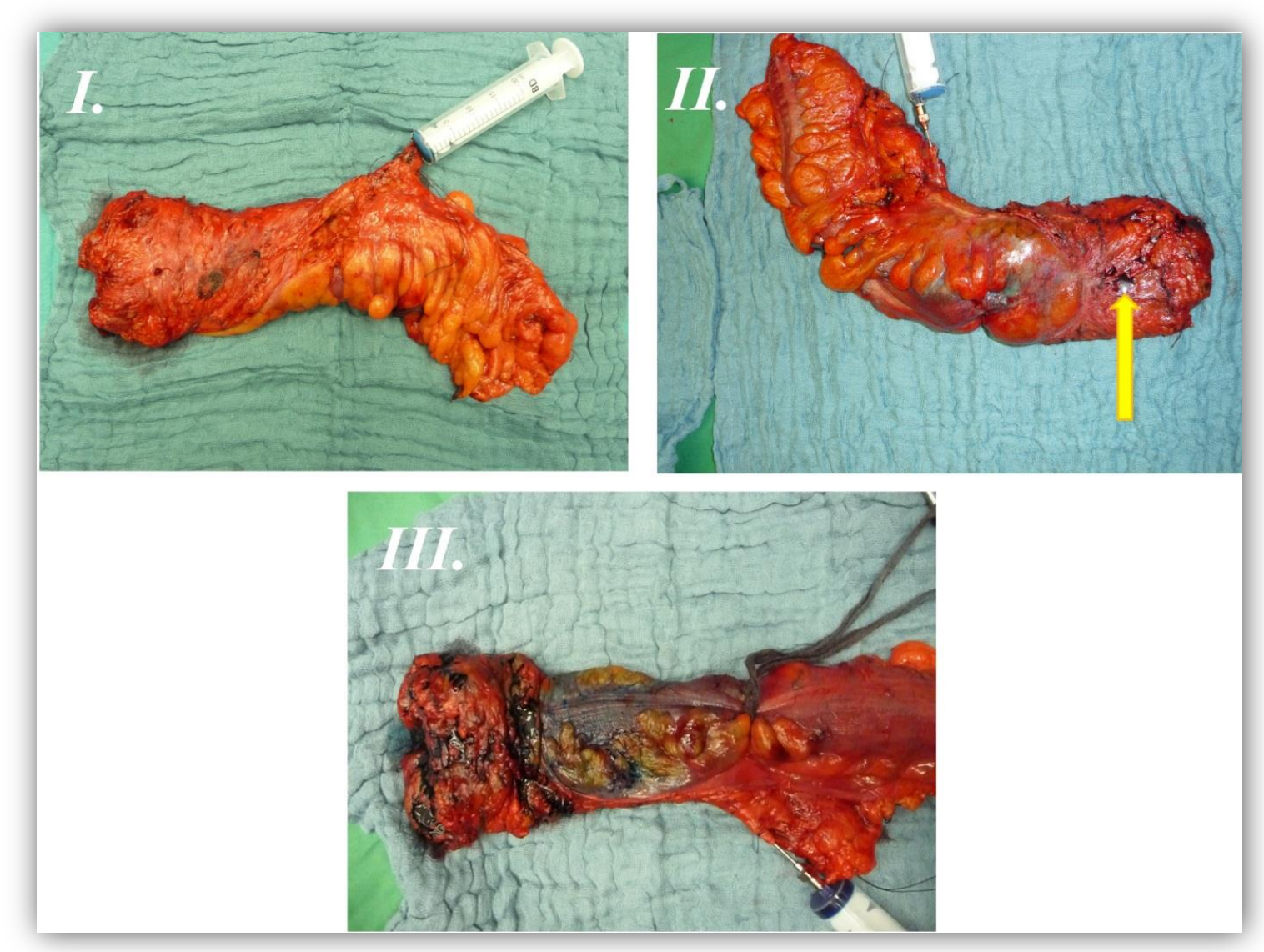

Abbildung 6: Qualitätsbeurteilung der TME (Grad I bis III) nach Methylenblau-Applikation

I. TME-Qualität Grad I: kein Austritt von Methylenblaufarbstoff erkennbar, vollständige TME

II. TME-Qualität Grad II: punktförmige Farbaustritte (z.B. siehe gelber Pfeil)

III. TME-Qualität Grad III: großflächiger, makroskopisch erkennbarer Farbaustritt von der aufgespannten Oberfläche des Mesorektums (ventralseitig, V.a. inkomplette TME)

\subsubsection{Histopathologische Aufarbeitung des Resektats}

Das native Präparat gelangte zur weiterführenden Diagnostik in die Pathologie. Anschließend wurde das Präparat zunächst von außen begutachtet und auf oberflächliche Tumorperforationen untersucht. Es folgte eine makroskopische Begutachtung des Resektats durch den Pathologen nach den M.E.R.C.U.R.Y-Kriterien zur Qualitätsbeurteilung der TME (MERCURY 2006; Fuchs et al. 20011/2012):

- Grad 1 (Gut): komplette Mesorektumexzision, nur geringe Unregelmäßigkeiten der glatten Mesorektumoberfläche.

- Grad 2 (Mäßig): beinahe komplette Mesorektumexzision mit unregelmäßiger Oberfläche, Muscularis propria an keiner Stelle sichtbar.

- Grad 3 (Schlecht): Inkomplette Mesorektumexzision mit großflächigen Defekten des Mesorektums, Muscularis propria gut sichtbar. 
Anschließend wurde das Präparat eröffnet, nach Möglichkeit ohne den Tumor anzuschneiden. Nun wurde der Abstand des Tumors zum aboralen Resektionsrand ermittelt. Außerdem wurde die exakte Größe des Tumors und des gesamten Resektats gemessen, die Wuchsform bestimmt und die Lage des Tumors zur peritonealen Umschlagfalte bestimmt (Becker und Liersch 2006). Es folgte die Beurteilung des Resektats nach den zum Zeitpunkt der Untersuchung geltenden Richtlinien der TNM-/ UICC-Klassifikation (Sobin und Fleming 1997; Wittekind und Sobin 2002; Wittekind und Meyer 2010):

- Lokalisation des Tumors im Resektat (v.a. in Bezug auf die peritoneale Umschlagfalte)

- Histologische Beurteilung des Karzinomtyps nach der aktuellen Klassifikation der World Health Organisation (WHO-Klassifikation)

- Invasionstiefe des Primärtumors (pT-Status)

- Regionärer Lymphknotenstatus (pN-Status)

- Grading: die Bestimmung des Differenzierungsgrades gibt an, wie stark die untersuchten Karzinomzellen vom ursprünglichen Gewebe abweichen (G 0-4) (siehe Anhang)

- Die Residualtumor-Klassifikation (R-Status) beschreibt das Vorhandensein oder Fehlen von Tumorresten an den Resektionsrändern des Präparates (R 0-2: keine Tumorreste vorhanden - mikroskopisch erkennbare Tumorreste - makroskopisch erkennbare Tumorreste)

- Invasion in die Venen $\left(\mathrm{V}_{0 / 1 / 2}\right)$ oder Lymphgefäße $\left(\mathrm{L}_{0 / 1}\right)$

- Angabe des Tumorregressionsgrades (TRG 0-4) bei vorausgegangener neoadjuvanter Therapie.

Durch den Tumorregressionsgrad lässt sich histopathomorphologisch die Response eines Tumors auf eine präoperative Therapie beurteilen. Die Einteilung erfolgt in sechs Gruppen und orientiert sich an den Vorgaben von Dworak et al. aus dem Jahr 1997. Aufgrund der erheblichen möglichen Unterschiede innerhalb eines TRG 3 (Regression von 50\% bis 99\%) wurde in der vorliegenden Arbeit noch zwischen TRG 3a und TRG 3b unterschieden (siehe Tabelle 3).

Abschließend wurde das Präparat in Formaldehyd fixiert und in Paraffin eingebettet. Eine weitere Verwendung, z.B. im Rahmen einer immunhistochemischen Anfärbung, war somit möglich (siehe Kapitel 2.5). 


\begin{tabular}{|l|l|}
\hline $\begin{array}{l}\text { Grad der } \\
\text { Tumorregression }\end{array}$ & Beschreibung \\
\hline TRG 0 & $\begin{array}{l}\text { Keine Regression } \\
\text { Leichte Regression (1-25\%): Tumormasse dominant mit sichtbaren Firbosen und/ oder } \\
\text { Vaskulopathien (bei <25\% der Tumormasse) } \\
\text { Moderate Regression (25-50\%): Überwiegend fibrotische Veränderungen (bei 25-50\% der } \\
\text { Tumormasse) mit wenigen Tumorzellen (leicht zu finden). }\end{array}$ \\
\hline TRG 3 & $\begin{array}{l}\text { Gute Regression (50-99\%): Sehr wenige Tumorzellen (schwer zu finden) im fibrotischen } \\
\text { Gewebe (<80 \%). } \\
\text { Zusätzliche Unterscheidung zwischen TRG 3a (Regression 50-75\%) und 3b (75-99\%) } \\
\text { möglich. } \\
\text { Komplette Regression (100\%): Keine Tumorzellen, komplett fibrotisches Gewebe }\end{array}$ \\
\hline TRG 4 &
\end{tabular}

Tabelle 3: Einteilung der Tumorregressionsgrade (modifiziert nach Dworak et al. 1997) *Modifikation innerhalb der vorliegenden Untersuchung

\subsection{Follow-Up-Untersuchungen}

Bei einem KRK im UICC-Stadium-II/-III, mit kurativ orientiertem Therapiekonzept, sollte nach erfolgter R0-Resektion eine regelmäßige Nachsorgeuntersuchung zur Früherkennung von Rezidiven stattfinden (Schmiegel et al. 2008a). Insgesamt treten postoperativ $80 \%$ der Metastasen in den ersten beiden Jahren auf (Liersch et al. 2005). Nicht zuletzt ist die Wahl der Operationstechnik und die operative Qualität entscheidend für die Lokalrezidivrate (Bülow et al. 2003). Nach den aktuellen Leitlinien (Schmiegel et al. 2008a) sollten sich die Nachsorgeuntersuchungen über mindestens 5 Jahre erstrecken und davon die ersten 2 Jahre alle 6 Monate stattfinden. Die einzelnen Untersuchungen haben dabei einen unterschiedlich hohen Stellenwert und sind in Tabelle 4 aufgeführt.

\begin{tabular}{|c|c|c|c|c|c|c|c|}
\hline Untersuchung & \multicolumn{2}{|c|}{ 1. Jahr } & \multicolumn{2}{|c|}{ 2. Jahr } & 3. Jahr & 4. Jahr & 5. Jahr \\
\hline Monat & 6 & 12 & 18 & 24 & 36 & 48 & 60 \\
\hline $\begin{array}{l}\text { Anamnese, körperliche } \\
\text { Untersuchung, CEA-Wert }\end{array}$ & $\mathrm{X}$ & $\mathrm{X}$ & $\mathrm{X}$ & $\mathrm{X}$ & $\mathrm{X}$ & $\mathrm{X}$ & $\mathrm{X}$ \\
\hline Sonographie des Abdomens & $X$ & $X$ & $X$ & $\mathrm{X}$ & $\mathrm{X}$ & $X$ & $X$ \\
\hline $\begin{array}{l}\text { Sigmoidoskopie } \\
\text { (Rektoskopie) }\end{array}$ & $\mathrm{X}$ & $\mathrm{X}$ & $X$ & $\mathrm{X}$ & & & \\
\hline gesamte Koloskopie & $X$ & & & & $\mathrm{X}$ & & \\
\hline
\end{tabular}

Tabelle 4: Tumornachsorgeplan bei Patienten mit Rektumkarzinom im UICC-Stadium-II/-III in der vorliegenden Arbeit 
Bei jeder Untersuchung sollte eine symptomorientierte Anamnese, eine körperlicher Untersuchung und eine CEA-Wert-Bestimmung im Blut durchgeführt werden. Bei einem im Verlauf ansteigenden CEA-Wert sollte eine weiterführende, intensivierte Diagnostik angeschlossen werden, um ein fernmetastatisches Rezidiv auszuschließen. Als kostengünstiges und einfaches Verfahren hat auch die Sonographie zum Ausschluss von Lebermetastasen einen hohen Stellenwert in der Nachsorgeuntersuchung.

Endoskopische Verfahren sind ebenfalls gut geeignet, Lokalrezidive oder Zweittumoren zu erkennen. Wenn präoperativ keine komplette Koloskopie möglich war (bei stenosierendem Tumor) sollte diese innerhalb von 6 Monaten postoperativ folgen. Nach dem 3. Jahr postoperativ sollte alle 5 Jahre eine routinemäßige Koloskopie erfolgen, nach Polypenabtragung bereits alle 2 Jahre (Fuchs et al. 20011/2012, S. 309).

\subsection{Herstellung der immunhistochemischen Präparate}

\subsubsection{Schnittherstellung}

Das in Paraffin eingebettete Material wurde standardisiert im Rahmen des Teilprojekts 5 der KFO asserviert und aufbereitet. Zunächst wurde das entnommene Tumorgewebe (siehe Kapitel 2.3.1 und 2.3.2) in einer 4\% neutral gepufferten Formaldehydlösung bei Raumtemperatur für 24 Stunden fixiert. Da Paraffin im Gegensatz zu Formaldehyd ein hydrophobes Medium ist, musste das Gewebe zunächst entwässert werden. Hierzu wurde eine aufsteigende Alkoholreihe verwendet, also Ethanol (Chemie Vertrieb, Hannover, Deutschland) in zunehmender Konzentration (75\% -96\% - 100\%). Ethanol entzieht dem Gewebe das Wasser, anschließend wurde ein sogenanntes Intermedium, Xylol (Mallinckrodt Baker B.V., Deventer, Niederlande), verwendet. Dieses verdrängt den Alkohol aus dem Gewebe, da Alkohol ebenso wie Wasser im Paraffin für schlechtere Schneidbarkeit sorgt. Man bezeichnet diese Vorgehensweise als Clearing. Anschließend wurde das Gewebe bei etwa $60^{\circ} \mathrm{C}$ mit Paraffin getränkt und anschließend ausgegossen. Der entstandene Block härtete daraufhin aus und konnte gelagert werden. Im Anschluss wurde mit Hilfe eines Schlittenmikrotoms (Schlittenmikrotom Microm HM 430, MICROM International, Walldorf, Deutschland; Mikrotomklingen von Feather, PFM, Köln, Deutschland) der Paraffinblock in $2 \mu \mathrm{m}$ dünne Schichten geschnitten. Diese wurden anschließend in einem Wasserbad gestreckt, auf einen Objektträger (Engelbrecht Medizin\& Labortechnik $\mathrm{GmbH}$, Edermünde, 
Deutschland) gezogen und in einem Wärmeschrank (Memmert GmbH, Schwabach, Deutschland) über Nacht getrocknet. Es folgte der Färbevorgang.

\subsubsection{Färbemethoden}

Bei den Präparaten handelte es sich um immunhistochemische Färbungen, die auf einer Antigen-Antikörper-Reaktion basieren. Die Färbetechnik wird als indirekte oder Zwei-SchrittMethode bezeichnet (siehe Abbildung 7). Bei dieser Methode wird ein spezifischer Antikörper eingesetzt, der an eine antigene Determinante der Thymidinphosphorylase (TP) im Zytoplasma bindet. Der monoklonale Antikörper gehört der Gruppe der GammaImmunglobuline (IgG) an und wurde aus der B-Zellreihe einer Maus nach der sogenannten Hybridom-Technik gezüchtet. Immunglobuline haben ebenfalls antigene Bereiche, an die weitere Antikörper binden können: sogenannte sekundäre Antikörper. Diese können nun mithilfe eines gekoppelten Enzyms, der Alkalischen Phosphatase, den Farbstoff aus den Chromogenen produzieren. Da an einen einzelnen monoklonalen primären Antikörper mehrere sekundäre Antikörper binden können, kommt es zu einer Signalamplifikation (Boenisch et al. 2006). 


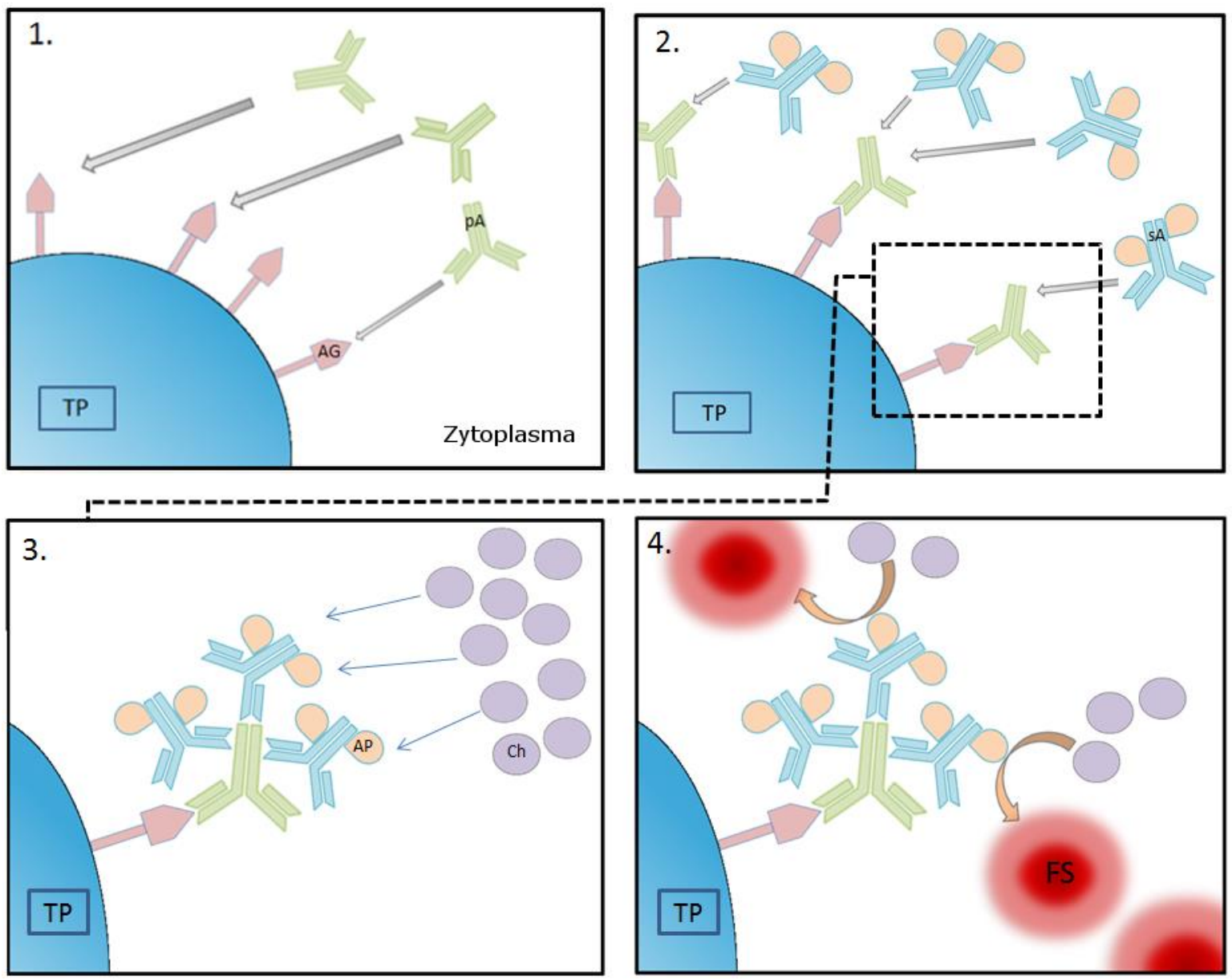

Abbildung 7: Indirekte Färbemethode durch Antigen-Antikörper-Reaktion

1. Primärer Antikörper bindet an antigene Determianten von TP

2. Sekundärer Antikörper bindet an den primären Antikörper

3. Chromogene werden hinzugegeben

4. Alkalische Phosphatase katalysiert die Reaktion von Chromogen zum Farbstoff

(Legende: $\underline{\mathrm{AG}}$ : Antigen von TP, pA: primärer Antikörper, $\underline{\mathrm{sA}}$; sekundärer Antikörper; AP: Alkalische Phosphatase, $\underline{\mathrm{Ch}}$ : Chromogen, $\underline{\mathrm{FS}}$ : Farbstoff)

\subsubsection{Automatisierte Färbung}

Die Färbung der Präparate wurde mit Hilfe des Färbeautomaten Benchmark XT der Firma Ventana (Ventana Medical Systems, Tucson, Arizona, USA) durchgeführt. Der automatisierte Prozess bietet den Vorteil von Standardisierung und Vereinheitlichung der verwendeten Lösungen und der Vermeidung von methodischen Unterschieden im Vergleich zur manuellen Färbemethode. Somit konnte für alle Gewebeschnitte eine gleichmäßige Behandlung garantiert werden, wodurch die Präparate besser untereinander vergleichbar waren. Die Standardisierung und Vereinheitlichung der Färbemethode ist demnach Voraussetzung für 
eine objektivere Vergleichbarkeit der Ergebnisse, sowohl innerhalb dieser Studie als auch studienübergreifend.

Zunächst wurde der primäre Antikörper in einer Konzentration von 1:100 auf den Schnitt aufgetragen und inkubiert. Anschließend wurde ein sogenanntes ultraView Universal Alkaline Phosphatase Red Detection Kit (Ventana Medical Systems, Mannheim, Deutschland) verwendet.

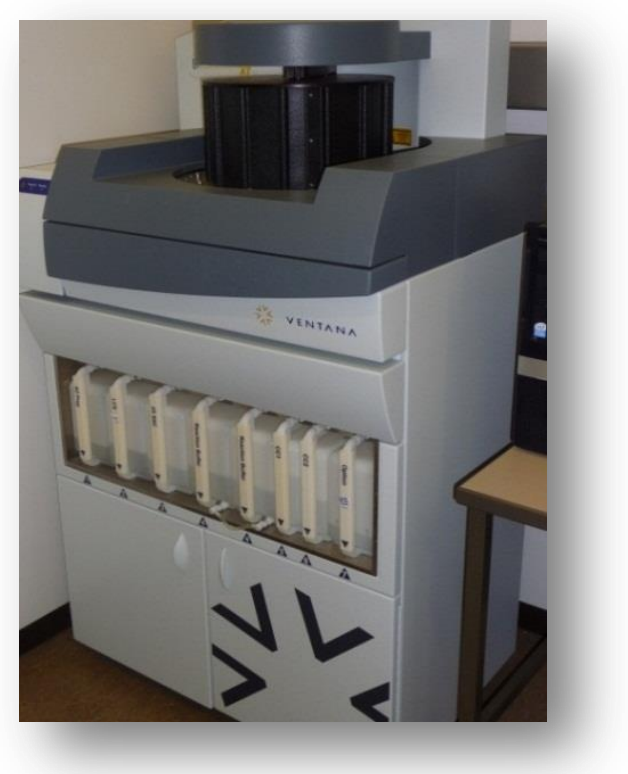

\section{Abbildung 8: Färbeautomat Benchmark XT der Firma Ventana}

Die Alkalische Phosphatase ist ein intrazelluläres Enzym, welches im humanen Gewebe der Darmschleimhaut ebenfalls natürlich vorkommt. Um eine Kreuzreaktion der Chromogene mit frei vorkommender Alkalischer Phosphatase zu vermeiden, wurde dem Gewebe Levamisol, ein Enhancer, hinzugefügt. Dieser hemmt die natürlich vorkommende Alkalische Phosphatase. Das oben genannte Detection Kit enthält außerdem den Sekundärantikörper, das Substrat Naphtol und die Chromogene Fast Red A und Fast Red B. Sobald das Färbeprogramm beendet war, wurden die Präparate mit spülmittelhaltigem Wasser gereinigt und erneut durch eine aufsteigende Alkoholreihe (75\% - 96\% - 100\%) gezogen. Xylol wird erneut genutzt um den Alkohol und das Wasser aus dem Präparat zu entfernen und mit VitroClud (R. Langenbrinck - Labor- und Medizintechnik, Emmendingen, Deutschland) wurde es mit einem Deckglas (Gerhard Menzel GmbH, Braunschweig, Deutschland) verschlossen. Somit waren die Gewebeschnitte frei von Wasser und Luft für viele Jahre haltbar. 


\subsection{Mikroskopische Beurteilung der Präparate}

Die gefärbten Präparate wurden anschließend unter dem Mikroskop mit unterschiedlichen Vergrößerungen (siehe unten) betrachtet und beurteilt. Das Mikroskop Axio Imager II (Carl Zeiss MicroImaging GmbH, Oberkochen, Deutschland) ist mit einer Digitalkamera ausgestattet und mit einem Desktop Computer verbunden. Somit konnten wichtige Präparate dokumentiert werden. Die Schnitte wurden nach folgendem Schema betrachtet, um die Intensität der immunhistochemischen Färbung zu beurteilen: zur Übersicht des Präparats wurde eine 5x-Vergrößerung gewählt. Für die genauere Betrachtung wurde zunächst eine 10x-, im Anschluss eine 20x- und eine 40x-Vergrößerung gewählt. Um eine bestmögliche Vergleichbarkeit der Ergebnisse gewährleisten zu können, wurden standardisiert bei einer 20x-Vergrößerung je 50 Zellen gitterartig abgezählt und ihre Färbeintensität bestimmt. Hellblau gefärbte Zellen wurden als nicht angefärbt (0) charakterisiert. Unterschieden werden musste zwischen leicht rosafarbene Zellen (Intensität 1), roten Zellen (Intensität 2) und kräftig angefärbten rot-violetten Zellen (Intensität 3) (siehe Abbildung 9). Das Ergebnis der Zählung wurde in einer Tabelle festgehalten (siehe Tabelle 5) und fotodokumentiert. Insgesamt wurden pro Präparat mindestens 200 Zellen beurteilt. Die Präparate wurden in einem zweiten Durchgang verblindet kontrolliert und mit den ersten Ergebnissen korreliert, um die Interobserver-Variabilität so gering wie möglich zu halten. Die Ergebnisse wurden von einem weiteren unabhängigen Untersucher (Pathologen, TP 5 KFO179) gegenkontrolliert und mit meinen Auswertungen verglichen. Bei allen Kontrollen bestand ein Konsens bzgl. der Färbeintensität.

Konnten in der mikroskopischen Untersuchung der Biopsien nicht mehr als 50 Tumorzellen detektiert werden, so wurden diese nicht in die Analyse und Auswertung einbezogen (cutoff).

\begin{tabular}{l|l}
\hline & Präparat \\
\hline Zellen 1-50 & \\
Zellen 51-100 & \\
Zellen 101-150 & \\
Zellen 151-200 & \\
& \\
Kommentar und Beurteilung & \\
\hline
\end{tabular}

Tabelle 5: Noch unbearbeitete Tabelle zur Beurteilung der Präparate

Jedes Präparat wurde einzeln nach einem bestimmten Muster untersucht und die Ergebnisse wurden in die obenstehende Tabelle eingetragen. Es wurden Zellgruppen von stets 50 Zellen ausgezählt und bewertet. 

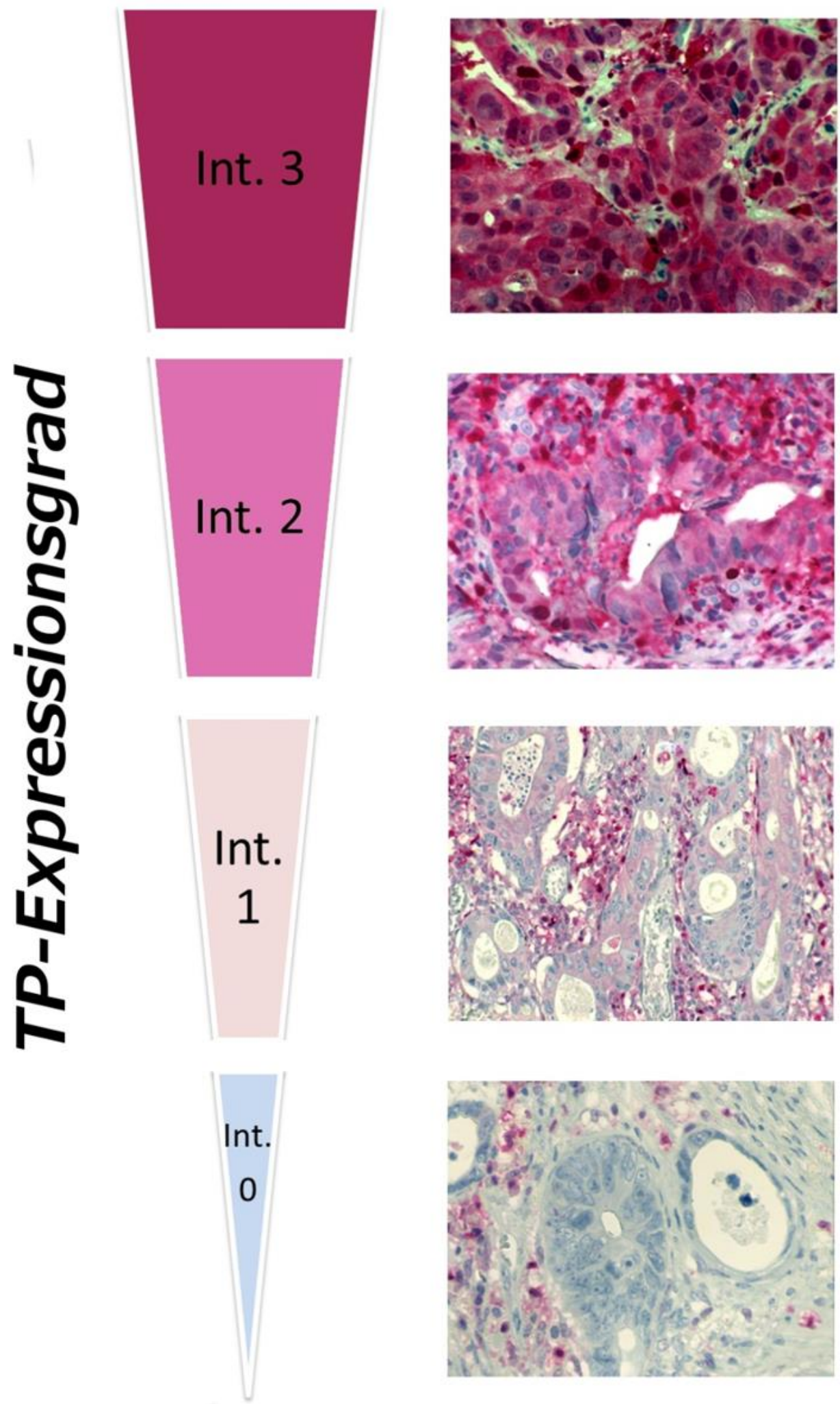

\section{Abbildung 9: Färbeintensitäten}

Färbeintensitäten der Präparate, geordnet nach steigendem TP-Ausprägungsgrad.

Unterteilt wurde nach (0) keiner erkennbaren Färbung der Karzinomzellen, (1) leichter, (2) mittlerer und (3) starker immunhistochemischer Färbung. 


\begin{tabular}{|c|c|}
\hline & Ident.Nr. des Präparates \\
\hline Zellen 1-50 & 50/50: Int. 0 \\
\hline Zellen 51-100 & 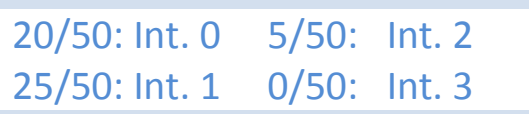 \\
\hline Zellen 101-150 & 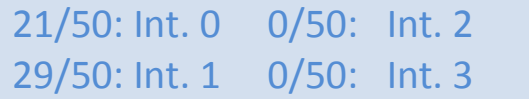 \\
\hline Zellen 151-200 & $\begin{array}{ll}\text { 0/50: Int. } 0 & \text { 15/50: Int. } 2 \\
\text { 35/50: Int. } 1 & \text { 0/50: } \text { Int. } 3\end{array}$ \\
\hline Kommentar und Beurteilung & $\begin{array}{l}\text { Kräftig angefärbtes Präparat, } \\
\text { viel Tumorgewebe sichtbar }\end{array}$ \\
\hline
\end{tabular}

Tabelle 6: Beispiel einer Tabelle zur Dokumentation einer Präparatbeurteilung

\subsection{Vorkehrungen zur Analyse der Korrespondenz von TP und TS}

Die nachfolgenden Daten zur immunhistochemischen Analyse von TS (siehe Kapitel 1.9.2) wurden nicht im Rahmen der vorliegenden Arbeit, sondern im Zuge der Dissertation von Frau Dr. med. Lena Conradi im Jahr 2010 erhoben. Bei dieser Analyse wurden Biomaterialien (prätherapeutische Biopsien und klinische Daten) und klinische Daten von 208 Patienten mit Rektumkarzinomen im UICC-II/-III einbezogen. Die Patienten stammten, vergleichbar mit der vorliegenden Arbeit, ebenfalls aus den Kollektiven der CAO/ARO/AIO-94- und der CAO/ARO/AIO-04-Studien. Ein Vergleich des Patientenkollektivs der vorliegenden Studie mit dem Kollektiv von Conradi et al. zeigte einen overlap von 177 Patienten, bei denen sowohl die TP- als auch die TS-Expression untersucht worden war. Eine Analyse der korrespondierenden Daten wurde ebenfalls im Rahmen dieser Arbeit vorgenommen, um die Beziehung dieser beiden Biomarker in Bezug auf eine potentielle Therapiestratifizierung evaluieren zu können.

Von den 177 Patienten erhielten 40 Patienten, aus dem Kontrollarm der CAO/ARO/AIO-94Studie, eine primäre Operation, 137 Patienten wurden einer neoadjuvanten Therapie unterzogen. Diese Patientenkollektive wurden getrennt voneinander untersucht, um einen möglichen Einfluss der neoadjuvanten Therapie beobachten zu können.

Die immunhistochemische Färbemethode für TS beruhte auf einer vergleichbaren AntigenAntikörper-Reaktion (Zwei-Schritt-Methode, siehe Kapitel 2.5.2) wie es die Untersuchung von TP beinhaltete. Für detaillierte Informationen zur Schnittherstellung, Färbemethode und 
zur mikroskopischen Beurteilung der TS-Präparate verweise ich auf die Arbeit von Lena Conradi.

\subsection{Statistische Auswertungsmethoden}

Die statistische Auswertung geschah in Kooperation mit Dr. Manuel Nietert (Abteilung für Medizinische Statistik der Universitätsmedizin Göttingen, Direktor: Univ.-Prof. Dr. Tim Friede). Für die Zusammenführung und Darstellung der Tabellen und Ergebnisse wurde die Open-Source Software KNIME (Version 2.5.4, www.knime.com GmbH, Zürich, Schweiz, access date 01.April 2012) verwendet. Mithilfe dieses Programms konnten spezifische Inhalte graphisch dargestellt (Boxplot, Kaplan-Meyer-Kurve, Histogramm) und tabellarisch (H-Score, Remmele-Score, p-Wert) zusammengeführt werden. Der Vorteil dieses Programms ist die Visualisierung aller berechneten statistischen Abschnitte auf einem schematischen Übersichtsplan (workbench). Außerdem bietet das Programm den Vorteil der Automatisierung der Arbeitsschritte: sobald sich in den ursprünglichen Tabellen Daten ändern, werden alle Ergebnisse und Darstellungen diesen jüngsten Veränderungen automatisch angepasst. Die Wahrscheinlichkeit für einen statistisch-methodischen Fehler wird somit bei geübtem Umgang mit der Software verringert.

Für die Auswertung wurde der sogenannte H-Score zur medizinisch-statistischen Untersuchung der Quantifizierung von immunhistochemischen Färbungen genutzt, um diese möglichst objektiv und gut reproduzierbar auswerten zu können. Er ist definiert als ein beliebiger Wert zwischen 0 und 300 und errechnet sich aus der Multiplikation der Färbeintensität X (0-3) und des prozentual gemessenen Anteils der Intensität (Vilmar et al. 2012).

\section{Beispiel:}

\begin{tabular}{|l|c|c|c|c|}
\hline Färbeintensität & 0 & 1 & 2 & 3 \\
\hline Anteil in Prozent \% & 15 & 35 & 25 & 25 \\
\hline
\end{tabular}

Rechnung: $0 \times 15+1 \times 35+2 \times 25+3 \times 25=160$

In diesem Beispiel ergibt sich für das Präparat ein H-Score von 160.

Zur Darstellung der Dynamik der TP-Expressionen zwischen Biopsien und Resektaten wurde eine Differenz aus dem H-Score der Biopsien und der korrespondierenden Resektate berechnet. Dies wurde graphisch in Form eines Boxplots (siehe unten) oder eines WasserfallDiagramms dargestellt. Dabei handelt es sich um ein spezielles Säulendiagramm, welches 
positive und negative Wertveränderungen im Verhältnis zueinander anzeigen kann. Auf diese Weise kann eine Herauf- und eine Herunterregulation der TP-Expression dargestellt werden:

\section{Beispiel:}

\section{1.)}

Biopsie H-Score: 212, Resektat HScore 95

$\mathrm{PE}(\mathrm{H}-\mathrm{Score})-$ Resektat $(\mathrm{H}-\mathrm{Score})=\mathrm{x}$
2.)

Biopsie H-Score: 10, Resektat H-Score 150 $\mathrm{PE}(\mathrm{H}-\mathrm{Score})-$ Resektat $(\mathrm{H}-\mathrm{Score})=\mathrm{x}$ $10-150=-140 \rightarrow$ Heraufregulation

\section{$212-95=117 \rightarrow$ Herunterregulation}

Der häufig verwendete Remmele-Score (Remmele und Stegner 1987) wurde in dieser Studie nur beim Vergleich von TP und TS angewendet. Er unterscheidet sich vom H-Score durch einen geringfügigen Informationsverlust bei der Datenberechnung aufgrund der Zusammenführungen von Datenintervallen in definierte Werte. Somit gibt der RemmeleScore nachträglich keinerlei Aufschluss über die Verteilung der Daten innerhalb dieser primären Intervalle. Da die Ergebnisse von Conradi et al. als Remmele-Score vorlagen, wurde zur besseren Vergleichbarkeit der Remmele-Score für TP ebenfalls berechnet.

Um herauszufinden, ob es eine Korrelation zwischen den ermittelten Intensitäten der TP-Expression und den klinischen Angaben aus der Datenbank gibt, wurde in der vorliegenden Arbeit der H-Score zunächst im Boxplot aufgetragen. Zur Darstellung der Verteilung quantitativer Merkmale ist die Methode des Box-und-Whiskerplots (Tukey 1977) besonders geeignet. Dabei wird jedes Kollektiv durch eine rechteckige Box repräsentiert und am oberen und unteren Rand vom 1. und 3. Quartil (25\% und 75\% Quantil) begrenzt. Der Median ist ein Wert, der im einfachsten Fall in der Box

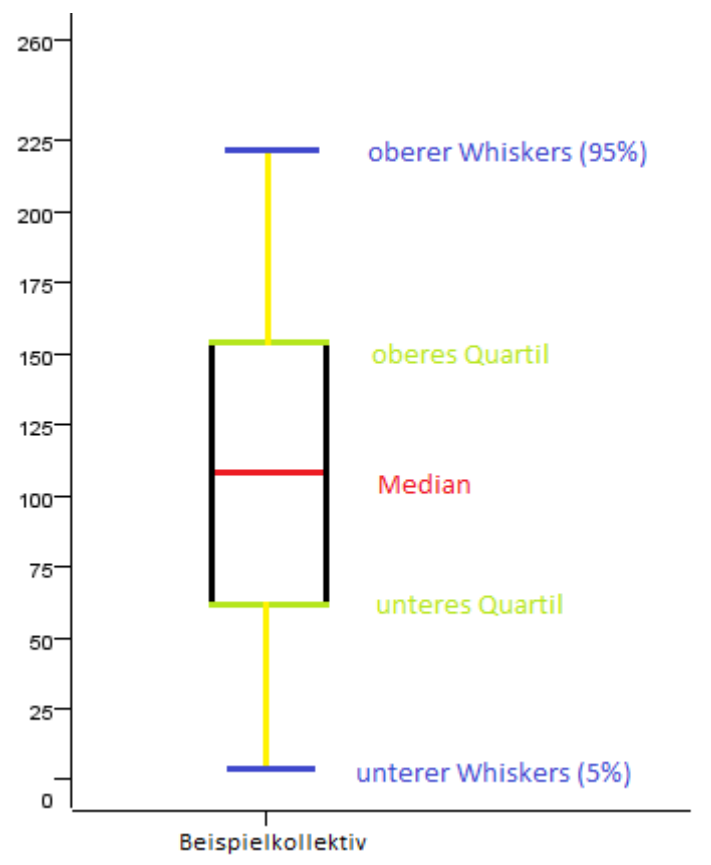

Abbildung 10: Schema zur Darstellung eines Boxplots liegt und anzeigt, dass $50 \%$ der Daten größer und $50 \%$ kleiner sind als dieser. Oberhalb und unterhalb der Quartile liegen die sogenannten Whiskers (engl. „Schnurrhaare“) an und begrenzen die 5\% und die 95\% Marke. 
Im Anschluss wurden Kaplan-Meier-Modelle (in Korrelation mit klinischen Ereignissen, wie dem Auftreten von Lokalrezidiven oder von Fernmetastasen) erstellt. Die bei dieser Schätzung entstehende Überlebenskurve ändert sich sprunghaft nach jedem aufgetretenen Endereignis (Kaplan und Meier 1958; Hilgers et al. 2007). Anhand der Kurve kann man beschreiben, wie viele Patienten (Anzahl N) zu Beginn der Studie starten und wie viele im Verlauf zu einem bestimmten Zeitpunkt ausscheiden (Anzahl d). Auf diese Weise ergibt sich für die betrachteten Kollektive eine Überlebenszeitanalyse (Weiß C 2010).

Der krankheitsfreie Zeitraum zwischen der Resektion des primären Rektumkarzinoms und dem histopathologischen und bildgebenden Nachweis eines lokalen oder fernmetastatischen Karzinomrezidivs wird als disease free survival (DFS) bezeichnet. Im Gegensatz dazu bezeichnet der Begriff cancer specific survival (CSS) das Malignom-spezifische Gesamtüberleben in einem bestimmten Zeitraum (Marubini und Valsecchi 1995). In dieser Studie entspricht das CSS dem Versterben an dem Rektumkarzinom, synonym wird auch vom krankheitsspezifischen Überleben gesprochen. 


\section{Ergebnisse}

\subsection{Perioperative Befunde}

Nachdem zuvor die prätherapeutischen Patientencharakteristika bereits beschrieben worden sind (siehe Kapitel 2.2), sind in den nachfolgenden Tabellen die Operationsmethoden (siehe Tabelle 7) und die postoperativen, klinikopathologischen Parameter (siehe Tabelle 8) dargestellt.

\subsubsection{Operationsmethode}

Wie aus Tabelle 7 ersichtlich erhielten alle 223 Patienten eine von Höhenlokalisation und Tumorstadium abhängige multimodale Therapie mit standardisierter Rektumresektion unter kurativer Therapieintention. Da die meisten Tumoren in den unteren beiden Rektumdritteln lokalisiert waren ( 0 bis $<6 \mathrm{~cm}$ und 6 bis $<12 \mathrm{~cm}$ ) (siehe Kapitel 2.2), wurde bei 158 Patienten $(70,9 \%)$ eine tiefe anteriore Rektumresektion (TARR) mit einer totalen mesorektalen Exzision (TME) durchgeführt. In 65 Fällen (29,1\%) war eine APR notwendig, da der Tumor entweder direkt supraanal lokalisiert oder eine Sphinkterinfiltration vorlag. Zusätzlich zur TME wurde daher eine kombinierte Sphinkter- und Beckenbodenexstirpation durchgeführt.

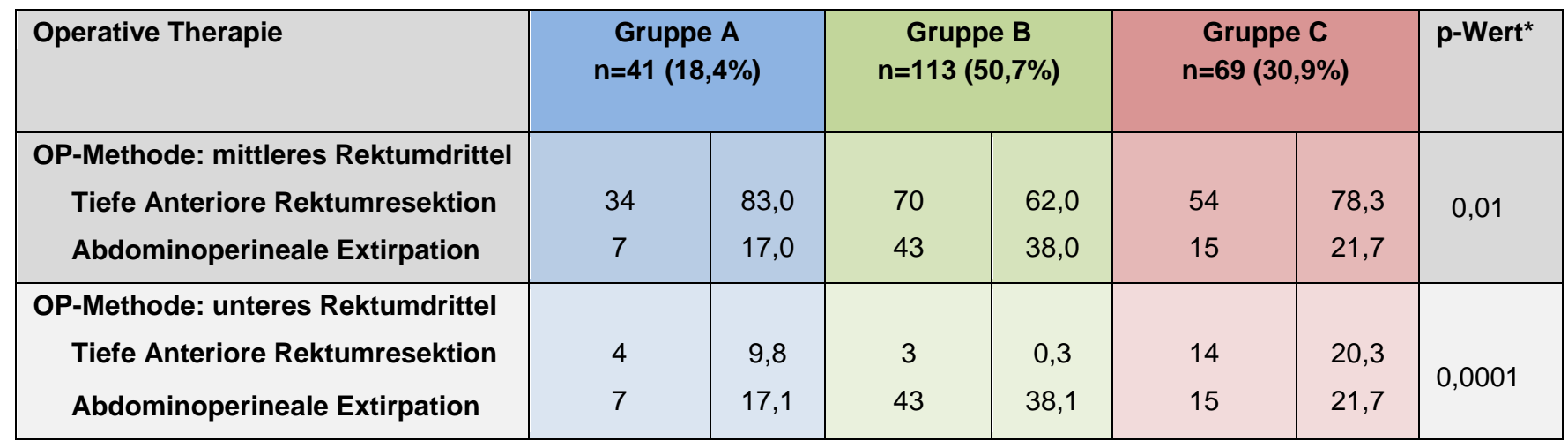

Tabelle 7: Operative Therapie

In Bezug auf die Möglichkeit der Kontinenzerhaltung für Operationen von Tumoren im unteren Rektumdrittel (siehe Tabelle 7) ergab sich in Gruppe A, dass von 11 Patienten, 7 eine APR unter Mitnahme des Sphinkterapparates erhielten (63,6\%, Prozentangabe bezieht sich auf Gesamtheit der Tumoren im unteren Rektumdrittel). In Gruppe B wurden sogar von 46 Patienten, mit Tumoren in diesem Bereich, 43 nicht kontinenzerhaltend operiert (93,5\%). 
Lediglich in Gruppe C erhielten nur 15 von 29 Patienten $(51,72 \%)$ nach der neoadjuvanten RT/CTx eine APR.

\subsubsection{Postoperative klinikopathologische Parameter}

Bei 219 Patienten (98,2\%) konnte die Entfernung des Tumors im gesunden Gewebe mit ausreichendem Sicherheitsabstand $\left(\mathrm{R}_{0}\right)$ stattfinden. In 3 Fällen $(1,3 \%)$ konnte der Tumor makroskopisch komplett entfernt werden, histopathologisch waren jedoch noch mikroskopisch erkennbare Tumoranteile im Resektionsrand nachweisbar $\left(\mathrm{R}_{1}\right)$. Nur bei einem Patienten $(0,5 \%)$ wurde eine makroskopisch unvollständige Resektion $\left(\mathrm{R}_{2}\right)$ des Tumors durchgeführt (siehe Tabelle 8).

Da Gruppe A eine primäre Operation mit anschließender adjuvanter Therapie erhielt, folgte die Bestimmung des Tumorregressionsgrades nur in den Gruppen B und C. In beiden Gruppen konnte oftmals eine Regression des Tumors nachgewiesen werden, die Unterschiede zwischen den beiden Gruppen sind demnach nicht signifikant (p-Wert=0,9). Eine gute Tumorregression (50-99\%) konnte bei 53,84\% aller Patienten aus den Gruppen B und C festgestellt werden. Eine komplette Regression (TRG 4, entsprechend einer histopathologisch bestätigten (y)pT0(y)pN0 Remission) des tumorösen Gewebes konnte bei 17 Patienten $(9,34 \%)$ verzeichnet werden.

Die histopathologische Resektatuntersuchung ergab, dass in Gruppe A 9 Patienten (22\%) mit dem primär im Staging ermittelten (c)UICC-Stadium-II/-III ein, anhand des Resektats ermitteltes, pUICC-Stadium-I aufwiesen. Da diese Patienten keine neoadjuvante Therapie erhielten, unterlagen sie bei der präoperativen Diagnostik somit einem overstaging. In den Gruppen B und $\mathrm{C}$ wurde hingegen eine neoadjuvante Therapie durchgeführt, sodass man anhand des (y)pUICC-Stadiums keine Aussage treffen kann, ob ein downsizing oder ein overstaging stattgefunden hat. Bei einem Patienten in Gruppe A wurde präoperativ ein UICCStadium-III, postoperativ histologisch ein Stadium-IV diagnostiziert.

Die postoperative Bestimmung des Tumorstadiums ergab ein (y)pT0-Stadium bei 16 Patienten (Gruppe B: 8\%, Gruppe C: 10,1\%). Eine Infiltration der Submukosa im Sinne eines (y)pT1-Stadiums hatten nach erfolgter neoadjuvanter Therapie 22 Patienten, 1 Patient in Gruppe A (2,4\%), 10 Patienten in Gruppe B (8,8\%) und 11 Patienten in Gruppe C (15,9\%). In Gruppe B wurden nach der neoadjuvanten Therapie mehr Tumoren mit (y)pT2-Status beschrieben als vor der Therapie (vor der neoadjuvanter Therapie 3, nach der Therapie 29). Ähnliche Ergebnisse fanden sich in Gruppe C (vor der neoadjuvanten Therapie 2, nach der Therapie 15). Dementsprechend wurden weniger (y)pT3 Tumoren diagnostiziert, welche die 
Muscularis propria perforierten und somit die Subserosa infiltrierten. Waren es in den Gruppen B und C vor der neoadjuvanten Therapie noch 163 als cT3 diagnostizierte Tumoren, so konnten nach der Therapie durch das T-Level-downsizing nur noch 89 (y)pT3 festgestellt werden. Ein organüberschreitendes Wachstum (y)pT4 wurde bei 14 Patienten diagnostiziert, präoperativ wurden 16 Patienten mit einem Tumor im Stadium cT4 ermittelt. Zusammenfassend war nach der neoadjuvanten Therapie ein downsizing in Gruppe B bei 55 Patienten (48,7\%) und in Gruppe C bei 35 Patienten (50,7\%) feststellbar.

Bei einem Großteil der Patienten konnten postoperativ keine Lymphknotenmetastasen ((y)pN0) mehr nachgewiesen werden. In Gruppe A waren dies 21 Patienten (52,2\%), in Gruppe B 73 Patienten (64,6\%) und in Gruppe C 51 Patienten (73,9\%). Im Stadium (y)pN1 gibt es kaum Unterschiede hinsichtlich der verschiedenen neoadjuvanten Therapiegruppen. Stadium (y)pN2 hingegen unterscheidet sich stark innerhalb der Gruppen: in Gruppe A wurde dieses Stadium bei 11 Patienten (25,8\%) ermittelt, in Gruppe B bei 14 Patienten $(12,4 \%)$, in Gruppe C bei 4 Patienten (5,8\%). Man kann somit beobachten, dass es unter einer stärkeren neoadjuvanten Therapie mit Oxaliplatin zu einer Zunahme des (y)pN0-Stadiums kommt. Umgekehrt kommt es zu einer Abnahme der Häufigkeit von Stadium (y)pN2 bei stärkerer neoadjuvanter Therapie. In der Cox-Regressionsanalyse konnte hierbei auch ein signifikanter Unterschied festgestellt werden $(p=0,03)$.

\begin{tabular}{|c|c|c|c|c|c|c|c|}
\hline \multirow{2}{*}{$\begin{array}{l}\text { Postoperative Therapie } \\
\text { (y)pT-Status }\end{array}$} & \multicolumn{2}{|c|}{$\begin{array}{c}\text { Gruppe A } \\
n=41(18,4 \%)\end{array}$} & \multicolumn{2}{|c|}{$\begin{array}{c}\text { Gruppe B } \\
n=113(50,7 \%)\end{array}$} & \multicolumn{2}{|c|}{$\begin{array}{c}\text { Gruppe C } \\
n=69(30,9 \%)\end{array}$} & \multirow[t]{2}{*}{ p-Wert } \\
\hline & & & & & & & \\
\hline 0 & 0 & 0 & 9 & 8,0 & 7 & 10,1 & \\
\hline 1 & 1 & 2,4 & 10 & 8,8 & 11 & 15,9 & \\
\hline 2 & 12 & 29,3 & 29 & 25,7 & 15 & 21,7 & 0,19 \\
\hline 3 & 26 & 63,4 & 57 & 50,4 & 32 & 46,4 & \\
\hline 4 & 2 & 4,9 & 8 & 7,1 & 4 & 5,8 & \\
\hline \multicolumn{8}{|l|}{ (y)pN-Status } \\
\hline 0 & 21 & 52,2 & 73 & 64,6 & 51 & 73,9 & \multirow{3}{*}{0,03} \\
\hline 1 & 9 & 22 & 26 & 23,0 & 14 & 20,3 & \\
\hline 2 & 11 & 25,8 & 14 & 12,4 & 4 & 5,8 & \\
\hline \multicolumn{8}{|l|}{ Tumorregressionsgrad } \\
\hline 0 keine Regression & - & - & 0 & 0 & 0 & 0 & \multirow{5}{*}{0,90} \\
\hline 1 leichte Regression (< 25\%) & - & - & 15 & 13,3 & 8 & 11,6 & \\
\hline 2 moderate Regression ( $<50 \%$ ) & - & - & 29 & 25,7 & 15 & 21,7 & \\
\hline 3 gute Regression (50-99\%) & - & - & 59 & 52,2 & 39 & 56,5 & \\
\hline 4 komplette Regression (100\%) & - & - & 10 & 8,8 & 7 & 10,1 & \\
\hline
\end{tabular}




\begin{tabular}{|c|c|c|c|c|c|c|c|}
\hline R-Status (lokal) & 39 & 95,1 & 112 & 99,1 & 68 & 98,6 & \\
$\mathrm{R}_{0}$ & 2 & 4,9 & 0 & 0 & 1 & 1,4 & 0,17 \\
$\mathrm{R}_{1}$ & 0 & 0 & 1 & 0,9 & 0 & 0 & \\
$\mathrm{R}_{2}$ & 0 & \\
\hline
\end{tabular}

Tabelle 8: Postoperative klinikopathologische Parameter

Postoperativ wurde der R-Status des Resektates bestimmt, der Tumorregressionsgrad, das T- und das N-Stadium. Die Ergebnisse des resultierenden UICC-Stadiums sind ebenfalls aufgeführt.

\begin{tabular}{|c|c|c|c|c|c|c|}
\cline { 2 - 7 } \multicolumn{1}{c|}{} & \multicolumn{2}{c|}{ Gruppe A } & \multicolumn{2}{c|}{ Gruppe B } & \multicolumn{2}{c|}{ Gruppe C } \\
\cline { 2 - 7 } & $\begin{array}{l}\text { cUICC- } \\
\text { Stadium }\end{array}$ & $\begin{array}{l}\text { pUICC- } \\
\text { Stadium }\end{array}$ & $\begin{array}{l}\text { cUICC- } \\
\text { Stadium } \\
\text { Stadium }\end{array}$ & $\begin{array}{l}\text { cUICC- } \\
\text { Stadium }\end{array}$ & $\begin{array}{l}\text { (y)pUICC- } \\
\text { Stadium }\end{array}$ \\
\hline 0 & $0(0 \%)$ & $0(0 \%)$ & $0(0 \%)$ & $9(8 \%)$ & $0(0 \%)$ & $7(10,1 \%)$ \\
I & $0(0 \%)$ & $9(22 \%)$ & $0(0 \%)$ & $28(24,8 \%)$ & $0(0 \%)$ & $25(36,3 \%)$ \\
II & $17(41,5 \%)$ & $13(31,7 \%)$ & $31(27,4 \%)$ & $34(30,1 \%)$ & $18(26,1 \%)$ & $16(23,2 \%)$ \\
III & $21(51,2 \%)$ & $15(36,6 \%)$ & $79(69,9 \%)$ & $36(31,8 \%)$ & $45(56,2 \%)$ & $15(21,7 \%)$ \\
IV & $3(7,3 \%)$ & $4(9,7 \%)$ & $3(5,3 \%)$ & $6(5,3 \%)$ & $6(8,7 \%)$ & $6(8,7 \%)$ \\
\hline
\end{tabular}

Tabelle 9: Vergleich von cUICC und pUICC/(y)pUICC

\subsection{Langzeit-Follow-Up der Patienten}

Alle Patienten wurden standardisiert über einen Zeitraum von mindestens 5 Jahren nachbeobachtet und einer systematischen onkologischen Nachsorge unterzogen, bei der alle Veränderungen, von Lokalrezidiven und Fernmetastasen, bis hin zu (tumorbedingten) Todesfällen dokumentiert wurden (siehe Kapitel 2.4). Der mediane Beobachtungszeitraum für die vorliegende Analyse betrug 66 Monate, bei einer Zeitspanne von 1 bis 177 Monaten.

In Gruppe A traten im Durchschnitt mehr Rezidive in Form von Lokalrezidiven oder Fernmetastasen auf (bei 14 Patienten, entspricht 34,1\%) als in den Gruppen B und C (Gruppe B bei 33 Patienten, entspricht 29,2\%, Gruppe C bei 20 Patienten, entspricht 29,0\%) (siehe Tabelle 10).

In der Gruppe A entwickelten sich drei isolierte Lokalrezidive (7,3\%). In Gruppe B traten isolierte Lokalrezidive nur bei einem Patienten (0,9\%) und in Gruppe C bei zwei Patienten (2,9\%) auf. Insgesamt wurden in Gruppe A aber 7 Lokalrezidive (3 isolierte und 4 kombinierte mit Fernmetastasen, entspricht 17,1\%), in Gruppe B ebenfalls 7 Lokalrezidive (1 isoliertes und 6 kombinierte, entspricht 6,2\%) und in Gruppe C 4 Lokalrezidive (2 isolierte, 2 kombinierte, entspricht 5,8\%) diagnostiziert. 
Isolierte Fernmetastasen traten in Gruppe B bei $23 \%$ der Patienten auf, in Gruppe C bei 23,2\%. In Gruppe A hatten 17\% der Patienten isolierte Fernmetastasen. Die Gesamtheit der Fernmetastasen betreffend (isolierte inkl. kombinierte) gab es in der Häufigkeit jedoch nur sehr geringe Unterschiede (Gruppe A 26,8\%, Gruppe B 28,3\%, Gruppe C 26,1\%).

Im Ganzen gab es in den Kollektiven 36 tumorbedingte Todesfälle (16,1\%). In Gruppe A starben im untersuchten Nachbeobachtungszeitraum 8 Patienten an den Folgen eines Rektumkarzinoms (19,0\%), in Gruppe B waren es 18 Patienten (15,9\%), in Gruppe C 10 Patienten (14,5\%). Die Nachbeobachtungszeiträume divergieren allerdings zwischen den Gruppen deutlich (im Durchschnitt: Gruppe A 97 Monate, Gruppe B 60 Monate und Gruppe C 41 Monate), da die neoadjuvante Therapie (v.a. die um Oxaliplatin erweiterte) erst seit wenigen Jahren angewendet wird.

\begin{tabular}{|c|c|c|c|c|c|c|c|}
\hline Follow-Up-Daten & \multicolumn{2}{|c|}{$\begin{array}{c}\text { Gruppe A } \\
n=41(18,4 \%)\end{array}$} & \multicolumn{2}{|c|}{$\begin{array}{c}\text { Gruppe B } \\
n=113(50,7 \%)\end{array}$} & \multicolumn{2}{|c|}{$\begin{array}{c}\text { Gruppe C } \\
n=69(30,9 \%)\end{array}$} & p-Wert ${ }^{\star}$ \\
\hline \multicolumn{8}{|c|}{ Follow-Up (letztes Update 01/2012; durchschnittliche Dauer des Follow-Up beträgt 66 Monate) } \\
\hline \multicolumn{8}{|l|}{ Rezidive } \\
\hline keine & 27 & 65,9 & 80 & 70,8 & 49 & 71 & \\
\hline Lokal (isolierte) & 3 & 7,3 & 1 & 0,9 & 2 & 2,9 & 0,30 \\
\hline Fernmetastasen (isolierte) & 7 & 17 & 26 & 23 & 16 & 23,2 & \\
\hline Lokal und Fernmetastasen & 4 & 9,8 & 6 & 5,3 & 2 & 2,9 & \\
\hline \multicolumn{8}{|l|}{ Metastasen } \\
\hline Leber & 3 & 27,3 & 7 & 21,9 & 8 & 44,4 & \\
\hline Lunge & 4 & 36,3 & 10 & 31,3 & 2 & 11,1 & 0,50 \\
\hline Leber und Lunge & 1 & 9,1 & 3 & 9,4 & 3 & 16,7 & \\
\hline Peritoneal und/oder andere & 3 & 27,3 & 12 & 37,4 & 5 & 27,8 & \\
\hline \multicolumn{8}{|l|}{ Follow-Up time } \\
\hline Durchschnitt & \multicolumn{2}{|c|}{97} & \multicolumn{2}{|c|}{60} & \multicolumn{2}{|c|}{41} & \\
\hline Bereich & \multicolumn{2}{|c|}{$1-177$} & \multicolumn{2}{|c|}{$1-163$} & \multicolumn{2}{|c|}{$2-93$} & \\
\hline KRK-bedingte Todesfälle & 8 & 19,0 & 18 & 15,9 & 10 & 14,5 & 0,10 \\
\hline
\end{tabular}

Tabelle 10: Follow-Up-Daten

In dieser Tabelle sind alle Daten zu Lokalrezidiven, Fernmetastasen, der Dauer der Nachbeobachtung (im Durchschnitt und im Intervall) und der Anzahl der karzinombedingten Tode aufgeführt. 


\subsection{TP-Expressionslevel}

Das TP-Expressionslevel wurde wie in Kapitel 2.3 und 2.5 beschrieben ermittelt und nach den in Kapitel 2.6 erläuterten Methoden ausgewertet. Für jede untersuchte Biopsie und jedes Resektat wurde ein H-Score (zwischen 0 und 300) berechnet und nach den drei Therapiegruppen (A, B und C) in einem Boxplot aufgetragen. Im Folgenden wird von einer geringen TP-Expression gesprochen, wenn ein H-Score von $<1$ vorlag. Dies beruht auf der Erkenntnis, dass TP in den meisten Zellen des Körpers physiologisch vorkommt (siehe Kapitel 1.8). Die Expression von TP war in diesen Zellen lediglich zu gering, um immunhistochemisch nachgewiesen werden zu können. Die untersuchten Präparate zeigten insgesamt eine schwache Färbeintensität. Die prätherapeutischen Biopsien exprimierten dabei deutlich weniger TP als die Resektate. Zuerst wurden alle Biopsien und Resektate getrennt voneinander betrachtet. Für die 163 Patienten mit gepaartem Probenmaterial (d.h. prätherapeutische Biopsie und Resektat) wurde auch die Dynamik der gemessenen Expression ausgewertet.

Im Folgenden werden diese Ergebnisse in Form von Boxplots dargestellt.

\subsubsection{TP-Expression in prätherapeutischen Biopsien}

Insgesamt wurden im Rahmen dieser Arbeit 186 Biopsien auf die Expression von TP untersucht, von denen 27 Biopsien Gruppe A (14,5\%), 95 Biopsien Gruppe B (51\%) und 64 Biopsien Gruppe C $(34,5 \%)$ zugeordnet wurden. Von allen Biopsien wiesen lediglich 33 eine verstärkte TP-Expression auf $(17,74 \%)$.

Der Median aller drei Gruppen liegt für die prätherapeutischen Biopsien bei 0 (siehe Abbildung 11). In Gruppe A konnte bei $26 \%$ der Biopsien ein positiver TP-Status festgestellt werden $(n=7)$. Dies waren in Gruppe B 17,9\% der Biopsien $(n=17)$. In Gruppe C waren $14,1 \%$ der Biopsien TP exprimierend $(n=9)$. Biopsien mit einer positiven TP-Expression hatten einen ermittelten $\mathrm{H}$-Score von 2 bis 55, ein einzelner H-Score betrug 200.

Der Großteil der ermittelten Ergebnisse lag somit bei 0 und spricht für eine geringe bis meist nicht vorhandene Färbeintensität in den Biopsien. 


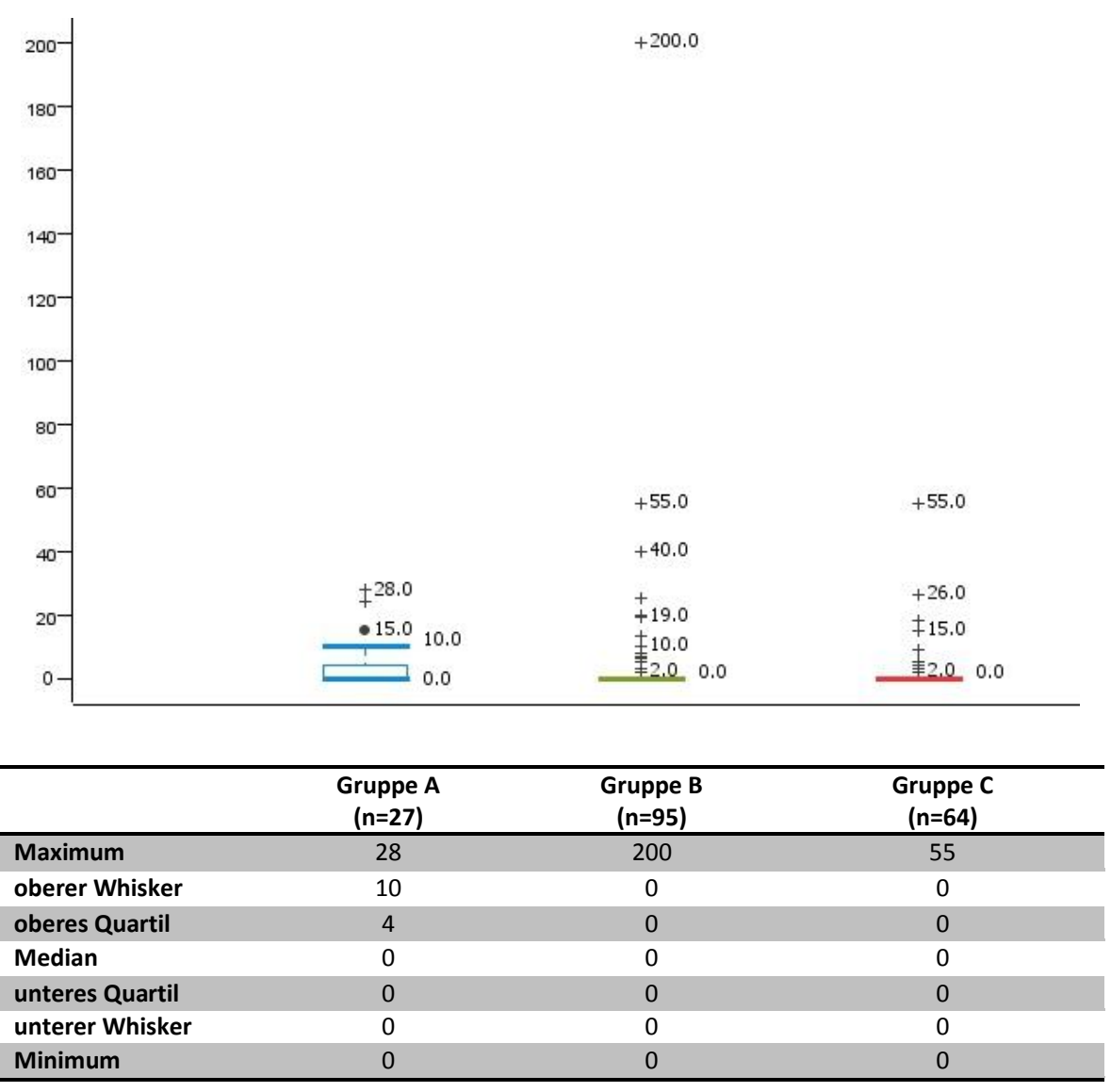

\section{Abbildung 11: Boxplot zur Darstellung der TP-Intensität in Biopsien}

Der Median liegt bei allen Gruppen bei 0. In Gruppe A wird für das obere Quartil ein Wert von 4 angegeben, der obere Whisker liegt bei 10. Der höchste gemessene Wert betrug 28. Für die Gruppen B und C liegen alle Grenzen bei 0, es wurden lediglich 9 Ausreißer in Gruppe B (maximaler Wert 200) und 11 Ausreißer in Gruppe $\mathrm{C}$ (maximaler Wert 55) gemessen.

\subsubsection{TP-Expression in Rektumresektaten}

Insgesamt standen für die Analyse 199 Präparate von Rektumresektaten zur Verfügung. Hier handelt es sich in Gruppe A um 40 (20,1\%), in Gruppe B um 99 (49,8\%) und in Gruppe C um $60(30,1 \%)$ Resektate.

Eine positive TP-Expression konnte in Gruppe A bei 19 von 40 Resektaten (47,5\%) gemessen werden. In Gruppe B ergaben die immunhistochemischen Untersuchungen eine positive TPExpression bei 56 von 105 Präparaten (53,3\%), in Gruppe C bei 40 von 62 Präparaten (64,5\%). Bei den Resektaten liegt der Score-Wert des Median für die Gruppe A und B bei 0 (siehe Abbildung 12). In der Gruppe C liegt der Median bei einem Wert von 12. 


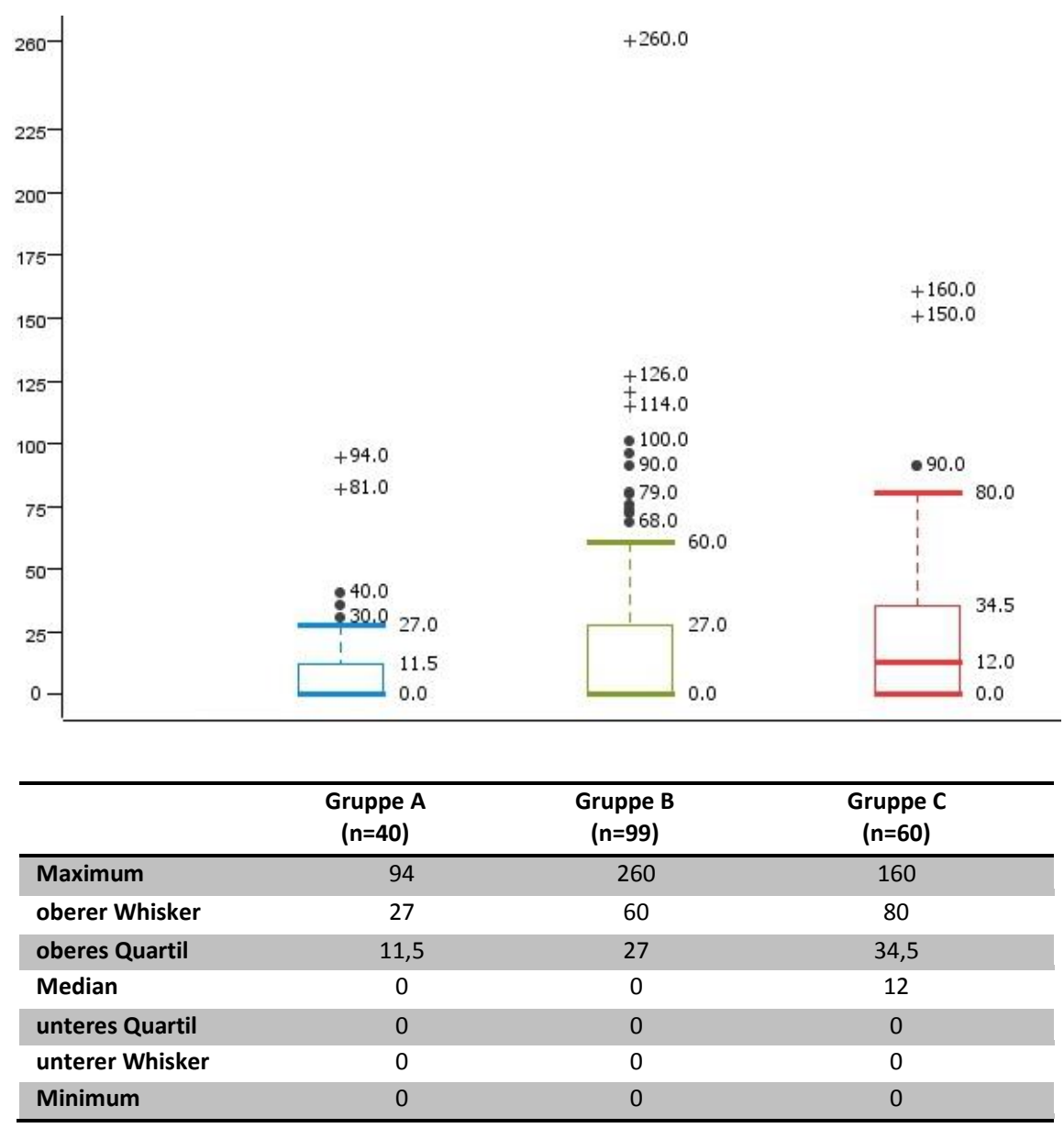

\section{Abbildung 12: Boxplot zur Darstellung der TP-Intensität in den ungepaarten Resektaten} In den Gruppen A und B liegt der Median bei 0, in Gruppe C bei 12. Das obere Quartil stellt sich mit einem Wert von 11,5 in Gruppe A, 27 in Gruppe B und 34,5 in Gruppe C dar. Der obere Whisker begrenzt in Gruppe A bei 27 genau 95\% aller Werte, in Gruppe B bei 60 und in Gruppe C bei 80. Der größte statistische Ausreißer liegt in Gruppe A bei 94, in Gruppe B bei 260 und in Gruppe C bei 160.

\subsubsection{TP-Expressionsgrad im direkten Vergleich prätherapeutischer Biopsien und OP-Resektate}

Wie bereits zu Beginn des Kapitels 3.3 erläutert, handelt es sich bei korrespondierenden Gewebeproben um Biomaterial von jenen Patienten, deren prätherapeutische Biopsien und Rektumresektate gleichermaßen zur immunhistochemischen Untersuchung in dieser Studie vorlagen. Insgesamt gab es somit 163 korrespondierende Präparate, davon 26 in Gruppe A, 82 in Gruppe B und 55 in Gruppe C.

Nicht für alle Patienten stand Material aus der Biopsie und dem Rektumresektat zur Verfügung, da einige Tumoren durch die neoadjuvante Therapie bereits einer starken Regression unterlagen und somit kein oder nicht mehr genügend Tumormaterial für eine 
immunhistochemische Untersuchung zur Verfügung stand. Diese Patienten hatten somit mindestens einen Tumorregressionsgrad 3b oder sogar Stadium 4 (pCR).

In Abbildung 13a wurde der TP-Expressionsgrad innerhalb der Biopsien des korrespondierenden Materials dargestellt. In Gruppe A zeigen 7 von 26 (26,9\%) Biopsien eine positive TP-Expression, in Gruppe B 16 von 82 (19,5\%) und in Gruppe C 8 von 55 (14,6\%). Auch in dieser Darstellung zeigt sich nur in wenigen Biopsien eine positive TP-Expression, denn der Median liegt bei allen Gruppen erneut bei 0 .

Abbildung 13b hingegen betrachtet die TP-Expressionsgrade von korrespondierenden Resektaten.

In Gruppe A hatten von 26 korrespondierenden Präparaten, 11 Resektate (42,3\%) eine positive TP-Expression. In Gruppe B wurde bei 44 von 82 Präparaten $(53,7 \%)$ eine positive TP-Expression gemessen und in Gruppe C bei 27 von $55(49,1 \%)$.

In Gruppe A liegt der Median, ebenso wie für die Gesamtheit aller betrachteten Resektate (siehe Kapitel 3.3.2), bei 0 (siehe Abbildung 13b). In Gruppe B liegt der Median bei einem HScore von 5,5, in Gruppe C wurde ein Median mit einem Score von 12 ermittelt. 
a)

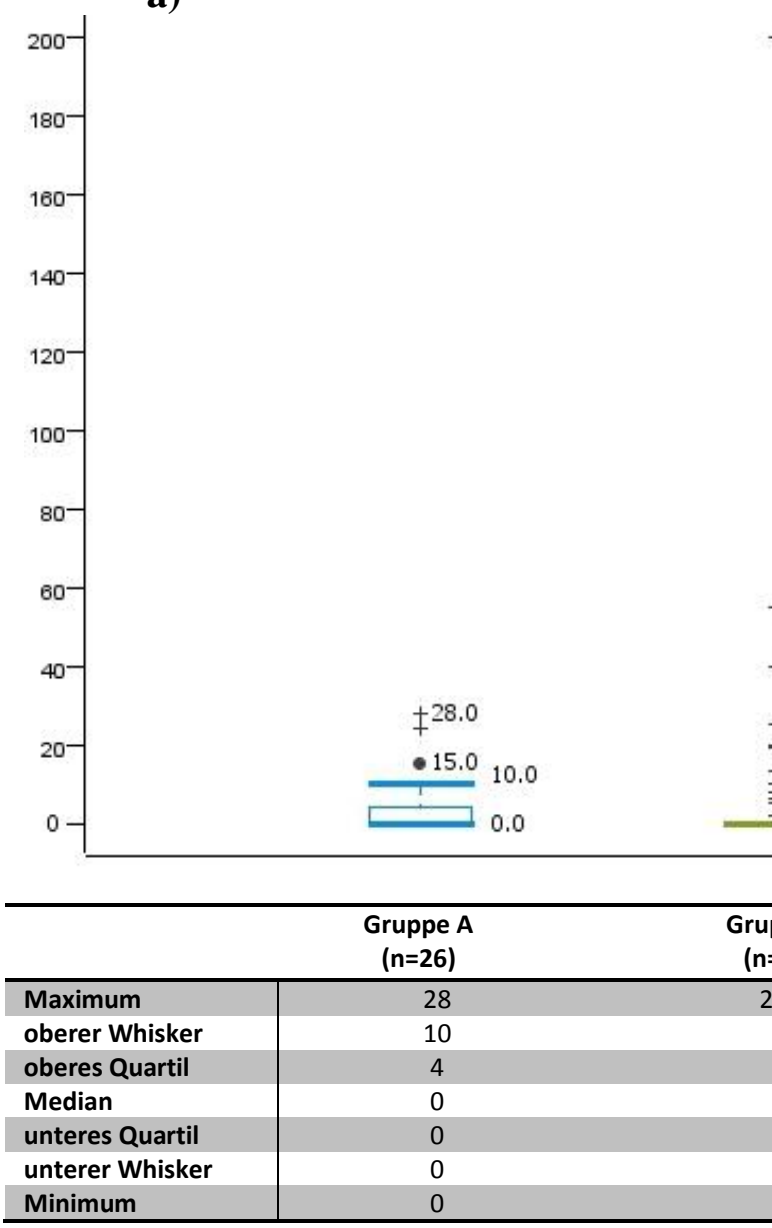

b)

$+200.0$

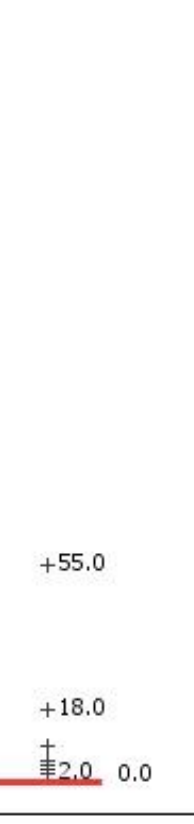

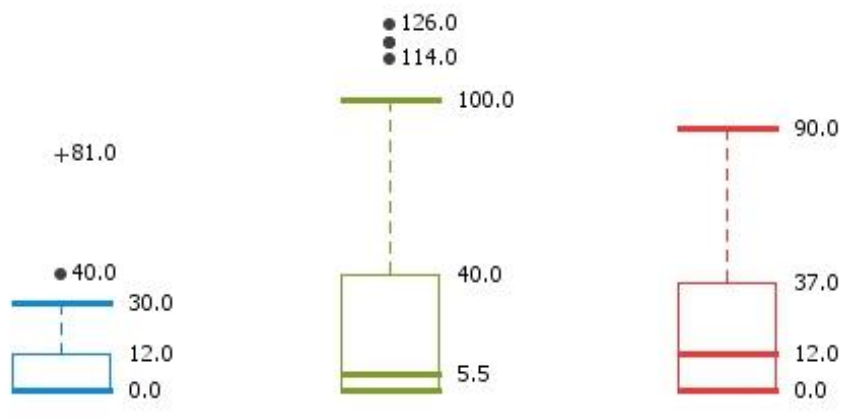

Gruppe A

$(n=26)$

Gruppe B

$(n=82)$

( $n=55$

$200 \quad 55$

$\begin{array}{cc}200 & 55 \\ 0 & 0\end{array}$

$\begin{array}{ll}0 & 0 \\ 0 & 0\end{array}$

0
0
0
0
0

a) Der Median liegt in allen Patientengruppen bei 0. In Gruppe A liegt das obere Quartil bei 4, in den Gruppen B und C bei 0. Der obere Whisker liegt in Gruppe A bei 10, in den Gruppen B und C wiederum bei 0. Oberhalb dieser Begrenzung liegt der größte H-Score in Gruppe A bei 28 , in Gruppe B bei 200 und in Gruppe C bei 55.

b) In der Gruppe A liegt der mediane H-Score bei 0, in Gruppe B bei 5,5 und in Gruppe C bei 12. Das obere Quartil ist in Gruppe A mit einem Wert von 12 angegeben, in Gruppe B mit 40, Gruppe C mit 37. Der obere Whisker liegt in Gruppe A bei 30, in Gruppe B bei 100 und in Gruppe C bei 90 . Der größte gemessene H-Score lag in Gruppe A bei 81, in Gruppe B bei 260 und in Gruppe C bei 160 


\subsubsection{Histogramme zur Darstellung der TP-Expressionslevel}

Zur weiteren graphischen Darstellung der TP-Scores wurden die Ergebnisse in Form von Histogrammen dargestellt. Auf der Ordinatenachse wurde hierbei die Anzahl n der ermittelten Ergebnisse aufgetragen, auf der Abszissenachse der jeweilige H-Score. Um eine übersichtlichere Darstellung zu ermöglichen wurden die gering TP-exprimierenden Proben (H-Score 0) mit einem separaten grauen Balken dargestellt. Stärker TP-exprimierende Proben hingegen sind mit einem roten Balken gekennzeichnet (H-Score > 0). Über den Balken finden sich jeweils die exakten Zahlen für die Anzahl der ermittelten Proben. Abbildung 14a) zeigt die Häufigkeitsverteilung innerhalb der Biopsien, Abbildung 14b) innerhalb der Resektate.

Unter den 186 Biopsien sind 153 Präparate ohne TP-Expression, oder die Expression des Enzyms war so gering, dass eine immhunhistochemische Anfärbung nicht möglich war. Diese Präparate haben somit den minimalen $\mathrm{H}$-Score 0 , weitere 33 Präparate haben einen H-Score $>1$.

Abbildung 14a stellt die TP-Expression in der Gesamtheit aller Biopsien dar. Ein einzelner roter Balken umfasst einen Bereich von 14 Punkten des H-Scores. Der erste rote Balken enthält demnach alle 20 Präparate die einen H-Score von 1-14 aufweisen. Dies sind 60,6\% der 33 angefärbten Biopsien. Weitere 9 Biopsien haben einen H-Score zwischen 15 und 29, eine Biopsie liegt im Intervall von 30 bis 44 und 2 weitere Biopsien liegen zwischen 45 und 59 Punkten. Der H-Score Bereich von 60 bis 199 enthält keine gemessenen Ergebnisse. Eine weitere Biopsie hat, wie bereits in Kapitel 3.4.1 aufgeführt, einen ermittelten H-Score von 200.

Abbildung 14b hingegen beschreibt die Verteilung der gesamten Resektate. Diese 199 Präparate enthalten $91(45,73 \%)$ die einen H-Score von 0 aufweisen. Genau 43 Präparate $(21,6 \%)$ haben eine Färbeintensität, die einen H-Score von 1 bis 18 aufweist. Folgende rote Balken des Histogramms markieren stets Intervalle von 18 Punkten des H-Scores. Zu erkennen ist, dass unter den angefärbten Präparaten die Verteilung in den niedrigen H-Score Intervallen deutlich größer ist, als in höheren Bereichen. Somit liegen 84 (77,78\%) der 108 angefärbten Präparate in den ersten 3 Intervallen (1 bis 54). 


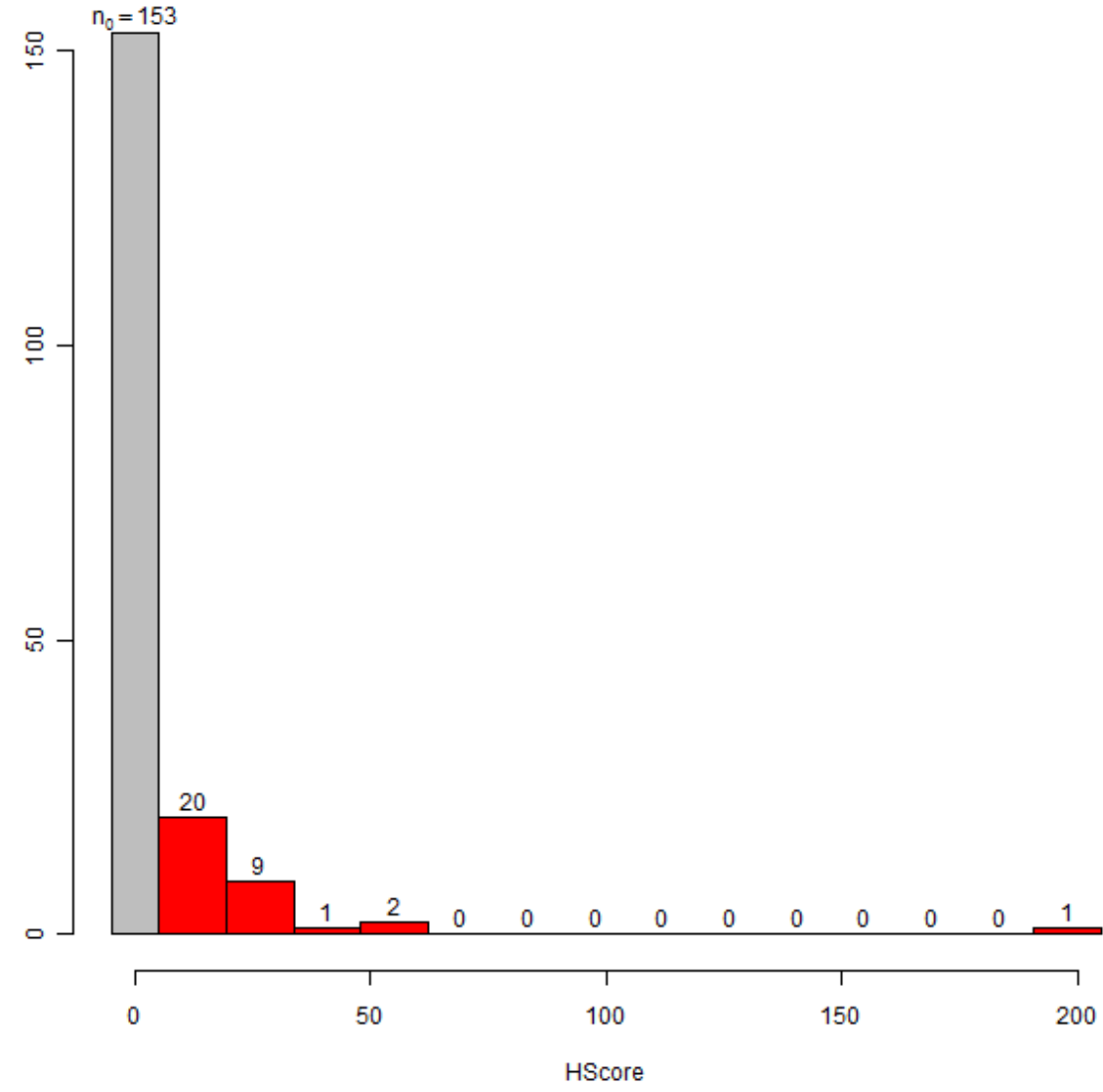

a)

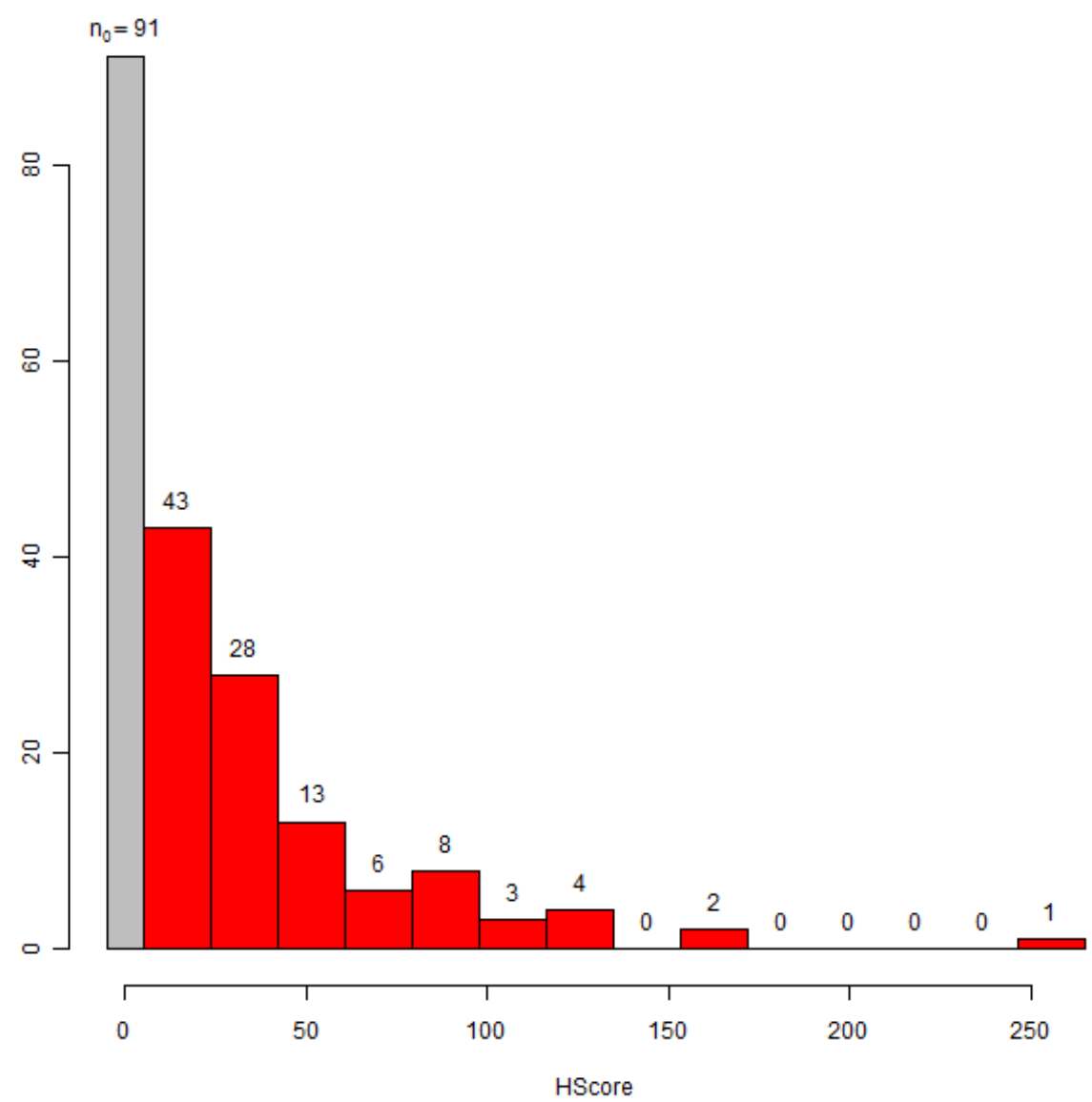

b)

Abbildung 14: Histogramme zur Darstellung der TP-Level in Biopsien und Resektaten

a) Histogramm zur Darstellung der TP-Expression in Biopsien anhand des H-Scores und der Anzahl der ermittelten Ergebnisse. Der graue Balken stellt die Verteilung der gering TP-exprimierenden Biopsien dar und enthält 153 Präparate, die roten Balken bilden Intervalle im Abstand von je 14 Einheiten des H-Scores. Die Expression der hoch TP-exprimierenden Biopsien ist vor allem auf den vorderen Bereich des H-Scores beschränkt (bis maximal 59).

b) Histogramm zur Darstellung der TP-Expression in Resektaten anhand des H-Scores und der Anzahl der ermittelten Ergebnisse. Der graue Balken stellt die Verteilung der gering TP-exprimierenden Resektate dar und enthält 91 Präparate, die roten Balken bilden Intervalle im Abstand von je 18 Einheiten des H-Scores. Von den 108 hoch TP-exprimierenden Präparaten liegen 84 (77,78\%) in einem Intervall von 1 bis 54. 


\subsubsection{Errechnete Differenz des H-Scores zwischen Biopsien und Resektaten}

Als weitere statistische Methode wurden die Ergebnisse der Differenz aus den H-Scores von Biopsie und Resektat ermittelt. Zur Darstellung der Dynamik der TP-Expression konnten in dieser Analyse lediglich die Ergebnisse von gepaarten Materialien verwendet werden, wobei der jeweilige H-Score des Resektats von dem H-Score der Biopsie desselben Patienten subtrahiert wurde um eine mögliche Hoch- oder Herunterregulation der TP-Expression zwischen der Biopsie- und der Rektumresektatentnahme feststellen zu können (siehe Kapitel 2.8).

Diese Methode erlaubt es, die Dynamik der TP-Expression zwischen Biopsie und Resektat zu beschreiben. Hat eine Biopsie beispielsweise einen hohen H-Score und das Resektat einen kleineren, so ergibt sich ein positiver Wert. Deutlich häufiger ist jedoch der ermittelte Wert der Biopsie kleiner als der des Resektats. Somit ergeben sich die errechneten negativen Werte bis zu einem Maximum von -220 in Gruppe B (siehe Abbildung 15a).

In Gruppe A liegt der Median bei 0, in Gruppe B hingegen bei einem Wert von -1. Der Boxplot in Gruppe C wurde mit einem Median von -9 errechnet. Eine Dynamik in der TPExpression zwischen den Biopsien und den Resektaten ist demnach durchaus erkennbar.

Eine weitere Methode zur graphischen Darstellung der Differenz des H-Scores von Biopsien und Resektaten ist das sogenannte Wasserfall-Balkendiagramm, welches die exakte Häufigkeitsverteilung der Ergebnisse anzeigt. Der mittlere graue Balken repräsentiert die Daten, die bei der Differenz 0 ergaben, d.h. für die derselbe H-Score der TP-Expression in Biopsie und Resektat bestimmt wurde. Die Zahl oberhalb bzw. unterhalb der Balken stellt jeweils die Anzahl der gemessenen Daten dar, im Falle der 0 sind dies 61 Daten (37,4\%). Dies sind vornehmlich Ergebnisse von Biopsien und Resektaten die gleichermaßen einen H-Score von 0 in der Untersuchung aufwiesen. Auf der rechten Hälfte der Graphik zeigen sich 16 Werte $(9,8 \%)$, die einen errechneten H-Score > 0 haben. Hierbei handelt es sich um jene Werte, bei denen in den Biopsien höhere TP-Expressionslevel gemessen wurden, als bei den dazugehörigen Resektaten. Die Berechnung des H-Scores der Biopsie abzüglich des H-Scores des Resektats, ergab somit einen positiven errechneten Wert in diesem Diagramm und spricht für eine Herunterregulation der TP-Intensität von der Biopsie zum Resektat.

Der weitaus größte Teil der errechneten Daten wies als Differenz einen negativen Wert auf. Die ermittelten H-Scores des Resektats müssen hier also größer gewesen sein als die der Biopsie. Wie schon in Abbildung 15b zu erkennen ist, erstreckt sich der größte Teil der errechneten H-Scores in den negativen Bereich aufgrund der deutlich stärker angefärbten 
Resektate. Insgesamt finden sich 86 Ergebnisse (52,8\%) auf der linken Seite der Graphik. Im Intervall des H-Scores von -1 bis -99 finden sich 77 von 86 dieser Daten, das entspricht 89,5\% der linksseitigen Ergebnisse.

Addiert man die Werte der linken Bildhälfte $\left(\mathrm{n}_{\text {(negativ) }}=86\right.$ ), mit denen der rechten Bildhälfte $\left(\mathrm{n}_{(\text {positiv })}=16\right)$ und der Anzahl der Ergebnisse mit einer $0\left(\mathrm{n}_{0}=61\right)$, errechnen sich 163 Ergebnisse, was der exakten Anzahl der gepaarten Datensätze entspricht. 

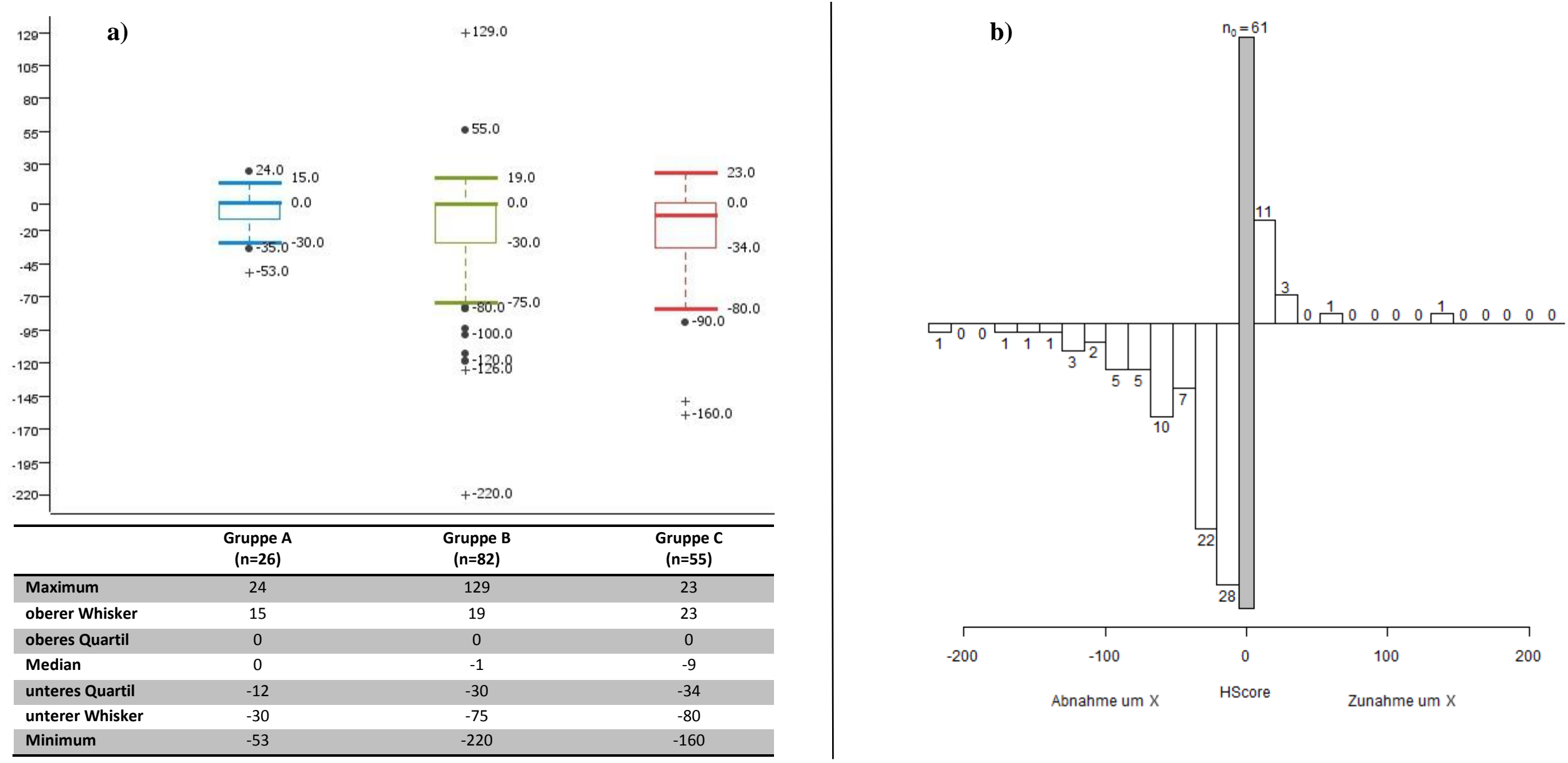

\section{Abbildung 15: Boxplot und Wasserfall-Balkendiagramm zur Darstellung der errechneten Differenz von Biopsie und Resektat}

a) Die Werte stellen die errechnete Differenz aus Biopsie und Resektat dar und lassen somit eine Veränderung zwischen den Färbeintensitäten der verschiedenen Materialien erkennen. Der Median liegt in Gruppe A bei 0, in Gruppe B bei -1 in Gruppe C bei -9.

b) In dieser Graphik wurden die errechneten Ergebnisse der Differenz aus dem H-Score der Biopsie und dem H-Score des jeweiligen Resektats in einem Balkendiagramm aufgetragen. Der graue Balken $\left(\mathrm{n}_{0}=61\right)$ gibt die Anzahl der Ergebnisse mit einer 0 als Differenz an. Auf der rechten Bildhälfte sind die positiven Ergebnisse der Differenz aufgetragen, die eine Herrunterregulation der TP-Expression beschrieben, mit der Anzahl $n_{\text {(positiv) }}=16$. Diese zeigen somit jene Daten, bei denen der H-Score der Biopsie größer war als der des dazugehörigen Resektats. Auf der linken Hälfte der Graphik sind hingegen die Daten aufgetragen, die einen negativ errechneten HScore aus der Differenz ergaben. Diese sind mit einer Anzahl von $n_{\text {(negativ) }}=86$ aufgetragen und zeigen eine Hochregulation der TP-Expression. 


\subsection{Korrelation des prätherapeutischen TP-Expressionsgrades mit dem Tumorregressionsgrad}

Die postoperative, histopathologische Beurteilung des TRG erlaubt Rückschlüsse über den unmittelbaren Effekt einer neoadjuvanten Therapie. Eine stake Tumorregression (TRG 3b/4) wird als prognostischer Surrogatparameter angesehen. In den Therapiegruppen B und C wurde bei 159 Patienten ein TRG bestimmt.

Bei nur 21 Patienten (grün = 13,2\%) konnte ein TRG 1 (<25\% Remission) festgestellt werden. Weitere 37 Patienten (rot $=23,3 \%)$ wiesen ein TRG $2(<50 \%$ Remission) auf, mehr als die Hälfte der Patienten (85 Patienten) hatten sogar ein TRG 3 (<75\% Remission) (dunkelblau + hellblau $=53,4 \%)$. Von diesen hatten 35 Patienten (dunkelblau $=22 \%)$ TRG $3 \mathrm{a}$ und 50 Patienten (hellblau $=31,4 \%$ ) TRG 3b. Eine komplette Remission des Tumorgewebes, im Sinne eines TRG 4 (100\% Remission), wurde in 16 Fällen (violett $=10,1 \%)$ diagnostiziert.

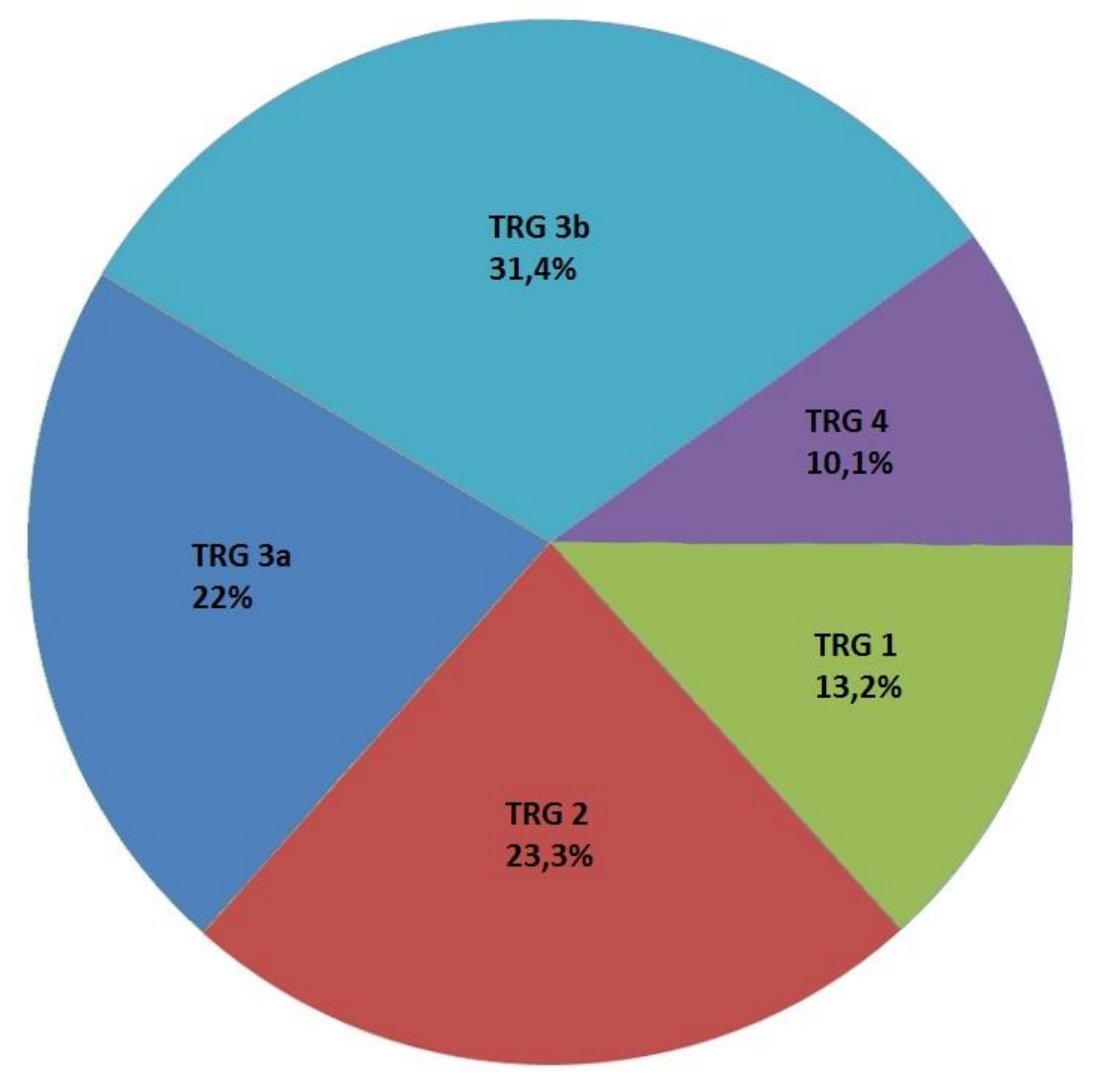
Abbildung 16: Häufigkeitsverteilung der Tumorregressionsstadien in den
Therapiegruppen $B$ und $C$

TRG: $T R G 1=21(13,2 \%)$ Patienten, $T R G 2=37$ (23,3\%) Patienten, $T R G 3 a=35$ (22\%) Patienten, $T R G$ $3 b=50(31,4 \%)$ Patienten, $T R G 4=16(10,1 \%)$ Patienten.

Es konnte kein statistischer Zusammenhang zwischen dem TP-Expressionslevel und dem Tumorregressionsgrad festgestellt werden. 
In Abbildung 17 wurde der Zusammenhang zwischen dem DFS und dem Tumorregressionsgrad graphisch dargestellt. In der Graphik ist deutlich zu erkennen $(\mathrm{p}=0,014)$, dass Patienten mit einem TRG 4 langfristig eine erheblich bessere Prognose haben als Patienten mit niedrigeren TRG.

a)

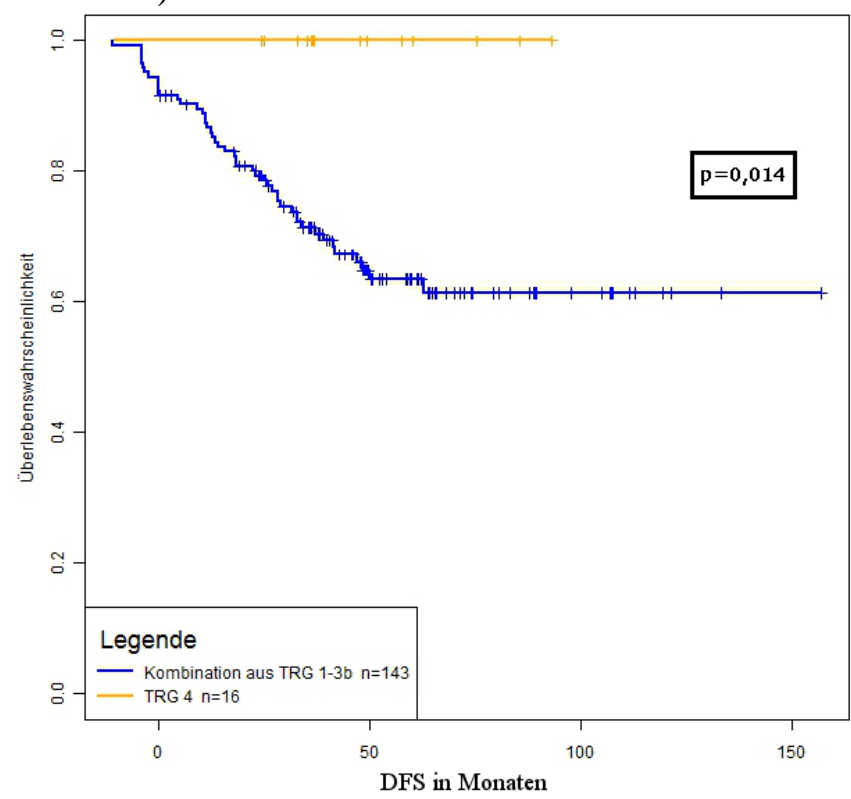

b)

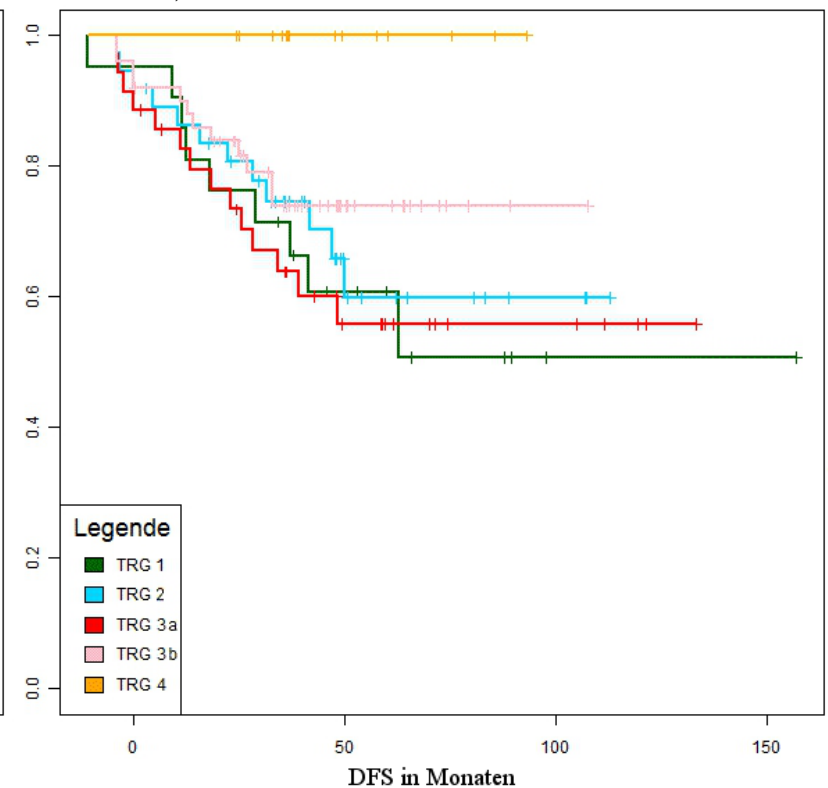

Abbildung 17: Korrelation des Tumorregressionsgrades mit dem DFS der Therapiegruppen B und C

a) Die Abbildung zeigt die mittlere Kurve, ermittelt aus den zusammengefassten Daten der Tumorregressionsgrade 1, 2, 3a und 3b. Der signifikante Unterschied $(\mathrm{p}=0,014)$ zwischen den beiden Überlebenskurven kann somit besser dargestellt werden.

b) In der Legende sind die TRG (1 bis 4) aufgelistet. Es findet sich kein statistischer Zusammenhang zwischen einem bestimmten Tumorregressionsgrad (1 bis $3 b$ ) und dem DFS. Patienten mit dem TRG 4 erhielten über den gesamten Nachbeobachtungszeitraum kein Rezidiv.

\subsection{Korrelation von TRG und Nodalstatus}

Wie bereits in Kapitel 1.3 beschrieben, konnte in unserer Arbeitsgruppe der KFO 179 gezeigt werden, dass der regionäre Lymphknotenstatus einen entscheidenden Einfluss auf die Langzeitprognose eines Patienten mit einem lokal fortgeschrittenen Rektumkarzinom hat (Sprenger et al. 2009). Basierend auf Vorarbeiten von Rödel et al. (2005) und Jakob et al. (2006) wurde gezeigt, dass der Nodalstatus einen stärkeren Einfluss als der TRG auf das DFS hat (Rödel et al. 2005; Jakob et al. 2006). Die Bedeutung des TRG im Vergleich zum postoperativen Nodalstatus wurde daher ebenfalls in der vorliegenden Arbeit analysiert. 
Abbildung 18 zeigt vier Gruppen. Diese sind unterteilt nach Nodalstatus (N0 vs. N1 und N2) und TRG (TRG 1 und 2 vs. TRG 3). Patienten mit einem negativen Nodalstatus hatten nach der neoadjuvanten Therapie - unabhängig vom TRG - ein signifikant längeres Überleben als Patienten mit einem positiven Nodalstatus. Der p-Wert aus der Cox-Regressionsanalyse zeigt einen signifikanten Unterschied zwischen den nodalpositiven (N1 und N2) und den nodalnegativen (N0) Patienten in Bezug auf das DFS $(p=0,003)$. Der TRG spielte beim Überleben der Patienten in Korrelation mit dem Nodalstatus eine untergeordnete Rolle.

Wie bereits in Kapitel 3.4 erwähnt, gab es keine Korrelation des TRG mit der TP-Expression. Daher wurde in Abbildung 18 keine weitere Analyse im Zusammenhang mit TP durchgeführt.

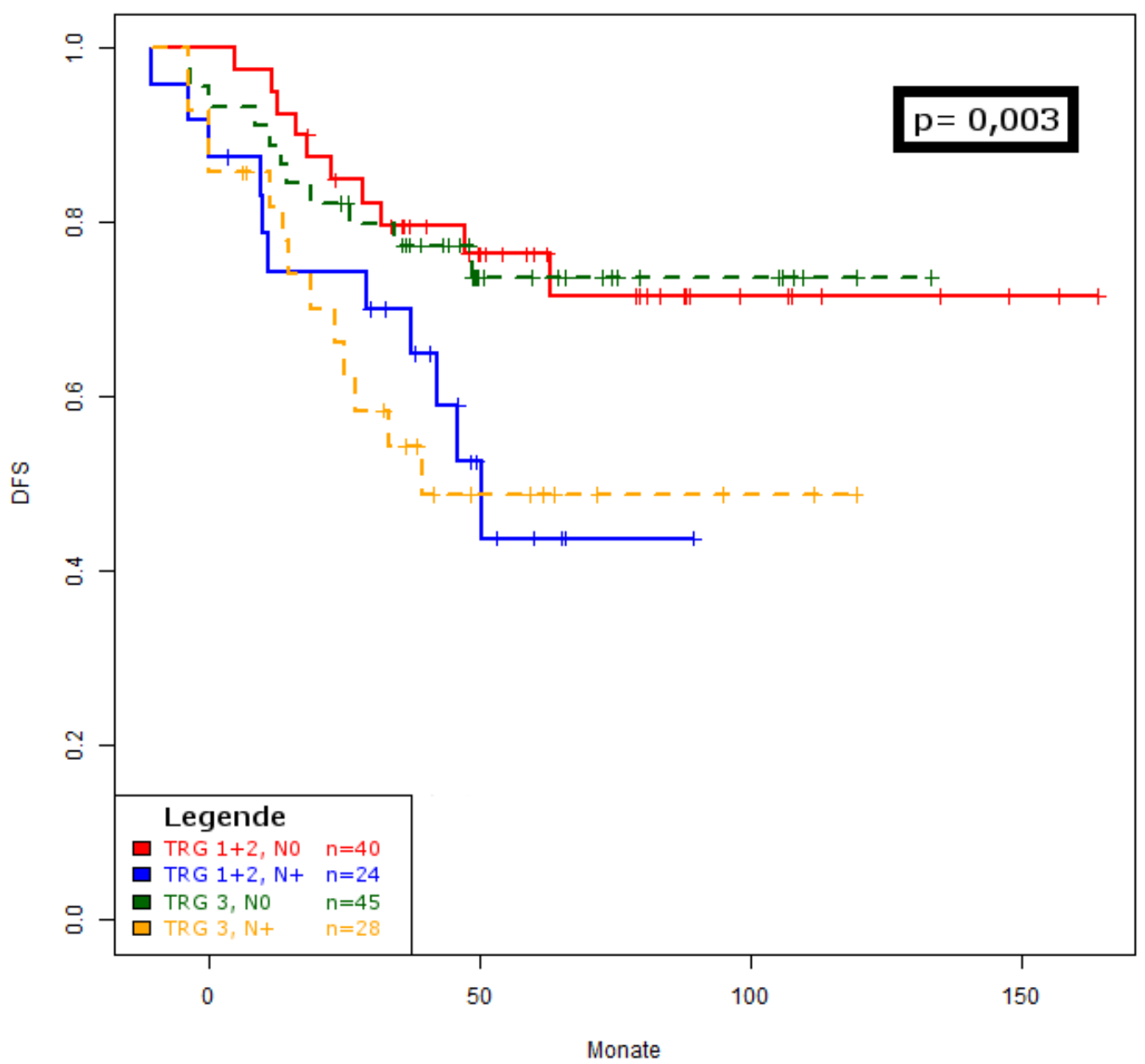

\section{Abbildung 18: Korrelation von TRG und Nodalstatus}

TRG 1 und TRG 2 bzw. TRG 3a und TRG 3b wurden jeweils als eine Gruppe zusammengefasst (Responder vs. Nonresponder). Durchgezogene Linien stellen einen geringen TRG dar (TRG 1 und TRG 2), gestrichelte Linien einen fortgeschrittenen TRG (TRG 3). Patienten mit einem negativen Nodalstatus überlebten deutlich länger als Patienten mit einem positiven Nodalstatus ( $\mathrm{p}-\mathrm{Wert}=0,003)$. 


\subsection{Ergebnisse der Langzeit-Analyse in Abhängigkeit von der TP-Expression}

Um das Auftreten bestimmter Ereignisse im Zusammenhang mit der TP-Expression und der Zeit im Follow-Up graphisch darzustellen, wurden die Daten auf Kaplan-Meier-Kurven aufgetragen. Hierbei wurde das Auftreten von Lokalrezidiven und Fernmetastasen, das tumorfreie Überleben (DFS) und das tumorspezifische Überleben (CSS) mit der TP-Expression der prätherapeutischen Biopsien und der Resektate korreliert.

Jedes dieser Ereignisse wurde in Bezug auf die Biopsien und die Resektate getrennt betrachtet und es entstanden jeweils vier Kaplan-Meier-Graphiken je Material (Biopsie oder Resektat). Zunächst wurden alle Gruppen in jeweils gemeinsamen Graphen abgebildet (Abbildung 19, Abbildung 20, Abbildung 22, Abbildung 23, Abbildung 25, Abbildung 26, Abbildung 28, Abbildung 29). Um die prognostische Bedeutung der TP-Expression unabhängig vom jeweiligen Therapieregime zu prüfen (therapeutische Gruppen A, B und C) folgte anschließend eine subgruppenspezifische Betrachtung (Abbildung 21, Abbildung 24, Abbildung 27).

Im Folgenden stellen alle roten Verläufe innerhalb der Kaplan-Meier-Kurve die TP-hochexprimierenden Präparate und die blauen Verläufe die gering TP-exprimierenden Proben dar. 


\subsubsection{Korrelation des TP-Expressionsstatus mit der Lokalrezidivrate}

\subsubsection{Korrelation der Lokalrezidivrate mit der TP-Expression in Biopsien}

Um den Zusammenhang der TP-Expressionslevel in den Biopsien mit dem Auftreten von Lokalrezidiven zu korrelieren, wurden die Ergebnisse der immunhistochemischen Auswertung aufgeteilt in TP-exprimierende und nicht-exprimierende Präparate und in einer Kaplan-MeierKurve dargestellt. Die Gruppe der wenig TP-exprimierenden prätherapeutischen Biopsien enthält 153 Biopsien, die der stark TP-exprimierenden lediglich 33. Es wurde der p-Wert aus der Cox-Regressionsanalyse bestimmt. Bei einem ermittelten p-Wert von 0,118 ergibt sich statistisch betrachtet kein signifikanter Unterschied zwischen den immunhistochemisch angefärbten und den nicht angefärbten Biopsien. Dennoch ergibt sich in dieser Kohorte für Patienten mit einem positiven TP-Status in der Biospie über einen Nachbeobachtungszeitraum von bis zu fünf Jahren ein leicht erhöhtes Risiko, ein Lokalrezidiv zu entwickeln. Das letzte Lokalrezidiv wurde bei den TP-exprimierenden Patienten nach 55 Monaten und bei den nicht TP-exprimierenden Patienten nach 56 Monaten festgestellt.

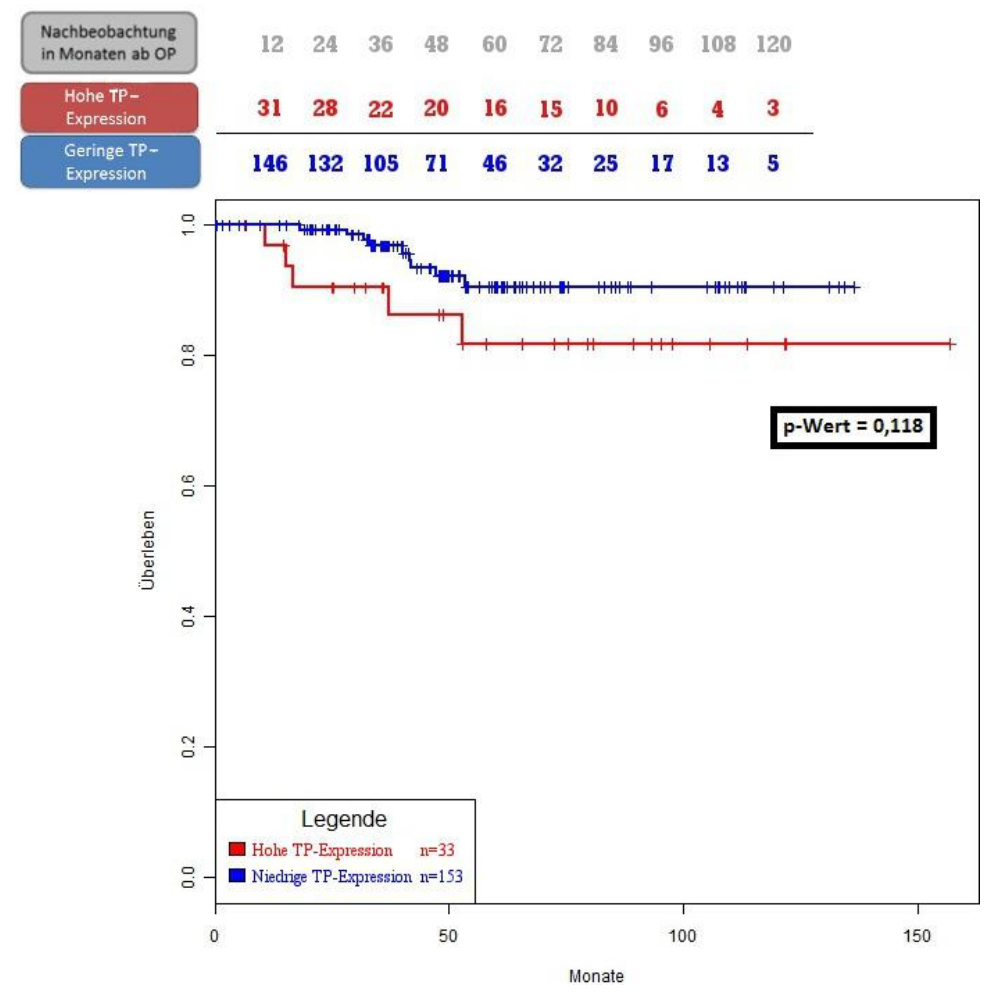

\footnotetext{
Abbildung 19: Lokalrezidivrate (LR) in Korrelation zur TP-Expression der Biopsien (alle Patientenkohorten)

Aufteilung in Patienten mit TP-exprimierenden Biopsien ( $\mathrm{n}=33$ ) und kaum TP-exprimierenden Biopsien ( $\mathrm{n}=153)$. P-Wert aus der Cox-Regressionsanalyse: $\mathbf{p}=\mathbf{0 , 1 1 8}$
} 


\subsubsection{Korrelation der Lokalrezidivrate mit der TP-Expression im residuellen Tumorgewebe}

Die Gruppengrößen (hohe TP-/ geringe TP-Expression) sind bei den Resektaten aufgrund der immunhistochemisch stärker angefärbten Resektate weniger unterschiedlich groß. Es finden sich somit insgesamt 108 Patienten mit einem TP-exprimierenden Tumorgewebe und 91 Patienten mit einem nicht TP-exprimierenden residuellen Gewebe.

Bei der Korrelation der aufgetretenen Lokalrezidive mit der im residuellen Tumorgewebe gemessenen TP-Expression, ist ein geringerer Unterschied zwischen den TP-positiven und TPnegativen Ergebnissen zu erkennen. Bei einem in der Cox-Regressionsanalyse gemessenen p-Wert von 0,352 verhalten sich die beiden Überlebenskurven ähnlicher zueinander als die Überlebenskurven der prätherapeutischen Biopsien.

Nach 87 Monaten konnte unter den nicht TP-exprimierenden Patienten das letzte Lokalrezidiv festgestellt werden, bei den TP-exprimierenden Patienten wurde das letzte Lokalrezidiv nach 55 Monaten festgestellt.

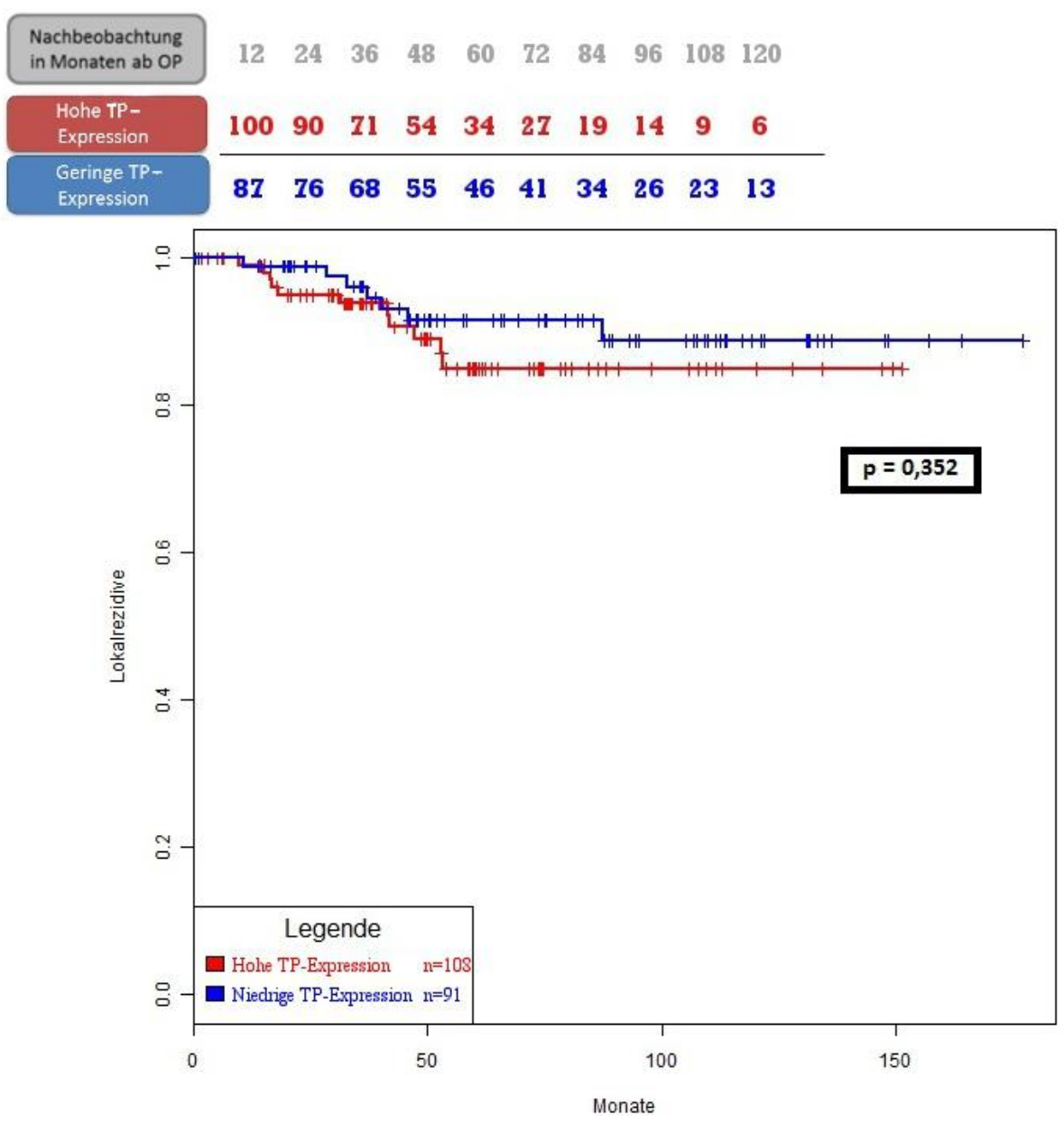

Abbildung 20: Lokalrezidivrate (LR) in Korrelation zur TP-Expression der Resektate (alle Patientenkohorten)

Aufteilung in Patienten mit TP-exprimierenden Resektaten $(\mathrm{n}=108)$ und nicht TP-exprimierenden Resektaten $(\mathrm{n}=91)$. P-Wert aus der Cox-Regressionsanalyse: $\mathbf{p}=\mathbf{0 , 3 5 2}$ 


\subsubsection{Korrelation der Lokalrezidivrate mit der TP-Expression in Biopsien der Patientenkohorte A}

Die TP-Expression der Lokalrezidive in Gruppe A ( $\mathrm{n}=27)$ zeigte deutliche Unterschiede bei der Korrelation von Lokalrezidiven gegenüber dem DFS. In Gruppe A zeigten 7 Patienten eine hohe, 20 Patienten eine geringe TP-Expression. Unter den 7 TP-positiven Biopsien erlitten 4 Patienten ein Lokalrezidiv, 3 dieser Patienten innerhalb der ersten 16 Monate. Dahingegen gab es nur ein Lokalrezidiv nach 55 Monaten bei den Patienten mit TP-negativen prätherapeutischen Biopsien. Aus der Cox-Regressionsanalyse konnte somit ein p-Wert von 0,001 berechnet werden. Dies ist ein statistisch signifikantes Ergebnis. Die Anzahl der untersuchten Biopsien mit einer geringen TP-Expression überwiegt auch in dieser Analyse (siehe Legende, Abbildung 21).

Ein Vergleich mit den Ergebnissen derselben Patientenkohorte aus den Resektaten ergibt, bei einem p-Wert von 0,145, kein statistisch signifikantes Ergebnis, zeigt jedoch einen ähnlichen Trend der Ergebnisse. Auch bei dieser Patientenkohorte A (hohe TP-Expression: n=19, geringe TP-Expression: $\mathrm{n}=21$ ) zeigte sich, dass Patienten mit TP-exprimierenden Resektaten häufiger und früher Lokalrezidive entwickeltenn als Patienten aus anderen Kohorten.

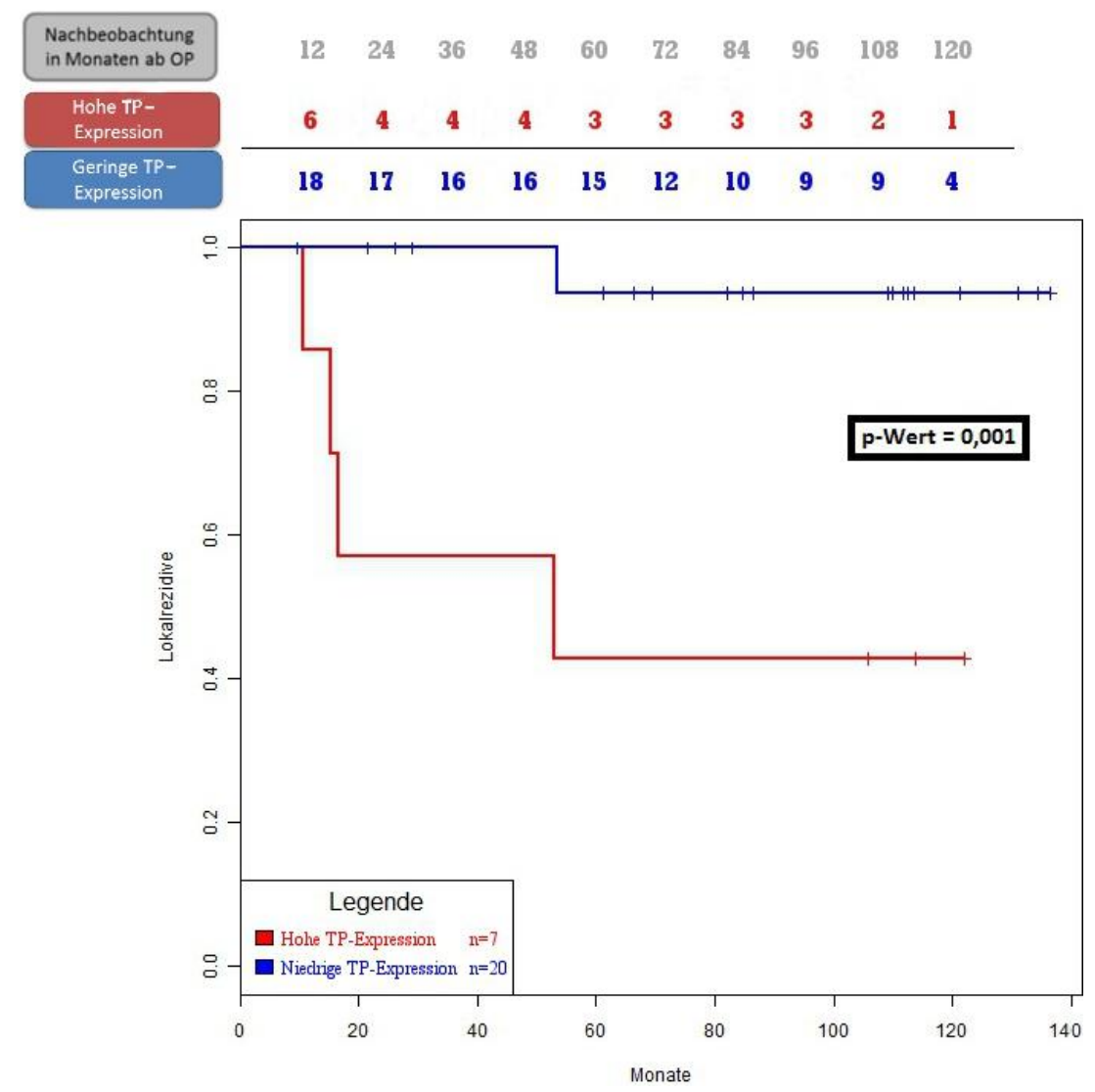

Abbildung 21: Lokalrezidivrate (LR) in Korrelation zur TP-Expression der Biopsien (Patientenkohorte A)

Aufteilung in Patienten mit TP-exprimierenden Resektaten $(n=7)$ und nicht TP-exprimierenden Resektaten $(n=20)$. P-Wert aus der Cox-Regressionsanalyse: $\mathbf{p}=\mathbf{0 , 0 0 1}$ 


\subsubsection{Korrelation des TP-Expressionsstatus mit dem Auftreten von Fernmetastasen}

\subsubsection{Korrelation der Metastasierungsrate mit der TP-Expression in Biopsien}

Weiterhin wurde die Auswirkung der TP-Expression in den prätherapeutischen Biopsien mit der Häufigkeit einer metachronen Fernmetastasierung korreliert. Da es sich um dasselbe Patientenkollektiv wie in Kapitel 3.6.1.1 handelt, sind die Gruppenverteilungen hinsichtlich der Anfärbungen identisch. Im Ergebnis zeigte sich ein p-Wert in der Cox-Regressionsanalyse von 0,185. Statistisch ist dieses Ergebnis nicht signifikant. Wie im Verlauf der Kaplan-Meier Kurve $\mathrm{zu}$ erkennen ist, scheint es allenfalls einen Trend $\mathrm{zu}$ geben, dass sich häufiger und früher Fernmetastasen bei Patienten mit einer positiven TP-Expression in der Biopsie ausbilden.

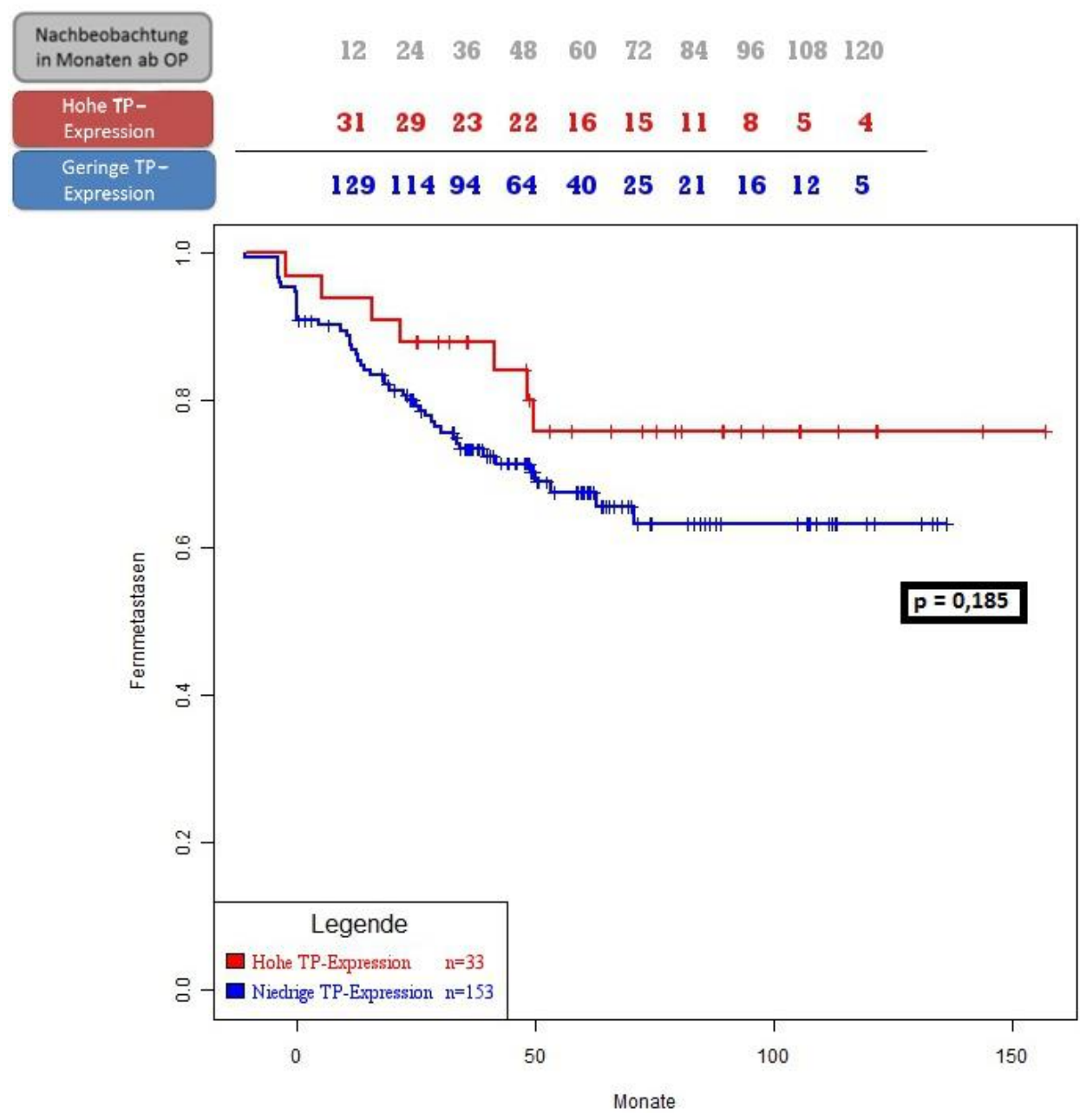

Abbildung 22: Fernmetastasenrate in Korrelation zur TP-Expression der Biopsien (alle Patientenkohorten)

Aufteilung in Patienten mit TP-exprimierenden Biopsien $(n=33)$ und nicht TP-exprimierenden Biopsien $(n=153)$. P-Wert aus der Cox-Regressionsanalyse: $\mathbf{p}=\mathbf{0 , 1 8 5}$ 


\subsubsection{Korrelation der Metastasierungsrate mit der TP-Expression im residuellen Tumorgewebe}

Um die Auswirkung der TP-Expression auf die Metastasierungswahrscheinlichkeit des Primärtumors $\mathrm{zu}$ bestimmen, wurden neben den prätherapeutischen Biopsien auch die Färbungen der Resektate mit den Fernmetastasierungen aus den Daten der Follow-UpUntersuchungen korreliert. Da es sich um dasselbe Patientenkollektiv wie in Kapitel 3.6.1.2 handelt, sind die Gruppenverteilungen hinsichtlich der Anfärbungen identisch. Das Ergebnis zeigt in der Cox-Regressionsanalyse einen p-Wert von 0,944. Die Kurven der gefärbten und der ungefärbten Resektate verlaufen somit so ähnlich, dass sie kaum Unterschiede aufweisen. Nach 5 Jahren wiesen insgesamt etwa 35\% aller Patienten eine Fernmetastasierung auf. Die meisten Patienten, die bis zu diesem Zeitpunkt noch keine Fernmetastasen hatten, entwickelten im Laufe der folgenden Jahre auch keine weiteren mehr. Interessant ist, dass bei einer Nachbeobachtungszeit von 5 Jahren keine weiteren Fernmetasten mehr auftraten.

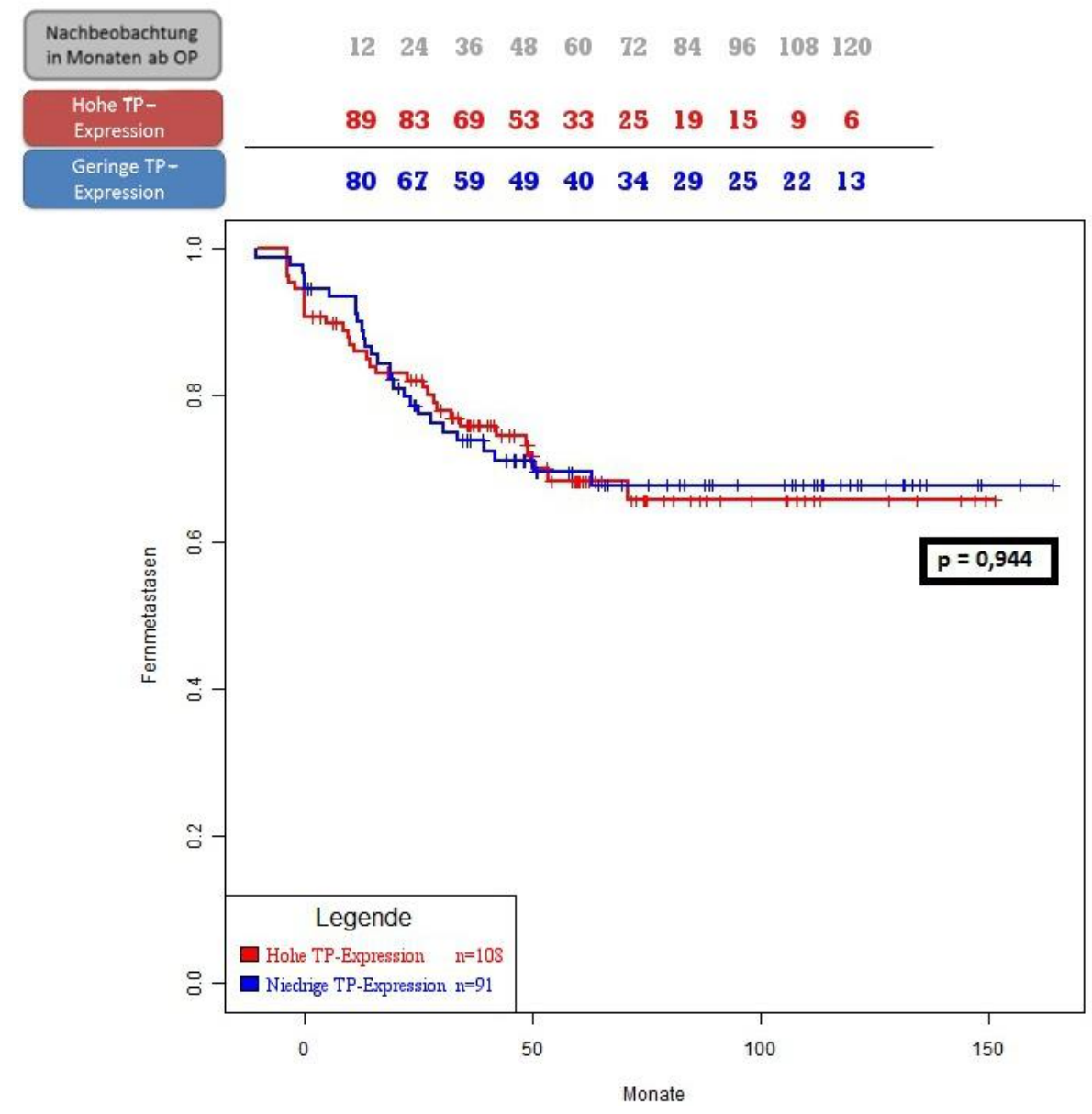

Abbildung 23: : Fernmetastasenrate in Korrelation zur TP-Expression der Resektate (alle Patientenkohorten)

Aufteilung in Patienten mit TP-exprimierenden Resektaten $(\mathrm{n}=108)$ und nicht TP-exprimierenden Resektaten $(\mathrm{n}=91)$. P-Wert aus der Cox-Regressionsanalyse: $\mathbf{p}=\mathbf{0 , 9 4 4}$ 


\subsubsection{Korrelation der Metastasierungsrate mit der TP-Expression in Biopsien der Patientenkohorte C}

In der Patientenkohorte C (intensivierte neoadjuvante Therapie) der Biopsien konnte bezüglich des Auftretens von Fernmetastasen ein statistisch signifikanter Zusammenhang entdeckt werden. Von insgesamt 64 Patienten hatten 9 Patienten eine Biopsie mit einer hohen TPExpression. Keiner dieser 9 Patienten entwickelte im Zeitraum der Follow-Up-Untersuchung eine Fernmetastase. Anders bei den 55 Biopsien mit einer geringen TP-Expression: hier entwickelten innerhalb der ersten 3 Jahre bereits 35\% der Patienten eine Fernmetastase. Der pWert aus der Cox-Regressionsanalyse ergab einen Wert von 0,035 .

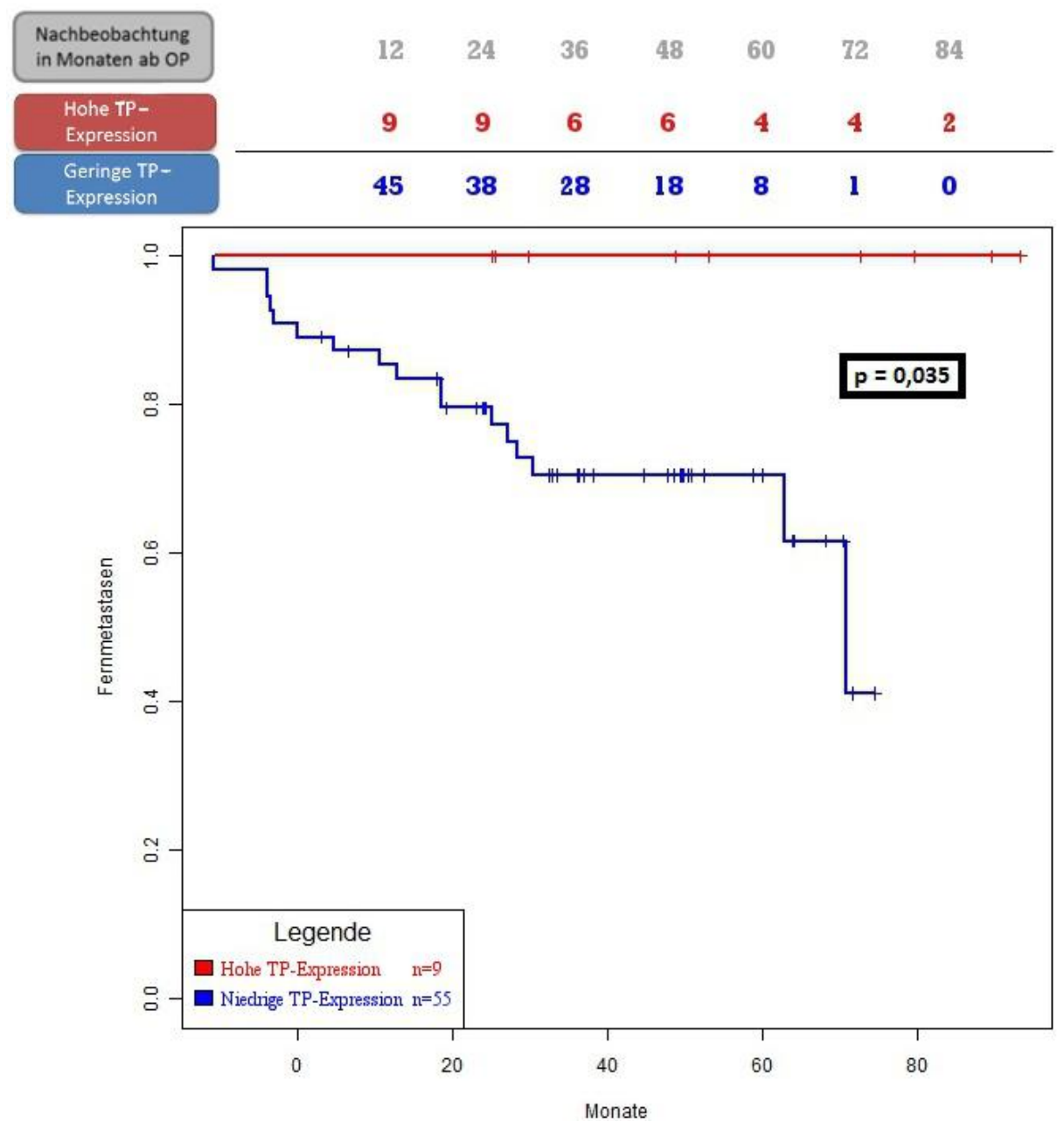

Abbildung 24: Fernmetastasenrate in Korrelation zur TP-Expression der Biopsien (Patientenkohorte C)

Aufteilung in Patienten mit TP-exprimierenden Biopsien ( $\mathrm{n}=9)$ und nicht TP-exprimierenden Biopsien ( $\mathrm{n}=55$ ). PWert aus der Cox-Regressionsanalyse: $\mathbf{p}=\mathbf{0 , 0 3 5}$ 


\subsubsection{Korrelation des TP-Expressionsstatus aus prätherapeutischen Biopsien und Tumorresektaten mit dem tumorfreien Überleben}

\subsubsection{Korrelation des TP-Expressionsstatus aus prätherapeutischen Biopsien mit dem tumorfreien Überleben}

Des Weiteren wurde das krankheitsfreie Überleben im Hinblick auf die TP-Expression innerhalb der prätherapeutischen Biopsien untersucht. Dieses gibt an, wie viel Zeit ohne Auftreten eines Lokalrezidivs oder einer Fernmetastase verstrichen ist. Die untersuchten Patientenkohorten sind identisch mit denen aus Kapitel 3.6.1.1 und 3.6.2.1. Zwischen den Resektaten mit einer hohen und einer geringen TP-Expression konnte kein signifikanter Unterschied bezüglich des krankheitsfreien Überlebens festgestellt werden. Dennoch zeigte sich ein allenfalls leichter Trend für ein besseres tumorfreies Überleben bei Patienten mit hoher TP-Expression. Der p-Wert in der Cox-Regressionsanalyse wurde mit 0,481 berechnet.

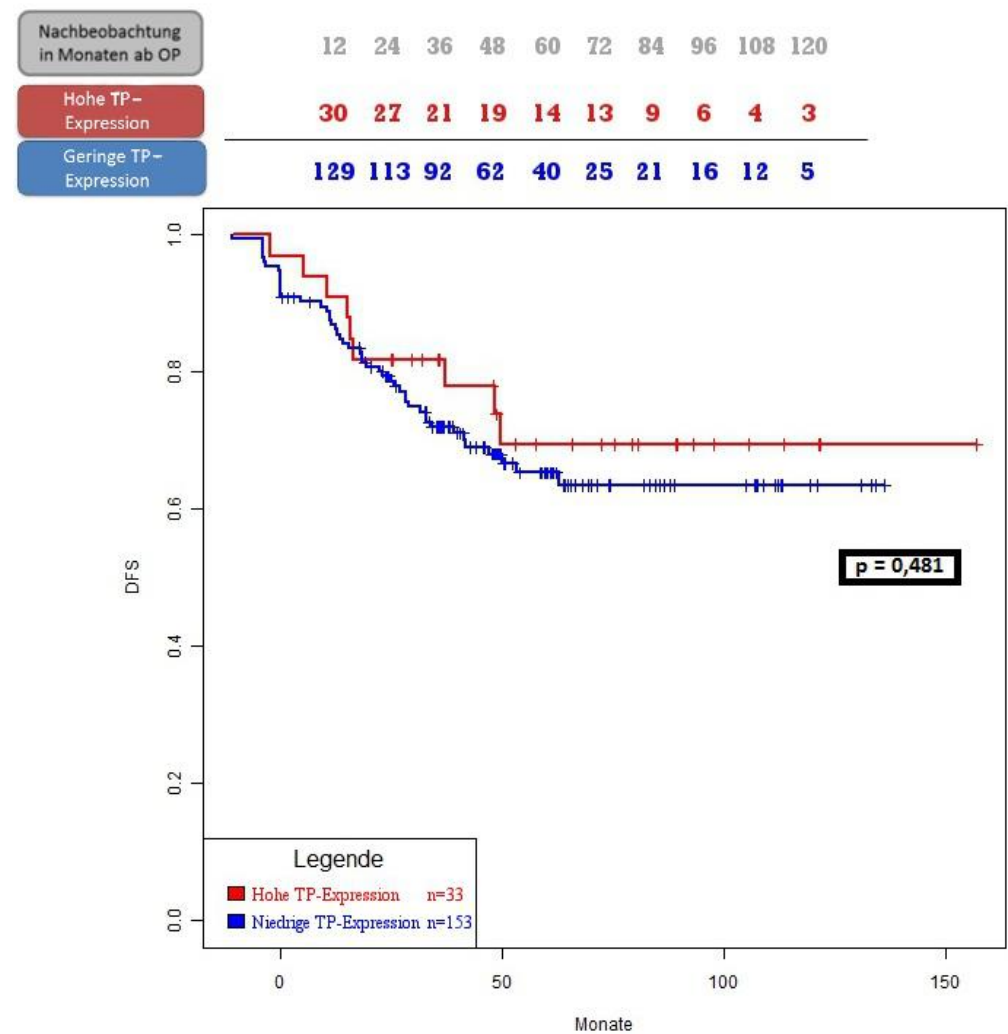

Abbildung 25: Krankheitsfreies Überleben (DFS) in Abhängigkeit von der TP-Expression innerhalb der Biopsien (alle Patientenkohorten)

Aufteilung in Patienten mit TP-exprimierenden Biopsien ( $\mathrm{n}=33)$ und nicht TP-exprimierenden Biopsien ( $\mathrm{n}=153)$. P-Wert aus der Cox-Regressionsanalyse: $\mathbf{p}=\mathbf{0 , 4 8 1}$ 


\subsubsection{Korrelation des TP-Expressionsstatus aus residuellem Tumorgewebe mit dem tumorfreien Überleben}

Der Trend, welcher sich in derselben Untersuchung bezüglich des krankheitsfreien Überlebens der Biopsien zeigte, findet sich nicht in den Ergebnissen des residuellen Tumorgewebes wieder. Die untersuchten Patientenkohorten sind identisch mit denen aus Kapitel 3.6.1.2 und 3.6.2.2. In der Cox-Regressionsanalyse ergab sich ein p-Wert von 0,697. Dies belegt, dass statistisch betrachtet keine signifikante Korrelation besteht.

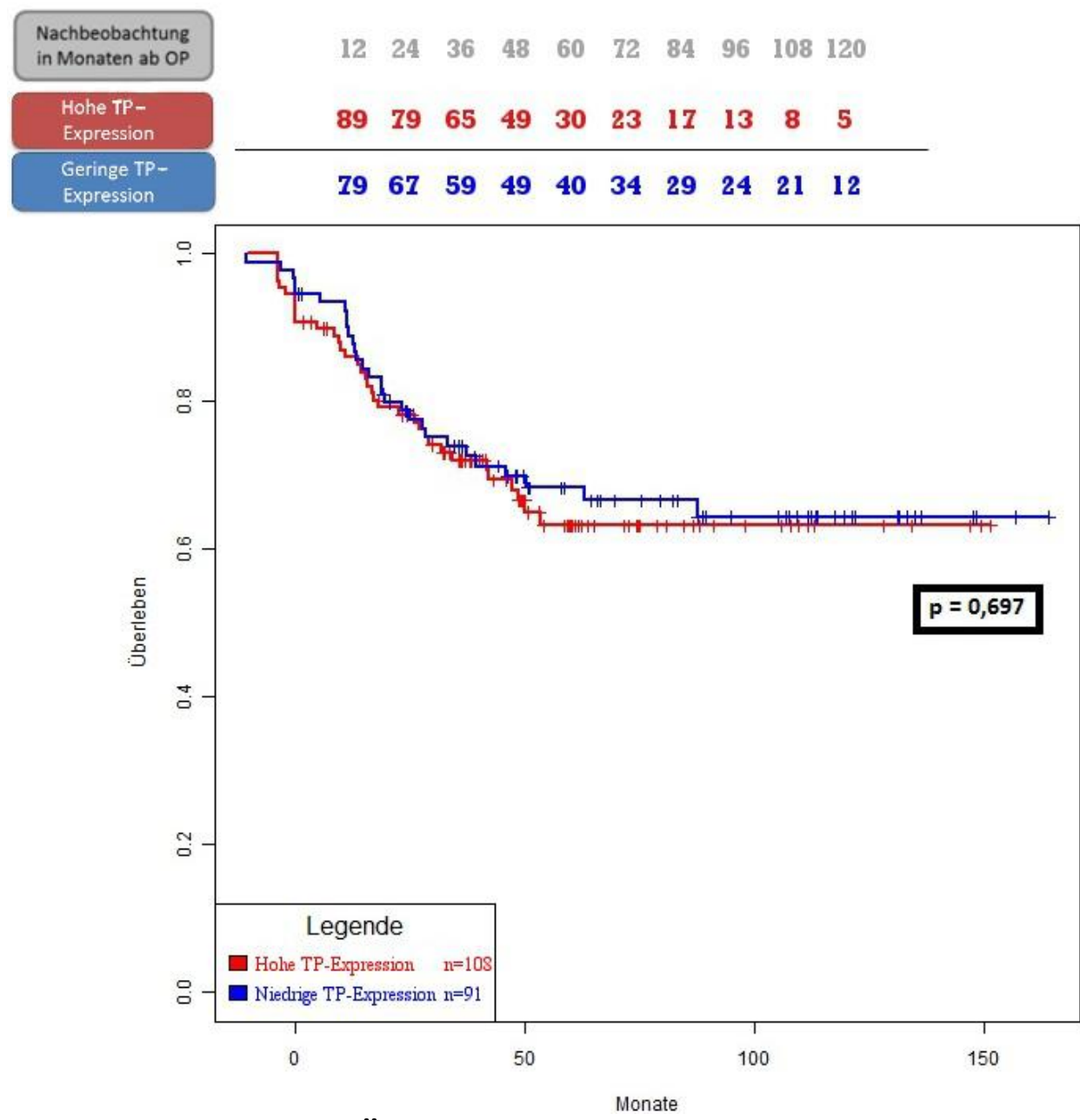

Abbildung 26: Krankheitsfreies Überleben (DFS) in Abhängigkeit von der TP-Expression innerhalb der Resektate (alle Patientenkohorten)

Aufteilung in Patienten mit TP-exprimierenden Resektaten ( $\mathrm{n}=108)$ und nicht TP-exprimierenden Resektaten ( $\mathrm{n}=91$ ). P-Wert aus der Cox-Regressionsanalyse: $\mathbf{p}=\mathbf{0 , 6 9 7}$ 


\subsubsection{Korrelation des TP-Expressionsstatus aus prätherapeutischen Biopsien mit dem tumorfreien Überleben der Patientenkohorte $C$}

Betrachtet man ausschließlich das krankheitsfreie Überleben der prätherapeutischen Gruppe C der Biopsien in Bezug auf die TP-Expression, stellt man fest, dass Patienten mit einer hohen TP-Expression bei intensivierter neoadjuvanter Therapie ein statistisch signifikantes, längeres Überleben aufweisen als Patienten mit einer geringen TP-Expression $(p=0,04)$. Unter den Patienten mit TP-positiven prätherapeutischen Biopsien gab es kein einziges Lokalrezidiv und keine Fernmetastasen. Patienten mit TP-negativen Biopsien in dieser Gruppe hatten eine deutlich höhere Wahrscheinlichkeit, Rezidive oder Metastasen zu entwickeln. Nach 2 Jahren waren bereits bei 13 Patienten (23,7\%) Ereignisse aufgetreten, nach 4 Jahren waren es insgesamt 22 Patienten (40\%) die Lokalrezidive oder Fernmetastasen entwickelt hatten

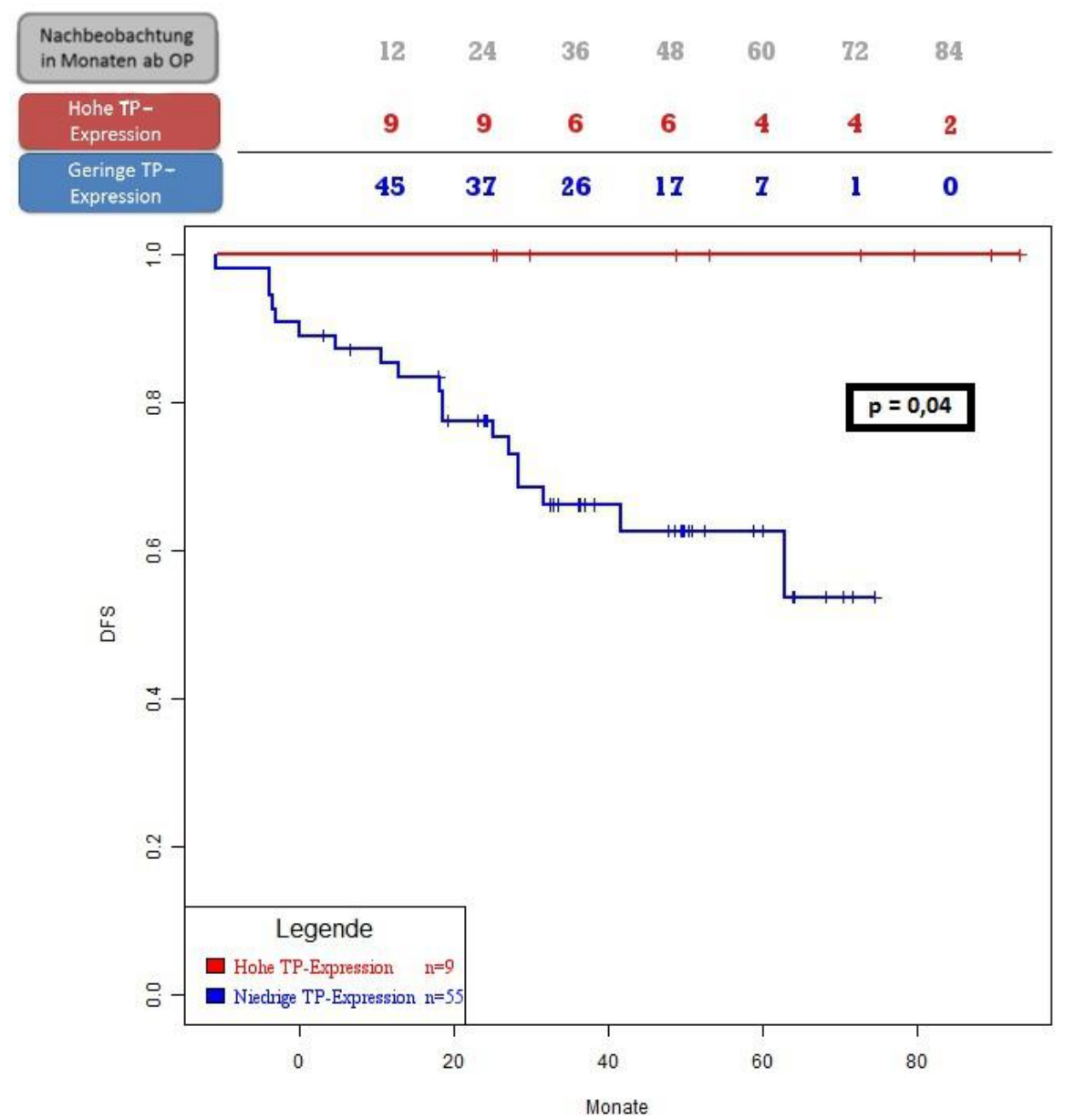

Abbildung 27: Krankheitsfreies Überleben (DFS) in Abhängigkeit von der TP-Expression innerhalb der Biopsien (Patientenkohorte C)

Aufteilung in Patienten mit TP-exprimierenden Biopsien ( $\mathrm{n}=9$ ) und nicht TP-exprimierenden Biopsien ( $\mathrm{n}=55$ ). p-Wert aus der Cox-Regressionsanalyse: $\mathbf{p}=\mathbf{0 , 0 4}$ 


\subsubsection{Korrelation des TP-Expressionsstatus aus prätherapeutischen Biopsien und residuellem Tumorgewebe mit dem krankheitsspezifischen Gesamtüberleben}

\subsubsection{Korrelation der TP-Expression aus prätherapeutischen Biopsien mit dem CSS}

Weiterhin wurde die TP-Expression mit dem CSS korreliert, um eine mögliche prognostische Bedeutung von TP innerhalb der prätherapeutischen Biopsien zu überprüfen. Die untersuchten Patientenkohorten sind identisch mit denen aus Kapitel 3.6.1.1; 3.6.2.1 und 3.6.3.1. Im Ergebnis fällt in den ersten 5 Jahren ein sehr ähnlicher Kurvenverlauf auf (siehe Abbildung 28). Im Anschluss kommt es häufiger bei Patienten ohne TP-Expression zu Malignom-bedingten Todesfällen. Insgesamt ist das Ergebnis aber nicht signifikant ( $\mathrm{p}-\mathrm{Wert}=0,372$.)

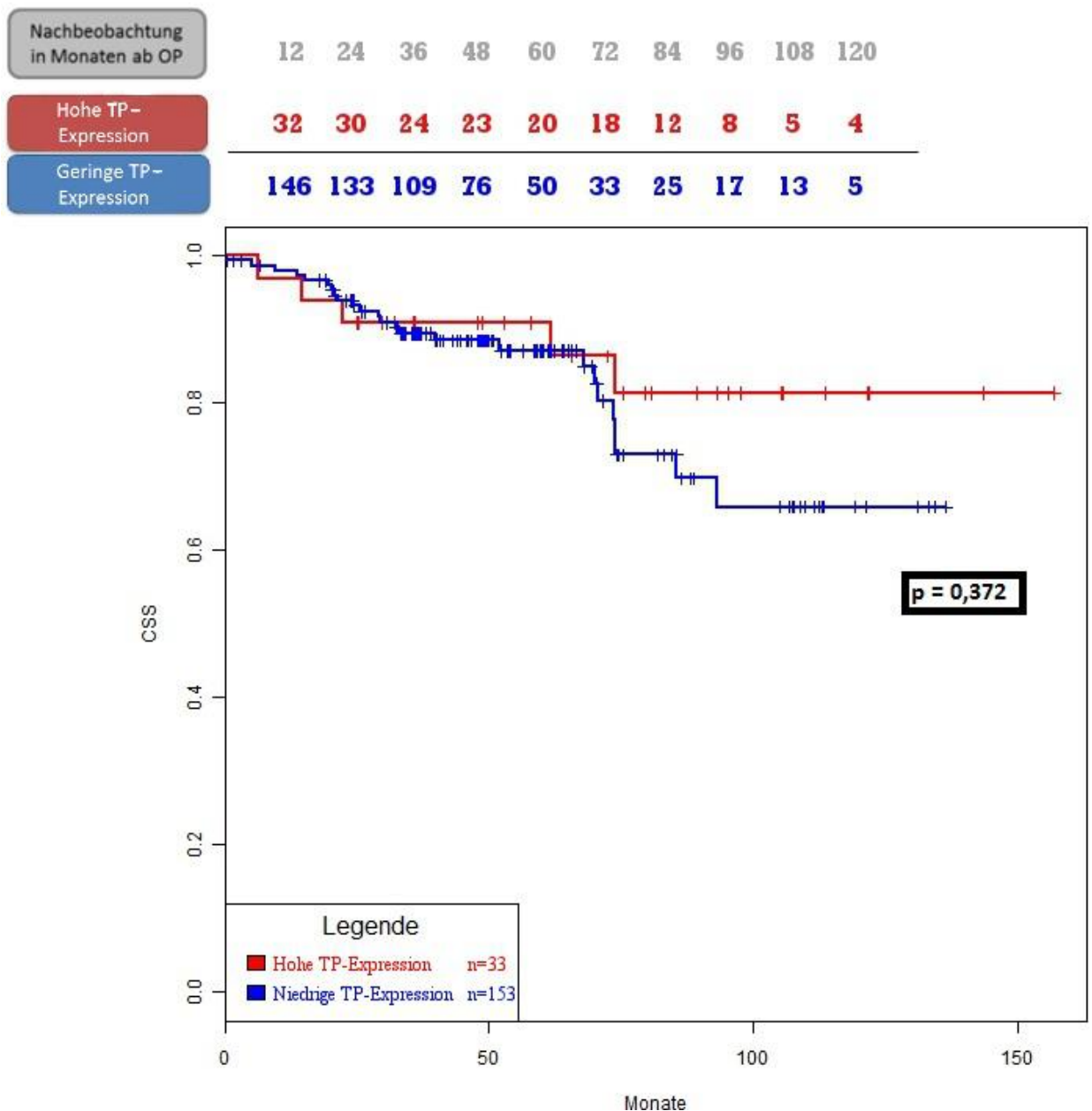

Abbildung 28: Krankheitsspezifisches Gesamtüberleben (CSS) in Abhängigkeit von der TPExpression innerhalb der Biopsien (alle Patientenkohorten)

Aufteilung in Patienten mit TP-exprimierenden Biopsien ( $\mathrm{n}=33)$ und nicht TP-exprimierenden Biopsien ( $\mathrm{n}=153)$. P-Wert aus der Cox-Regressionsanalyse: $\mathbf{p}=\mathbf{0 , 3 7 2}$ 


\subsubsection{Korrelation des TP-Expressionsstatus aus residuellem Tumorgewebe mit dem CSS}

Das Malignom-spezifische Gesamtüberleben wurde ebenso mit den TP-Expressionen der Resektate korreliert. Die untersuchten Patientenkohorten sind identisch mit denen aus Kapitel 3.6.1.2, 3.6.2.2 und 3.6.3.2. Die Kurvenverläufe und der p-Wert der Cox Regressionsanalyse mit 0,559 zeigen keinen signifikanten Unterschied zwischen den TP-positiven und den TPnegativen Resektaten.

Nach 5 Jahren Follow-Up wurde bei 68 (63\%) Patienten mit hoher TP-Expression in den Resektaten ein malignombedingter Tod festgestellt. Unter den Patienten mit geringer TPExpression in den Resektaten verstarben 43 (47,3\%).

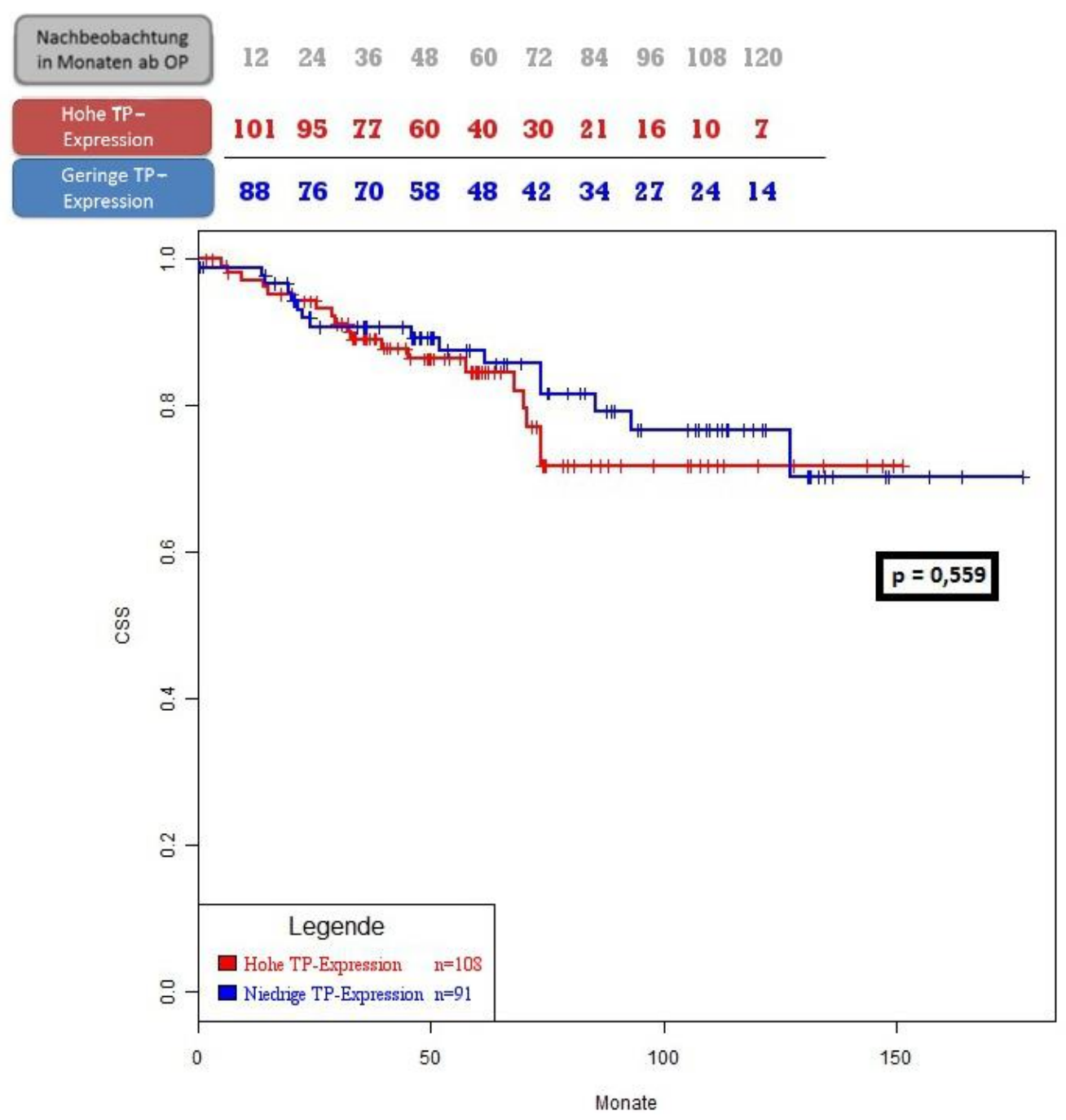

Abbildung 29: Krankheitsspezifisches Gesamtüberleben (CSS) in Abhängigkeit von der TPExpression innerhalb der Resektate (alle Patientenkohorten)

Aufteilung in Patienten mit TP-exprimierenden Resektaten $(\mathrm{n}=108)$ und nicht TP-exprimierenden Resektaten ( $\mathrm{n}=91$ ). P-Wert aus der Cox-Regressionsanalyse: $\mathbf{p}=\mathbf{0 , 5 5 9}$ 


\subsection{Korrelation von TP und TS}

Wie bereits in Kapitel 2.7 erörtert, handelt es sich bei den nachfolgenden Ergebnissen der immunhistochemischen Analyse von TS um Daten aus der medizinischen Dissertation von Frau Dr. med. Conradi (Conradi 2010; Conradi et al. 2011) aus unserer TP5-KFO179 Arbeitsgruppe. Eine Analyse der korrespondierenden TS- und TP-Daten aus dem overlap der untersuchten Patienten-Kollektive $(n=177)$ wurde in der vorliegenden Arbeit vorgenommen, um das Potential beider Biomarker bezüglich möglicher Therapiestratifizierungen zu evaluieren.

\subsubsection{TP- und TS-Expressionslevel korrespondierender Präparate}

Um einen direkten Vergleich der Expressionslevel von TS und TP zu ermöglichen, wurden die Daten für TP zusätzlich mit Hilfe des Remmele-Score (siehe Kapitel 2.8) dargestellt. Zunächst wurden die Expressionslevel von TP und TS mit Hilfe von Boxplots dargestellt.

Bei den primär operierten Rektumkarzinom-Patienten $(n=40)$ lag der Remmele-Score annähernd bei 0 . Patienten, die eine neoadjuvante Therapie erhielten $(n=137)$, wiesen eine stärkere Anfärbung von TP auf (vergleiche mit Kapitel 3.3.2; $\mathrm{p}=0,055)$.

Ergebnisse von Conradi et al. zeigten, im direkten Vergleich zu TP, eine deutlich stärkere Färbung von TS. Ein Großteil der nicht vorbehandelten Patienten wies einen Remmele-Score von etwa 6 auf. Patienten, die eine neoadjuvante Therapie erhalten hatten, zeigten - ähnlich wie bei TP - einen etwas höheren TS-Score (>7). Der Unterschied zwischen der neoadjuvant therapierten und der primär operierten Kohorte war in Bezug auf die TS-Expression signifikant $(\mathrm{p}=0,019)$.
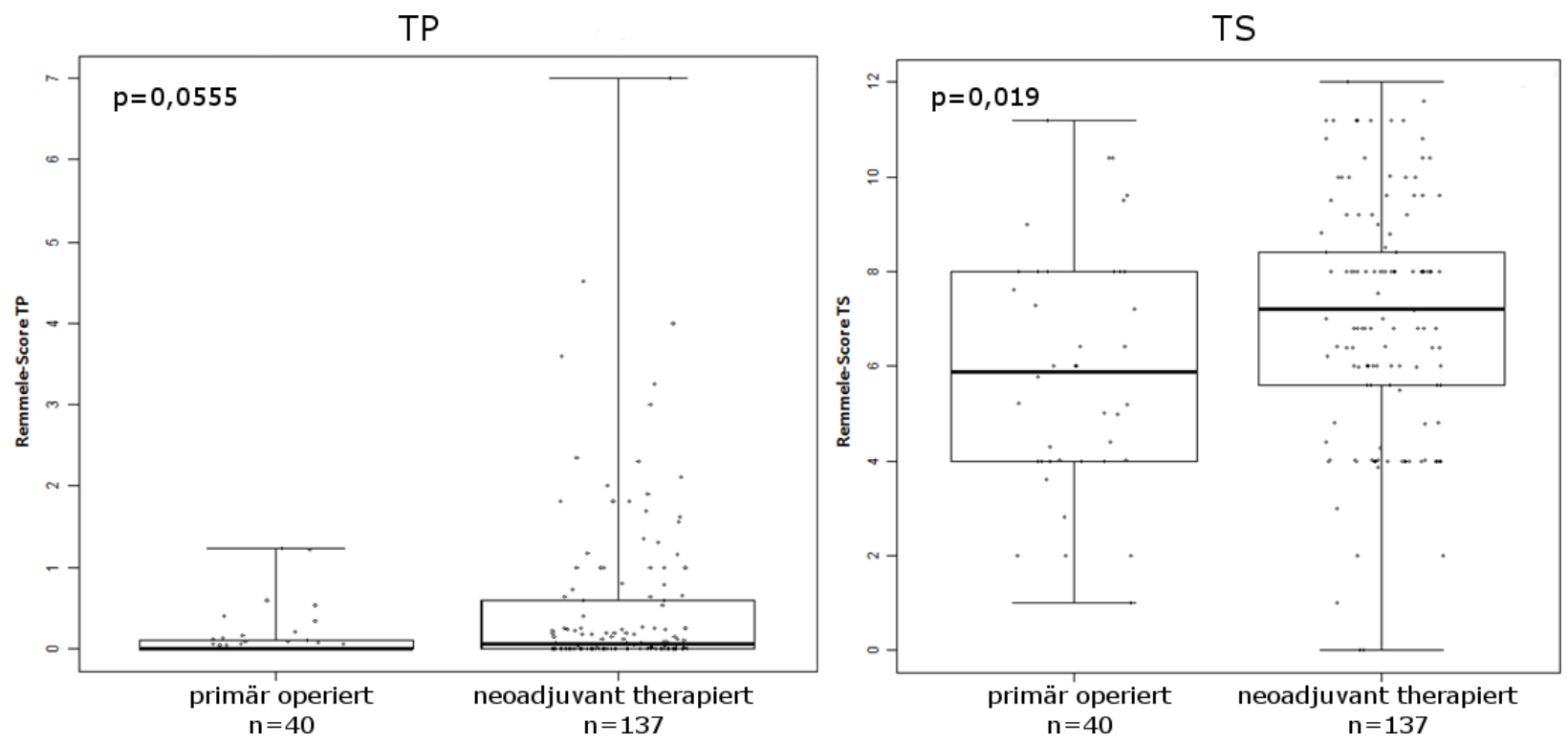

Abbildung 30: Boxplot zum Vergleich der TP- und TS-Expression 


\subsubsection{TP und TS in Korrelation mit dem TRG}

Zur weiteren Analyse wurde innerhalb des Remmele-Score von TS ein cut-off von $\leq 6,8$ gewählt (Conradi et al. 2011). Werte oberhalb des cut-offs wurden als hohe TS-Expression, unterhalb dieses Wertes als geringe TS-Expression bezeichnet. Der cut-off für TP lag bei einem Remmele-Score von $\leq 0,5$.

Es wurden vier Gruppen gebildet, um alle Kombinationen von geringer und hoher TS- und TPExpression mit dem TRG (nach neoadjuvanter RT/CTx) korrelieren zu können (siehe Abbildung 31). Dabei wurden nur Patienten aus den Therapiegruppen B und C berücksichtigt, da Patienten aus Gruppe A keine neoadjuvante Therapie erhalten hatten.

Bei einem Großteil der Patienten mit gleichzeitig hoher Expression von TP und TS ( $\mathrm{n}=23$ ) ergab sich in der histopathologischen Aufarbeitung der Rektumresektate ein TRG 3b (75\%-99\% Tumorzellregression). Lag eine geringe TP- und TS-Expression vor ( $\mathrm{n}=43$ ), so wurde lediglich ein TRG 2 ermittelt. Patienten bei denen in den Resektaten entweder nur eine hohe TS- oder eine hohe TP-Expression diagnostiziert wurde, zeigten zumeist einen TRG 3a (50\%-75\% Tumorzellregression). In der Darstellung zeigt sich, dass die Koexpression von TP und TS in Bezug zur RT/CTx induzierten Tumorregression bedeutsamer zu sein scheint als die jeweilige Einzelexpression (p-Wert: 0.0609).

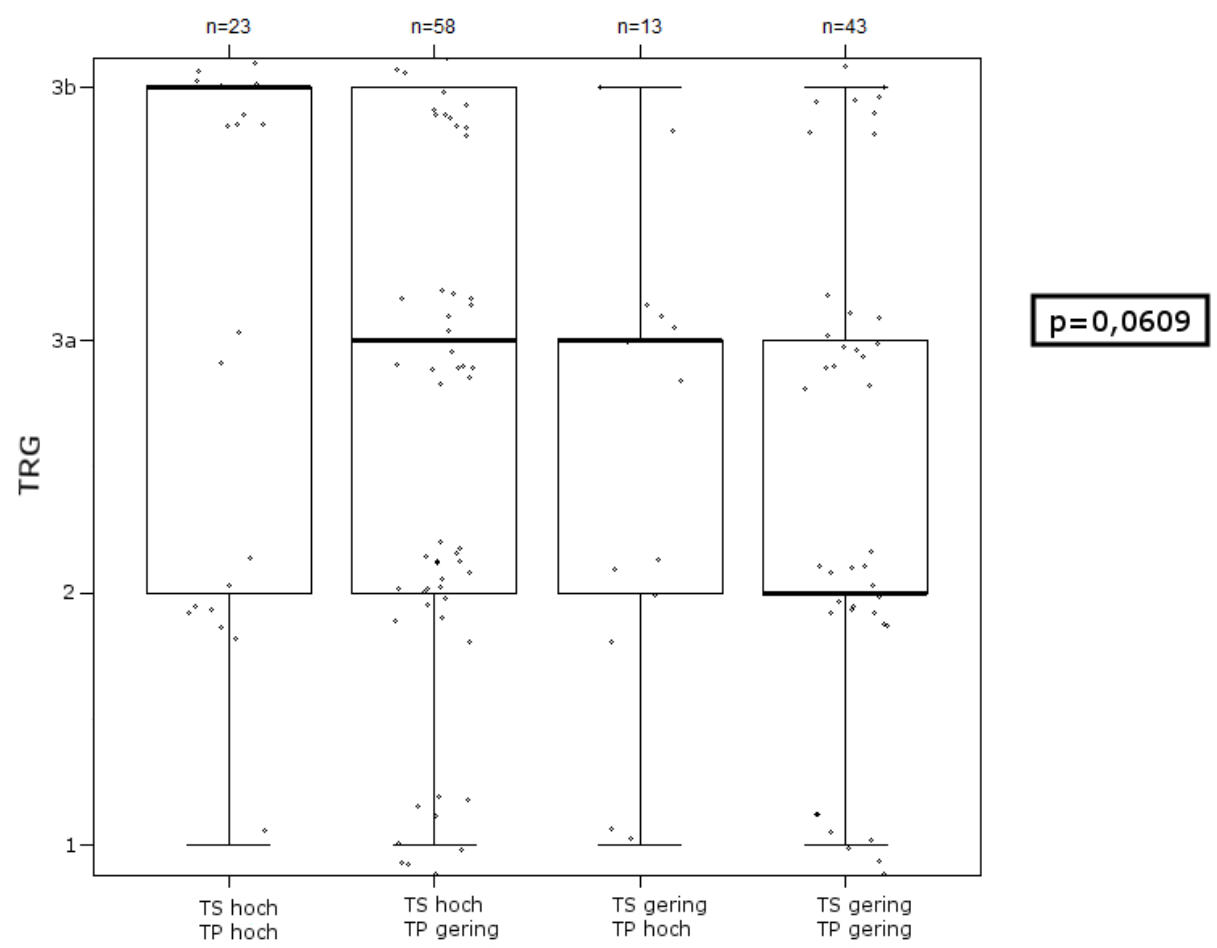

Abbildung 31: Korrelation der TP- und TS-Expression mit dem TRG

Abhängig von den TP- und TS-Expressionsleveln wurden vier Gruppen gebildet. Diese Gruppen wurden mit ihrem TRG in Boxplots aufgetragen. Hohe TP- und TS-Expressionslevel zeigen einen Median bei TRG 3b, geringe Expressionslevel einen Median bei TRG 2. Der p-Wert in der Cox-Regressionsanalyse beträgt 0,0609. 


\subsubsection{TP und TS in Korrelation mit dem DFS}

Neben der Korrelation mit dem TRG wurde auch eine Korrelation mit dem DFS aller Patienten durchgeführt. Im Unterschied zu Abbildung 31 wurden in Abbildung 32 die Therapiegruppe A der Analyse wieder mit einbezogen. Aus diesem Grund sind die Fallzahlen der untersuchten Patienten in den Subgruppen größer als in Kapitel 3.7.2. Die Daten der Gruppen, welche die untersuchten Enzyme gemischt stark exprimierten (TS hoch/ TP gering und TS gering/ TP hoch), sind in Abbildung 32 nicht dargestellt (nicht signifikant).

Die Grafik zeigt den Kurvenverlauf von Patienten mit gleichzeitig hoher TS- und TPExpression gegenüber Patienten mit geringer TS- und TP-Expression $(p=0,567)$. Weitere Analysen zur Korrelation der TP- und TS-Expression mit dem Auftreten von Lokalrezidiven und Fernmetastasen und mit dem CSS waren ebenfalls nicht signifikant und wurden hier graphisch nicht dargestellt.

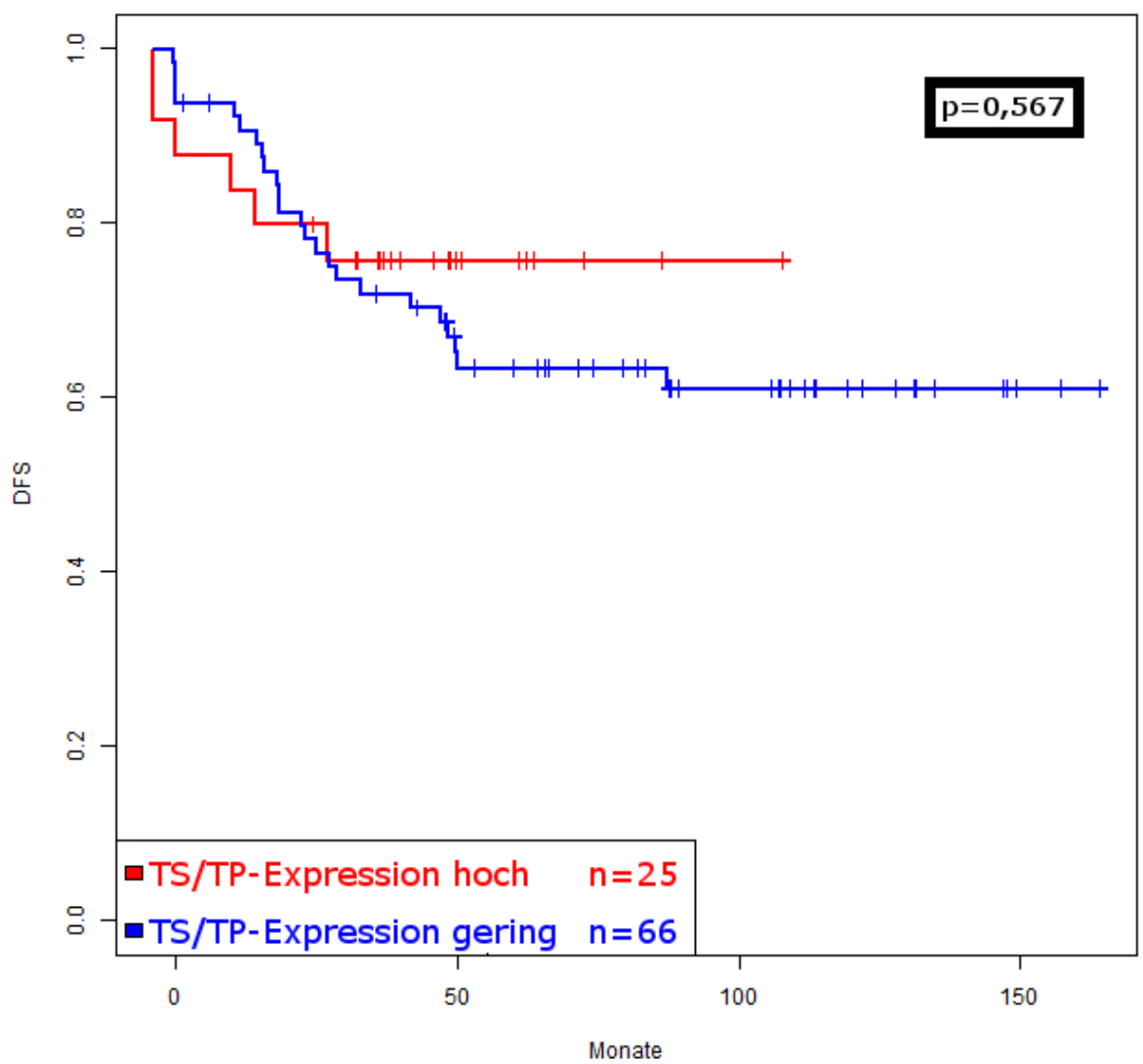

Abbildung 32: Korrelation der TP- und TS-Expression mit dem DFS 


\subsection{Capecitabin in der neoadjuvanten Therapie}

\subsubsection{Verteilung innerhalb der Gruppe C}

Einige Patienten wurden innerhalb der CapOx-Studie nach dem XELOX Schema (Xeloda® + Oxaliplatin) mit oralem 5-FU behandelt (siehe Kapitel 2.2 und Anhang). Hierbei handelte es sich um 12 Patienten, den verbliebenen 57 Patienten aus der Therapiegruppe C wurde 5-FU intravenös verabreicht. Zunächst wurden die Größen der Kollektive verglichen. In Abbildung 33 und Abbildung 34 werden die Gruppen der Patienten, die Xeloda ${ }^{\circledR}$ erhielten, und diejenigen, die 5-FU intravenös erhielten, direkt verglichen. Es werden jeweils die Ergebnisse aus den Biopsien und den Resektaten getrennt betrachtet. Da die Biopsien im Vergleich zu den Resektaten meist in ihrer TP-Expression negativ bewertet wurden und die Gruppengröße der mit Xeloda ${ }^{\circledR}$ behandelten Patienten auch lediglich 12 Personen umfasst, finden sich unter den Ergebnissen nur 2 Patienten, die Xeloda ${ }^{\circledR}$ erhielten und in ihrer Biopsie TP exprimierten. Einer dieser beiden Patienten verstarb an einer nicht tumorbedingten Ursache nach 78 Monaten, der andere stand zur weiteren Untersuchung innerhalb der Studie nicht länger zur Verfügung, somit wurde das Follow-Up nach 71 Monaten (bis dahin bestand Rezidivfreiheit) beendet. Die Ergebnisse der Biopsien sind hier daher in ihrer Aussagekraft zu hinterfragen.

Aufgrund der stärkeren Anfärbung des Tumorgewebes innerhalb der Resektate, kann man eine mögliche Korrelation von Capecitabin mit der Expression von TP im Tumorgewebe besser beurteilen. Von den 12 Patienten, die 5-FU in oraler Form erhielten, konnten 2 Resektate im Ergebnis nicht verwendet werden, da bedingt durch die Tumorregression nach neoadjuvanter Therapie nur wenig vitales Tumorgewebe verblieben war. Somit konnten noch 10 Patienten beobachtet werden, die Xeloda ${ }^{\circledR}$ neoadjuvant appliziert bekamen. In 7 Resektaten konnte eine positive TP-Expression festgestellt werden, die drei anderen Resektate hatten eine geringe TPExpression. Dies entspricht $11,67 \%$ der Gruppe C. Die meisten Patienten erhielten kein Xeloda ${ }^{\circledR}$, insgesamt waren dies $78,33 \%$.

Von den 12 Patienten konnte bei keinem einzigen eine pCR festgestellt werden. 2 Patienten hatten aber ein TRG 3b, 5 Patienten ein TRG 3a. Bei 7 Patienten (58,33\%) konnte ein downstaging festgestellt werden. Bei allen Patienten konnte in der histopathologischen Aufarbeitung des Resektates ein R0-Status (100\%) nachgewiesen werden. 


\section{Gruppe C der Biopsien}

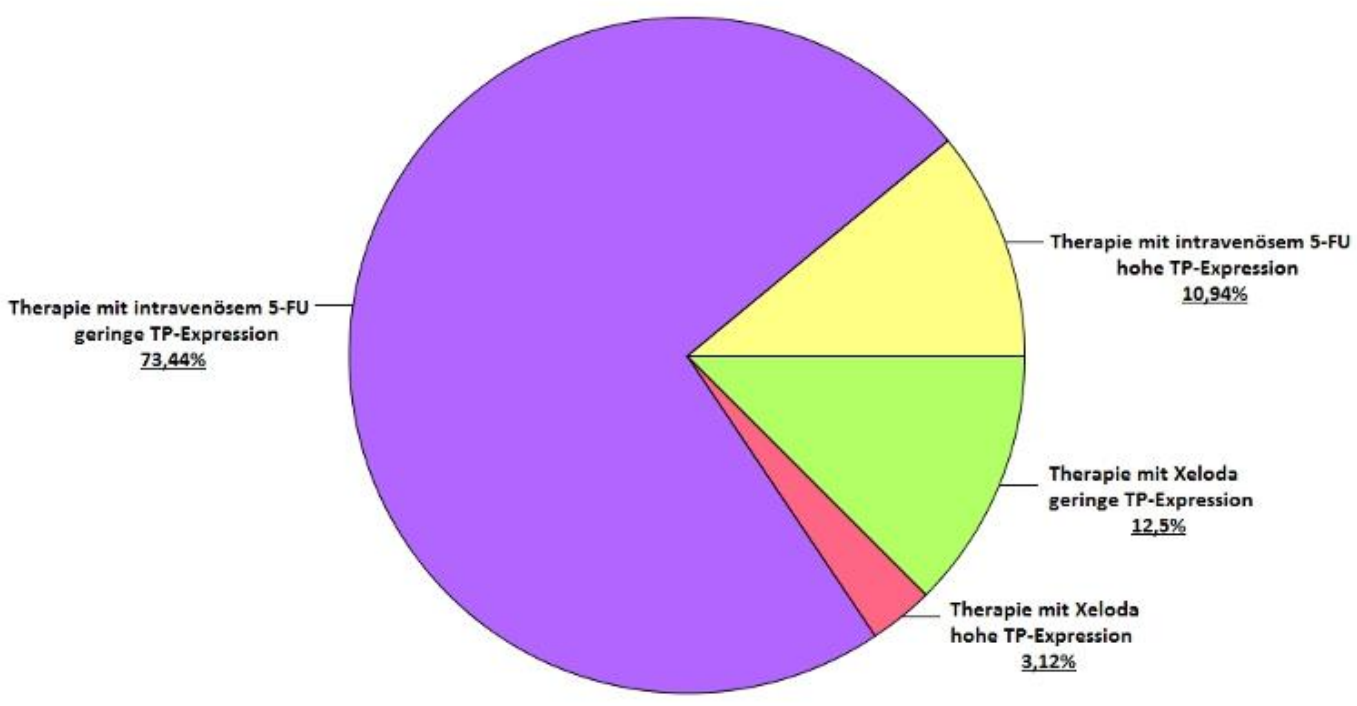

Therapie mit 5-FU i.v.

Therapie mit Xeloda

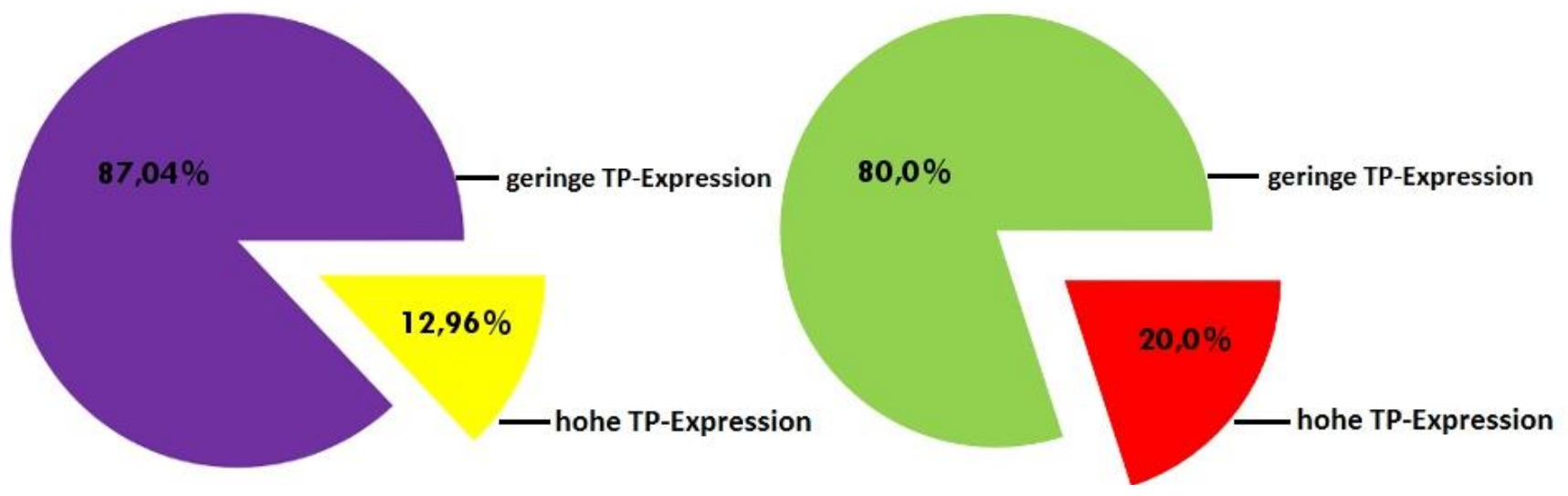

\section{Abbildung 33: Verteilung der Biopsien von Patienten aus der neoadjuvanten} Therapiegruppe $\mathrm{C}$ bezogen auf die Applikationsform von 5-FU und die TP-Expression

Im oberen, großen Kreisdiagramm ist die Verteilung aller Patienten dargestellt. Den größten Anteil haben hierbei die Patienten, die kein Xeloda ${ }^{\circledR}$ erhielten und eine negative TP-Expression aufwiesen (73,44\%). In chronologisch absteigender Ordnung folgen jene Patienten, die Xeloda ${ }^{\circledR}$ erhielten und eine negative TP-Expression aufwiesen (12,5\%), dann jene Patienten, die kein Xeloda erhielten und eine positive TP-Expression aufwiesen $(10,94 \%)$ und mit dem kleinsten Anteil die Patienten, die sowohl Xeloda ${ }^{\circledR}$ appliziert bekamen, als auch eine positive TPExpression hatten.

Das linke, untere Kreisdiagramm zeigt die separate Darstellung der Patienten, die kein Xeloda ${ }^{\circledR}$ erhielten mit dem Anteil derer, die eine TP-positive Expression und derer, die eine negative Expression hatten. Der Großteil dieser Patienten wies keine TP-Expression in den Biopsien auf.

Das rechte, untere Kreisdiagramm zeigt die Patienten, die Xeloda ${ }^{\circledR}$ im Rahmen der neoadjuvanten Therapie erhielten. Nur 20\% dieser Patienten hatten eine positive TP-Expression. 


\section{Gruppe C der Resektate}

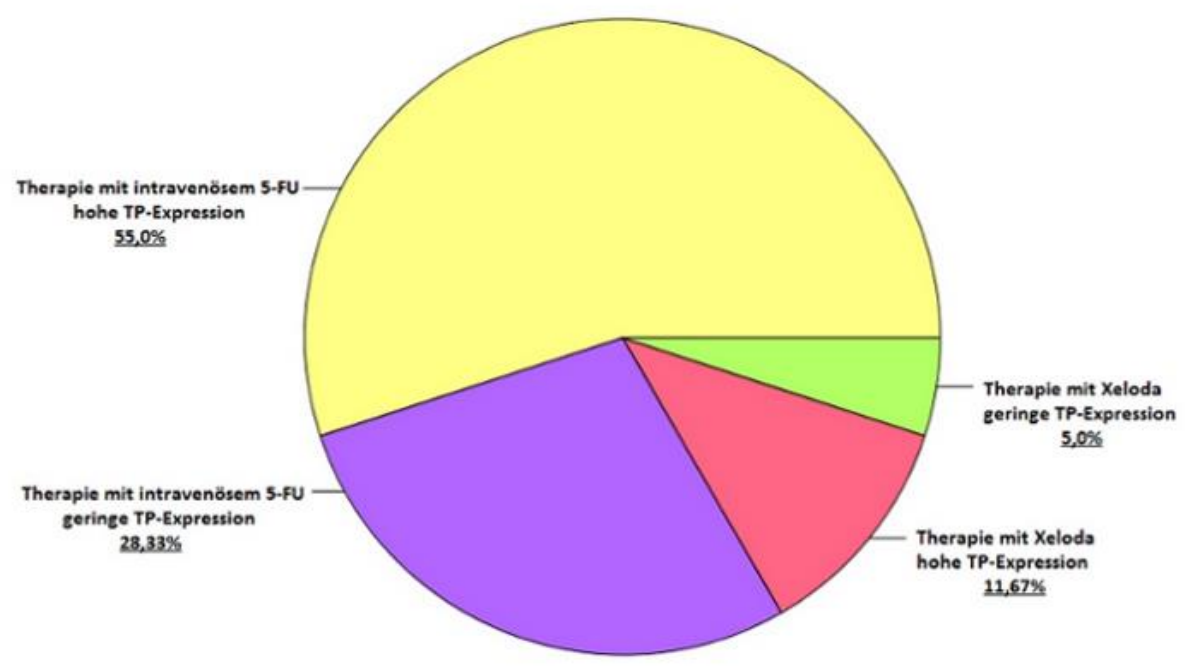

Therapie mit 5-FU i.v.

Therapie mit Xeloda
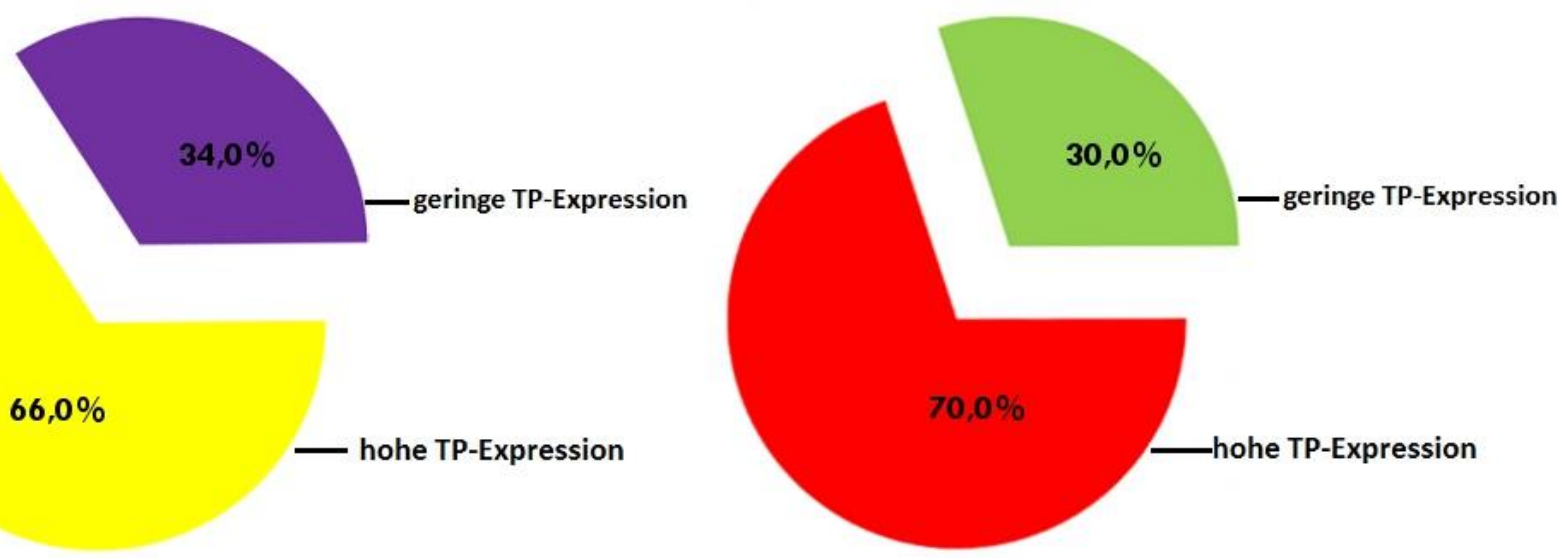

\section{Abbildung 34: Verteilung der Resektate von Patienten aus der neoadjuvanten} Therapiegruppe $\mathrm{C}$ bezogen auf die Applikationsform von 5-FU und die TP-Expression

Das obere, große Kreisdiagramm ist in 4 Anteile gegliedert, nach denen die Patienten hier klassifiziert wurden. Der größte Anteil am Kreisdiagramm geht auf die Gruppe von Patienten zurück, die kein Xeloda® in der neoadjuvanten Therapie erhalten hatten und bei denen man TP in der immunhistochemischen Untersuchung nachweisen konnte (55\%). Der zweitgrößte Anteil beschreibt die Patienten, die zwar ebenfalls kein Xeloda® erhielten, bei denen aber ebenso wenig eine TP-Expression nachgewiesen werden konnte $(28,33 \%)$. Der dritte Anteil enthält Patienten, die Xeloda ${ }^{\circledR}$ erhielten und TP im Resektat exprimierten (11,67\%). Der kleinste Anteil enthält Patienten, die Xeloda ${ }^{\circledR}$ einnahmen aber eine negative TP-Expression aufwiesen (5\%).

Der linke, untere Kreis stellt ausschließlich die Patienten dar, die kein Xeloda ${ }^{\circledR}$ erhielten. Das rechte, untere Kreisdiagramm zeigt die Verteilung der TP-Expression unter den 10 Patienten, die eine Therapie mit Xeloda ${ }^{\circledR}$ bekamen. 


\subsection{2 Überlebenskurven in Bezug auf die Behandlung mit Capecitabin}

Um feststellen zu können, ob die Behandlung mit Xeloda einen Unterschied hinsichtlich der Lokalrezidivraten, der Metastasierungswahrscheinlichkeit und dem DFS und CSS zum herkömmlichen intravenösen 5-FU macht, wurden die in Kapitel 3.6.1 beschriebenen Gruppen mit dem DFS und CSS der jeweiligen Patienten korreliert und gegeneinander auf KaplanMeier-Kurven aufgetragen.

Zunächst wurde nicht zwischen TP-positiven und -negativen Präparaten unterschieden. Die beiden Kurven in Abbildung 35 unterscheiden sich demnach lediglich darin, ob die Patienten Xeloda erhielten oder nicht. Nach der Cox-Regressionsanalyse ergibt sich ein p-Wert von 0,489. In dieser Analyse entsteht der Eindruck, dass Patienten mit einer oralen 5-FU Behandlung durchschnittlich länger krankheitsfrei leben, als Patienten mit einer intravenösen Behandlung. Über einen Nachbeobachtungszeitraum von 60 Monaten ergibt sich jedoch kein statistisch signifikanter Unterschied. $\mathrm{Zu}$ beachten sind nämlich (a) die großen Gruppenunterschiede und (b) das Ergebnis, dass in beiden Gruppen nach etwa 5 Jahren Nachbeobachtungszeitraum, prozentual betrachtet, etwa gleich viele Patienten Lokalrezidive oder Fernmetastasen entwickelt hatten.

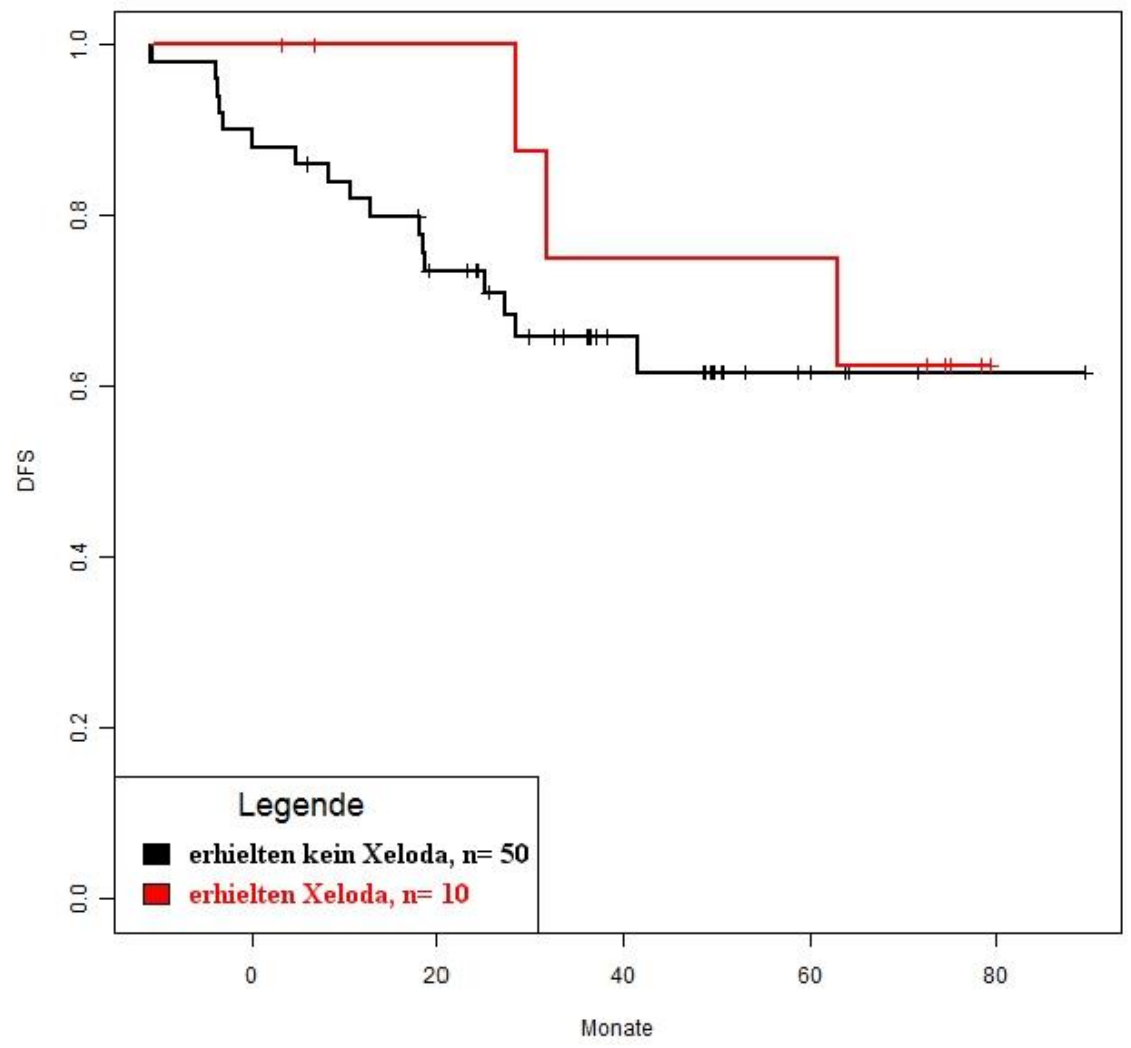

Abbildung 35: DFS der Patienten aus der neoadjuvanten Therapiegruppe C der Resektate in Bezug auf eine Behandlung mit oral oder intravenös appliziertem 5-FU

Insgesamt konnten Resektate von 60 Patienten (Gruppe $\mathrm{C} n=69$, abzüglich der Komplettresponder) in diesem Bezug ausgewertet werden. Von diesen erhielten 50 Patienten kein Xeloda ${ }^{\circledR}, 10$ Patieten erhielten es. Ermittelter p-Wert $=0,489$. 
Im Anschluss wurden Kaplan-Meier Kurven in direktem Bezug auf das DFS und das CSS innerhalb dieser Gruppen erstellt. Hier wurde zwecks einer Subgruppenanalyse die primäre Einteilung der Patienten nach 5-FU intravenös und Xeloda ${ }^{\circledR}$, weiter unterteilt in TPexprimierende und nicht-exprimierende Präparate. Patienten, die Xeloda ${ }^{\circ}$ einnahmen sind in farblich gekennzeichneten Kurven aufgetragen. Graue und schwarze Kurvenverläufe kennzeichnen Patienten, die kein Xeloda® erhielten.

Patienten, die kein Xeloda ${ }^{\circledR}$ erhielten und nur eine geringe TP-Expression im Tumorgewebe aufwiesen, hatten tendenziell das kürzeste krankheitsfreie Überleben aller Patienten in Gruppe C. Nach 28 Monaten hatten bereits etwa $48 \%$ der Patienten ein Lokalrezidiv oder eine Fernmetastase entwickelt. Patienten, die Xeloda ${ }^{\circledR}$ erhielten und TP exprimierten entwickelten die ersten krankheitsbezogenen, rezidivierenden Ereignisse deutlich später, ebenso Patienten, die Xeloda ${ }^{\circledR}$ erhielten und TP-negativ waren. Bei der Interpretation der Daten sollten jedoch auch die unterschiedlichen Gruppengrößen beachtet werden (siehe Kapitel 4.7).
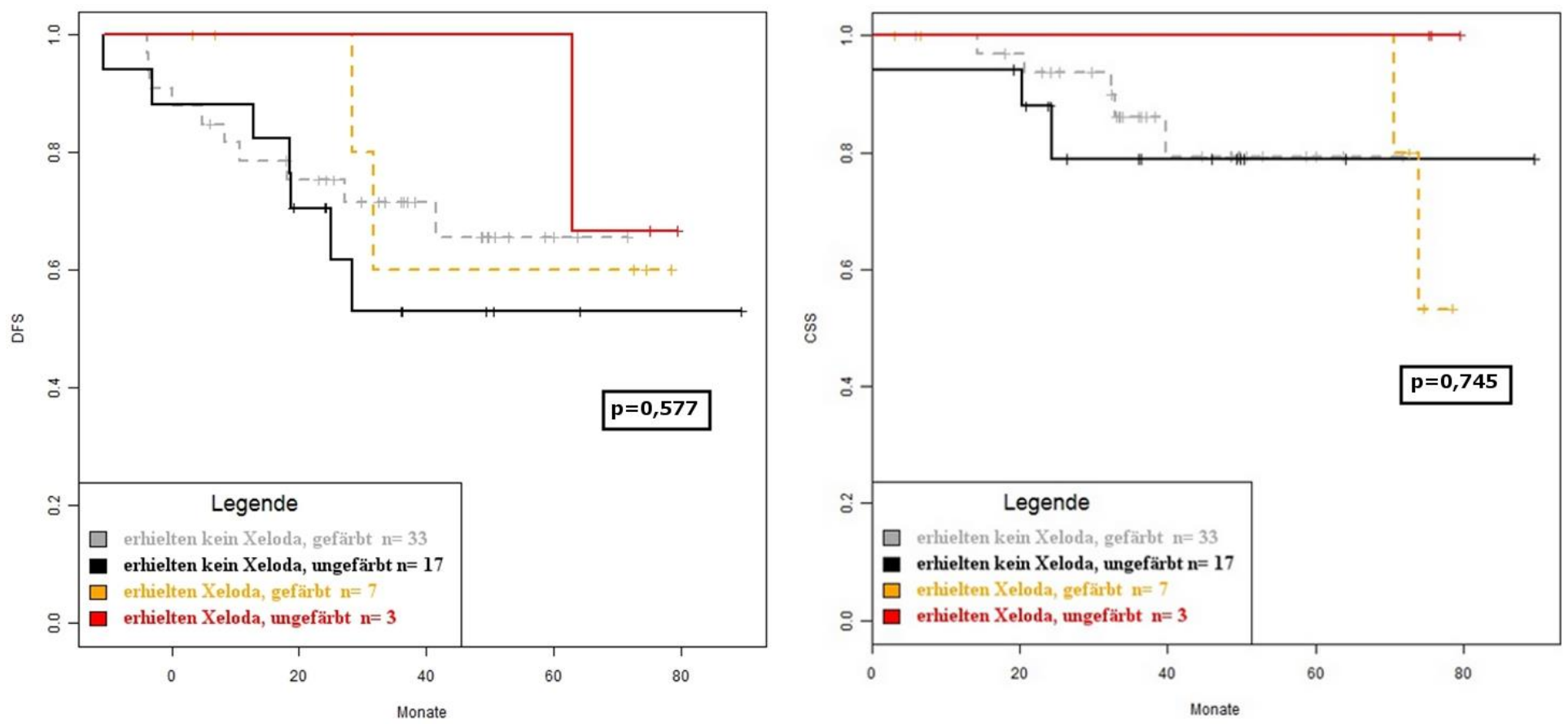

Abbildung 36: DFS und CSS von Patienten aus Therapiegruppe $C$ in Bezug auf eine Behandlung mit oder ohne Capecitabin und einen möglichen Einfluss von TP

a) Die Abbildung zeigt vier Kurvenverläufe, davon zwei von Patienten, die kein Xeloda® erhielten und zwei von Patienten, die Xeloda® einnahmen. Die Gruppengrößen der Patienten, die kein Xeloda® erhielten waren deutlich größer als die Patientengruppen die Xeloda® verschrieben bekamen. Nach 30 Monaten hatten $47 \%$ der Patienten, die kein Xeloda® bekamen und geringe TP-Expression aufwiesen ein Lokalrezidiv oder eine Fernmetastase entwickelt. p-Wert $=\mathbf{0 , 5 7 7 .}$

b) In der Abbildung werden vier Kurvenverläufe dargestellt. Die farbig (rot und gelb) markierten Verläufe zeigen das CSS der Patienten über etwa 80 Monate hinweg, die Xeloda® erhielten und im residuellen Tumorgewebe TP exprimierten (gelb) oder kaum TP exprimierten (rot). Ähnliche Kurvenaufteilung für Patienten, die kein Xeloda $®$ erhielten. Das Patientenkollektiv der hellgrauen Kurve exprimierte TP stärker, das Kollektiv der schwarzen Kurve kaum. $\mathbf{p}=\mathbf{0 , 7 4 5}$. 


\section{Diskussion}

Die vorliegende Dissertationschrift beschäftigt sich mit der Korrelation der Expressionsstärke von TP und klinikopathologischen Parametern von Patienten mit lokal fortgeschrittenen Rektumkarzinomen (UICC-II/-III). TP ist ein entscheidendes Enzym für den Metabolismus des Chemotherapeutikums 5-FU und wurde daher im Rahmen des Teilprojekts 5 der KFO 179 in dieser Arbeit untersucht. Insgesamt wurden in dieser Studie 223 Patienten in der UMG innerhalb großer, multizentrischer Phase-III-Studien, basierend auf den Protokollen der GRCSG, therapiert. Somit ist dies derzeit, soweit dem Autor bekannt, die umfangreichste standardisierte Untersuchung und beschäftigt sich mit der Frage, ob TP zur Therapiestratifizierung als prädiktiver und prognostischer Biomarker beim Rektumkarzinom eingesetzt werden kann.

Die aktuelle Studienlage ist recht heterogen (siehe Tabelle 11), und die Vergleichbarkeit mit der vorliegenden Untersuchung ist nur eingeschränkt möglich. Das liegt zum einen daran, dass viele Studien nicht zwischen Kolon- und Rektumkarzinomen unterscheiden (siehe Kapitel 1.2). Zum anderen sind auch die sehr unterschiedlichen Patientenkohorten (Fallzahlen) und verschiedene Methoden zur TP-Expressionsbestimmung für die Datenheterogenität verantwortlich. .

Die vorliegende Arbeit befasst sich erstmals mit der TP-Expression von 223 Patienten mit einem lokal fortgeschrittenen Rektumkarzinom (cUICC-II und -III-Stadien) unter dem Einfluss multimodaler Therapien.

\subsection{Prätherapeutische Stagingergebnisse}

Innerhalb der Therapiestudien (siehe Kapitel 1.4) unterscheiden sich die neoadjuvanten Therapien hinsichtlich Intensität und Dauer. Demnach wurde das Patientenkollektiv in entsprechende Gruppen eingeteilt, die Ergebnisse des Stagings wurden in der statistischen Auswertung berücksichtigt. Die präoperativ ermittelten Parameter sind in Tabelle 2 aufgelistet.

In der multizentrischen Phase-III Studie CAO/ARO/AIO-04, wurden von Beginn an Patienten mit Tumoren im oberen Rektumdrittel ausgeschlossen und der GAST-05-Studie zugeführt (siehe Kapitel 1.4.1). Grund hierfür ist der fragliche Effekts der RT/CTx, unter 
anderem hervorgerufen durch die Erkenntnisse der niederländischen TME Studie (Liersch et al. 2009). So konnte in der niederländischen Studie gezeigt werden, dass die präoperative RT bei Patienten mit Tumoren im oberen Rektumdrittel keinen signifikanten Effekt hat (Kapiteijn et al. 2001). Des Weiteren wurden auch bei Patienten in der CAO/ARO/AIO-94-Studie, nur wenige mit Karzinomen im proximalen Drittel diagnostiziert (13\% des Gesamtkollektivs) (Sauer et al. 2004). Da ein Großteil der Patienten aus ursprünglich der CAO/ARO/AIO-94Studie oder der CAO/ARO/AIO-04-Studie stammt, erklärt sich in der vorliegenden Arbeit der signifikante Unterschied bezüglich der Höhenlokalisation der Rektumkarzinome (siehe Tabelle 2). Bei insgesamt 206 Patienten (92,37\%) wurden Karzinome im unteren und mittleren Rektumdrittel diagnostiziert.

Patienten mit Rektumkarzinomen im proximalen Drittel und UICC-Stadium-II/-III werden, in der GAST-05-Studie (siehe Kapitel 1.4.1) randomisiert einer primären PME oder TME unterzogen und anschließend einer adjuvanten Chemotherapie zugeführt (Liersch et al. 2009). Auf diese Weise werden derzeit erste „Individualisierungsmöglichkeiten“ in der operativen Behandlung von Rektumkarzinomen geprüft. Ein Ergebnis der sogenannten „Individualisierung“ könnte durchaus eine schonendere OP (z.B. die partielle mesorektale Exzision) mit möglichst hohem Funktionserhalt (z.B. des Sphinkterapparates, der Harnblasenentleerung, der Erektions-/Ejakulationsfunktion etc.) bei gleichzeitigem Gewährleisten ausreichender onkologischer Sicherheit sein.

$\mathrm{Da}$ in der vorliegenden Arbeit der Zusammenhang einer TP-Expression unter Einsatz neoadjuvanter Therapieverfahren untersucht werden sollte, wurden nur Patienten mit einem lokal fortgeschrittenen Rektumkarzinom in die Studie eingeschlossen. Dadurch ergibt sich die in Tabelle 2 dargestellte Verteilung der cT-Stadien (87,9\% der Patienten hatten einen cT3Status, siehe Tabelle 2, $\mathrm{p}=0,03$ ). Unter Berücksichtigung des Nodalstatus lag bei der Mehrzahl der Patienten ein UICC-Stadium-III vor.

\subsection{Perioperative Befunde, klinische Patientencharakteristika und Nachbeobachtungen}

Um eine kontinenzerhaltende Operation zu ermöglichen, sollte nach der neoadjuvanten Therapie (nach einem möglichen downsizing und downstaging) wenigstens ein Abstand von 3 bis $4 \mathrm{~cm}$ zwischen aboralem Tumorrand und Sphinkterbeginn liegen, um eine funktionell gute Anastomose anlegen zu können (Becker et al. 2006). Diese Sichtweise gilt für Rektumkarzinome im mittleren Rektumdrittel. Bei tiefsitzenden Rektumkarzinomen im 
unteren Rektumdrittel sollte ein Sicherheitsabstand von 1-2 cm zwischen distaler Resektionsebene und aboralem Tumorrand eingehalten werden (dies gilt auch für das Anlegen von koloanalen Anastomosen mit partieller Resektion des Sphinkteroberrandes).

Grundsätzlich muss für jeden Patienten mit einem lokal fortgeschrittenen Rektumkarzinom im unteren Rektumdrittel individuell die Frage geklärt werden, ob überhaupt kontinenzerhaltend operiert werden kann oder eine abdomino-perineale Rektumexstirpation erfolgen muss. Diese Frage wird immer vor Einleitung der neoadjuvanten Therapie geprüft und nach erfolgter RT/CTx nochmalig evaluiert, unter Berücksichtigung des lokoregionären Tumoransprechens. Wie in Tabelle 7 beim Vergleich der Patientenguppen B und C dargestellt, konnte bei $20 \%$ der Patienten (Gruppe C), entgegen der primären Einschätzung unter weitgehender Schonung des Sphinkterapparates, kontinenzerhaltend operiert werden gegenüber Patientengruppe B $(\mathrm{p}<0,0001)$. Dies deutet auf einen möglichen Effekt der intensivierten neoadjuvanten RT/CTx an unserem monozentrisch untersuchten Kollektiv hin. Die eher geringe Anzahl an analysierten Patienten $(n=223)$ sollte jedoch bei der Ergebnisbewertung gegenüber der CAO/AIO/ARO-04 Studie berücksichtigt werden.

In einer ersten Darstellung des gesamten Patientenkollektivs der multizentrischen CAO/ARO/AIO-04-Studie ( $\mathrm{n}=1265$ Patienten, 88 Zentren in Deutschland) zeigte sich kein signifikanter Unterschied zwischen den mit Oxaliplatin intensiver behandelten Patienten und den einer 5-FU Standardtherapie zugeführten Patienten, in Bezug auf die Anzahl durchgeführter kontinenzerhaltender Operationen (Rödel et al. 2012).

In der vorliegenden Arbeit ergab sich zwischen den beiden neoadjuvanten Therapieregimen (Gruppe B und C) kein Unterschied bezüglich des Tumorregressionsgrades (siehe Tabelle 8, p=0,9). Bei mehr als der Hälfte der Patienten konnte allerdings allein durch die neoadjuvante Therapie eine gute bis komplette Tumorregression erzielt werden $(63,5 \%$ aller Patienten hatten einen TRG $3_{(\mathrm{a} / \mathrm{b})}$ oder TRG 4).

Bezüglich des postoperativ untersuchten Lymphknotenstatus ließ sich zwischen den beiden Gruppen folgendes feststellen: In Gruppe C lag postoperativ in 73,9\% ein (y)pN0-Status vor; in Gruppe B hatten 64,6\% der Patienten einen (y)pN0-Status und in Gruppe A wurde bei 52,2\% der Patienten ein pN0-Status diagnostiziert. Hinsichtlich der (y)pN1-Stadien ergaben sich kaum Unterschiede zwischen den Gruppen. Demgegenüber zeigte sich interessanterweise, dass bei den intensiv vorbehandelten Rektumkarzinompatienten (Gruppe C) nur in 5,8\% ein prognostisch sehr ungünstiger (y)pN2-Status vorlag, gegenüber Gruppe B mit 12,4\% (y)pN2-Status und der nicht neoadjuvant behandelten Patientengruppe A mit 25,8\% pN2-Status (siehe Tabelle 8). 
Ergebnisse einer Studie von Rödel et al. aus dem Jahr 2005, die ursprünglich die Auswirkung des TRG auf das DFS untersuchen sollte, und eine französische Studie von Chapet aus dem Jahr 2005, zeigten, dass der Lymphknotenstatus nach erfolgter neoadjuvanter Therapie, nach wie vor der wichtigste prognostische Faktor ist (Chapet et al. 2005; Rödel et al. 2005). Tumoren von Patienten mit einem posttherapeutischen positiven Lymphknotenstatus wiesen (a) ein aggressiveres malignes Potential und (b) eine Resistenz der tumorösen Zellen gegenüber der RT/CTx auf. Somit hatten diese Patienten eine signifikant schlechtere Prognose als Patienten mit einem negativen Lymphknotenstatus (Rödel et al. 2005). Schlussfolgernd lässt sich die Hyphothese ableiten, dass eine intensivierte RT/CTx mit Oxaliplatin die Wahrscheinlichkeit auf zahlreiche residuelle Lymphknotenmetastasen verringern und somit die Prognose der Patienten verbessern könnte. Aus der weiteren Aufarbeitung der 3-Jahres-DFS-Daten der CAO/ARO/AIO-04-Studie wird sich diese Hypothese überprüfen lassen (Publikation der Ergebnisse frühestens August 2014) (Liersch et al. 2009).

Aus den hier vorliegenden Daten der Follow-Up-Untersuchung geht hervor, dass im Patientenkollektiv der Gruppe A tendenziell mehr Lokalrezidive und Metastasen auftraten als in den Gruppen mit einer neoadjuvanten Therapie (Gruppe B und C, Tabelle 10). Der Vorteil einer neoadjuvanten RT/CTx wird in dieser Untersuchung bezüglich isolierter Lokalrezidive deutlich. In Gruppe A traten häufiger isolierte Lokalrezidive auf; isolierte Fernmetastasen kamen häufiger in den Gruppen B und C vor.

An den Folgen des Rektumkarzinoms verstarben in Gruppe A die meisten Patienten während der Nachbeobachtung (19\%), in den Gruppen B und C waren dies 15,9\% und 14,5\% (p=0,07). Ursächlich für diese Beobachtung könnte (a) der Effekt der neoadjuvanten Therapie (Sauer et al. 2004) und (b) die durchschnittlich kürzere Nachbeobachtungszeit in den Gruppen B und C sein (Gruppe A 97 Monate, Gruppe B 60 Monate, Gruppe C 41 Monate).

\subsection{TP-Expressionslevel in prätherapeutischen Biopsien und Resektaten}

Voraussetzung für eine valide, reproduzierbare Aussage zur prognostischen Rolle der Thymidinphosphorylase war zunächst die Messung und Dokumentation des Expressionsgrades von TP im gesamten verfügbaren Biomaterial mit standardisierten Methoden. Die Ergebnisse zeigen eine insgesamt schwache immunhistochemische Färbung der prätherapeutischen Biopsien und somit eine sehr geringe TP-Expression. Mit hoher 
Wahrscheinlichkeit ist die sehr kleine Menge des vorhandenen Tumormaterials aus der gewonnen Biopsie ausschlaggebend für die geringen Färbeintensitäten. Eine Biopsie enthält zumeist nur oberflächlich abgetragenes Biomaterial. Analysen von Biopsien aus zentraleren Tumorarealen oder aus Teilen der Invasionsfront könnten deutlich repräsentativere Ergebnisse liefern, da TP als angiogener Faktor vor allem an der Invasionsfront des Tumors exprimiert wird. Das entnommene Material war meist nur 1-2 mm groß und lieferte somit nur wenig Zellmaterial für die mikroskopische Untersuchung. Biopsien, die weniger als 50 tumoröse Zellen enthielten, wurden nicht mit in die Analyse einbezogen (cutoff).

Auch bei den Resektaten ist die schwache immunhistochemische Färbung der Präparate an der Lage des Median zu erkennen. In den Gruppen A und B liegt der Median bei 0, in Gruppe $\mathrm{C}$ bei 12. Der maximal erreichbare Wert beträgt nach der Berechnung des H-Scores 300, dieser Wert wurde jedoch in keiner einzigen Messung erreicht. Die Verteilung der Daten zeigt innerhalb der immunhistochemisch angefärbten Präparate ein gehäuftes Vorkommen in den unteren Bereichen des H-Scores (Abbildung 14). Nur wenige Ausreißer überschreiten bei den Biopsien einen H-Score von 50 und bei den Resektaten einen H-Score von 100.

Ganz im Gegensatz zu den geringen Zellzahlen der Biopsien, konnten in den Resektaten zumeist große Zellkolonien des Tumors angefärbt und untersucht werden. Die methodische Schwierigkeit in der Untersuchung dieser Zellen bestand darin, möglichst repräsentative Bereiche innerhalb der Zellgruppen zu wählen. Anschließend wurden aus 4 verschiedenen Bereichen des Präparates Zellkolonien gewählt und 50 Zellen nach ihrer Färbung beurteilt. Somit ergab sich ein Gesamtwert in den Färbeintensitäten, und der H-Score konnte im Anschluss berechnet werden. Auf diese Weise wurde eine größtmögliche Objektivität bei der Untersuchung angestrebt.

Damit die Untersuchung jedoch objektiv und mit möglichst geringer Intra- und Interobservervariabilität gestaltet werden kann, wurden verschiedene Bildanalysesysteme entwickelt, mit denen eine Computer-gestützte Erfassung immunhistochemischer Daten ermöglicht wird. In unserer Arbeitsgruppe wurde von Susanna Posern das digitale Bildanalysesystem VIAS in Hinblick auf die p53- und Ki67-Expression in Rektumkarzinomgewebe erstmals evaluiert. Die Ergebnisse zeigen, dass eine verlässliche Erfassung immunhistochemischer Daten möglich ist, und der Einsatz von digitalen Bildanalysesystemen, beispielsweise zur Überprüfung der gesammelten Ergebnisse, zukünftig eine sinnvolle Ergänzung in der immunhistochemischen Analyse sein kann (Posern 2013). 
Nachdem die Biopsien und Resektate unabhängig voneinander betrachtet worden waren, wurde nur jenes korrespondierende Material von Patienten untersucht, welches sowohl in Form einer Biopsie als auch eines Resektats vorlag.

In den Boxplot Darstellungen zur errechneten Differenz von Biopsie und Resektat kann man die Dynamik der Expression von TP in den Biopsien und Resektaten beobachten (siehe Abbildung 15). Die größten Differenzen lassen sich in Gruppe B beobachten. Hier liegt auch die größte Patientenanzahl vor. Die Darstellung macht aber deutlich, dass korrespondierende Präparate teilweise sehr unterschiedlich angefärbt sind. Dies könnte damit zusammenhängen, dass immunhistochemisch untersuchtes Material aus Biopsie und Resektat häufig aus unterschiedlichen Tumorarealen stammt und weil der Tumor nach der RT/CTx alteriert ist. Wie bereits erwähnt wird die Biopsie meist weit entfernt von der Invasionsfront des Tumors entnommen. Daher gibt es eine breite Verteilung der Daten über einen großen Bereich des HScores, insgesamt gab es eine Tendenz zur Hochregulation von TP. Eine vergleichbare Beobachtung konnten auch Jakob et al. in ihrer Studie aus dem Jahr 2004 machen.

\subsection{Einfluss des prätherapeutischen TP-Expressionslevels auf den TRG}

Anhand des Tumorregressionsgrades kann man das Ansprechen einer neoadjuvanten Therapie beurteilen (Surrogatmarker). Im Rahmen dieser Arbeit sollte geklärt werden, ob TP einen Einfluss auf den Therapieerfolg (Tumorregression) und somit auf den Tumorregressionsgrad hat. Es konnte jedoch kein signifikanter Zusammenhang zwischen der Expression von TP im Tumorgewebe und dem TRG erkannt werden. Vergleichbare Ergebnisse zeigte bereits eine kleinere Studie von Jakob et al. $(n=40)$ aus dem Jahr 2006, bei der kein statistischer Zusammenhang zwischen einer intratumoralen TP-Genexpression und Tumorregression festgestellt werden konnte (Jakob et al. 2006). Eine prognostische Bedeutung von TP konnte demnach mit den Ergebnissen der vorliegenden Arbeit nicht festgestellt werden, sodass die Ergebnisse von Jakob et al. anhand eines deutlich größeren, unabhängigen Patientenkollektivs nun bestätigt werden konnten. 


\subsection{Prognostische Bedeutung des postoperativen Nodalstatus im Vergleich zum TRG}

Die Daten der vorliegenden Arbeit bestätigen allerdings die grundsätzliche, prognostische Bedeutung der RT/CTx-induzierten Tumorregression bei lokal fortgeschrittenen Rektumkarzinomen erneut. In einer Studie von Rödel et al. wurde 2005 bereits deutlich, dass die komplette Tumorremission ein sehr früher (direkt postoperativ bestimmbarer) SurrogatParameter für eine langfristig gute Prognose ist. Je höher der Grad der Tumorregression war, desto besser war das DFS der Patienten innerhalb von 5 Jahren Nachbeobachtung (Rödel et al. 2005).

Diese Aussagen lassen sich auch anhand der eigenen Ergebnisse in Abbildung 17 gut nachvollziehen. Patienten mit pathologischer Komplettremission (pCR, (y)pT0 (y)pN0 M0) lebten nach 90 Monaten noch immer krankheitsfrei! Bei allen anderen TRG wurden im Laufe der Nachbeobachtungszeit Rezidive oder Fernmetastasen diagnostiziert. Vor allem in den ersten 40 Monaten des Nachbeobachtungszeit traten gehäuft Rezidive und Metastasen in den TRG-Gruppen 1 bis 3 a auf.

Ein geringfügiger Unterschied zur Studie von Rödel et al. konnte bei den Kurven von TRG 2 und TRG 3a festgestellt werden. Die Patienten mit TRG 3a scheinen einen schlechteren Krankheitsverlauf aufzuweisen als Patienten mit TRG 2. Dieser Unterschied ist jedoch nicht signifikant. Würde man TRG 3a und 3b zu einer Gruppe zusammenfassen (TRG 3), so würde Abbildung 17 einen, wie von Rödel et al. beschriebenen, stufenhaften Verlauf (von TRG 1-4) aufweisen.

In der Summe hatten $53,4 \%$ der neoadjuvant therapierten Patienten eine gute Tumorregression im Sinne eines TRG 3, 10,1\% hatten eine pCR. Der Stellenwert der neoadjuvanten Therapie wird auf diese Weise hervorgehoben.

$\mathrm{Ob}$ eine intensivierte neoadjuvante RT/CTx mit Oxaliplatin langfristig bessere therapeutische Ergebnisse auf der Basis einer signifikant höheren pCR-Rate (Rödel et al. 2012) hervorbringt, wird sich erst in den anstehenden DFS-Analysen der CAO/ARO/AIO-04-Studie zeigen lassen. Jede Verbesserung der neoadjuvanten RT/CTx mit Steigerung der pCR-Rate bei für die Patienten akzeptablem Nebenwirkungsprofil, scheint derzeit das Gesamtüberleben der Patienten $\mathrm{zu}$ verbessern. Somit sollte eine hohe pCR-Rate stets das Therapieziel einer neoadjuvanten Behandlung darstellen.

Eine pCR des Primarius bedeutet für den Rektumkarzinom-Patienten zumeist eine komplette Heilung. Entscheidend für diese hervorragende Prognose (siehe Abbildung 17) ist, nach einer 
Subgruppenanalyse einer Studie von Rödel et al. aus dem Jahr 2005, der postoperative Nodalstatus. Um diese Hypothese zu überprüfen, wurden in der vorliegenden Arbeit die TRG 1-3 im direkten Vergleich mit dem postoperativen Nodalstatus korreliert (siehe Abbildung $18)$.

Die Analyse von Rödel et al. an 385 Patienten aus dem Prüfarm der CAO/ARO/AIO-94-Studie zeigte, dass eine geringe Tumorregression (TRG 0 und TRG 1) mit einem höheren Risiko für einen positiven Nodalstatus verknüpft war und umgekehrt eine pCR des Primarius in $90 \%$ mit einem negativen regionären Nodalstatus assoziiert war. In der vorliegenden Arbeit hatten sogar 100\% der Patienten mit einem TRG 4 des Primarius postoperativ einen negativen Nodalstatus.

Diese Ergebnisse lassen annehmen, dass die bisher vermutete prognostische Bedeutung des TRG auch mit dem regionären Nodalstatus direkt zusammenhängt.

Auch zwei weitere Studien aus den Jahren 2005 und 2006 konnten nachweisen, dass ein negativer histopathologischer N-Status signifikant mit einem besseren outcome eingeht (Chapet et al. 2005; Jakob et al. 2006).

Alle drei oben genannten Studien schlussfolgerten, dass bei einem lokal fortgeschrittenen Rektumkarzinom der posttherapeutische, histopathologisch determinierte Nodalstatus der wichtigste prognostische Faktor für das DFS sei.

Aus diesem Grund wurde in der vorliegenden Arbeit eine Analyse zur Erfassung der Korrelation des Nodalstatus und des TRG in Bezug auf das DFS durchgeführt. In Abbildung 18 ist deutlich zu erkennen, dass Patienten mit einem negativen Nodalstatus ein signifikant längeres Überleben haben, als Patienten mit einem positiven Nodalstatus $(p=0,003)$. Dieses Ergebnis ist unabhängig vom jeweiligen TRG und unterstreicht die prognostische Relevanz des histopathologisch ermittelten lokoregionären Lymphknotenstatus.

\subsection{Die prognostische Bedeutung der Thymidinphosphorylase}

Zu Beginn der Arbeit stellten sich vor allem die Fragen, ob TP zur Therapiestratifizierung ein geeigneter Laborparameter sei. Zur Beantwortung dieser Fragestellungen wurde die TPExpression mit der Entstehung von Lokalrezidiven, Fernmetastasen, DFS und CSS korreliert (Kapitel 3.6). 
Bei der Entstehung von Lokalrezidiven in allen therapeutischen Gruppen gemeinsam konnte sowohl bei den Biopsien als auch bei den Resektaten kein signifikanter Unterschied hinsichtlich der TP-Expression festgestellt werden.

Patienten mit untersuchten Proben, die mit TP immunhistochemisch anfärbbar waren, entwickelten jedoch tendenziell häufiger ein Lokalrezidiv als solche Patienten ohne eine Exprimierung von TP (siehe Abbildung 21). Ein besonders signifikantes und interessantes Ergebnis konnte in Gruppe A der prätherapeutischen Biopsien erkannt werden. Diese Patienten, die nach der Biopsieentnahme keine neoadjuvante Therapie erhielten, entwickelten signifikant schneller und häufiger Lokalrezidive, wenn sie TP überexprimierten, gegenüber Patienten ohne TP-Expression ( $p=0,001)$. Ein ähnlicher Trend wie bei den Biopsien $(p=0,145)$ konnte bei den Rektumresektaten der Therapiegruppe A (primäre Operation) festgestellt werden.

Eine holländische Studie aus dem Jahr 2000 von van Triest et al. konnte ebenfalls ein vermehrtes Auftreten von Rezidiven, im Zusammenhang mit einer hohen TP-Expression, bei Patienten ohne neoadjuvante Therapie nachweisen (van Triest et al. 2000).

Diese Ergebnisse lassen vermuten, dass TP-exprimierende Gewebe mit einem aggressiveren, lokalen Wachstum einhergehen könnten. Zusammenhängen könnte dies mit der angiogenen Funktion von TP in seiner Rolle als „Platelet-derived endothelial cell growth factor“. In dieser Funktion könnte das Enzym (bei fehlender neoadjuvanter Therapie) ein verstärktes Tumorwachstum gefördert haben, wie es bereits in verschiedenen Experimenten untersucht wurde (Ishikawa et al. 1989; Moghaddam et al. 1995; Toi et al. 2005). Dies könnte eine mögliche Erklärung für die Ergebnisse in Abbildung 21 sein (siehe Kapitel 3.6.1.3). Interessanterweise konnten in den Gruppen B und C (nach präoperativer RT/CTx) dieser Arbeit keine vergleichbaren Erkenntnisse nachgewiesen werden.

Bei der Ausbildung von Fernmetastasen aus dem bioptisch gesicherten Material ergibt sich dahingegen ein leichter Trend $(\mathrm{p}=0,185)$ zur besseren Prognose bei Patienten mit stark TPexprimierendem Gewebe, als bei solchen mit wenig TP. Dieser Trend ist in den Resektaten nicht zu erkennen, Gruppe $\mathrm{C}$ der Biopsien liefert dahingegen wiederum ein interessantes und statistisch signifikantes Ergebnis $(\mathrm{p}=0,035)$ bezüglich der Fernmetastasierung. Da keiner der Patienten, die TP exprimierten, an Fernmetastasen erkrankte, könnte man vermuten, dass diese Patienten von der frühen Therapie mit Oxaliplatin profitierten. Diese Vermutung liegt nahe, da der einzige Unterschied in der Behandlung zur Gruppe B (hier $\mathrm{p}=0,863$ ) in der neoadjuvanten Applikation von Oxaliplatin lag. 
Ein ähnliches Ergebnis zeigt sich bei der Betrachtung des DFS. Kein einziger Patient aus Gruppe $\mathrm{C}$ der untersuchten Biopsien mit hohen TP-Expressionen entwickelte innerhalb des (im Vergleich $\mathrm{zu}$ den anderen Gruppen kürzeren) Nachbeobachtungszeitraums ein Lokalrezidiv oder eine Fernmetastasierung. Oxaliplatin könnte sich demnach nicht nur hemmend auf die Entstehung von Fernmetastasen, sondern auch auf die Entstehung von Lokalrezidiven bei Patienten mit TP-Expression ( $\mathrm{p}=0,04)$ auswirken. Eine Bestätigung dieser Hypothese kann es aber erst nach Auswertung der CAO/ARO/AIO-04-Studie geben.

Die Ergebnisse der Korrelation von TP-Expression und CSS waren alle nicht signifikant. Eine hohe oder niedrige Expression von TP hat demnach keinen Einfluss auf das Überleben der Rektumkarzinom-Patienten.

Ein weiterer Umstand, den es bei der Auswertung und Diskussion der Ergebnisse zu beachten gilt, ist, dass die Gruppen, welche TP enthielten, stets kleiner waren als Gruppen mit negativen TP-Expressionen. Bei kleineren Gruppengrößen können bereits wenige Ereignisse zu signifikanten Unterschieden innerhalb der Ergebnisse führen.

\subsection{Aktuelle Studienlage zu TP}

Im Jahr 1991 wurde die Entdeckung gemacht, dass es sich bei den Enzymen Thymidinphosphorylase (TP), welches 1951 in Escherichia Coli entdeckt wurde (Schwartz 1971) und ,platelet-derived endothelial cell growth factor“ (PD-ECGF), welches 1989 von Miyazono et al. erstmals beschrieben wurde (Miyazono und Heldin 1989), um dasselbe Protein handelt (Barton et al. 1992). Im physiologischen Sinne erfüllt dieses Protein den Zweck eines angiogenen Faktors mit chemotaktischer Aktivität in den Endothelzellen (Metzger et al. 1998). Zudem katalysiert dieses Enzym unterschiedliche Reaktionen, die im Zusammenhang mit der Wirkung von 5-FU stehen (siehe Kapitel 1.8), welches seit nunmehr 50 Jahren zur Behandlung verschiedener Arten von Krebs (u.a. KRK, Pankreaskarzinom, Mammakarzinom, als Salbe auch für Basaliome und Morbus Bowen) eingesetzt wird und noch immer backbone der Behandlung von KRK ist (Salonga et al. 2000). Es wurde bereits in einigen Studien versucht herauszufinden, ob TP als Biomarker für eine geplante Therapie mit 5-FU von prognostischer Bedeutung sein könnte.

Einige Studien bestimmten die TP-Expression nach erfolgter neoadjuvanter Therapie (Jakob et al. 2004; Tanaka et al. 2012), bei anderen gab es keine neoadjuvante Therapie und die 
Bestimmung von TP erfolgte vor der adjuvanten Therapie (Metzger et al. 1998; Salonga et al. 2000).

Die Ergebnisse dieser Studien sind dementsprechend sehr heterogen und kommen zu teilweise sehr kontroversen Ergebnissen. So wurde in einer Untersuchung festgestellt, dass eine hohe mRNA Expression von TP in prätherapeutischen Biopsien, weniger gutes Ansprechen auf eine Therapie mit 5-FU birgt (Metzger et al. 1998). Aus gemeinsamen Vorarbeiten unserer Forschergruppe mit Jakob et al. (2004) konnte in einer neueren Studie gezeigt werden, welchen Einfluss die TP-Expression auf das Ansprechen einer 5-FU basierten RT/CTx haben könnte. Bei 40 Patienten wurden nach der neoadjuvanten RT/CTx aus den TME-Rektumresektaten der TP-Gehalt anhand der Genexpression durch eine RealTime-Polymerasekettenreaktion (RT-PCR) bestimmt. In dieser Studie war eine niedrige TPExpression im residuellen Tumorgewebe (nach RT/CTx) mit einem guten Ansprechen (bezogen auf den TRG) auf die neoadjuvante Therapie assoziiert (Jakob et al. 2004). Ähnliche Ergebnisse brachte eine Studie aus Australien, bei der ein gutes Ansprechen auf die RT/CTx und ein hohes Überleben der Patienten mit einer niedrigen TP-Expression assoziiert waren (Soong et al. 2008). Eine japanische Studie ergab hingegen, dass Patienten mit einer hohen TP-Expression im untersuchten kolorektalen Karzinomgewebe, eine geringere Rate an lymphatischen und hämatogenen Metastasen aufwiesen und somit auch insgesamt eine bessere Prognose hatten, als Patienten mit einer geringen TP-Expression (Saito et al. 2000). In den Studien wurden zudem unterschiedliche Methoden zur Bestimmung der TP-Expression angewendet. So erfolgte entweder der direkte Nachweis von TP über eine Messung der mRNA-Expression von TP oder über eine indirekte Intensitätsdarstellung durch IHCAnfärbungen, wie sie in der vorliegenden Arbeit durchgeführt wurden. Die hohe Genexpression von TP muss jedoch nicht zwangsläufig eine hohe intrazelluläre Proteinexpression des Enzyms TP bedeuten (Metzger et al. 1998). Daten vergleichbarer Studienergebnisse sind in Tabelle 11 zusammengefasst.

Bei einem direkten Vergleich der Studiendaten mit den Ergebnissen dieser Arbeit ist zu beachten, dass sich sowohl die diagnostischen und therapeutischen Methoden, als auch die Patientenkollektive deutlich voneinander unterscheiden. Zudem werden Kolon- und Rektumkarzinome häufig als eine gemeinsame Tumorentität (KRK) gewertet (vergleiche Kapitel 1.1.1). 


\begin{tabular}{|c|c|c|c|c|c|}
\hline Autor und Jahr & $\begin{array}{l}\text { Anrahl } \\
\text { Patienten }\end{array}$ & $\begin{array}{l}\text { Untersuchtes } \\
\text { Material }\end{array}$ & Methode & Therapie & Ergebnisse der Studie in Bezug auf TP \\
\hline $\begin{array}{l}\text { Takebayashi et al. } \\
\text { (1996) } \\
\text { Journal of the National Cancer } \\
\text { Institute }\end{array}$ & 163 & $\begin{array}{l}\text { Kolorektale Resektate } \\
\left(\text { Dukes A-C }{ }^{l}\right)\end{array}$ & $\begin{array}{l}\text { IHC mit } \\
\text { monoklonalen } \\
\text { Antikörpern }\end{array}$ & $\begin{array}{l}\text { - Operation } \\
\text { (Dukes C: anschließend } \\
\text { adjuvante Therapie mit 5-FU) }\end{array}$ & $\begin{array}{l}\text { Hohe TP-Expression korreliert mit } \\
\text { fortgeschrittenen Dukes-Stadien, sowie mit } \\
\text { Lymphknotenmetastasen und verstärkter } \\
\text { Angiogenese }\end{array}$ \\
\hline $\begin{array}{l}\text { Metzger et al. (1998) } \\
\text { Clinical Cancer Research }\end{array}$ & 38 & $\begin{array}{l}\text { Prätherapeutische } \\
\text { Biopsien }\end{array}$ & $\begin{array}{l}\text { TP-Genexpression } \\
\left(\text { RT-PCR }^{2}\right)\end{array}$ & $\begin{array}{l}\text { - Adjuvante CTx } \\
\text { (5-FU i.v. + Leukovorin) }\end{array}$ & $\begin{array}{l}\text { Hohe TP-Expression ist assoziiert mit einem } \\
\text { Nichtansprechen auf eine Therapie mit 5-FU }\end{array}$ \\
\hline $\begin{array}{l}\text { Salonga et al. (2000) } \\
\text { Clinical Cancer Research }\end{array}$ & 33 & $\begin{array}{l}\text { Prätherapeutische } \\
\text { Biopsien }\end{array}$ & $\begin{array}{l}\text { TP-Genexpression } \\
\text { (RT-PCR) }\end{array}$ & $\begin{array}{l}\text { - Adjuvante CTx } \\
\text { (5-FU i.v. + Leukovorin) }\end{array}$ & $\begin{array}{l}\text { Aussage zur TP-Expression ist nur in Kombination } \\
\text { mit TS und DPD möglich: Patienten mit einer } \\
\text { geringen Expression aller } 3 \text { Enzyme hatten ein } \\
\text { sign. längeres Überleben als Pat. mit einer hohen } \\
\text { Expression von nur einem dieser Enzyme }\end{array}$ \\
\hline $\begin{array}{l}\text { Jakob et al. (2004) } \\
\text { The Journal of Pathology }\end{array}$ & 40 & $\begin{array}{l}\text { Prätherapeutische } \\
\text { Biopsien und } \\
\text { Rektumesektate } \\
\text { ((c)UICC-II/-III) }\end{array}$ & $\begin{array}{l}\text { TP-Genexpression } \\
\text { (RT-PCR) }\end{array}$ & $\begin{array}{l}\text { - Neoadjuvante RT/CTx }(5- \\
\text { FU) } \\
\text { • Operation } \\
\text { - Adjuvante CTx (5-FU) }\end{array}$ & $\begin{array}{l}\text { PE: es konnte keine signifikante Korrelation von } \\
\text { TP mit dem TRG gemessen werden } \\
\text { Resektate: eine niedrige TP-Expression korrelierte } \\
\text { signifikant mit besserem therapeutischem } \\
\text { Ansprechen (gemessen am TRG) }\end{array}$ \\
\hline
\end{tabular}




\begin{tabular}{|c|c|c|c|c|c|}
\hline $\begin{array}{l}\text { Goto et al. (2012) } \\
\text { Anticancer Research }\end{array}$ & 180 & $\begin{array}{l}\text { Kolorektale Resektate } \\
\text { (pUICC I-IV) }\end{array}$ & $\begin{array}{l}\text { TP-Genexpression } \\
\text { (RT-PCR) }\end{array}$ & $\begin{array}{l}\text { - Neoadjuvante RT/CTx } \\
\text { - Operation } \\
\text { - Adjuvante CTx } \\
\text { (Tegafur, Capecitabin, 5-FU } \\
\text { i.v.) }\end{array}$ & $\begin{array}{l}\text { Stadium I-III: keine signifikante Korrelation } \\
\text { konnte gefunden werden } \\
\text { Stadium IV: Schlechteres outcome (OS) für } \\
\text { Patienten mit hoher TP-Expression }\end{array}$ \\
\hline $\begin{array}{l}\text { Tanaka et al. (2012) } \\
\text { Journal of Surgical Oncology }\end{array}$ & 40 & Rektumresektate & $\begin{array}{l}\text { TP-Genexpression } \\
\text { (RT-PCR) }\end{array}$ & $\begin{array}{l}\text { - Neoadjuvante RT/CTx (5- } \\
\text { FU) } \\
\text { - Operation }\end{array}$ & $\begin{array}{l}\text { Keine signifikante Korrelation der TP-Expression } \\
\text { mit dem DFS }\end{array}$ \\
\hline $\begin{array}{l}\text { Lindskog et al. (2012) } \\
\text { Clinical Medicine Insights: Oncology }\end{array}$ & 254 & $\begin{array}{l}\text { Kolon- und } \\
\text { Rektumresektate cUICC- } \\
\text { III, zusätzliche Kontrolle } \\
\text { durch Probe aus Mukosa } \\
\text { (10cm entfernt vom } \\
\text { Primärtumor) }\end{array}$ & $\begin{array}{l}\text { TP-Genexpression } \\
\text { (RT-PCR) }\end{array}$ & $\begin{array}{l}\text { - Adjuvante CTx } \\
\text { (5-FU i.v. + Leukovorin) }\end{array}$ & $\begin{array}{l}\text { Hohe TP-Expression war signifikant mit einem } \\
\text { vermehrten regionären Lymphknotenbefall und } \\
\text { einem niedriger differenziertem Tumorgewebe } \\
\text { assoziiert }\end{array}$ \\
\hline Specking et al. (2013) & 223 & $\begin{array}{l}\text { Prätherapeutische } \\
\text { Biopsien und } \\
\text { Rektumresektate } \\
\text { ((c)UICC-II/-III) }\end{array}$ & $\begin{array}{l}\text { IHC mit } \\
\text { monoklonalen } \\
\text { Antikörpern }\end{array}$ & $\begin{array}{l}\text { - } 3 \text { Therapiegruppen } \\
\text { A: keine neoadj. Therapie } \\
\text { B: neoadj. 5-FU mono + RT } \\
\text { C: neoadj. 5-FU + Oxal.+ RT } \\
\text { - Operation } \\
\text { - Adjuvante CTx }\end{array}$ & $\begin{array}{l}\text { 1. Mehr Lokalrezidive bei hoher TP-Expr. ohne } \\
\text { neoadjuvante Therapie (nur signifikant für PE) } \\
\text { 2. Weniger Fernmetastasen/ besseres DFS bei } \\
\text { hoher TP-Expression bei anschließender neoadj. } \\
\text { Therapie (nur signifikant für PE) } \\
\text { 3. Keine signifikante Korrelation von TP mit dem } \\
\text { CSS der Patienten } \\
\text { 4. Keine Korrelation der TP-Expression mit dem } \\
\text { TRG }\end{array}$ \\
\hline
\end{tabular}

\section{Tabelle 11: Studienlage zur Ermittlung des prognostischen Potentials von TP}

Tabelle zur Darstellung bisher durchgeführter Studien bezüglich des prognostischen Potentials von TP. Aufgelistet sind Patientenzahl, untersuchtes Material, die Methodik zur Messung der TP-Gen-/Proteinexpression, die therapeutischen Maßnahmen und die Ergebnisse (und Schlussfolgerungen) der Studien.

1: Dukes-Stadien: A - Tumorinfiltration maximal bis in die Tunica muscularis; B - T3 oder T4, keine Lymphknotenmetastasen; C-pos.

Lymphknotenmetastasen; D-pos. Fernmetastasierung

2: RT-PCR: real-time quantitative PCR 


\subsection{Korrelation der Ergebnisse von TP und TS}

Die Messung eines einzelnen Biomarkers zur Abschätzung der unmittelbaren Auswirkung einer neoadjuvanten Therapie und einer möglichen Prognose ist nicht ausreichend. Eine multivariable Analyse von relevanten Biomarkern könnte in Zukunft ein wichtiger Schritt in Richtung „Individualisierung der onkologischen Therapie“ sein.

In einer aktuellen Studie von Unger et al. aus dem Jahr 2011 wurde aus diesem Grund die Expression von TP und TS in Adenokarzinomen des Rektums untersucht und miteinander korreliert. Hierzu wurden 20 Patienten mit einem lokal fortgeschrittenem Rektumkarzinom in die Studie eingeschlossen. Alle Patienten erhielten eine neoadjuvante RT/CTx mit Capecitabin und die Tumoren wurden postoperativ histopathologisch nach ihrem TRG klassifiziert (Responder: TRG 2-4, Nonresponder: TRG 0-1). Die Expression der Biomarker TP und TS wurde immunhistochemisch bestimmt (Unger et al. 2011).

Aufbauend auf den Daten der Dissertation von Frau Dr. med. Lena Conradi aus unserer Arbeitsgruppe des TP5, der KFO 179, wurde im Rahmen der vorliegenden Arbeit eine zusätzliche Analyse der Korrelation von TP und TS mit klinikopathologischen Parametern und Ereignissen aus der Langzeitanalyse durchgeführt.

Ergebnisse von Unger et al. zeigten, dass sieben von acht Responder, eine nicht messbare oder sehr geringe TS-Expression aufwiesen. Umgekehrt zeigten drei von vier Nonrespondern eine hohe TS-Expression. Dieser Zusammenhang konnte in der Studie von Conradi et al. nicht nachgewiesen werden, es gab keinen erkennbaren signifikanten Zusammenhang zwischen dem TRG und der TS-Expression.

Die Studie von Unger et al. zeigte zudem, dass eine hohe Expression von TP mit einem guten Ansprechen auf die neoadjuvante Therapie signifikant korrelierte. In der vorliegenden eigenen Arbeit konnte jedoch kein statistisch signifikanter Zusammenhang zwischen der Expression von TP und dem TRG gemessen werden. Eine mögliche Erklärung für die verschiedenen Ergebnisse in Bezug auf die TP- und TS-Expression und den TRG könnte die geringe Patientenzahl der Studie von Unger et al. (die Untersuchung fand an lediglich 12 Patienten statt: 8 Responder, 4 Nonresponder) sein.

Ein überraschendes und sehr interessantes Ergebnis ist in Abbildung 31 dargestellt, in der eine starke Tendenz zur Korrelation von fortgeschrittenen TRG (TRG 3b) mit hohen Expressionsleveln von TP und TS auffällt. Niedrige Werte dieser Enzyme korrelierten hingegen vermehrt mit einem geringen TRG. Wie jedoch bereits in Kapitel 4.5 erörtert, ist die Bedeutung des TRG zum Teil noch unklar. Lediglich der prognostische Wert einer pCR 
konnte bislang in der Studie von Rödel et al. aus dem Jahr 2005 und unter anderem auch durch die vorliegende Arbeit (siehe Abbildung 17) bestätigt werden.

Unger et al. konnten des Weiteren zeigen, dass Patienten in ihrer Studie, die ein Lokalrezidiv entwickelten, signifikant höhere Expressionslevel von TS und signifikant geringere Wert von TP aufwiesen. Jakob et al. konnten 2006 eine signifikante Korrelation bei hohen Expressionen von TS und der Wahrscheinlichkeit eines Tumorrezidivs nachweisen. Weder Conradi et al. noch die vorliegende Arbeit konnten die Ergebnisse von Unger et al. und Jakob et al. reproduzieren. Abbildung 32 verdeutlicht, dass die Analyse der Korrelation der TP- und TSExpression mit dem DFS keinen signifikanten Zusammenhang erkennen lässt. Es lässt sich lediglich ein leichter Trend erkennen, dass hohe TP- und TS-Expressionen vermehrt mit einem besseren DFS einhergehen. Auch in Bezug auf die Entwicklung von Lokalrezidiven konnte keine signifikante Korrelation mit der TP- und TS-Expression, wie Unger et al. zeigten, nachgewiesen werden. Die Kombination aus diesen beiden enzymatischen Biomarkern mit weiteren Biomarkern könnte jedoch zukünftig durchaus Grundlage für eine individuell angepasste Therapie bieten.

\subsection{Capecitabin in der neoadjuvanten Therapie}

In der Summe erhielten 12 Patienten aus der neoadjuvanten Therapiegruppe C Capecitabin (Xeloda®) anstelle des intravenös verabreichten 5-FU. Zur Umwandlung dieses oral verabreichten Prodrugs wird ein 3-stufiger enzymatischer Prozess benötigt, dessen letzter Schritt durch TP katalysiert wird (Patel 2011). Da im Vergleich zu normalem Gewebe in kolorektalen Tumoren eine vermehrte Expression von TP vorhanden ist (Shimma et al. 2000), sollte der Umsatz von Capecitabin zu 5-FU in diesem Gewebe ebenfalls erhöht sein. Auf diese Weise verspricht man sich eine verbesserte zytotoxische Wirkung und lokale Beschränkung von 5-FU. In diesem Sinne ist eine Untersuchung des Zusammenhangs zwischen TP-exprimierenden Tumoren und der Wirksamkeit von Xeloda ${ }^{\circledR}$ ein sinnvoller Aspekt im Rahmen dieser Arbeit.

Es erhielten jedoch lediglich 12 Patienten Xeloda ${ }^{\circledR}$. Innerhalb der Biopsien konnte eine starke TP-Expression bei 2 Gewebeproben nachgewiesen werden, bei den Resektaten konnte bei 7 Gewebeproben TP nachgewiesen werden. Abbildung 35 verdeutlicht, dass es statistisch betrachtet (unabhängig von TP) keinen Unterschied macht, ob man neoadjuvant mit Xeloda® oder intravenösem 5-FU behandelt wird. Für beide Patientengruppen ergibt sich nach 5 Jahren 
Nachbeobachtungszeitraum ein DFS von 60\%. In Abbildung 36 wird ein möglicher Einfluss von TP auf das DFS und CSS bei Patienten mit Xeloda ${ }^{\circledR}$ und intravenösem 5-FU geprüft. Die höchste Wahrscheinlichkeit für ein Lokalrezidiv oder eine Fernmetastase hatten, nach Abbildung 36, Patienten, die 5-FU intravenös appliziert bekamen und kein TP in den Tumorzellen exprimierten. Hier lag das DFS nach 28 Monaten noch bei 53\%. Im direkten Vergleich kann man erkennen, dass Patienten, die hier TP exprimierten, ein DFS von 65\% nach 42 Monaten hatten. Patienten, die Xeloda ${ }^{\circledR}$ erhielten $(n=10)$ entwickelten deutlich später Lokalrezidive oder Fernmetastasen als solche, die 5-FU intravenös $(n=50)$ bekamen. Nach 28 Wochen entwickelte der erste TP-exprimierende Tumor ein Lokalrezidiv. Patienten ( $n=3)$, die kein TP exprimierten, entwickelten nur ein Lokalrezidiv im Beobachtungszeitraum von 78 Monaten und dieses trat nach 64 Monaten auf.

Das CSS in Abbildung 36 zeigt, dass Patienten, die Xeloda ${ }^{\circledR}$ erhielten, deutlich später an ihrem Tumor verstarben als Patienten, die mit intravenösem 5-FU behandelt wurden. Den ersten tumorspezifischen Todesfall gab es somit erst nach 61 Monaten, bei 5-FU behandelten Patienten bereits nach 15 Monaten. Auch hier sollte jedoch auf den gravierenden Unterschied bezüglich der Gruppengrößen erneut hingewiesen werden. Diese Ergebnisse sollten in einer Studie mit größerer Patientenzahl erneut durchgeführt werden, um signifikante Ergebnisse und somit auch fundierte Erkenntnisse liefern zu können.

In präklinischen Studien konnte gezeigt werden, dass in vitro eine RT die enzymatische Umwandlung von Capecitabin zu 5-FU durch TP steigern kann (Sawada et al. 1999). Ähnliche Ergebnisse konnten mit intravenös verabreichtem 5-FU nicht erreicht werden (Dunst et al. 2002). Außerdem bietet Xeloda ${ }^{\circledR}$ den Vorteil der oralen Einnahme. Dies senkt das Risiko von Infektionen im Vergleich zu 5-FU, da dieses über einen peripheren Venenkatheter oder eine Infusionspumpe appliziert werden muss. Zudem könnte es für viele Patienten angenehmer sein, das Medikament in oraler Form einzunehmen.

Auf der anderen Seite sollten auch die negativen Auswirkungen eines oral applizierten Medikaments bedacht werden. So muss der Patient sich in höchstem Maße compliant verhalten, indem er regelmäßig Xeloda ${ }^{\circledR}$ einnimmt. Eine genaue Überwachung, ob die Dosierung korrekt eingehalten wird, kann durch den behandelnden Arzt somit nicht gewährleistet werden. Außerdem liegt der reine Medikamentenpreis des vergleichsweise neuen Medikaments Xeloda ${ }^{\circledR}$ deutlich höher, als der des seit 1962 im Handel befindlichen intravenösen 5-FU. Nicht zuletzt ist die Bioverfügbarkeit des Chemotherapeutikums ein entscheidendes Kriterium bei der Wahl eines geeigneten Medikaments. In Studien konnte nachgewiesen werden, dass sowohl das enteral aufgenommene als auch das intravenös 
applizierte 5-FU schlecht steuerbar ist und starken individuellen Schwankungen unterliegen kann (Findlay et al. 1996). Um jedoch eine möglichst effektive CTx durchführen zu können, werden konstante 5-FU Spiegel im Blutplasma benötigt. Aus diesem Grund wird in unserer Arbeitsgruppe des TP5 der KFO179 derzeit eine Methode zur standardisierten Bestimmung des 5-FU-Plasmaspiegels durchgeführt

Eine aktuelle Pilotstudie von Makihara et al. aus dem Jahr 2012 konnte zeigen, dass die Messung von Capecitabin im Blutplasma und somit eine individuelle Therapieanpassung möglich ist. Durchgeführt wurde diese Messung mit Hilfe eines My5-FU (nanoparticle antibody-based immunoassay). In einem Vergleich der Plasmaspiegel fiel auf, dass Patienten, die Capecitabin erhielten, breitere Konzentrationsschwankungen und insgesamt niedrigere Plasmawerte aufwiesen als Patienten, die intravenöses 5-FU erhielten. Eine Dosisbeurteilung von Capecitabin ist somit möglich und könnte schon bald in den klinischen Alltag eingebunden werden (Makihara et al. 2012).

Diese Faktoren, allen voran der radiosensibilisierende Einfluss auf TP, haben zu einer Aufnahme von Xeloda ${ }^{\circledR}$ als einer möglichen Therapieoption in das multimodale Therapiekonzept des lokal fortgeschrittenen Rektumkarzinoms geführt.

Durch eine aktuelle Studie aus Heidelberg von Hofheinz et al. (2012) konnte an 392 Patienten nachgewiesen werden, dass eine Behandlung mit Capecitabin sich positiv auf das DFS der Patienten auswirke. Als Kontrollgruppe dienten bei dieser Studie Patienten mit intravenös verabreichtem 5-FU (5-Jahres DFS: 68\% für Capecitabin vs. 54\% für 5-FU i.v.). Der Effekt konnte sowohl für die adjuvante als auch für die neoadjuvante Therapie nachgewiesen werden.

In verschiedenen Studien konnte die gute Wirksamkeit von Capecitabin in Verbindung mit Oxaliplatin bewiesen werden. So konnte ein downstaging von 33-72\% nachgewiesen werden bei einer pCR von bis zu 28\% (Glynne-Jones 2005). In der vorliegenden Studie konnte, unter kompletter Aufarbeitung des mesorektalen Weichgewebes, bei keinem einzigen Patienten, der Xeloda ${ }^{\circledR}$ erhielt, eine pCR nachgewiesen werden. Bei 2 Patienten konnte jedoch ein TRG 3b (bis zu 99\% Tumorregression) gefunden werden. Eine R0-Resektion erfolgte bei allen 12 mit Xeloda ${ }^{\circledR}$ behandelten Patienten $(100 \%)$. 


\begin{tabular}{lcccc}
\hline Autor und Jahr der Studie & $\begin{array}{l}\text { Anzahl (n) } \\
\text { Patienten }\end{array}$ & $\begin{array}{l}\text { downstaging } \\
(\%)\end{array}$ & pCR (\%) & $\begin{array}{l}\text { R0-Resektion } \\
(\%)\end{array}$ \\
\hline $\begin{array}{l}\text { Fakih et al. (2006) } \\
\text { International Journal of Radiation Oncology }\end{array}$ & 12 & 64 & 27 & 27 \\
$\begin{array}{l}\text { Glynne-Jones (2005) } \\
\text { Annals of Oncology }\end{array}$ & 18 & 72 & 28 & 78 \\
$\begin{array}{l}\text { Hospers et al. (2007) } \\
\text { Annals of Surgical Oncology }\end{array}$ & 21 & 33 & 10 & 81 \\
$\begin{array}{l}\text { Machiels (2005) } \\
\text { Annals of Oncology }\end{array}$ & 40 & 53 & 14 & n/a \\
$\begin{array}{l}\text { Rödel (2003) } \\
\text { Journal of Clinical Oncology }\end{array}$ & 32 & 55 & 19 & 79 \\
\hline \begin{tabular}{l} 
Specking et al. (2013) \\
\hline
\end{tabular} & 12 & 58 & $0 *$ & 100 \\
\hline
\end{tabular}

Tabelle 12: Studienlage zur neoadjuvanten Therapie mit Capecitabin bei Rektumkarzinomen

In dieser Tabelle werden 6 Studien aufgelistet, deren Patienten neoadjuvant alle Xeloda ${ }^{\circledR}$ und Oxaliplatin erhielten. Betrachtet wurde hierbei die Anzahl der Patienten, das downstaging (in \%), die pCR (in \%) und der R0-Resektionsstatus (in \%).

* unter der Maßgabe der kompletten mesorektalen Aufarbeitung. TRG 3b (Regression von 95-99\%) gab es bei 3 Patienten (25\%).

\subsection{Ausblick}

Abschließend muss die Frage diskutiert werden, welche Relevanz die vorliegende Arbeit für den klinischen Alltag und künftige wissenschaftliche Forschungen hat.

Prätherapeutische Biopsien werden im Rahmen einer Koloskopie/Rektoskopie gewonnen. Hierbei wird ein relativ oberflächlicher Anteil des verdächtigen Tumors entnommen und histologisch untersucht. Da das entnommene Gewebe häufig weit entfernt von der Invasionsfront des Karzinoms liegt, TP an der Invasionsfront jedoch verstärkt exprimiert wird, konnten folglich in den prätherapeutischen Biopsien lediglich geringe TP-Expressionen nachgewiesen werden. Da Biopsien auch in Zukunft eher aus randständigen Tumorregionen entnommen werden, erscheint die Messung der TP-Expression in prätherapeutischen Biopsien zur Therapiestratifizierung wenig aufschlussreich. Die wenigen Patienten, deren Biopsien in der vorliegenden Untersuchung jedoch TP vermehrt exprimierten, zeigten eine signifikante Korrelation bei der Entstehung von Lokalrezidiven. Diese Ergebnisse konnten nur in der primär operierten Patientenkohorte nachgewiesen werden.

In den Rektumresektaten konnten höhere Expressionen von TP gemessen werden als in den prätherapeutischen Biopsien. Hier konnten jedoch keine signifikanten Zusammenhänge zwischen der TP-Expression und klinikopathologischen Parametern oder Ereignissen im 
Follow-Up gefunden werden. Nach den ermittelten Ergebnissen der vorliegenden Studie hat TP allein somit keinen prognostischen Wert bezüglich des DFS und des CSS. Eine Möglichkeit, TP als Parameter zur Therapiestratifizierung nutzen zu können, konnte daher nicht nachgewiesen werden.

Die Ergebnisse der vorliegenden Arbeit zeigen jedoch auch, dass eine Kombination verschiedener Biomarker die Basis für eine „individuellere onkologische Therapie“ sein kann. Die Korrelation von TP und TS mit dem TRG zeigte, dass eine kombinierte, starke Ausprägung beider Enzyme zu einem höheren Tumorregressionsgrad beim Rektumkarzinom nach RCT/CTx führte als Zeichen eines guten und unmittelbaren Therapieansprechens mit mutmaßlich günstigerer Prognose. Dieses Ergebnis sollte in einer größeren Studie unter Anwendung präoperativer multimodaler Therapie untersucht werden.

Des Weiteren konnte die vorliegende Studie zeigen, dass der postoperative histopathologische Nodalstatus der wichtigste unabhängige prognostische Faktor für das Rektumkarzinom ist. Ein direkter Vergleich mit dem TRG konnte dies bestätigen. Aus diesem Grund sollte postoperativ verstärkt auf eine präzise histopathologische Resektataufarbeitung unter besonderer Berücksichtigung des Nodalstatus geachtet werden. 


\section{Zusammenfassung}

Das KRK ist sowohl bei Männern als auch bei Frauen der zweithäufigste bösartige Tumor in Deutschland. In den vergangenen Jahren konnten gerade in der Therapie des lokal fortgeschrittenen Rektumkarzinoms in erhebliche Fortschritte erzielt werden.

Die Einführung einer 5-FU basierten neoadjuvanten Radiochemotherapie in die S-3 Leitlinien führte zu einer langfristigen Reduktion der Lokalrezidivrate und einer Verringerung der akuten und chronischen Toxizität im Vergleich zur primären Operation gefolgt von adjuvanter RT/CTx. Das mit der neoadjuvanten Therapie einhergehende downsizing und downstaging führte vermehrt $\mathrm{zu}$ sphinktererhaltenden Operationen (in 19\% der Fälle, CAO/AIO/ARO-94-Studie). Erste Ergebnisse der CAO/ARO/AIO-04-Studie zeigten unter Intensivierung der neoadjuvanten Therapie mit Oxaliplatin bereits einen signifikanten Anstieg der kompletten Remission des Primärtumors auf $17 \%$ gegenüber einem 5-FUStandardregime; allerdings liegen aus der Studie noch keine Daten zum Einfluss auf das DFS vor.

Trotz aller genannten Fortschritte in der Therapie des lokal fortgeschrittenen Rektumkarzinoms konnte bisher keine Reduktion der Fernmetastasierungsrate (etwa 30\% über 10 Jahre Nachbeobachtung) oder des Gesamtüberlebens erzielt werden. Aus diesem Grund ist es von entscheidender Bedeutung, die molekularen und enzymatischen Mechanismen des Karzinoms zu verstehen und künftig Biomarker zu identifizieren, die eine prognostische und prädiktive Funktion haben und eine Individualisierung der onkologischen Therapie ermöglichen könnten.

Einer dieser potentiellen Biomarker ist TP, ein Enzym, welches in den physiologischen Stoffwechsel einer jeden Zelle eingebunden ist. Dort dient es als angiogener Faktor, katalysiert aber des Weiteren mindestens drei bekannte Reaktionen, die im Zusammenhang mit dem 5-FU-Metabolismus stehen. In früheren Studien wurde festgestellt, dass in Karzinomzellen (verglichen mit normalem Gewebe) eine erhöhte Expression von TP gemessen werden kann.

Aus diesem Grund wurden in der vorliegenden Studie 223 Patienten mit einem lokal fortgeschrittenen Rektumkarzinom auf eine Expression von TP immunhistochemisch untersucht. Alle Patienten wurden, unter Gewährleistung standardisierter Bedingungen, multimodalen Therapieschemata zugeführt. Diese basierten auf randomisierten, multizentrischen Phase-II/-III Studien. Die Operationen fanden in der Klinik für Allgemein-, Viszeral- und Kinderchirurgie an der Universitätsklinik Göttingen statt. Für die Analyse des 
in der vorliegenden Arbeit untersuchten Patientenkollektivs standen 186 Biopsien und 223 Rektumresektate zur Verfügung. Daten von klinikopathologischen Parametern und der Nachbeobachtungszeit wurden erhoben, außerdem wurden die Patienten in Therapiegruppen aufgeteilt: Gruppe A $(n=41)$ wurde primär operiert, Gruppe B $(n=69)$ erhielt eine neoadjuvante RT/CTx mit 5-FU, in Gruppe C (n=113) wurde eine neoadjuvante RT/CTx mit 5-FU plus Oxaliplatin appliziert. Alle Patienten wurden zudem einer ihrem jeweiligen Therapieschema entsprechenden postoperativen (adjuvanten) Chemotherapie zugeführt.

Die immunhistochemisch bestimmte TP-Expression wurde untersucht und statistisch aufgearbeitet. Biomaterial aus residuellem Tumorgewebe zeigte eine kräftigere TP-Expression als bioptisch gesichertes Material. Die Ergebnisse wurden mit den klinisch evaluierten Patientencharakteristika und den oben genannten Therapiegruppen korreliert und einer weiteren statistischen Analyse unterzogen.

Die Ergebnisse der Analyse der prätherapeutischen Biopsie zeigten, dass primär operierte Patienten mit einer erhöhten TP-Expression im untersuchten Gewebe signifikant häufiger Lokalrezidive entwickelten $(\mathrm{p}=0,001)$. Des Weiteren zeigten die Untersuchungen der prätherapeutischen Biopsien, dass Patienten in Gruppe C mit einer hohen TP-Expression signifikant seltener Fernmetastasen ausbildeten, als Patienten mit einer geringen TPExpression $(p=0,035)$. In Gruppe B konnten keine vergleichbaren Ergebnisse festgestellt werden.

Die genannten Ergebnisse ließen sich allerdings nicht für die Resektate reproduzieren, hier gab es keine signifikante Korrelation. Auch konnte bei der Untersuchung der TP-Expression weder innerhalb der prätherapeutischen Biopsien noch der Tumorresektate ein signifikanter Zusammenhang hinsichtlich des krankheitsspezifischen Gesamtüberlebens aufgedeckt werden.

Korrelationen der Expression von TP in prätherapeutischen Biopsien mit dem TRG waren statistisch ebenfalls nicht signifikant.

Bei der Korrelation des Tumorregressionsgrades (Responder und Nonresponder) mit dem postoperativ und histopathologisch bestimmten lokoregionären Nodalstatus zeigte sich ein signifikanter Unterschied $(\mathrm{p}=0,003)$. Abgesehen von einer $\mathrm{pCR}$, hatte der TRG keinen signifikanten Einfluss auf den Verlauf der Patienten. Wichtigster Prognosefaktor war der Nodalstatus. Patienten mit einem positiven Nodalstatus entwickelten häufiger Rezidive als Patienten mit einem negativen Nodalstatus $(p=0,003)$.

Ein Abgleich der Daten mit den Ergebnissen der Dissertation von Conradi et al. aus dem Jahr 2010 bezüglich der Expression von TS wurde ebenfalls durchgeführt. Patienten aus dem 
overlap $(\mathrm{n}=177)$ wurden auf die Expression der potentiellen Biomarker TP und TS überprüft und mit klinikopathologischen Parametern und Ereignissen aus dem Follow-Up korreliert. Die kombinierte Untersuchung der Expression von TP und TS zeigte keinen Zusammenhang mit dem DFS oder dem CSS, eine weitere Untersuchung mit Bezug auf den TRG zeigte jedoch eine starke Tendenz zu einer Korrelation: Patienten mit einer hohen Expression der beiden Enzyme zeigten eine stärkere RT/CTx-induzierte Tumorregression als Patienten mit einer geringen Enzymexpression ( $\mathrm{p}=0,0609)$.

Abschließend wurde exemplarisch die Wirkung von Capecitabin (Xeloda®) in der neoadjuvanten Therapie in Bezug auf die TP-Expression untersucht, da TP für die intrazelluläre Umwandlung von Capecitabin $\mathrm{zu}$ 5-FU verantwortlich ist. Die Subgruppenanalyse zeigte jedoch keinen Zusammenhang, vermutlich war das untersuchte Patientenkollektiv für repräsentative Ergebnisse nicht groß genug $(n=12)$.

Schlussfolgernd ist TP den Ergebnissen dieser Studie zufolge ein wenig geeigneter molekularer Laborparameter zur Therapiestratifizierung. In prätherapeutischen Biopsien konnte nur bei wenigen Patienten eine hohe TP-Expression festgestellt werden, da dieses Biomaterial zumeist aus eher peripheren Tumoranteilen stammte. TP in Tumorresektaten korrelierte nicht signifikant mit Ereignissen des Follow-Ups. Eine Kombination mit weiteren Biomarkern könnte den Einsatz von TP als prädiktiven und prognostischen Marker im klinischen Alltag wahrscheinlicher machen. 


\section{Anhang}

\section{a) Mason-Kriterien}

\begin{tabular}{ll}
\hline Beschreibung & Stadium \\
\hline I & $\begin{array}{l}\text { Der Tumor ist auf die Mukosa begrenzt und gegenüber der } \\
\text { Submukosa verschiebbar }\end{array}$ \\
II & $\begin{array}{l}\text { Der Tumor ist mit der Wand des Rektums, in Bezug auf die } \\
\text { Umgebung des Darms, verschiebbar }\end{array}$ \\
III & $\begin{array}{l}\text { Der Tumor hat alle Wandschichten durchbrochen. Somit ist die } \\
\text { Beweglichkeit des Rektums gegenüber der Umgebung eingeschränkt }\end{array}$ \\
IV & Der Tumor fixiert das Rektum gegenüber der Umgebung \\
V & Es liegen bereits Fernmetastasen vor \\
\hline
\end{tabular}

\section{b) Histologische Differenzierungsgrade}

Einteilung
$\begin{aligned} & \text { Low-Grade- } \\ & \text { Karzinome }\end{aligned}$ $\begin{cases}\text { G1 } & \text { Beurteilung } \\ \text { G2 } & \begin{array}{l}\text { Hochdifferenziertes malignes Gewebe, hohe } \\ \text { Übereinstimmung mit ursprünglichem Gewebe } \\ \text { Mäßig differenziertes malignes Gewebe } \\ \text { Karzinome }\end{array}\end{cases}$


c) Aktuelle TNM-Klassifikation des Rektumkarzinoms nach Wittekind und Meyer, 2010

\begin{tabular}{cl}
\hline \multicolumn{2}{c}{ TNM-Klassiffkation } \\
\hline Tis & Carcinoma in situ \\
T1 & Tumor infiltriert die Submukosa \\
T2 & Tumor infiltriert Muscularis propria \\
T3 & Tumor infiltriert Subserosa und perirektales Gewebe \\
T4 & Tumor infiltriert angrenzende Organe und/oder das viszerale Peritoneum \\
T4a & Perforation des viszeralen Peritoneums \\
T4b & Direkte Infiltration benachbarter Organe \\
N0 & keine regionären Lymphknotenmetastasen \\
N1 & Metastasen in 1-3 regionären Lymphknoten \\
N1a & 1 regionär befallener Lymphknoten \\
N1b & 2-3 regionär befallene Lymphknoten \\
N1c & Befall von Fettgewebe der Subserosa \\
N2 & Metastasen in 4 oder mehr regionären Lymphknoten \\
N2a & 4-6 regionäre Lymphknoten befallen \\
N2b & mehr als 6 regionäre Lymphknoten sind befallen \\
\hline M0 & keine Fernmetastasen \\
M1 & Fernmetastasen vorhanden \\
M1a & die Fernmetastasen sind auf ein Organ beschränkt (Lunge, Leber, etc.), jedoch keine Metastasen im \\
Peritoneum & Fernmetastasen in verschiedenen Organen oder im Peritoneum \\
\hline
\end{tabular}

d) Stadieneinteilung KRK nach der neuen UICC-Klassifikation (nach Wittekind und Meyer 2010)

\begin{tabular}{l|lll}
\hline $\begin{array}{l}\text { Stadiengruppierung } \\
\text { nach UICC }\end{array}$ & T-Stadium & N-Stadium & M-Stadium \\
\hline Stadium 0 & Tis & N0 & M0 \\
\hline Stadium I & T1, T2 & N0 & M0 \\
\hline Stadium II A & T3 & N0 0 \\
\hline Stadium II B & T4a & N0 & M0 \\
Stadium II C & T4b & N0 & M0 \\
\hline Stadium III & Jedes T & N1, N2 & M0 \\
\hline Stadium III A & T1, T2 & N1a & M0 \\
Stadium III B & T1 & N2a & M0 \\
& T3, T4a & N1 & M0 \\
Stadium III C & T2, T3 & N2a & M0 \\
& T1, T2 & N2b & M0 \\
& T4a & N2a & M0 \\
\hline Stadium IV A & T3, T4b & N2b & M0 \\
\hline Stadium IV B & T4b & N1, N2 & M1a \\
\hline
\end{tabular}




\section{e) CAO/ARO/AIO-94-Studie: Therapieschema}

\section{CAO / ARO / AlO - 94 - Studie}

beim cUICC-II/III Rektumkarzinom (0-16 cm ab Anokutanlinie)

$\begin{array}{lllll}5-\mathrm{FU} & 5-\mathrm{FU} & 5-\mathrm{FU} \quad 5-\mathrm{FU} & 5-\mathrm{FU} & 5-\mathrm{FU} \\ 5 \times 1000 \mathrm{mg} / \mathrm{m}^{2} & 5 \times 1000 \mathrm{mg} / \mathrm{m}^{2} & 500 \mathrm{mg} / \mathrm{m}^{2} / \mathrm{d} \\ 120 \mathrm{~h} \mathrm{Infusion} & 120 \mathrm{~h} \mathrm{Infusion}^{\text {i.v. Bolus }} & & \end{array}$

Arm I:
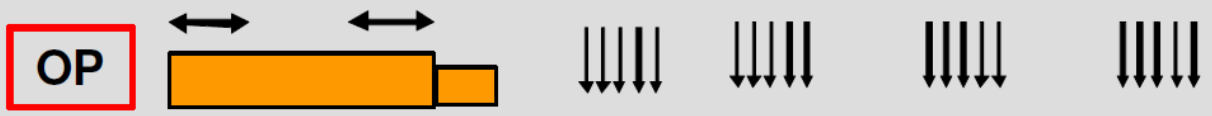

RT: $50.4+5.4$ Gy Boost

$$
5 \text {-FU }
$$

$5 \times 1000 \mathrm{mg} / \mathrm{m}^{2} \quad 5 \times 1000 \mathrm{mg} / \mathrm{m}^{2}$ $120 \mathrm{~h}$ Infusion

120 Infusion

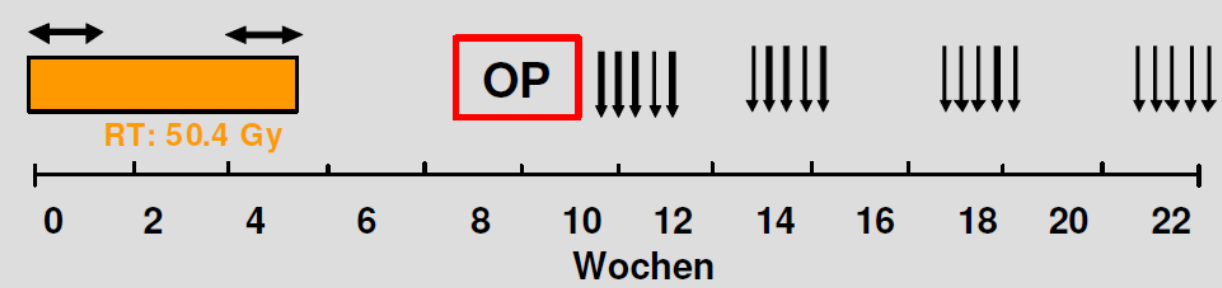

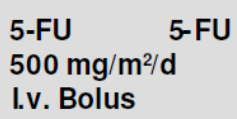

Arm II:

\section{f) CAO/ARO/AIO-04-Studie: Therapieschema}

Studienschema

\section{KONTROLL-ARM:}

Radiotherapie :
$28 \times 1.8 \mathrm{~Gy}$

Chemotherapie:

5-Fluorouracil

$1000 \mathrm{mg} / \mathrm{m}^{2} / \mathrm{d}$

Dauerintusion

1.+5. RT-Woche
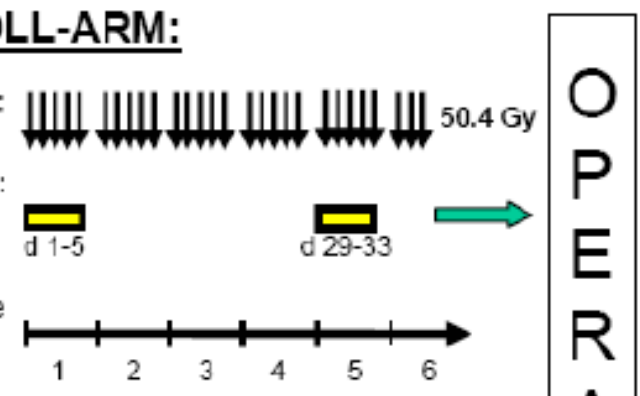

\section{PRÜF-ARM:}

Rediotherapie: $28 \times 1.8$ Gy

Chemotherapie:

5-Fluorouracil

$250 \mathrm{mg}^{2} \mathrm{~m}^{2} / \mathrm{d}$

Dauerinfusion

Oxaliplatin

$50 \mathrm{mg} / \mathrm{m}^{2} / \mathrm{d}$

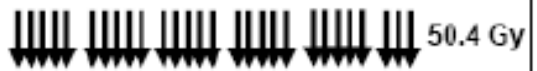
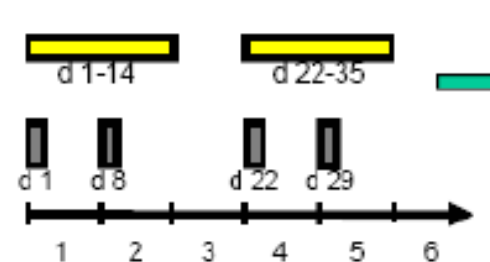

5-FU: $500 \mathrm{mg} / \mathrm{m}^{2} / \mathrm{d}$ als Bolus über 2-5 min. (Tag 1-5), Wiederholung Tao 29, insoesamt 4 Kurse

Folinsäure $400 \mathrm{mg} / \mathrm{m}^{2} ;$ 2h-Infusion Oxaliplatin $100 \mathrm{mg} / \mathrm{m}^{2} ; 2 \mathrm{~h}-$ Infusion 5-FU Infusion $2400 \mathrm{mg} / \mathrm{m}^{2} ; 46 \mathrm{~h}$-Infusion

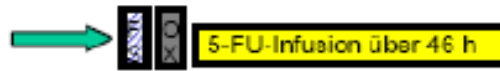

d 1

Wiederholung d 15; insgesamt 8 Kurse 


\section{Literaturverzeichnis}

Aaltonen LA, Salovaara R, Kristo P, Canzian F, Hemminki A, Peltomäki P, Chadwick RB, Kääriäinen H, Eskelinen M, Järvinen H et al. (1998): Incidence of hereditary nonpolyposis colorectal cancer and the feasibility of molecular screening for the disease. N Engl J Med $\underline{338}$, $1481-1487$

Aktories K, Forth W, Förstermann U: Allgemeine und spezielle Pharmakologie und Toxikologie. 9. Auflage; Urban \& Fischer, München 2006, 938-939

Al-Taie O, Mörk H, Seufert J, Treis H, Jakob F, Scheurlen M (2001): Hereditäres NonPolyposis kolorektales Karzinom (HNPCC). Medizinische Klinik - Intensivmedizin und Notfallmedizin $\underline{96}, 529-538$

Arastéh K, Baenkler HW, Bieber C: Innere Medizin. 2. Auflage; Thieme (Duale Reihe), Stuttgart 2009, 553

Barton G, Ponting C, Spraggon G, Finnis C, Sleep D (1992): Human platelet-derived endothelial cell growth factor is homologous to Escherichia coli thymidine phosphorylase. Protein Sci $1,688-690$

Becker H, Liersch T: Viszeralchirurgie. 2. Auflage; Urban \& Fischer, München 2006, 601631

Boenisch T, Farmilo AJ, Stead RH, Key M, Welcher R, Harvey R. Atwood KN: Handbuch Immunhistochemische Färbemethoden, 3. Auflage, Dako North America Inc. Carpinteria, CA, USA 2006, 34-42

Borsdorff EE (2010): MRT des Rektumkarzinoms: Wert der kontrastmittelgestützten Bildgebung für das präoperative Staging unter Berücksichtigung neuerer zeitsparender Bildaufnahmetechniken. Med. Diss. Berlin 2010

Boskos CS, Liacos C, Korkolis D, Aygerinos K, Lamproglou I, Terpos E, Stoupa E, Baltatzis G, Beroukas K, Papasavvas P et al. (2010): Thymidine phosphorylase to dihydropyrimidine dehydrogenase ratio as a predictive factor of response to preoperative chemoradiation with capecitabine in patients with advanced rectal cancer. J Surg Oncol 102, 408-412 
Brenner H, Chang-Claude J, Seiler CM, Rickert A, Hoffmeister M (2011): Protection from colorectal cancer after colonoscopy: population-based case-control study. Ann Intern Med $\underline{154}, 22-30$

Bülow S, Christensen IJ, Harling H, Kronborg O, Fenger C, Nielsen HJ (2003): Recurrence and survival after mesorectal excision for rectal cancer. Br J Surg $\underline{90}$, 974-980

Chapet O, Romestaing P, Mornex F, Souquet J, Favrel V, Ardiet J, D’Hombres A, Gerard J (2005): Preoperative radiotherapy for rectal adenocarcinoma: Which are strong prognostic factors? Int J Radiat Oncol Biol Phys $\underline{61}, 1371-1377$

Conradi L: Prädiktives und prognostisches Potential der Thymidylatsynthase Prädiktives und prognostisches Potential der Thymidylatsynthase als Biomarker im multimodalen Therapiekonzept 5-FU-basierter Radiochemotherapie des lokal fortgeschrittenen Rektumkarzinoms.: Immunhistochemische Analyse prätherapeutischer Biopsien und korrespondierenden residuellen Tumorgewebes. Med. Diss. Göttingen 2010

Conradi L, Bleckmann A, Schirmer M, Sprenger T, Jo P, Homayounfar K, Wolff HA, Rothe H, Middel P, Becker H et al. (2011): Thymidylate Synthase as a Prognostic Biomarker for Locally Advanced Rectal Cancer after multimodal Treatment. Ann Surg Oncol 18, 24422452

Dunst J, Reese T, Sutter T, Zühlke H, Hinke A, Kölling-Schlebusch K, Frings S (2002): Phase I Trial Evaluating the Concurrent Combination of Radiotherapy and Capecitabine in Rectal Cancer. J Clin Oncol 20, 3983-3991

Dworak O, Keilholz L, Hoffmann A (1997): Pathological features of rectal cancer after preoperative radiochemotherapy. Int J Colorect Dis $\underline{12}, 19-23$

Efferth T: Molekulare und zelluläre Pharmakologie und Toxikologie: Biologische Grundlagen der Arzneimittelwirkung. 1. Auflage, Springer Berlin 2006, 81-82

Fakih MG, Rajput A, Yang GY, Pendyala L, Toth K, Smith JL, Lawrence DD, Rustum YM (2006): A Phase I study of weekly intravenous oxaliplatin in combination with oral daily capecitabine and radiation therapy in the neoadjuvant treatment of rectal adenocarcinoma. Int J Radiat Oncol Biol Phys $\underline{65}$, 1462-1470 
Fearon ER, Vogelstein B (1990): A genetic model for colorectal tumorigenesis. Cell $\underline{61}, 759$ 767

Fendrich V, Bartsch DK (2005): Hereditäre gastrointestinale Neoplasien. Z Gastroenterol $\underline{43}$, 219-225

Fieldling LP, Arsenault PA, Chapuis PH, Dent O, Gathright B, Hardcastle JD, Hermanek P, Jass JR, Newland RC (1991): Clinicopathological staging for colorectal cancer: An International Documentation System (IDS) and an International Comprehensive Anatomical Terminology (ICAT). J Gastroenterol Hepatol 므, 325-344

Findlay MP, Raynaud F, Cunningham D, Iveson A, Collins DJ, Leach MO (1996): Measurement of plasma 5-fluorouracil by high-performance liquid chromatography with comparison of results to tissue drug levels observed using in vivo 19F magnetic resonance spectroscopy in patients on a protracted venous infusion with or without interferon-alpha. Ann Oncol ㄱ, 47-53

Fuchs R, Guggenberger D, Trautwein C: Diagnostik und Therapie gastrointestinaler Tumore 2011/2012., 20. Auflage; Nora-Verlag, Stolberg 2011

Gastrointestinal Tumor Study Group (1985): Prolongation of the Disease-Free Interval in Surgically Treated Rectal Carcinoma. N Engl J Med 312, 1465-1472

Gehoff A, Scheel A, Conradi L, Sprenger T, Wolff HA, Ghadimi M, Liersch T, Rüschoff J (2012): Vollständige Lymphknotenaufarbeitung beim Rektumkarzinom (cUICC-II/IIIStadium) durch Aceton-Kompression. Gastroenterologie up2date 08, 172-176

Ghadimi BM, Langer C, Liersch T, Becker H (2003): Primäres Rektumkarzinom. Der Onkologe 9, 184-198

Glynne-Jones R (2005): A phase I dose escalation study of continuous oral capecitabine in combination with oxaliplatin and pelvic radiation (XELOX-RT) in patients with locally advanced rectal cancer. Ann Oncol 17, 50-56

Goto T, Shinmura K, Yokomizo K, Sakuraba K, Kitamura Y, Shirahata A, Saito M, Kigawa G, Nemoto H, Sanada Y et al. (2012): Expression levels of thymidylate synthase, dihydropyrimidine dehydrogenase, and thymidine phosphorylase in patients with colorectal cancer. Anticancer Res 32, 1757-1762 
Heald RJ, Husband EM, Ryall RD (1982): The mesorectum in rectal cancer surgery - the clue to pelvic recurrence? Br J Surg $\underline{69}$, 613-616

Hermanek P (1995): pTNM and residual tumor classifications: Problems of assessment and prognostic significance. World J Surg 19, 184-190

Hilgers R, Bauer P, Scheiber V: Einführung in die medizinische Statistik, 2. Auflage; Springer, Berlin 2007

Hofheinz R, Wenz F, Post S, Matzdorff A, Laechelt S, Hartmann T, Müller L, Link H, Moehler M, Kettner E et al. (2012): Chemoradiotherapy with capecitabine versus fluorouracil for locally advanced rectal cancer: a randomised, multicentre, non-inferiority, phase 3 trial. Lancet Oncol 13, 579-588

Holm T, Ljung A, Haggmark T, Jurell G, Lagergren J (2007): Extended abdominoperineal resection with gluteus maximus flap reconstruction of the pelvic floor for rectal cancer. $\mathrm{Br} \mathbf{J}$ Surg $\underline{94}, 232-238$

Hong TS, Clark JW, Haigis KM (2012): Cancers of the Colon and Rectum: Identical or Fraternal Twins? Cancer Discov $\underline{2}, 117-121$

Hospers GA, Punt CJA, Tesselaar ME, Cats A, Havenga K, Leer JWH, Marijnen CA, Jansen EP, Krieken HHJM, Wiggers T et al. (2007): Preoperative Chemoradiotherapy with Capecitabine and Oxaliplatin in Locally Advanced Rectal Cancer. A Phase I-II Multicenter Study of the Dutch Colorectal Cancer Group. Ann Surg Oncol 14, 2773-2779

Ishikawa F, Miyazono K, Hellman U, Drexler H, Wernstedt C, Hagiwara K, Usuki K, Takaku F, Risau W, Heldin CH (1989): Identification of angiogenic activity and the cloning and expression of platelet-derived endothelial cell growth factor. Nature $\underline{338}, 557-562$

Jakob C, Aust DE, Meyer W, Baretton GB, Schwabe W, Häusler P, Becker H, Liersch T (2004): Thymidylate synthase, thymidine phosphorylase, dihydropyrimidine dehydrogenase expression, and histological tumour regression after 5-FU-based neo-adjuvant chemoradiotherapy in rectal cancer. J Pathol 204, 562-568

Jakob C, Liersch T, Meyer W, Baretton GB, Schwabe W, Häusler P, Kulle B, Becker H, Aust DE (2006): Prognostic Value of Histologic Tumor Regression, Thymidylate Synthase, 
Thymidine Phosphorylase, and Dihydropyrimidine Dehydrogenase in Rectal Cancer UICC Stage II/III After Neoadjuvant Chemoradiotherapy. Am J Surg Pathol 30, 1169-1174

Kapiteijn E, Marijnen CA, Nagtegaal ID, Putter H, Steup WH, Wiggers T, Rutten HJ, Pahlman L, Glimelius B, van Krieken JHJ et al. (2001): Preoperative Radiotherapy Combined with Total Mesorectal Excision for Resectable Rectal Cancer. N Engl J Med 4ㅗ, 638-646 Kaplan EL, Meier P (1958): Nonparametric Estimation from Incomplete Observations. J Am Stat Assoc 53, 457-481

Krook JE, Moertel CG, Gunderson LL, Wieand HS, Collins RT, Beart RW, Kubista TP, Poon MA, Meyers WC, Mailliard JA et al. (1991): Effective Surgical Adjuvant Therapy for HighRisk Rectal Carcinoma. N Engl J Med $\underline{324}$, 709-715

Kuremsky JG, Tepper JE, McLeod HL (2009): Biomarkers for Response to Neoadjuvant Chemoradiation for Rectal Cancer. Int J Radiat Oncol Biol Phys $\underline{74}$, 673-688

Leibl S, Tsybrovskyy O, Denk H (2003): How many lymph nodes are necessary to stage early and advanced adenocarcinoma of the sigmoid colon and upper rectum?. Virchows Arch $\underline{443}$, $133-138$

Liersch T, Langer C, Jakob C, Müller D, Ghadimi BM, Siemer A, Markus P, Füzesi L, Becker H (2003): Präoperative Diagnostik beim lokal fortgeschrittenen Rektumkarzinom ( $\leq$ T3 oder N+). Der Chirurg 74, 224-234

Liersch T, Langer C, Ghadimi BM, Becker H (2005): Aktuelle Behandlungsstrategien beim Rektumkarzinom. Chirurg 므, 309-334

Liersch T, Becker H, Langer C (2007): Rektumkarzinom. Allgemein- und Viszeralchirurgie up2date $\underline{1}, 41-72$.

Liersch T, Rothe H, Ghadimi BM, Becker H (2009): Therapie beim lokal fortgeschrittenen Rektumkarzinom. Chirurg $\underline{80}, 281-293$

Liersch T, Gaedcke J, Grade M, Sprenger T, Conradi L, Becker H, Ghadimi BM (2010): Molekulare Marker zur Responseprädiktion beim lokal fortgeschrittenen Rektumkarzinom. Der Onkologe 16, 779-788 
Lindskog EB, Wettergren Y, Odin E, Gustavsson B, Derwinger K (2012): Thymidine Phosphorylase Gene Expression in Stage III Colorectal Cancer. Clin Med Insights Oncol $\underline{6}$, $347-353$

Lordick F, Siewert J, Rothmund M, Schumpelick V: Praxis der Viszeralchirurgie: Onkologische Chirurgie. Springer, Berlin 2010, 188-190

Machiels J (2005): Phase II study of preoperative oxaliplatin, capecitabine and external beam radiotherapy in patients with rectal cancer: the RadiOxCape study. Ann Oncol 16, 1898-1905

Makihara K, Mishima H, Azuma S, Matsuyama K, Komori K, Hasegawa H, Yasui M, Ikenaga M, Tsujinaka T (2012): A pilot study of pharmacokinetically guided dose management of capecitabine in CRC patients. J Clin Oncol $\underline{30}$, Abstr. 510

Marubini E, Valsecchi MG: Analysing survival data from clinical trials and observational studies. 1. Auflage; Wiley, New York 1995

Mason AY (1976): Rectal cancer: the spectrum of selective surgery. Proc R Soc Med $\underline{69}$, $237-244$

Matzel KE, Merkel S, Hohenberger W (2003): Lokale Therapieprinzipien beim Rektumkarzinom. Der Chirurg 느, 897-904

MERCURY SG (2006): Diagnostic accuracy of preoperative magnetic resonance imaging in predicting curative resection of rectal cancer: prospective observational study. BMJ $\underline{333}, 779$

Metzger R, Danenberg K, Leichman CG, Salonga D, Schwartz EL, Wadler S, Lenz HJ, Groshen S, Leichman L, Danenberg PV (1998): High basal level gene expression of thymidine phosphorylase (platelet-derived endothelial cell growth factor) in colorectal tumors is associated with nonresponse to 5-fluorouracil. Clin Cancer Res $\underline{4}$, 2371-2376

Miyazono K, Heldin CH (1989): High-yield purification of platelet-derived endothelial cell growth factor: structural characterization and establishment of a specific antiserum.

Biochemistry $\underline{28}, 1704-1710$

Moghaddam A, Zhang HT, Fan TP, Hu DE, Lees VC, Turley H, Fox SB, Gatter KC, Harris AL, Bicknell R (1995): Thymidine phosphorylase is angiogenic and promotes tumor growth. Proc Natl Acad Sci U S A 92, 998-1002 
Munding J, Tannapfel A (2009): Pathogenese des sporadischen und hereditären

Kolonkarzinoms. Onkologe $\underline{15}, 1182-1192$

Patel PA (2011): Evolution of 5-fluorouracil-based chemoradiation in the management of rectal cancer. Anticancer Drugs 22, 311-316

Petz C: In vivo-Untersuchung zum möglichen Pathomechanismus der Chemotherapieinduzierten Kardiotoxizität. Nachweis einer 5-Fluorouracil assoziierten Vasokonstriktion. Med. Diss. Bochum 2006

Pinedo HM, Peters GF (1988): Fluorouracil: biochemistry and pharmacology. Journal of Clinical Oncology $\underline{6}, 1653-1664$

Posern S: Prädiktive und prognostische Relevanz von p53 und Ki67 beim lokal fortgeschrittenen Rektumkarzinom cUICC-II/III. Med. Diss. Göttingen 2013

Remmele W, Stegner HE (1987): Recommendation for uniform definition of an immunoreactive score (IRS) for immunohistochemical estrogen receptor detection (ER-ICA) in breast cancer tissue. Pathologe $\underline{8}, 138-140$

Robert Koch Institut: Gesundheit in Deutschland, Berlin 2006

Robert Koch Institut (2012): Krebs in Deutschland 2007/2008 Krebs in Deutschland 8. Ausgabe, Berlin 2012, 36-39

Rödel C, Grabenbauer GG, Papadopoulos T, Hohenberger W, Schmoll HJ, Sauer R. (2003): Phase I/II Trial of Capecitabine, Oxaliplatin, and Radiation for Rectal Cancer. J Clin Oncol $\underline{21}, 3098-3104$

Rödel C, Martus P, Papadoupolos T, Fuzesi L, Klimpfinger M, Fietkau R, Liersch T, Hohenberger W, Raab R, Sauer R et al. (2005): Prognostic significance of tumor regression after preoperative chemoradiotherapy for rectal cancer. J Clin Oncol 23 $\underline{3}, 8688-8696$

Rödel C, Liersch T, Becker H, Fietkau R, Hohenberger W, Hothorn T, Graeven U, Arnold D, Lang-Welzenbach M, Raab H et al. (2012): Preoperative chemoradiotherapy and postoperative chemotherapy with fluorouracil and oxaliplatin versus fluorouracil alone in locally advanced rectal cancer: initial results of the German CAO/ARO/AIO-04 randomised phase 3 trial. Lancet Oncol 13, 679-687 
Saito S, Tsuno N, Nagawa H, Sunami E, Zhengxi J, Osada T, Kitayama J, Shibata Y, Tsuruo T, Muto T (2000): Expression of platelet-derived endothelial cell growth factor correlates with good prognosis in patients with colorectal carcinoma. Cancer $\underline{88}, 42-49$

Salonga D, Danenberg KD, Johnson M, Metzger R, Groshen S, Tsao-Wei DD, Lenz HJ, Leichman CG, Leichman L, Diasio RB et al. (2000): Colorectal tumors responding to 5fluorouracil have low gene expression levels of dihydropyrimidine dehydrogenase, thymidylate synthase, and thymidine phosphorylase. Clin Cancer Res $\underline{6}, 1322-1327$

Sauer R, Becker H, Hohenberger W, Rödel C, Wittekind C, Fietkau R, Martus P, Tschmelitsch J, Hager E, Hess CF et al. (2004): Preoperative versus Postoperative Chemoradiotherapy for Rectal Cancer. N Engl J Med 351, 1731-1740

Sauer R, Liersch T, Merkel S, Fietkau R, Hohenberger W, Hess C, Becker H, Raab H, Villanueva M, Witzigmann H et al. (2012): Preoperative Versus Postoperative Chemoradiotherapy for Locally Advanced Rectal Cancer: Results of the German CAO/ARO/AIO-94 Randomized Phase III Trial After a Median Follow-Up of 11 Years. J Clin Oncol 16, 1926-1933

Sawada N, Ishikawa T, Sekiguchi F, Tanaka Y, Ishitsuka H (1999): X-ray irradiation induces thymidine phosphorylase and enhances the efficacy of capecitabine (Xeloda) in human cancer xenografts. Clin Cancer Res $\underline{5}$, 2948-2953

Schilsky RL (1998): Biochemical and clinical pharmacology of 5-flourouracil. Oncology $\underline{12}$, $13-18$

Schmiegel W, Pox C, Adler G, Fleig W, Folsch UR, Fruhmorgen P, Graeven U, Hohenberger W, Holstege A, Kuhlbacher T et al. (2005): S3-guideline conference "Colorectal Cancer" 2004. Dtsch Med Wochenschr 130 Suppl 1, 5-53

Schmiegel W, Pox C, Reinacher-Schick A, Adler G, Fleig W, Fçlsch U, Fruhmorgen P, Graeven U (2008a): S3-Leitlinie „Kolorektales Karzinom“ Ergebnisse evidenzbasierter Konsensuskonferenzen am 6./7. Februar 2004 und am 8./9. Juni 2007 (für die Themenkomplexe IV, VI und VII), Z Gastroenterol $\underline{46}$, 18-52

Schmiegel W, Reinacher-Schick A, Arnold D, Graeven U, Heinemann V, Porschen R, Riemann J, Rödel C, Sauer R, Wieser M et al. (2008b): Update S3-guideline "colorectal cancer" 2008. Z Gastroenterol 46, 799-840 
Schmoll HJ, van Cutsem E, Stein A, Valentini V, Glimelius B, Haustermans K, Nordlinger B, van de Velde CJ, Balmana J, Regula J et al. (2012): ESMO Consensus Guidelines for management of patients with colon and rectal cancer. A personalized approach to clinical decision making. Ann Oncol 23, 2479-2516

Schwartz M (1971): Thymidine Phosphorylase from Escherichia coli. Properties and Kinetics. Eur J Biochem 21, 191-198

Shimma N, Umeda I, Arasaki M, Murasaki C, Masubuchi K, Kohchi Y, Miwa M, Ura M, Sawada N, Tahara H et al. (2000): The design and synthesis of a new tumor-selective fluoropyrimidine carbamate, Capecitabine. Bioorganic \& Medicinal Chemistry $\underline{8}, 1697-1706$

Siegel R, Naishadham D, Jemal A (2012): Cancer statistics, 2012. CA Cancer J Clin $\underline{62}, 10$ 29

Sobin LH, Fleming ID (1997): TNM Classification of Malignant Tumors, fifth edition (1997). Union Internationale Contre le Cancr and the American Joint Committee on Cancer. Cancer $\underline{80}, 1803-1804$

Soong R, Shah N, Salto-Tellez M, Tai BC, Soo RA, Han HC, Ng SS, Tan WL, Zeps N, Joseph D et al. (2008): Prognostic significance of thymidylate synthase, dihydropyrimidine dehydrogenase and thymidine phosphorylase protein expression in colorectal cancer patients treated with or without 5-fluorouracil-based chemotherapy. Ann Oncol 19, 915-919

Spencker S, Schmittel A, Westermann D, Marek A, Schultheiss HP, Witzenbichler B (2007): Angina Pectoris und ST-Hebungen nach Chemotherapie mit 5-FU. Internist $\underline{48}, 69-74$

Sprenger T, Rothe H, Langer C, Becker H, Liersch T (2009): Comment on "Lymph Nodes After Preoperative Chemoradiotherapy for Rectal Carcinoma: Number, Status, and Impact on Survival". Am J Surg Pathol $\underline{33}, 1107$

Sprenger T, Rothe H, Homayounfar K, Beissbarth T, Ghadimi BM, Becker H, Liersch T (2010a): Preoperative Chemoradiotherapy Does Not Necessarily Reduce Lymph Node Retrieval in Rectal Cancer Specimens-Results from a Prospective Evaluation with Extensive Pathological Work-up. J Gastrointest Surg 14, 96-103

Sprenger T, Rothe H, Jung K, Christiansen H, Conradi LC, Ghadimi BM, Becker H, Liersch $\mathrm{T}$ (2010b): Stage II/III rectal cancer with intermediate response to preoperative 
radiochemotherapy: Do we have indications for individual risk stratification? World J Surg Oncol $\underline{8}, 27$

Sterk P, Nagel T, Günter S, Schubert F, Klein P (2000): Methods for postoperative evaluation of complete excision of the mesorectum. Zentralbl Chir $\underline{125}, 370-374$

Takebayashi Y, Akiyama S, Yamada K, Akiba S, Aikou T (1996): Angiogenesis as an unfavorable prognostic factor in human colorectal carcinoma. Cancer $\underline{78}, 226-231$

Tanaka K, Saigusa S, Toiyama Y, Koike Y, Okugawa Y, Yokoe T, Inoue Y, Kobayashi M, Miki C, Kusunoki M (2012): TS and DPD mRNA levels on formalin-fixed paraffinembedded specimens as predictors for distant recurrence of rectal cancer treated with preoperative chemoradiotherapy. J Surg Oncol 105, 529-534

TEVA Deutschland Fachinformation (2007): Zusammenfassung der Merkmale des Arzneimittels 5-Fluorouracil.

Toi M, Rahman MA, Bando H, Chow LWC (2005): Thymidine phosphorylase (plateletderived endothelial-cell growth factor) in cancer biology and treatment. Lancet Oncol $\underline{6}, 158$ 166

Tukey JW: Exploratory data analysis. 1. Auflage; Addison-Wesley Pub. Co., Reading 1977, $39-55$

Unger KR, Romney DA, Koc M, Moskaluk CA, Friel CM, Foley EF, Rich TA (2011): Preoperative Chemoradiation for Rectal Cancer Using Capecitabine and Celecoxib Correlated With Posttreatment Assessment of Thymidylate Synthase and Thymidine Phosphorylase Expression. Int J Radiat Oncol Biol Phys 무, 1377-1382

Van Triest B, Pinedo HM, Blaauwgeers JL, van Diest PJ, Schoenmakers PS, Voorn DA, Smid K, Hoekman K, Hoitsma HF, Peters GJ (2000): Prognostic role of thymidylate synthase, thymidine phosphorylase/platelet-derived endothelial cell growth factor, and proliferation markers in colorectal cancer. Clin Cancer Res $\underline{6}, 1063-1072$

Vilmar A, Garcia-Foncillas J, Huarriz M, Santoni-Rugiu E, Sorensen JB (2012): RT-PCR versus immunohistochemistry for correlation and quantification of ERCC1, BRCA1, TUBB3 and RRM1 in NSCLC. Lung Cancer $\underline{75}, 306-312$ 
Vogelstein B, Fearon ER, Hamilton SR, Kern SE, Preisinger AC, Leppert M, Nakamura Y, White R, Smits AM, Bos JL (1988): Genetic alterations during colorectal-tumor development. N Engl J Med $\underline{319}$, 525-532

Weiß C: Basiswissen medizinische Statistik. 5. Auflage; Springer, Berlin 2010, 283-284

Weiß M (2007): Was schützt vor Krebs und Diabetes? MMW - Fortschritte der Medizin 16

Wingo PA, Tong T, Bolden S (1995): Cancer statistics, 1995. CA Cancer J Clin 45, 8-30

Wittekind C, Sobin LH: TNM classification of malignant tumours. 6. Auflage; Wiley-LissVerlag, New York 2002

Wittekind C, Meyer H: TNM: Klassifikation Maligner Tumoren. 7. Auflage; John Wiley \& Sons, Limited 2010

Wollmer E, Neubauer A (2011): Nebenwirkungen der medikamentösen Tumortherapie. Internist $\underline{52}, 1429-1446$

Yoshimura A, Kuwazuru Y, Furukawa T, Yoshida H, Yamada K, Akiyama S (1990):

Purification and tissue distribution of human thymidine phosphorylase; high expression in lymphocytes, reticulocytes and tumors. Biochim Biophys Acta 1034, 107-113 


\section{Danksagung}

Zum Abschluss möchte ich mich bei all jenen Personen bedanken, die auf ihre Weise zum Gelingen dieser Arbeit beigetragen haben.

Zunächst möchte ich mich bei Frau Dr. med. Lena Conradi für diese einzigartige und herausragende Betreuung während des Promotionsvorhabens bedanken.

Ich danke Ihr für das große Engagement bei der geduldigen Durchsicht dieser Arbeit, die motivierenden Worte und die unerschöpfliche Hilfsbereitschaft!

Des Weiteren möchte ich mich herzlichst bei Herrn PD Dr. med. Torsten Liersch, Leiter des Teilprojektes 5 der KFO 179, für die Überlassung des überaus interessanten und praxisrelevanten Themas bedanken. Mit seiner freundlichen Unterstützung und stets konstruktiven Kritik hat er wesentlich zum Gelingen dieser Arbeit beigetragen.

Prof. Dr. med. B. Michael Ghadimi danke ich als dem Direktor der Klinik für Allgemein-, Viszeral- und Kinderchirurgie für die Möglichkeit, in seiner Abteilung zu promovieren. Als Leiter der KFO 179 hat er unter anderem dieses Forschungsprojekt ermöglicht.

Prof. Dr. Gisbert Vogt möchte ich für seine Unterstützung bei der Umsetzung der Projekte innerhalb der KFO 179 danken. Er hat unserer Forschergruppe auf diese Weise viele Chancen eröffnet, da die Zusammenarbeit durch die Laborseminare/-fahrten maßgeblich gestärkt wurde.

Frau Birgit Jünemann möchte ich vielmals für die Herstellung der zahlreichen Paraffinschnitte und die Hilfestellungen bezüglich der Immunhistochemie danken. Vielen Dank außerdem für die stets fürsorgliche Betreuung unserer Arbeitsgruppe!

Herrn Dr. Manuel Nietert möchte ich für die wertvolle Unterstützung und Zusammenarbeit bei der Erstellung der statistischen Analysen danken. Ohne sein Engagement wäre diese umfangreiche Auswertung kaum möglich gewesen. 